UNIVERSIDAD NACIONAL DE LA PLATA

FACULTAD DE CIENCIAS NATURALES Y MUSEO

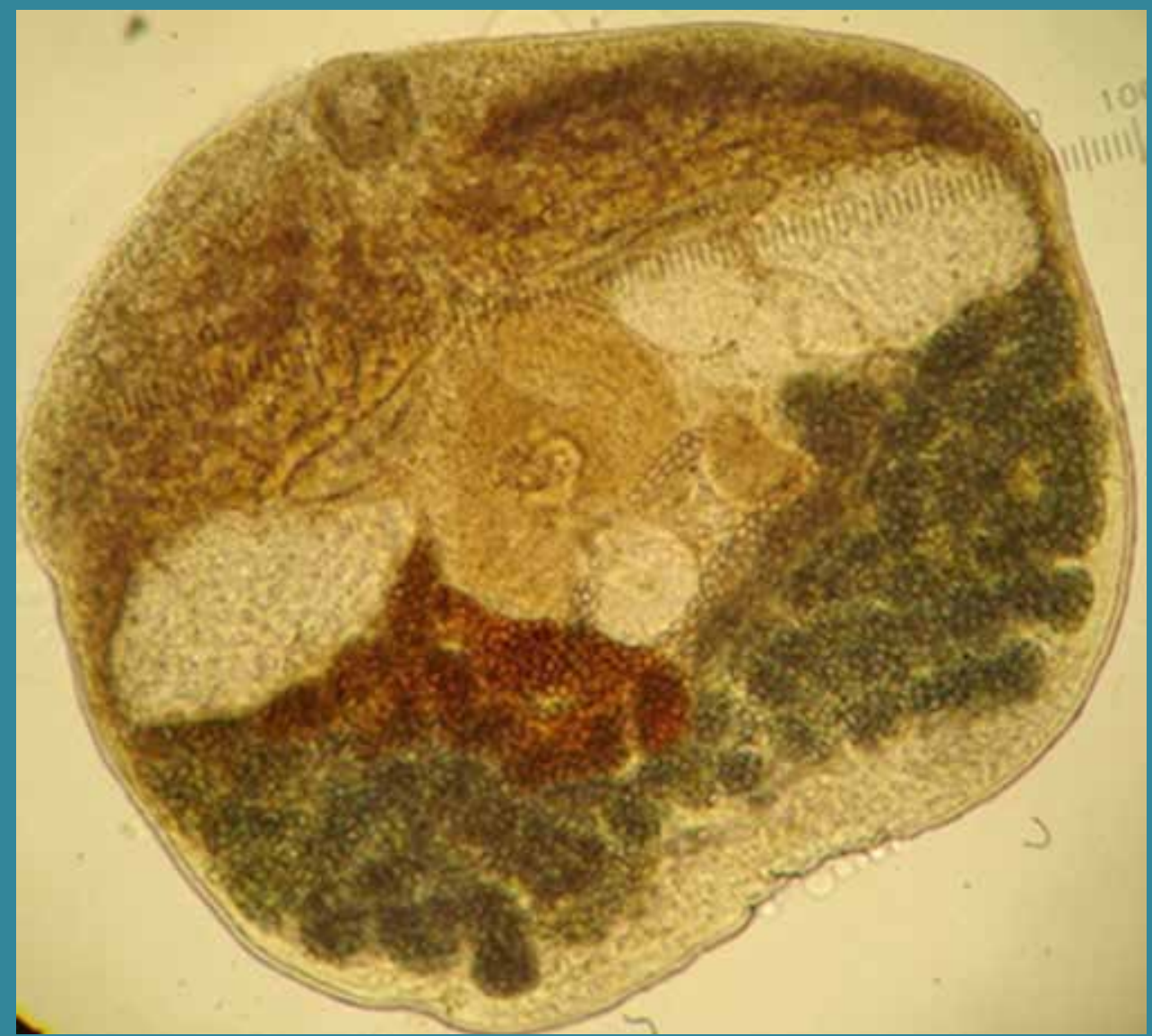

\title{
HELMINTOFAUNA DE MURCIÉLAGOS (CHIROPTERA) DEL NORDESTE ARGENTINO
}

\author{
ALICIA M. FRANCISCA MILANO \\ TRABAJO DE TESIS PARA OPTAR POR EL \\ TÍTULO DE DOCTOR EN CIENCIAS NATURALES
}

\author{
DIRECTORAS \\ GRACIELA T. NAVONE \\ LÍA I. LUNASCHI
}




\section{Para Ale y Fran}




\section{AGRADECIMIENTOS}

En primer lugar quiero agradecer a mi maestra, amiga, madre, compañera, jefa, hermana, mujer que en sus múltiples roles me demostró siempre su generosidad de corazón y su bondad infinita. Gracias Bea.

A mis directoras Graciela Navone y Lía Lunaschi por la atención, la paciencia, la confianza, el sostén y el impulso que me han dado en estos años.

A mis compañeros de campaña, principalmente a Fabricio Idoeta, pieza fundamental para el logro de los objetivos. A Mónica Díaz y Rubén Barquez por enseñarme a trabajar con los "murcis".

A mis compañeros de laboratorio (en orden de aparición) Valeria, Virginia, Susana, Ángeles, Carlos, Analía y Desirée, por la colaboración y el acompañamiento cotidiano. A mis amigos biólogos que son referentes para mi y me acompañaron en este proceso, María Esther, Cristina, Sylvina, Cynthya, Miryam, Gilberto, Mario, Fabiana y especialmente Martina que me recibió tantas veces en su casa.

A mis amigos, por el aliento y entusiasmo permanente.

A mi familia, mi refugio total.

\section{RECONOCIMIENTOS INSTITUCIONALES}

A la Universidad Nacional del Nordeste por haber subsidiado las actividades complementarias de posgrado y la impresión de la tesis.

A la Facultad de Ciencias Exactas y Naturales y Agrimensura (UNNE) por haber apoyado y facilitado la realización de la carrera doctoral.

A la División Invertebrados del Museo de La Plata y al Centro de Estudios Parasitológicos y Vectores (CEPAVE), UNLP, por brindar el espacio y los recursos para la realización del trabajo.

A la Facultad de Ciencias Naturales y Museo de la Universidad Nacional de La Plata, especialmente al Departamento de Posgrado por propiciar y facilitar la concreción del doctorado. 
ÍNDICE

Agradecimientos

Reconocimientos institucionales

Resúmen IV

Abstract VI

Capítulo I. Introducción general 2

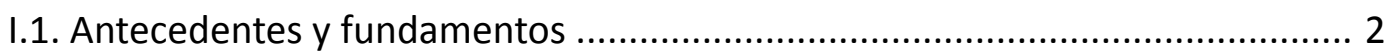

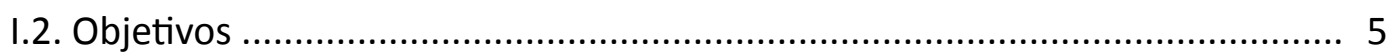

Capítulo II. Materiales y Métodos ......................................................................... 7

II.1. Área de estudio ........................................................................... 7

II.2. Caracterización de los hospedadores ..................................................... 12

II.3. Muestreo de hospedadores y procesamiento de helmintos .......................... 16

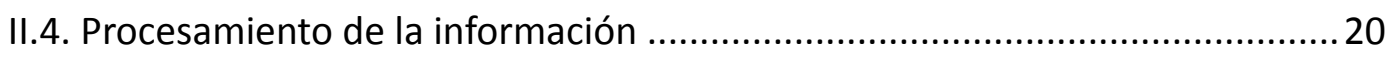

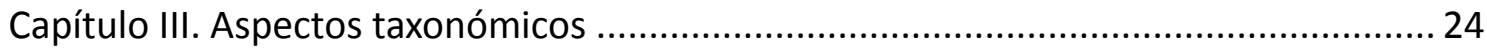

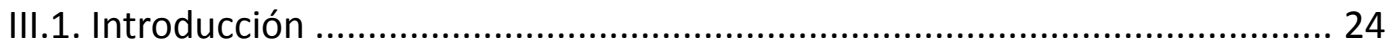

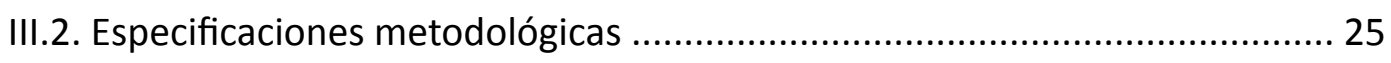

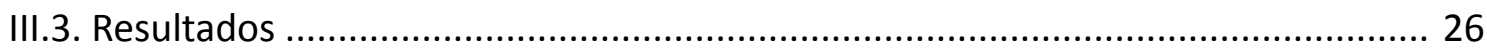

III.3.1. Familia Hymenolepididae ............................................................... 27

Vampirolepis guarany Rego, 1961 ..................................................... 28

Vampirolepis cf macroti Zdzitwiecki y Rutkowska, 1980 ....................... 30

III.3.2. Familia Anenterotrematidae ............................................................ 32

Anenterotrema eduardocaballeroi (Freitas, 1960) Caballero, 1960 ........33

Anenterotrema liliputianum (Travassos, 1928) Caballero, 1964 ........... 35

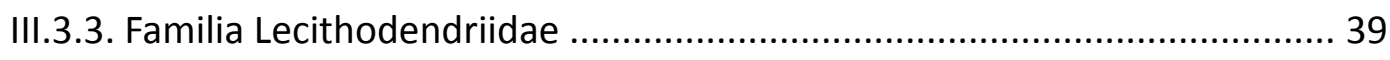

Gymnoacetabulum talavarensis (Lunaschi, 2002) .............................. 39

Ochoterenatrema labda Caballero y C, 1943 ..................................... 42

Paralecithodendrium aranhai Lent, Freitas y Prença, 1945 ....................46

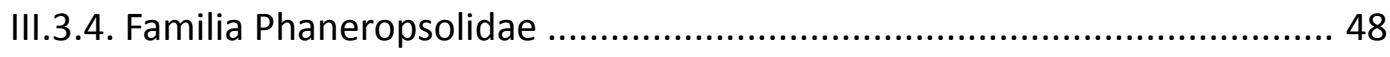

Limatulum oklahomense Macy, 1932 .................................................. 49

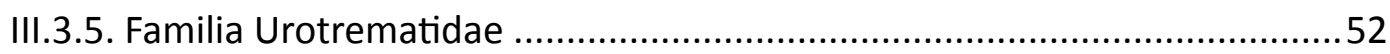




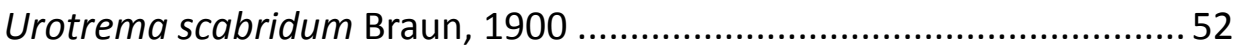

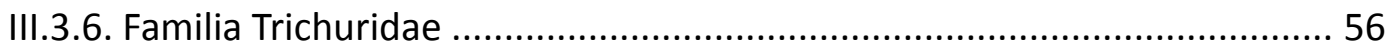

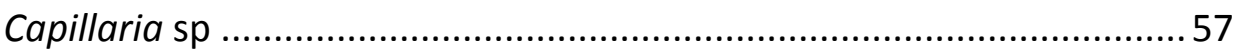

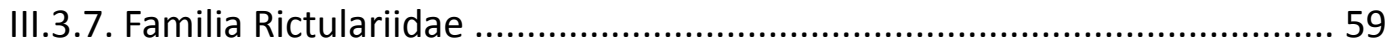

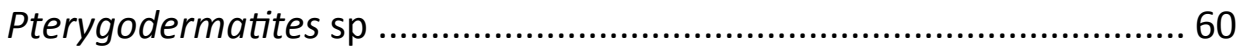

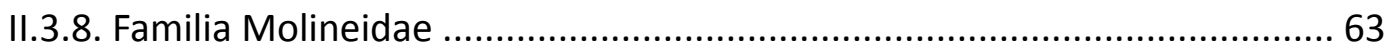

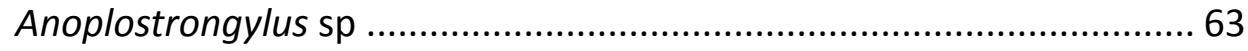

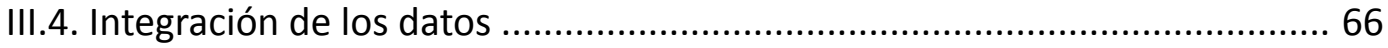

III.4.1. Lista de parásitos y sus especies hospedadoras ............................... 66

III.4.2. Lista de murciélagos y sus helmintos parásitos ............................... 67

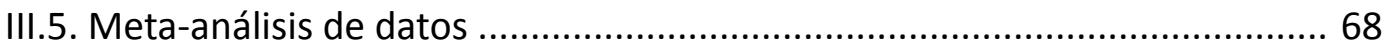

III.5.1. Helmintos parásitos de murciélagos de Sudamérica ........................ 69

III.5.2. Helmintos parásitos de murciélagos de Argentina ...........................72

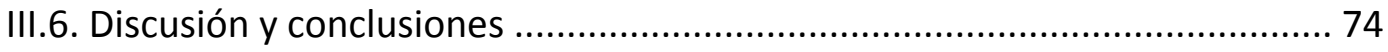

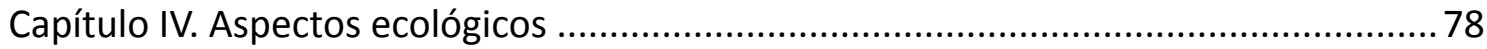

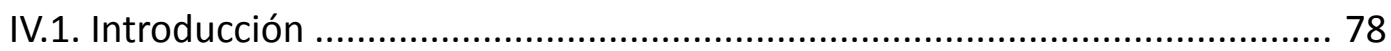

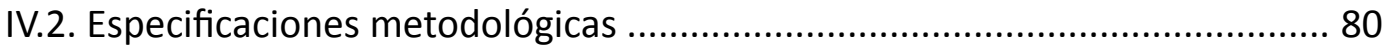

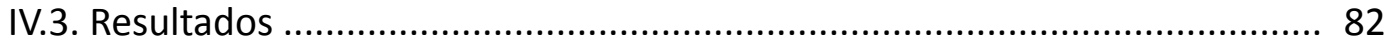

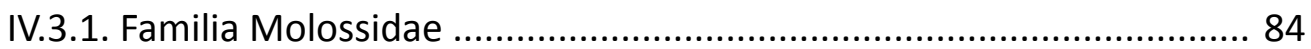

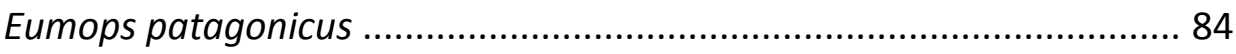

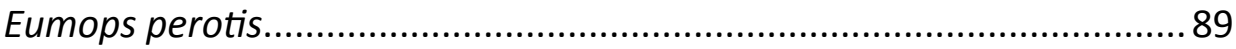

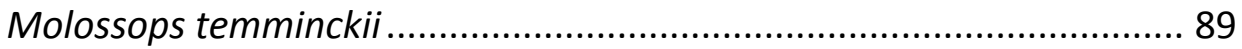

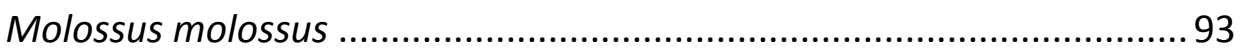

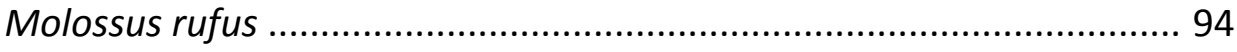

Integración Familia Molossidae ......................................................... 98

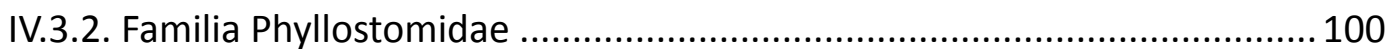

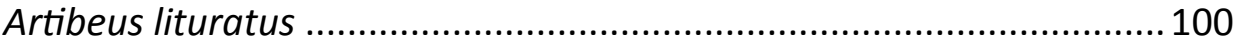

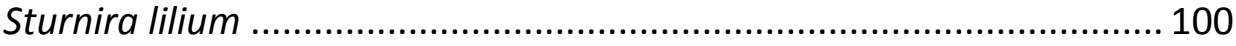

Integración Familia Phyllostomidae .................................................101

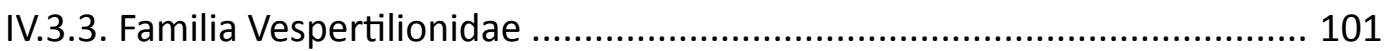


Eptesicus furinalis ................................................................... 101

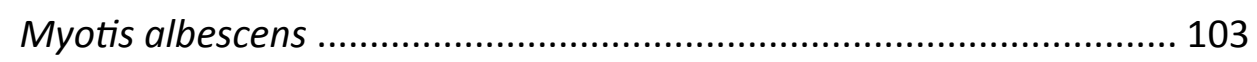

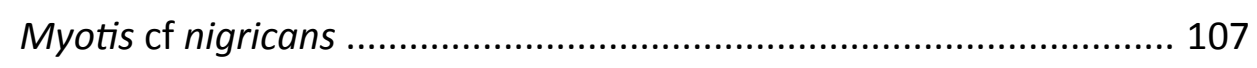

Integración Familia Vespertilionidae ................................................ 111

IV.3.4. Análisis de la helmintofauna a nivel Familia ................................. 113

IV.3.5. Ensamble de la helmintofauna a nivel Gremio trófico .................... 114

IV.3.6. Fauna parásita local y Fauna parásita regional .............................. 116

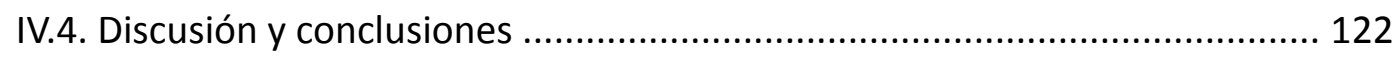

Capítulo V. Discusión general y conclusiones ....................................................... 128

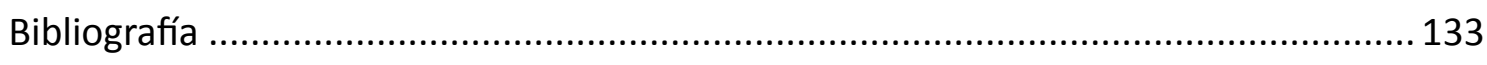

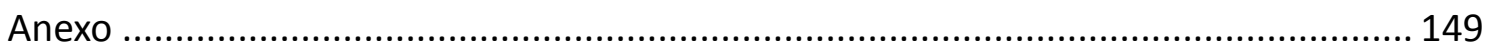




\section{RESUMEN}

En el presente trabajo se abordan aspectos taxonómicos y ecológicos de los helmintos parásitos asociados a 12 especies de tres familias de murciélagos de 11 localidades de la provincia de Corrientes y una de Misiones: Eumops patagonicus, Eumops perotis, Molossops temminckii, Molossus molossus, Molossus rufus (Molossidae), Artibeus lituratus, Desmodus rotundus, Platyrrhinus lineatus, Sturnira lilium (Phyllostomidae), Eptesicus furinalis, Myotis albescens y Myotis cf nigricans (Vespertilionidae).

Se describió la presencia y caracterizaron morfológicamente 12 taxones de helmintos: dos especies de cestodes Vampirolepis guarany y V. cf macroti (Hymenolepididae), siete especies de digeneos Anenterotrema eduardocaballeroi, A. liliputianun (Anenterotrematidae), Gymnoacetabulum talavarensis, Ochoterenatrema labda, Paralecithodendrium aranhai (Lecithodendriidae), Limatulum oklahomense (Phaneropsolidae), Urotrema scabridum (Urotrematidae) y tres taxones de nematodes Anoplostrongylus sp. (Trichostrongylidae), Pterygodermatites sp. (Rictulariidae) y Capillaria sp. (Trichuridae). Para cada taxón se elaboró una ficha taxonómica y un mapa de distribución a fin de visualizar los registros previos y el aporte de este estudio. Se efectuó la modificación parcial del inventario actual que compendia los helmintos parásitos de murciélagos de la región neotropical y se elaboró un inventario sobre los helmintos parásitos de murciélagos de Argentina.

Se evaluaron 212 murciélagos, cuya prevalencia general de infección parasitaria fue $61,3 \%$. Se observó que U. scabridum es la especie con mayor distribución hospedatoria, estando presente en seis especies de murciélagos de las familias Molossidae (E. patagonicus, $M$. temminckii, $M$. molossus y $M$. rufus) y Vespertilionidae ( $M$. albescens y $M$. cf nigricans), al contrario A. liliputianum y Pterygodermatites sp. estuvieron presentes en una sola especie hospedadora ( $M$. rufus y E. patagonicus respectivamente). A excepción de $A$. liliputianum, se amplía el rango de especies hospedadoras de todas las especies de helmintos hallados.

Respecto a los cestodes se registran nueva asociación entre $V$. guarany y $A$. lituratus y entre Vampirolepis of macroti y $E$. furinalis. En los digeneos se registran cuatro nuevas asociaciones entre $O$. labda y E. patagonicus, $M$. temminckii, $M$. rufus, $M$. albescens; dos entre U. scabridum y E. patagonicus, $M$. albescens; dos entre G. talavarensis y E. patagonicus, $M$. albescens; dos entre $P$. aranhai y E. patagonicus, Myotis cf nigricans; dos entre L. oklahomense y M. rufus, M. albescens y una entre $A$. eduardocaballeroi, M. temminckii.

En cuanto a los nematodes se registran cuatro nuevas asociaciones entre Anoplostrongylus sp. y E. patagonicus, E. perotis, M. rufus, E. furinalis; tres nuevas asociaciones entre Capillaria sp. y M. temminckii, M. rufus, S. lilium y una entre Pterygodermatites sp. y E. patagonicus.

Respecto a la distribución geográfica, se citan por primera vez dos especies de cestodes asociados a murciélagos argentinos: Vampirolepis guarany y $V$. cf macroti. Por primera vez se registran en Argentina los digeneos Paralecithodendrium aranhai y Anen- 
terotrema eduardocaballeroi y el nematode Anoplostrongylus sp. Además se amplía la distribución geográfica de los helmintos ya citados para Argentina, adicionando nuevas localidades en la provincia de Corrientes y Misiones.

Todos los helmintos se localizaron en el tracto intestinal, a excepción de Limatulum oklahomense que se ubicó únicamente en el estómago. En referencia a los análisis ecológicos, la mayor riqueza específica se observa en Molossus rufus, con un registro de ocho especies de helmintos, cinco trematodes, dos nematodes y un cestode. En Artibeus lituratus, Sturnira lilium y Eumops perotis solo pudo observarse una especie parásita ( $V$. guarany, Capillaria sp. y Anoplostrongylus sp., respectivamente), no obstante, los tres casos representaron nuevas asociaciones parásito/hospedador. En los filostómidos Platyrrhinus lineatus y Desmodus rotundus no se hallaron helmintos.

Al analizar las poblaciones componentes se observó que en los molósidos, Urotrema scabridum fue la especie dominante y de mayor prevalencia $(68,4 \%)$, alcanzando su máxima abundancia media $(50,0)$ e intensidad media $(56,9)$ en E. patagonicus. En los vespertiliónidos la especie dominante y de mayor prevalencia $(29,3 \%)$ fue L. oklahomense, alcanzando su máxima abundancia media $(2,4)$ en $M$. albescens y su máxima intensidad media $(13,7)$ en $M$. cf nigricans. No obstante, al comparar la comunidad componente de las distintas especies hospedadoras de ambas familias se observaron valores similares de diversidad, equitabilidad y dominancia, reflejando baja dominancia y una representatividad equivalente de los taxones parásitos. A nivel de infracomunidad se observaron infecciones mono y biespecíficas como predominantes, salvo en Eumops patagonicus en el cual el porcentaje de infecciones múltiples (tres a cinco especies) fue elevado (55,0\%).

Se definieron especies centrales, secundarias y satélites al analizar la comunidad de helmintos de E. patagonicus, definiendo a U. scabridum como especie central a Pterygodermatites sp. como satélite y el resto (Vampirolepis guarany, Gymnoacetabulum talavarensis, Ochoterenatrema labda, Paralecithodendrium aranhai y Anoplostrongylus sp.) resultaron especies secundarias.

El hábito trófico de los hospedadores marcó una clara distinción de la fauna de helmintos, dado que en los murciélagos frugívoros (Artibeus lituratus y Sturnira lilium (Phyllostomidae) solo se hallaron dos especies de helmintos (Vampirolepis guarany (Cestoda) y Capillaria sp (Nematoda), a diferencia de los insectívoros en los que se encontraron todos los taxones identificados en el presente trabajo.

Respecto a la relación entre el sexo y los indicadores parasitológicos se observó diferencia significativa respecto a la intensidad media registrada únicamente en los machos de E. patagonicus. En cuanto a la relación entre el tamaño y los indicadores parasitológicos se observaron relaciones inversas significativas tanto con la intensidad de infección general como con algunas específicas en E. patagonicus y solamente con la intensidad de infección de U. scabridum en Molossus rufus y Myotis albescens. 
Al integrar los resultados con la fauna de helmintos conocidos para Sudamérica, se obtuvieron 23 nuevas asociaciones hospedador/parásito. Respecto a los molósidos, se adicionan seis taxones a la lista conocida para E. patagonicus (Gymnoacetabulum talavarensis, Ochoterenatrema labda, Paralecithodendrium aranhai, Urotrema scabridum (Trematoda), Anoplostrongylus sp., Pterygodermatites sp. (Nematoda), cuatro a M. rufus (Limatulum oklahomense, Ochoterenatrema labda (Trematoda), Anoplostrongylus sp., Capillaria sp. (Nematoda), tres a M. temminckii (Anenterotrema eduardocaballeroi, $O$. labda (Trematoda), Capillaria sp.) y uno a E. perotis (Anoplostrongylus sp.). Respecto a los filostómidos: se adiciona un taxón a Artibeus lituratus (V. guarany) y uno a S. lilium (Capillaria sp.). En referencia a los vespertiliónidos se adicionan cuatro taxones a Myotis albescens (G. talavarensis, L. oklahomense, O. labda, U. scabridum -Trematoda-), una a Myotis of nigricans (P. aranhai-Trematoda-) y dos a Eptesicus furinalis (Vampirolepis of macroti -Cestoda-), Anoplostrongylus sp.-Nematoda-).

Al orientar estos resultados con una perspectiva regional, se pone de relieve la contribución del presente estudio al conocimiento parasitológico de los murciélagos de Argentina elevando el número de especies de helmintos conocidas para el país de 20 a 25 y enriqueciendo el inventario faunístico de helmintos asociados a nueve especies de murciélagos con 23 nuevas asociaciones. La continuidad y profundización del estudio taxonómico y la aproximación en las estimaciones ecológicas, como fueron desarrolladas en esta investigación, permiten avanzar en el conocimiento y generar las bases para el estudio sobre la relación parásito/hospedador/ambiente y su impacto en la fauna parasitaria de animales silvestres, domésticos e incluso el hombre.

\section{ABSTRACT}

In the present study, taxonomic and ecological aspects of helminth parasites associated to twelve species of three families of bats were set up: Eumops patagonicus, Eumops perotis, Molossops temminckii, Molossus molossus, Molossus rufus (Molossidae), Artibeus lituratus, Desmodus rotundus, Platyrrhinus lineatus, Sturnira lilium (Phyllostomidae), Eptesicus furinalis, Myotis albescens and Myotis of nigricans (Vespertilionidae). Eleven locations of the province of Corrientes and one location of the province of Misiones where study.

The presence and morphological characterization of twelve helminth taxa were described. Two cestode species Vampirolepis guarany and V. cf macroti (Hymenolepididae), seven digeneans species Anenterotrema eduardocaballeroi, A. liliputianun (Anenterotrematidae), Gymnoacetabulum talavarensis, Ochoterenatrema labda, Paralecithodendrium aranhai (Lecithodendriidae), Limatulum oklahomense (Phaneropsolidae), Urotrema scabridum (Urotrematidae) and three nematodes Anoplostrongylus sp. (Trichostrongylidae), Pterygodermatites sp. (Rictulariidae) and Capillaria sp. (Trichuri- 
dae) taxa. In addition, and in order to envision previous reports and all possible inputs from the present study, a taxonomic file and a distribution map was made for every taxon. A partial modification of the existing inventory, which summarizes the neotropical region bats helminth parasites was made. Furthermore, an Argentinian Bats helminth parasites inventory was elaborated.

Two hundred and twelve bats were evaluated. The general prevalence of parasite infection was $61,3 \%$. Urotrema scabridum is the major distributed host, being present in six species of Molossidae (E. patagonicus, M. temminckii, M. molossus and M. rufus) and Vespertilionidae ( $M$. albescens y $M$. cf nigricans) bats family. In contrast, $A$. liliputianum and Pterygodermatites sp. were present in only one host specie ( $M$. rufus and E. patagonicus respectively). With the exception of $A$. liliputianum, host rank of all helminth species found was enlarge.

New associations for cestodes such as V. guarany with $A$. lituratus and Vampirolepis cf macroti with $E$. furinalis were registered. Four new associations were registered among digeneans: O. labda and E. patagonicus M. temminckii, M. rufus, M. albescens; two associations between U. scabridum and E. patagonicus, M. albescens; two between G. talavarensis and E. patagonicus, M. albescens; two between $P$. aranhai and E. patagonicus, Myotis cf nigricans; two between L. oklahomense and M. rufus, M. albescens and one more between $A$. eduardocaballeroi, M. temminckii.

Four new associations of nematodes were registered among Anoplostrongylus sp. and E. patagonicus, E. perotis, M. rufus, E. furinalis, three new associations between Capillaria sp. and M. temminckii, M. rufus; S. Iilium and one between Pterygodermatites sp. and E. patagonicus.

Considering their geographical distribution, two cestodes species associated to Argentinian bats are cited for the first time: Vampirolepis guarany and $\mathrm{V}$. cf macroti. Also, Paralecithodendrium aranhai and Anenterotrema eduardocaballeroi digenea and the Anoplostrongylus sp. nematode are register for the first time in Argentina. Furthermore, the geographical distribution of cited Argentinian helminths is broadened, adding in this study new locations of the provinces of Corrientes and Misiones.

With the exception of Limatulum oklahomense, which was located solely in the stomach, all helminths were located in the intestinal track. Considering the ecological analysis, Molossus rufus was observed the most abundant one, being present in eight helminth species, five trematodes, two nematodes and one cestode. In Artibeus lituratus, Sturnira lilium and Eumops perotis only one parasite specie was observed (V. guarany, Capillaria sp. and Anoplostrongylus sp., respectively). Nevertheless, all three cases represented new associations host/parasite. No helminth were found in filostomides Platyrrhinus lineatus and Desmodus rotundus.

When component populations of molosides were analyzed, Urotrema scabridum was the dominant and most prevalent specie $(68,4 \%)$, reaching its maximum media abun- 
dance $(50,0)$ and media intensity $(56,9)$ in $E$. patagonicus. Also, in vespertilionida the dominant and most prevalent specie $(29,3 \%)$ was L. oklahomense, reaching its maximum media abundance $(2,4)$ in $M$. albescens and its maximum media intensity $(13,7)$ in $M$. cf nigricans. Nevertheless, when comparing the component community of each host species in both families, similar values of diversity, equitability and dominance was observed. This reflects a low dominance and an equivalent representability of the taxa parasites. At infracommunity level, mono and bispecific infections were observed to be predominant; with the exception of Eumops patagonicus in which multiple infections (three to five species) percentage was elevated $(55,0 \%)$.

Central, secondary and satellite species were defined when analyzing E. patagonicus helminth community. U. scabridum was defined as a central specie; Pterygodermatites sp. a satellite one and all the rest (Vampirolepis guarany, Gymnoacetabulum talavarensis, Ochoterenatrema labda, Paralecithodendrium aranhai and Anoplostrongylus sp.) were secondary species.

Host trophic habit clearly determined a distinction of the helminth fauna found in them. In one hand, frugivorous bats were found only two helminth species (Vampirolepis guarany (Cestoda) and Capillaria sp (Nematoda). On the other hand, insectivorous bats were found all taxa identified in the present work.

Considering the relationship between parasitological indicators and sex, a significant difference with respect to media intensity was registered in E. patagonicus males. In addition, considering the relationship between parasitological indicators and size, inverse significant relationship with the intensity of the general infection such as some specific E. patagonicus were only observed with the U. scabridum in Molossus rufus and Myotis albescens intensity of infection.

When integrating these results with the known South American helminth fauna, 23 new host/parasite associations were found. Six new taxa were added to E. patagonicus molossid (Gymnoacetabulum talavarensis, Ochoterenatrema labda, Paralecithodendrium aranhai, Urotrema scabridum (Trematoda), Anoplostrongylus sp., Pterygodermatites sp. (Nematoda), four to M. rufus (Limatulum oklahomense, Ochoterenatrema labda (Trematoda), Anoplostrongylus sp., Capillaria sp. (Nematoda), three to M. temminckii (Anenterotrema eduardocaballeroi, O. labda (Trematoda), Capillaria sp.) and one to E. perotis (Anoplostrongylus sp.). Considering phyllostomids, one taxon is added to Artibeus lituratus (V. guarany) and one more to S. lilium (Capillaria sp.). Examining vespertilionids four taxa were added to Myotis albescens (G. talavarensis, L. oklahomense, O. labda, $U$. scabridum -Trematoda-), one to Myotis cf nigricans (P. aranhai -Trematoda-) and two to Eptesicus furinalis (Vampirolepis cf macroti -Cestoda-), Anoplostrongylus sp.-Nematoda-).

Finally, when oriented the results to a regional perspective, this study contribution to Argentinian bats parasites has been notoriously accomplished. The number of helminth species known in Argentina upgraded from 20 to 25, enriching the inventory of helminth 
associated to nine bats species with 23 new associations. The continuity and widening of the taxonomic study and the approximation of the ecological estimations, such as were developed in the present investigation; improve the knowledge and the generation of the foundations for the parasite/host/environment relationship study. It will influence not only in wild and domestic animals but also in men parasite fauna. 

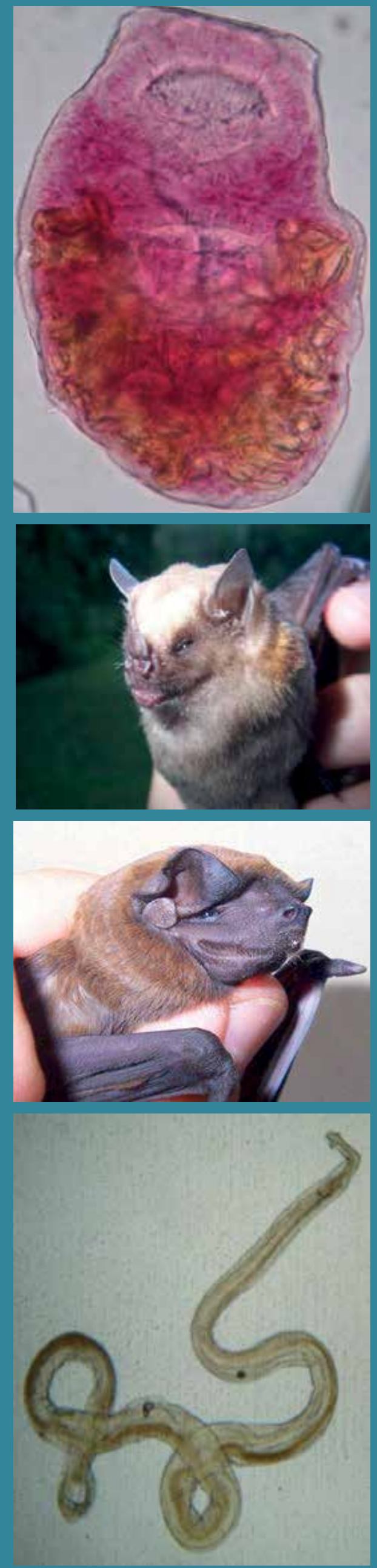

Capítulo I

\section{INTRODUCCIÓN}




\section{CAPÍTULO I}

\section{INTRODUCCIÓN GENERAL}

\section{I.1 Antecedentes y fundamentos}

Usualmente la biodiversidad está relacionada con organismos de vida libre, olvidando a los parásitos como representantes de la biodiversidad global. Más aun, las formas parásitas constituyen una gran parte de la diversidad de vida y el parasitismo es posiblemente el más común entre todas las estrategias de alimentación (Sukhdeo y Bansemir, 1996). De este modo podemos afirmar que el parasitismo es una de las estrategias de vida más exitosa y diseminada sobre la Tierra e implica una interacción íntima y permanente entre dos organismos, el hospedador y el parásito, cuyas historias de vida están sincronizadas (Windsor, 1998; Graczyk y Fried, 2001).

Dichas relaciones entre parásitos y hospedadores ocurren dentro de una compleja red de interacciones ecológicas, que da oportunidad a nuevas adaptaciones y nuevos resultados evolutivos (Morand et al., 2006). Así, la amplitud y composición de la dieta de los hospedadores influye directamente sobre la riqueza de endoparásitos que presentan; las características del hábitat que frecuentan los hospedadores también pueden explicar la presencia de ciertos parásitos en una población o especie hospedadora. De esta manera, los microhábitats aislados restringen la exposición del hospedador a nuevos parásitos, así como los factores ambientales característicos actúan sobre la supervivencia de los estadios infectivos de huevos o larvas que se encuentran libres en el mismo. Por otro lado, la distribución geográfica que superponen diferentes hospedadores (distribución sintópica o simpátrica), facilita la transferencia de parásitos y como resultado es común hallar mayor riqueza específica en aquellos hospedadores que presentan rangos geográficos amplios, que en aquellos que tienen rangos restringidos (Poulin y Morand, 2004).

En este sentido, los parásitos son utilizados también por la ecología contemporánea como indicadores del comportamiento de sus hospedadores. Sus complejos ciclos de vida están integrados dentro de intrincadas tramas etológicas y tróficas, y de este modo, pueden ser buenos indicadores de la estructura de estas redes, como así también de las preferencias y el modo de desplazamiento de sus hospedadores. En este marco, los parásitos pueden sugerir diferencias en una misma población hospedadora -cambios de dieta o uso diferencial de microhábitats- o determinar el rol de cada población hospedadora dentro de la comunidad, diferenciándolas en residentes y colonizadoras (Brooks yHoberg, 2000).

Asimismo, se reconoce al parasitismo como un fenómeno que contribuye a la configuración de las comunidades hospedadoras al afectar su supervivencia y modificar sus interacciones tróficas. Esto significa que las infecciones parasitarias actúan como potentes agentes de selección natural de las poblaciones hospedadoras ya que, aunque posible- 
mente no tengan un efecto mortal, las cargas subletales afectan la eficiencia de la digestión y absorción de alimentos reduciendo la biomasa del hospedador, afectando su movilidad y reduciendo la fecundidad (Wisnivesky, 2003).

De este modo, todas aquellas investigaciones que tiendan a dilucidar alguno de los aspectos mencionados acerca del sistema parásito-hospedador contribuirán, de manera concomitante, a clarificar aspectos bioecológicos de las poblaciones hospedadoras y el rol de los parásitos dentro de los ecosistemas (Hudson, 2006).

Si bien en Argentina se están llevando a cabo importantes investigaciones sobre biodiversidad y ecología parasitaria, las mismas están orientadas fundamentalmente al estudio en peces, aves y roedores (Sardella y Timi, 2004; Sutton y Lunaschi, 1980; 1990; 1994; Sutton et al., 1997; Drago y Lunaschi 2008; 2010; 2011a; 2011b; Drago et al. 2007b; 2011; Lunaschi y Drago, 2004; 2005; 2006; 2009a; 2009b; 2010a; 2010b; 2012; Lunaschi et al. 2007; Digiani y Durette-Desset, 2003a; 2003b; Digiani et al., 2003; Notarnicola, 2004; Navone et al., 2010, entre otros).

En este sentido, los micromamíferos ofrecen un extraordinario ejemplo de radiación evolutiva entre los mamíferos modernos. Su ubicuidad y gran tamaño poblacional hacen de estos uno de los modelos favoritos para desarrollar estudios parasitológicos (Morand et al., 2006). En particular los quirópteros presentan una diversidad en cuanto a hábitos alimenticios que los convierten en un buen modelo para el estudio de parasitofauna.

A nivel global, se estima que las 1116 especies de murciélagos conocidas podrían albergar unas 4400 especies parásitas (Gardner y Jimenez Ruiz, 2009). En la Región Neotropical los quirópteros superan en número de especies a todos los demás mamíferos (excepto roedores) y están representados por nueve familias, tan ricas en número de especies como en hábitos de comportamiento (Gardner, 2007). Sólo cuatro de estas familias (Phyllostomidae, Noctilionidae, Molossidae y Vespertilionidae) se distribuyen en la Argentina y de las 63 especies de murciélagos presentes en nuestro país, aproximadamente la mitad habita la región mesopotámica en el nordeste argentino (Barquez y Díaz, 2009).

Los murciélagos ocupan varios niveles en las cadenas alimenticias, lo que sumado a su alta diversidad los hace reguladores de importantes y complejos procesos ecológicos en los bosques tropicales (Ochoa, 1992). Así, tienen un gran potencial como indicadores de niveles de intervención en el hábitat y pueden ofrecer una buena visión del estado de conservación de un ecosistema debido a que explotan diferentes recursos tróficos (Fenton et al., 1992; Ochoa, 1992). Además, viven mucho tiempo con bajas tasas de reproducción y ciclos poblacionales (Findley, 1993). Estas características los hacen vulnerables en hábitats modificados, lo que ha llevado a la declinación de muchas poblaciones de quirópteros y algunas están en peligro o amenazadas como consecuencia de la alteración del hábitat. Resulta entonces fundamental fomentar los estudios sobre este grupo de mamíferos (Barquez y Díaz, 2009). 
En este sentido, el conocimiento de la diversidad de quirópteros ha sido acompañado por estudios parasitológicos en México, Cuba, Costa Rica, Ecuador, Colombia, Paraguay y Brasil desde 1900 (Braun, 1900; Travassos 1921; 1928; Viana,1924; Stunkard, 1938, entre los más antiguos) llegando a las últimas décadas del siglo XX con los trabajos de Mañé-Garzón yTelias (1965) Mañé-Garzón y González (1976) Marshall y Miller (1979), Odening (1973), Vaucher (1981), Boeger et al. (1985), Vélez y Thatcher (1992a; 1992b), Pérez-Ponce de León et al. (1996) y Portes Santos y Gibson (1998) quienes ampliaron considerablemente el conocimiento de su parasitofauna.

Si bien estos estudios tuvieron continuidad en algunos países de la región Neotropical, en Argentina han tenido un tratamiento esporádico. De este modo Boero y Led (1971), Lunaschi (2002a; 2004; 2005), Lunaschi et al. (2003), Lunaschi y Notarnicola (2010) y Lunaschi y Drago (2011) han estudiado principalmente la fauna trematodológica de algunas especies pertenecientes a la familia Mollossidae y Vespertilionidae.

Recientes estudios amplían el conocimiento acerca de nematodes de murciélagos del noroeste de Argentina (Oviedo y Claps, 2010; Oviedo et al., 2012).

Es evidente el escaso conocimiento existente en nuestro país sobre la endoparasitofauna de quirópteros, siendo el presente trabajo el primer estudio sistemático para la región nordeste.

En este contexto regional se plantean algunos interrogantes respecto a los helmintos parásitos y a las relaciones existentes entre las características biológicas de las especies hospedadoras y los aspectos ambientales:

¿Cuáles son las especies de helmintos que parasitan los murciélagos del nordeste argentino?

¿Las diferentes especies hospedadoras comparten especies parásitas o poseen una fauna parasitaria exclusiva? ¿A qué se debe? ¿Cómo se distribuyen entre las distintas especies hospedadoras?

¿La riqueza específica varía entre especies hospedadoras? ¿Y entre las que pertenecen al mismo gremio trófico? ¿Por qué?

¿A qué nivel taxonómico del hospedador se expresa la especificidad parasitaria?

¿Cómo se distribuyen las poblaciones parásitas respecto a diferentes variables biológicas del hospedador, tales como sexo, peso y longitud?

¿Existen diferencias cualitativas o cuantitativas de la parasitofauna de las mismas especies hospedadoras respecto a otras regiones del país? ¿Y respecto a países limítrofes?

¿Cómo se estructura la comunidad parasitaria?

¿Cuáles son las variables bioecológicas que influyen en la estructura de la comunidad parasitaria? 
Estos interrogantes son los que dan lugar a los objetivos del presente trabajo:

\section{I.2 Objetivos}

\section{Objetivo General:}

- Ampliar el conocimiento acerca de la diversidad de helmintos parásitos de las especies de quirópteros más representativas del Nordeste argentino.

\section{Objetivos específicos:}

- Ampliar el conocimiento taxonómico de parásitos, describiendo potenciales nuevas especies o redescribiendo especies conocidas cuando fuera necesario.

- Estimar la riqueza específica y los indicadores parasitológicos de los helmintos asociados a cada especie hospedadora.

- Comparar la riqueza de helmintos parásitos entre los gremios tróficos de los hospedadores.

- Detectar y seleccionar aquellas asociaciones parásito-hospedador que permitan sugerir si son el resultado de una co-ocurrencia de factores ambientales. 


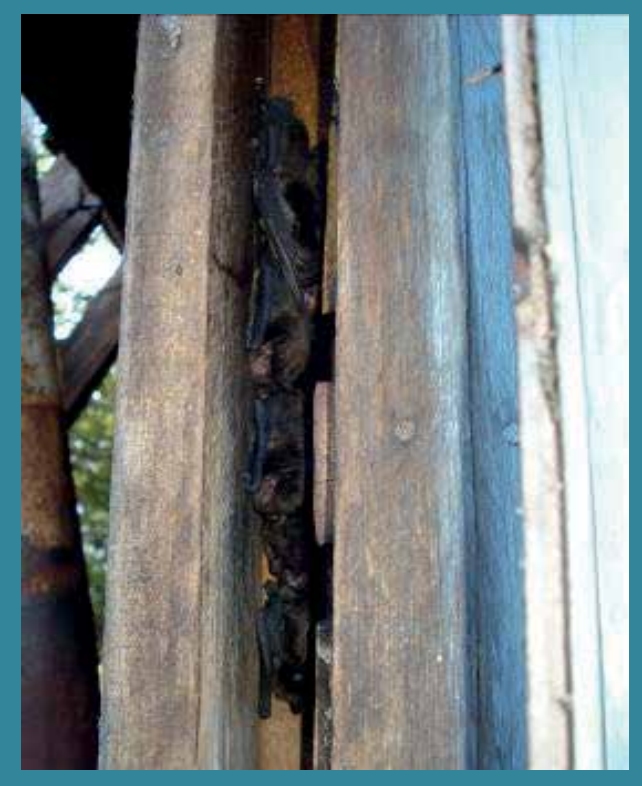

Capítulo II MATERIALES Y MÉTODOS

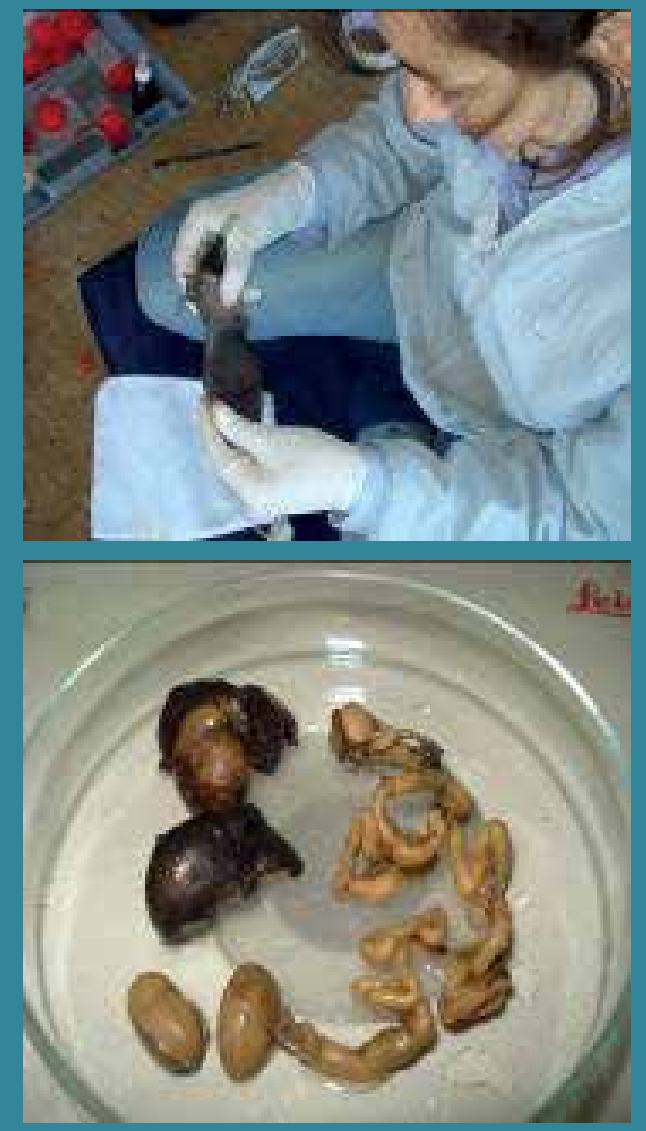




\section{CAPÍTULO II}

\section{MATERIALES Y MÉTODOS}

\section{II.1 Área de estudio}

El Nordeste argentino presenta regiones que reflejan características ecológicas predominantes y particulares que se encuentran relacionadas con límites faunísticos. El número de regiones ecológicas o eco-regiones reconocidas para Argentina varía según los autores desde una docena a 18 (Cabrera y Willink, 1980, Burkart et al., 1999, Brown et al., 2006). Estos autores definen como eco-región a un territorio geográficamente definido, con determinadas condiciones geomorfológicas y climáticas relativamente uniformes o recurrentes, caracterizado por una fisonomía vegetal de comunidades naturales y seminaturales que comparten especies dominantes y una dinámica indispensable para su persistencia a largo plazo. En este contexto, la Argentina comprende 15 eco-regiones terrestres continentales, dos marinas y la correspondiente al sector antártico argentino.

Particularmente, en el área de estudio, que incluyó 11 localidades de la provincia de Corrientes y una de la provincia de Misiones, están representadas cinco de las 15 ecorregiones continentales: Campos y Malezales, Chaco Húmedo, Deltas e Islas del Paraná, Espinal y Esteros del Iberá (Figura II.1.1). En esta área existe una escasa variación térmica anual, que determina un clima mesotermal, con un régimen pluvial de aproximadamente $1500 \mathrm{~mm}$ anuales. A continuación se caracteriza en forma sintética cada una de ellas:

* Campos y Malezales: su paisaje predominante es el de extensos pastizales de llanura con relieve ondulado en el norte, mientras que en el sur la llanura es una planicie sedimentaria de escurrimiento lento, sin cauces definidos y con bañados que desaguan en los ríos Miriñay y Aguapey o directamente en el Uruguay. El clima es subtropical húmedo; con lluvias de alrededor de $1500 \mathrm{~mm}$ anuales, uniformes a lo largo del año.

* Chaco Húmedo: el paisaje predominante es un mosaico de franjas de tierras altas, alternando con interfluvios bajos, de esteros y cañadas, con fisonomías de pastizal, sabana, palmares y pajonal. La concentración estacional de lluvias, los desbordes de los ríos, la escasa pendiente y los suelos arcillosos dan lugar a repetidas inundaciones. El clima es subtropical cálido; la temperatura media anual disminuye de norte a sur, desde 23ㅇ a 18 y las lluvias disminuyen de este a oeste (1300 -750 mm medios anuales).

- Delta e Islas del Paraná: comprende los valles de inundación de los trayectos medios e inferiores de los ríos Paraná y Paraguay. En el tramo austral incluye el delta de Paraná y el cauce del Río de la Plata. Puede ser considerada como azonal, debido a que sus rasgos no responden a los grandes factores continentales, como el 
clima y la geología de las zonas que atraviesa. Las lluvias ocasionan el desborde de los cauces de los ríos Paraná y Paraguay y la inundación de las islas vecinas. La presencia de grandes cuerpos de agua produce alta humedad y atenuada diferencia entre los extremos de temperatura diarios y estacionales.

* Espinal: el paisaje predominante es el de llanura plana a suavemente ondulada, ocupada por bosques xeromórficos bajos, sabanas y pastizales, hoy convertidos en gran parte a la agricultura. Las características del suelo son variables. El clima es cálido y húmedo en el norte, templado y seco con déficit hídrico hacia el oeste y sur.

- Esteros del Iberá: cubeta hidromórfica con pendiente general hacia el suroeste y otros esteros menores. Se reconocen diversos componentes del paisaje como lagunas, embalsados de vegetación flotante, esteros y bañados. Los suelos y los albardones son arenosos y con napa freática poco profunda. El clima es subtropical húmedo.

Estas regiones ecológicas tan diversas albergan a su vez una gran riqueza de micromamíferos entre los que se incluyen a los Chiroptera. Si bien no se efectuaron comparaciones de los resultados entre las ecorregiones, se deja planteado el escenario ambiental a fin de enmarcar futuros análisis. En la Tabla II.1.1 se consignan las referencias geográficas de las localidades de muestreo y en la Figura II.1.2 se aprecian algunos de los ambientes relevados. 


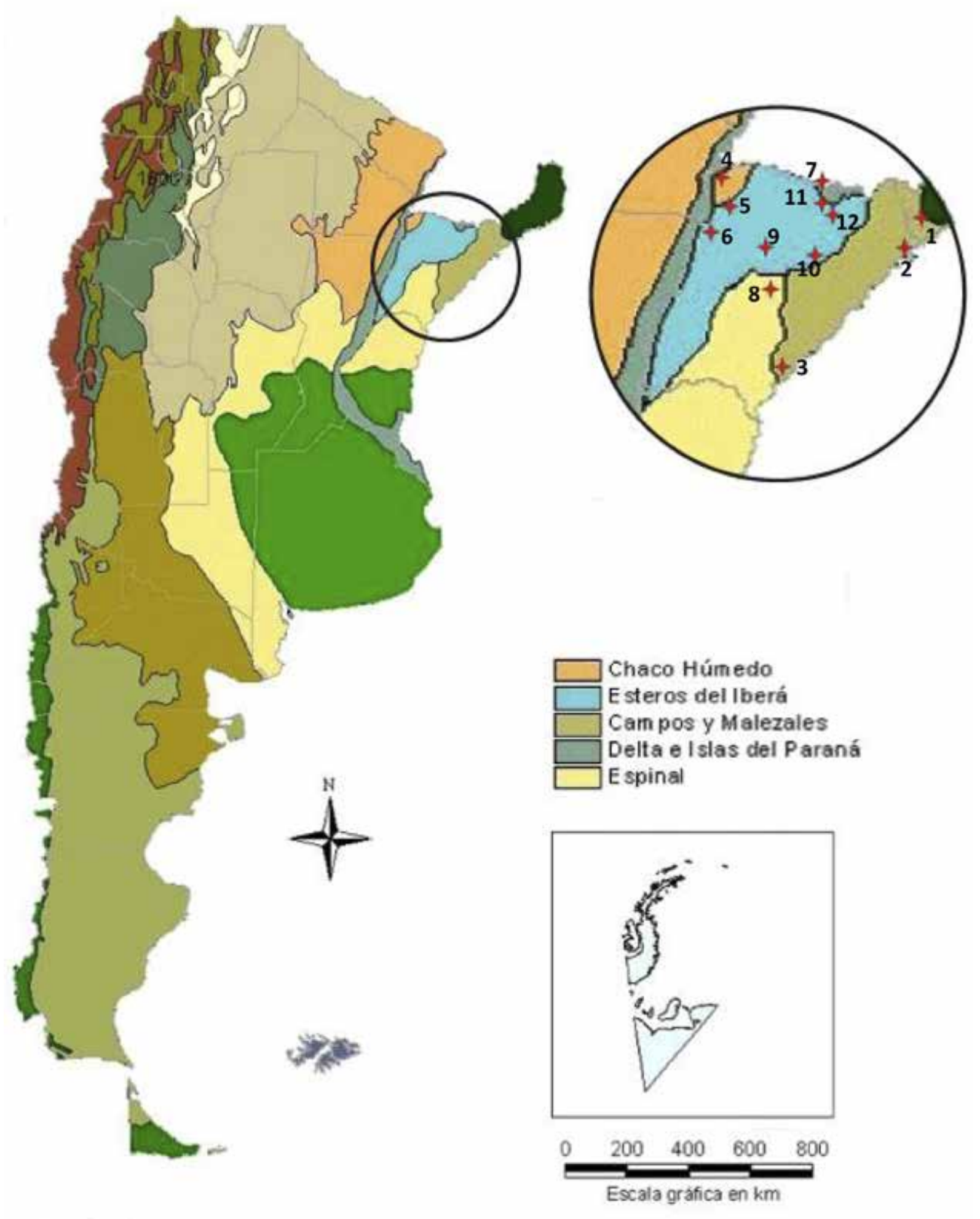

Figura II.1.1: Eco-regiones de Argentina y localidades de muestreo. 
Tabla II.1.1: Localidades de muestreo.

\begin{tabular}{|c|c|c|c|}
\hline Referencia & Provincia & Localidades & Coordenadas \\
\hline 1 & Misiones & Apóstoles & $27 \div 54^{\prime} S-55 \div 45^{\prime} W$ \\
\hline 2 & Corrientes & Garabí & $28 \div 14^{\prime} \mathrm{S}-55 \div 46^{\prime} \mathrm{W}$ \\
\hline 3 & & Cabred & $30 \div 01^{\prime} \mathrm{S}-57 \div 37^{\prime} \mathrm{W}$ \\
\hline 4 & & Capital & $27 \div 28^{\prime} \mathrm{S}-58 \div 50^{\prime} \mathrm{W}$ \\
\hline 5 & & San Isidro & $27 \div 50^{\prime} \mathrm{S}-58 \div 44^{\prime} \mathrm{W}$ \\
\hline 6 & & San Lorenzo & $28 \div 07^{\prime} S-58 \div 46^{\prime} W$ \\
\hline 7 & & Isla Apipé & $27 \div 34^{\prime} \mathrm{S}-56946^{\prime} \mathrm{W}$ \\
\hline 8 & & Mercedes & $29 \div 21^{\prime} \mathrm{S}-57 \div 49^{\prime} \mathrm{W}$ \\
\hline 9 & & Rincón del Socorro & $28 \div 24^{\prime} \mathrm{S}-57 \div 52^{\prime} \mathrm{W}$ \\
\hline 10 & & Carlos Pellegrini & $28 \div 31^{\prime} \mathrm{S}-57010^{\prime} \mathrm{W}$ \\
\hline 11 & & Puerto Valle & $27 \div 37^{\prime} S-56 \div 23^{\prime} W$ \\
\hline 12 & & Rincón Santa María & $27 \div 32^{\prime} \mathrm{S}-56 \div 37^{\prime} \mathrm{W}$ \\
\hline
\end{tabular}



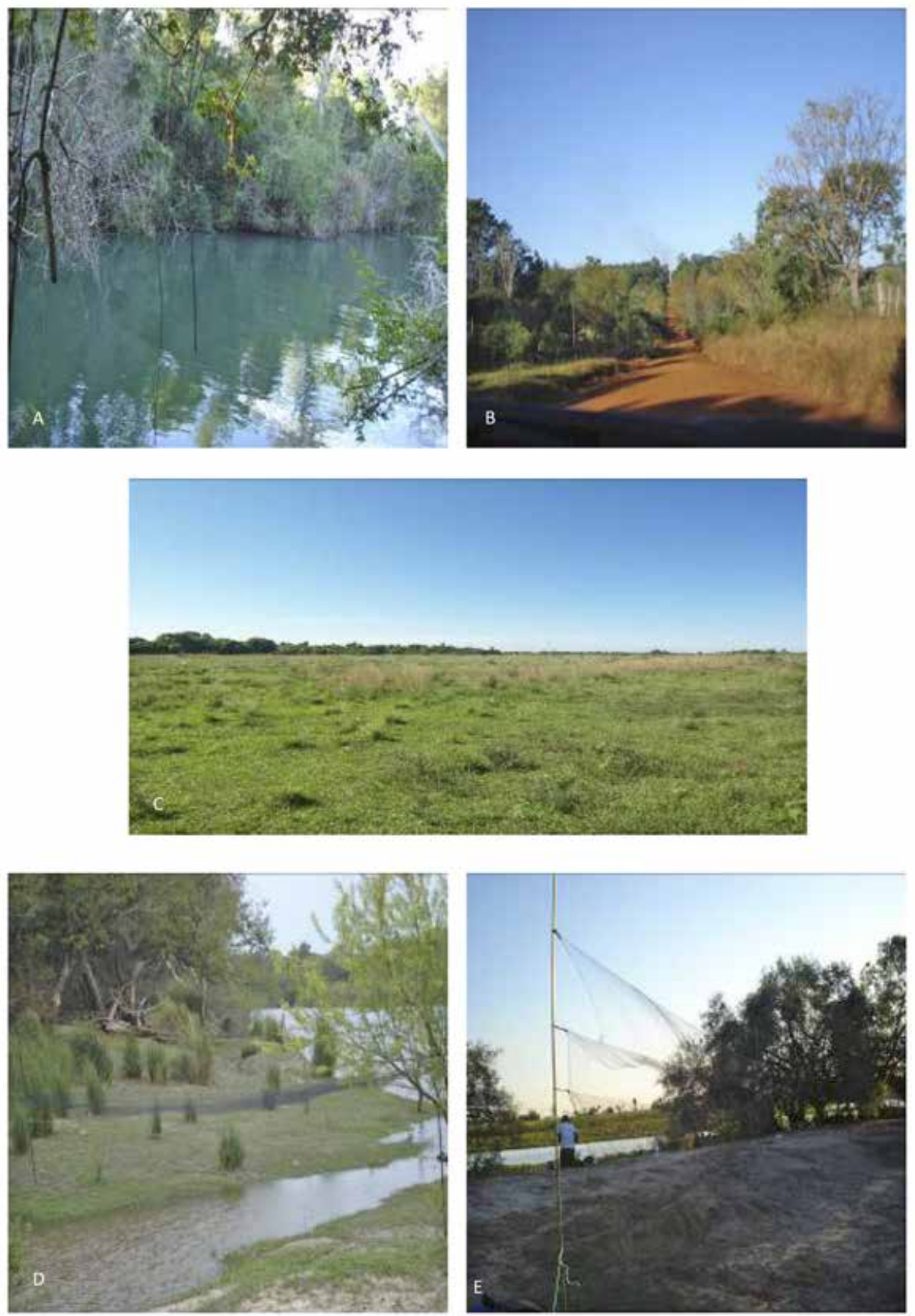

Figura II.1.2: Escenarios de muestreo. A- Puerto Valle; B- Garabí; C- Isla Apipe Grande; D- Cabred; E- Rincón del Socorro. 


\section{II.2 Caracterización de los hospedadores}

Se estudiaron 12 especies de murciélagos pertenencientes a tres familias Mollosidae, Phyllostomidae y Vespertilionidae (Barquez 1993). En la Figura II.2.1 se observan ejemplares de cada especie. A continuación se caracteriza brevemente a cada una de las especies analizadas y se consigna el ambiente en que se efectuó el hallazgo y el método de captura.

\section{Familia Mollosidae Gervais, 1855}

Los molósidos son murciélagos de pequeño a moderado tamaño, caracterizados por poseer uropatagio de considerable tamaño. El uropatagio es una extensión de la piel del abdomen que se extiende hasta la punta de los dígitos uniendo las extremidades superiores con el cuerpo. Todas sus especies poseen unas alas largas y estrechas, aparentemente adaptadas para el vuelo rápido en espacios abiertos. Su distribución es muy amplia: se encuentran en todos los continentes excepto en la Antártica, siendo oportunistas respecto a la ocupación de refugios. Los miembros de esta familia son exclusivamente insectívoros.

Eumops patagonicus (Thomas, 1924): especie abundante en el norte de Argentina, conocida en las provincias de Salta, Jujuy, Tucumán, Santiago del Estero, Formosa, Chaco, Santa Fe, Corrientes y Misiones, con registros aislados en Chubut y Buenos Aires. Su alimentación es insectívora. Común en áreas antropizadas como viviendas y galpones. Numerosos individuos fueron capturados en edificaciones humanas, tanto en áreas urbanas como rurales; asimismo se obtuvieron ejemplares de áreas silvestres capturados en redes de niebla. En el presente trabajo es la especie mejor representada.

$>\quad$ Eumops perotis (Schinz, 1821): abundante, distribuida en las provincias de Salta, Jujuy, Tucumán, Santiago del Estero, Córdoba, Formosa, Chaco y Corrientes. Alimentación insectívora, encuentra sus refugios en grietas, árboles, edificios y viviendas. La captura de un único ejemplar fue fortuita, se halló un macho en el edificio del Campus Universitario, ubicado en las afueras de la ciudad de Corrientes.

$>\quad$ Molossops temminckii (Burmaister, 1854): abundante en la región chaqueña, de distribución en las provincias de Salta, Jujuy, Tucumán, Santiago del estero, Chaco, Formosa, norte de Santa Fe, Corrientes y sur de Misiones. Insectívora, sus refugios son huecos de árboles y viviendas. Escasos ejemplares fueron capturados solamente en áreas silvestres mediante redes de niebla.

Molossus molossus (Pallas, 1776): especie abundante en Salta, Jujuy, Tucumán, Santiago del estero, Córdoba, Formosa, Chaco, Corrientes, Misiones, Entre Ríos y Buenos Aires. Su alimentación es insectívora. Se refugia en huecos de árboles, grietas, cuevas, túneles, alcantarillas, puentes y viviendas. Se obtuvieron escasos individuos provenientes de una colonia mixta con E. patagonicus, localizada en área urbana. La captura se efectuó utilizando redes ubicadas a la salida del refugio. 
Molossus rufus (É. Goeffroy Saint-Hilaire, 1806): es una especie común de Salta, Jujuy, Córdoba, Formosa, Chaco, Corrientes y Misiones. De hábito insectívoro, se refugia en huecos de árboles y techos de viviendas. Se los capturó en ambientes silvestres representados por bosques y refugiados en construcciones humanas, se utilizaron redes de niebla.

\section{Familia Phyllostomidae Gray, 1825}

Es una familia muy diversa en cuanto a su morfología y a su comportamiento. La mayor parte son insectívoros, pero hay muchas especies polinívoras y nectarívoras como los Glossophaginae y frugívoras como los Stenodermatinae y Carolliinae. Hay especies que depredan sobre peces, ranas, lagartos, y otros vertebrados, incluyendo en su dieta otros murciélagos como Vampyrum spectrum L., el Falso vampiro, que es capaz de cazar aves del tamaño de una tórtola pequeña. Incluso hay especies hematófagas (subfamilia Desmodontinae).

Artibeus lituratus (Olfers, 1818): es una especie común en los bosques en galería de Formosa y Corrientes y abundante en Misiones. Su dieta es principalmente frugívora, incluye hojas y flores y algunos autores han reportado insectos y frutos cultivados. Se refugia entre el follaje de árboles altos, cuevas y grietas. Varios ejemplares fueron observados al atardecer alimentándose de frutos y capturados mediante redes de niebla, en ambientes silvestres del Noreste de Corrientes y Sur de Misiones.

$>$ Desmodus rotundus (É. Goeffroy Saint-Hilaire, 1810): Especie abundante distribuida ampliamente en todos los ambientes fitogeográficos del país hasta los 33 o S. Se alimenta de sangre de mamíferos. Sus refugios son cuevas naturales, túneles, pozos de agua, huecos de árboles, alcantarillas y viviendas abandonadas. Los ejemplares fueron capturados manualmente de refugios consistentes en construcciones humanas.

Platyrrhinus lineatus (É. Goeffroy Saint-Hilaire, 1810): especie escasa de distribución en las Provincias de Chaco, Misiones y Corrientes. Reconocida como frugívora, aunque algunos autores han reportado insectos dentro de su dieta. Sus refugios son desconocidos en Argentina. Los dos ejemplares estudiados fueron colectados mediante redes de niebla.

Sturnira lilium (É. Goeffroy Saint-Hilaire, 1810): es una especie abundante, de distribución en las provincias de Salta, Jujuy, Tucumán, Catamarca, Formosa, Chaco, Santa Fe, Entre Ríos, Misiones y Corrientes. De hábito alimenticio frugívora, probablemente también se alimente de pólen y néctar. Su refugio se halla entre hojas y huecos de árboles. Los individuos fueron capturados en ambientes silvestres con redes de niebla y manualmente de una construcción humana utilizada como refugio. 


\section{Familia Vespertilionidae Gray, 1821}

Es la familia más diversificada, se distribuyen por toda clase de hábitats, desde tropicales hasta desérticos. Anidan en cuevas y otros refugios. Según la especie, pueden ser solitarios o gregarios; las especies de zonas templadas pueden emigrar o hibernar. Está compuesta por especies únicamente insectívoras de amplia dispersión. En la región Mesopotámica se encuentran representados todos los géneros de Argentina.

Eptesicus furinalis (d`Orbigny y Gervais, 1847): abundante, se la encuentra prácticamente en todas las provincias del norte y centro de argentina, hasta los $37^{\circ} \mathrm{S}$, aunque no fue registrada en San Juan ni San Luis. De hábito insectívoro, sus refugios son poco conocidos, utilizaría corteza y huecos de árboles y techos de viviendas rurales. Los individuos fueron colectados en ambientes silvestres mediante redes de niebla.

Myotis albescens (É. Goeffroy Saint-Hilaire, 1806): especie abundante de distribución en las provincias de Salta, Tucumán, Santiago del Estero, Formosa, Chaco, Buenos Aires, Entre Ríos, Misiones y Corrientes. De hábito insectívoro. Sus refugios son grietas de rocas, corteza de árboles y viviendas de áreas urbanas y rurales. Los ejemplares fueron capturados en ambientes silvestres mediante redes de niebla y extraccción manual de refugios.

> Myotis nigricans (Schinz, 1821): especie abundante, comparte la distribución de $M$. albescens y el mismo hábito alimenticio. Como refugio prefiere ambientes antropizados como puentes, alcantarillas y techos de viviendas, además de encontrárselo bajo corteza de árboles. Fueron colectados de ambientes silvestres tanto mediante redes de niebla como manualmente de refugios (construcción humana). 

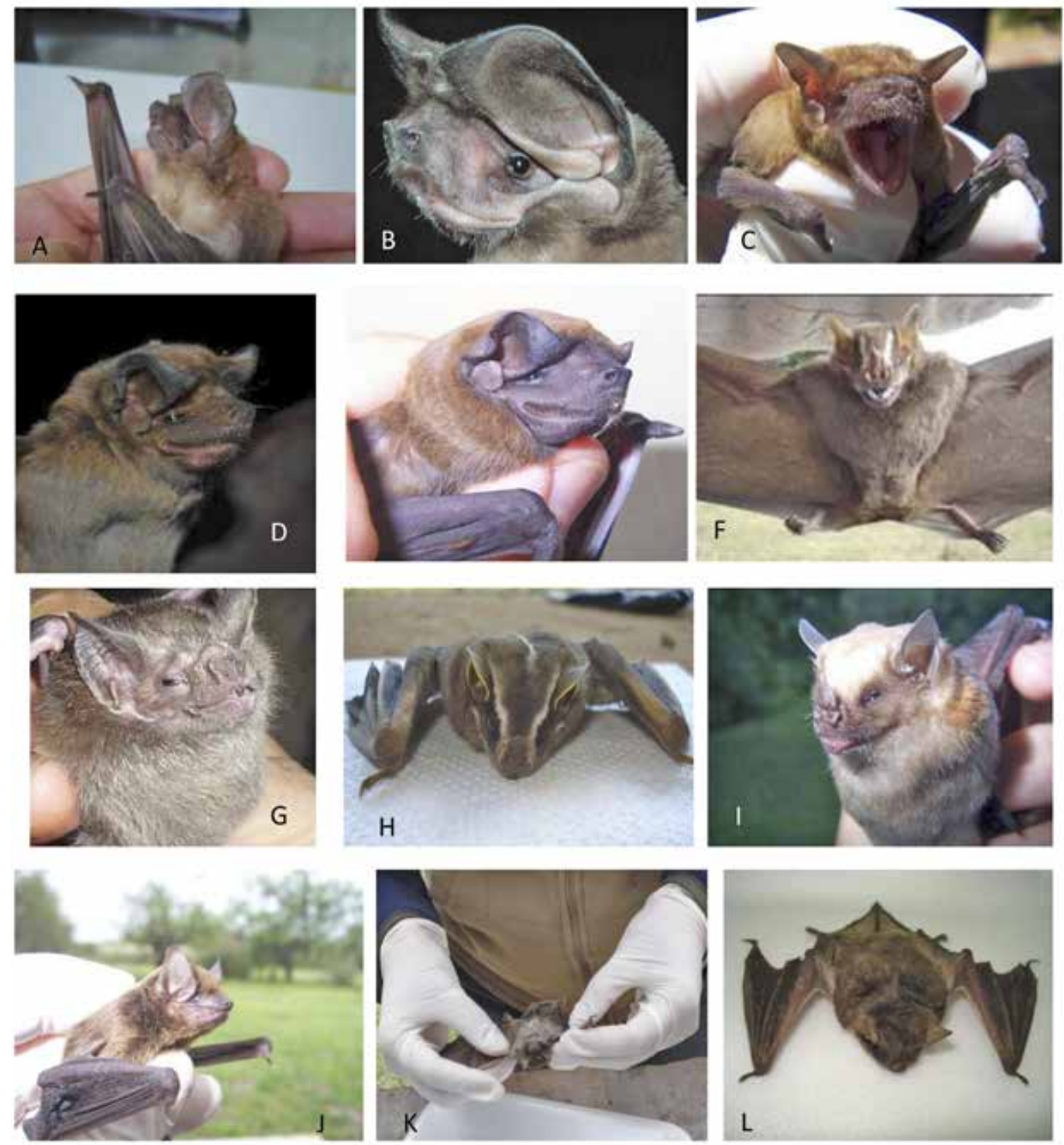

Figura II.2.1. Especies hospedadoras. Familia Mollosidae: A-Eumops patagonicus; B-Eumops perotis; C-Molossops temminckii; D-Molossus molossus; E-Molossus rufus. Familia Phyllostomidae: F-Artibeus lituratus; G-Desmodus rotundus; H-Plathyrrinus lineatus; I-Sturnira lilium. Familia Vespertilionidae: J-Eptesicus furinalis; K-Myotis albescens; L-Myotis of nigricans. 


\section{II.3 Muestreo de hospedadores y procesamiento de helmintos}

Se efectuaron muestreos entre diciembre 2008 y abril de 2011. Los murciélagos se capturaron manualmente y mediante el uso de redes de niebla. En cada localidad se efectuó un muestreo de cuatro noches y se utilizaron seis redes (dos de doce metros y cuatro de seis metros) por noche. Lo que implicó un esfuerzo de muestreo de 192 metros por localidad y 48 noches de exposición. Las redes se colocaron en distintos ambientes del área y permanecieron abiertas desde las 19 hs hasta las 5 hs. Dependiendo de la abundancia de murciélagos, cada red fue controlada cada dos o tres horas, momento en el cual cada uno de los individuos fue retirado y colocado, individualmente, en bolsas de tela. Además se detectaron refugios naturales y artificiales en los cuales se efectuó captura activa en forma manual (Figura II.3.1).

En el campo, los hospedadores fueron sacrificados mediante éter sulfúrico, sexados, pesados y medidos, los instrumentos utilizados fueron una balanza de precisión de 0,5 g y un calibre mecánico. La identificación taxonómica se efectuó utilizando la clave de murciélagos de Argentina de Barquez y Díaz (2009) y se contó con la participación del Lic. Fabricio Idoeta del Laboratorio de Anatomía Comparada de la Facultad de Ciencias Naturales y Museo (UNLP), dedicado al estudio de murciélagos. Se efectuó la evisceración de órganos y se examinó la cavidad del cuerpo, los órganos se conservaron individualmente en formol $10 \%$ y trasladados al laboratorio a fin de efectuar el análisis parasitológico. En el laboratorio, cada órgano fue colocado en una cápsula de Petri y analizado bajo microscopio binocular estereoscópico (Leica EZ4); en estas condiciones se procedió a la colecta de los helmintos. El número de parásitos y su localización fue registrado durante la prospección en planillas confeccionadas "ad-hoc". Los helmintos fueron conservados en alcohol $70^{\circ}$ y para su identificación, los ejemplares fueron estudiados en un microscopio óptico (Olympus $\mathrm{CH} 30$ ). Se realizaron dibujos con cámara clara y las medidas fueron tomadas mediante el empleo de un ocular micrométrico.

Para su estudio, los nematodes fueron diafanizados en Lactofenol de Aman. Los cestodes y digeneos fueron procesados de acuerdo a Salgado Maldonado (2007), siguiendo los pasos de compresión, coloración, deshidratación, diafanización y montaje: Previamente a la coloración, los digeneos fueron comprimidos entre porta y cubreobjetos y sumergidos en alcohol 70\% durante 24 horas. Para la coloración se utilizó Carmín Acético por un lapso muy corto (menos de un minuto) debido al pequeño tamaño de los digeneos y entre dos y cinco minutos para los cestodes. El proceso de deshidratación incluyó una serie de alcohol etílico en concentraciones crecientes (70, 80, 90, 96ㅇ y alcohol absoluto). Se utilizó Xilol para la aclaración y para el montaje se traspasaron los ejemplares a un portaobjeto con una gota de Bálsamo de Canadá sintético y luego se cubrió con el cubreobjetos dejándose secar (Figura II.3.2).

Para la determinación específica se utilizaron claves taxonómicas convencionales para cada grupo parásito. En el caso de los cestodes se utilizó Khalil et al. (1994), para los digeneos Gibson et al. (2002) y para los nematodes Anderson et al. (2009). Asimismo, se 
utilizaron descripciones de trabajos específicos, cuando fue necesario. Los murciélagos se encuentran depositados en el Laboratorio de Anatomía Comparada de la Facultad de Ciencias Naturales y Museo (UNLP) y los helmintos en el Laboratorio de Biología de los Parásitos de la Facultad de Ciencias Exactas y Naturales y Agrimensura (UNNE).

En la sección Anexo se provee de información correspondiente a las variables biológicas sexo, peso y longitud de los hospedadores analizados (Tabla A.1). 

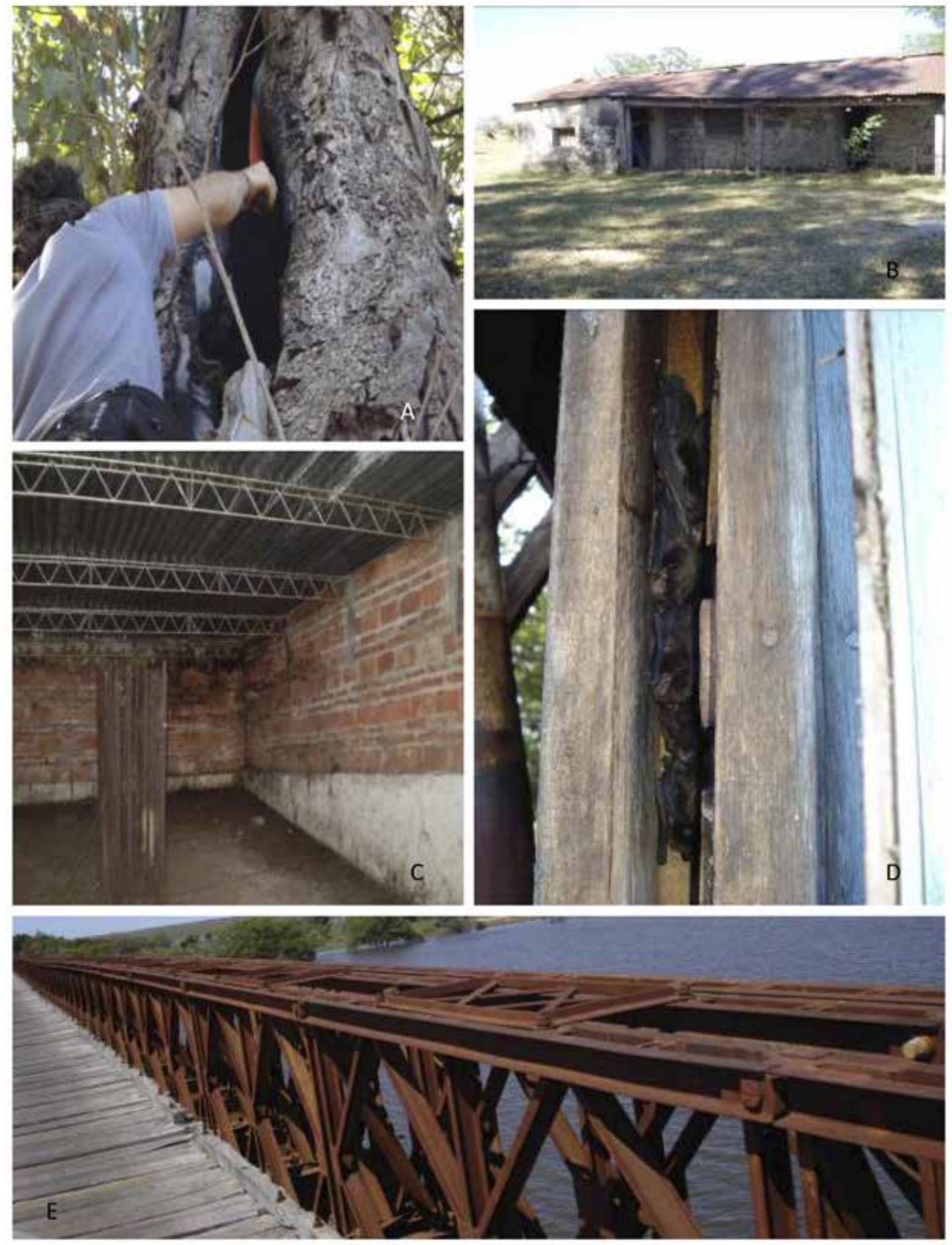

Figura II.3.1 Refugios naturales y artificiales utilizados por los murciélagos. A- hueco de árbol; B- depósito; C- entrepiso; D- espacio entre tablas de pared externa; E- estructura de puente. 

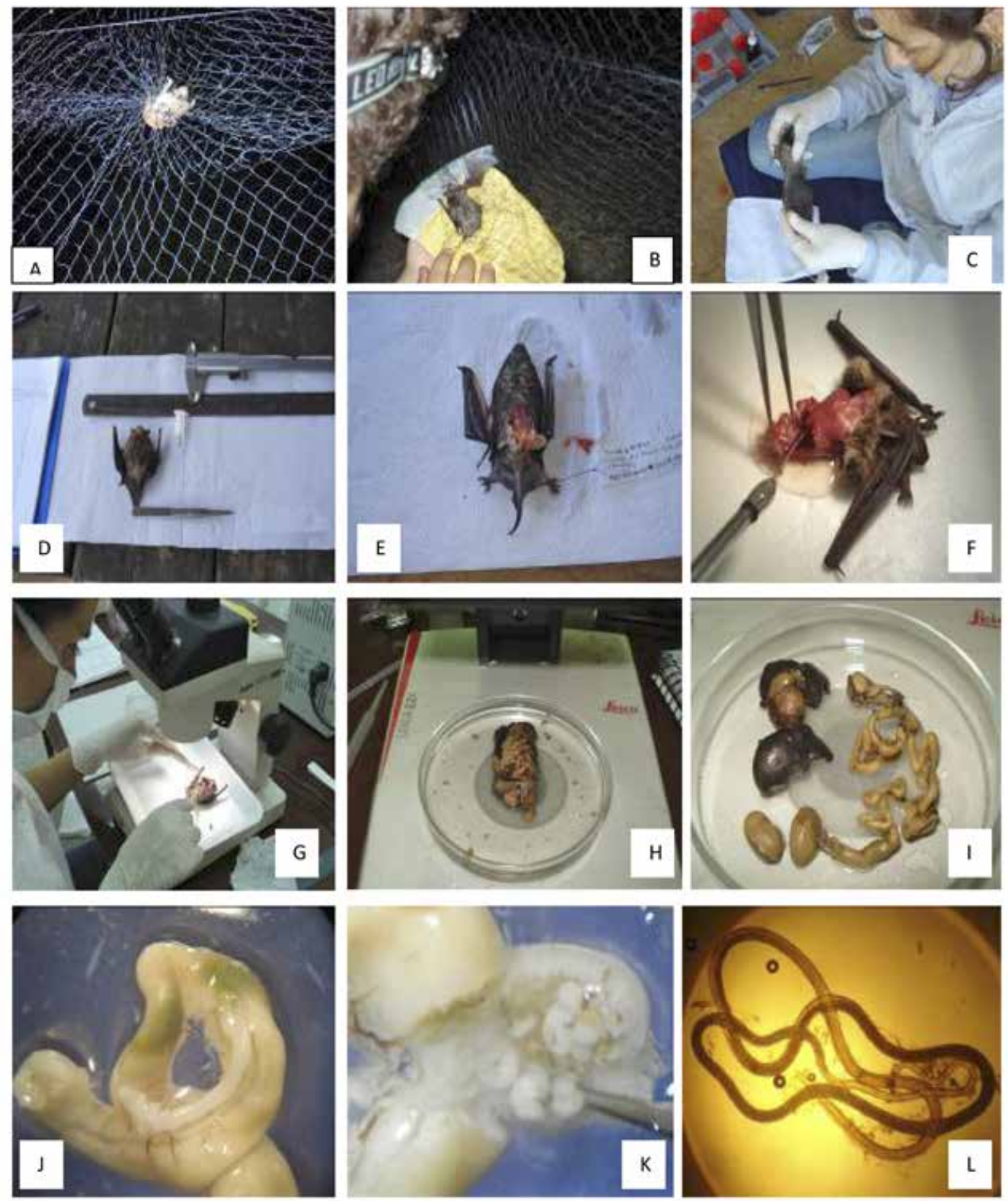

Figura II.3.2 Obtención del hospedador, prospección de órganos y recolección de helmintos. A-G trabajo de campo; $\mathrm{H}-\mathrm{L}$ trabajo de laboratorio. 


\section{II.4 Procesamiento de la información}

Análisis estadístico

Los datos se registraron en una base de datos diseñada en una planilla de Excel. Para obtener los indicadores de infección parasitaria y los índices ecológicos se utilizaron los software Quantitative Parasitology 3.0 (Reiczigel y Rozsa, 2005), PAST (Hammer et al., 2001), Infostat. Las pruebas de significación se hicieron a nivel $\alpha=0,05$.

Los niveles de estudio parasitológico abarcados fueron infrapoblación y población componente e infracomunidad y comunidad componente, de acuerdo a Bush et al. (1997).

A nivel de población se estimaron los índices parasitológicos (prevalencia, abundancia e intensidad de las especies parásitas presentes) y el índice de dispersión.

\section{Parámetros cuantitativos evaluados a nivel de población}

Se calcularon los siguientes índices parasitológicos:

- Prevalencia (P): número de hospedadores infectados con 1 o más individuos de una especie particular de parásito (o grupo taxonómico), respecto del número total de hospedadores examinados en un momento dado, se expresa en porcentaje.

- Abundancia: número de individuos parásitos de una especie particular en un individuo hospedador examinado (esté o no infectado).

- Abundancia media (AM): media aritmética del número de parásitos de una especie por hospedador examinado, considerando tanto hospedadores infectados como no infectados.

- Intensidad: número de individuos de una especie particular de parásito en un único hospedador infectado.

- Intensidad media (IM): intensidad promedio de un taxón particular de parásito, entre los miembros infectados de una especie particular de hospedador.

La distribución espacial de cada población de digeneos se calculó mediante:

- Relación varianza/media: para calcular el índice de dispersión (iD):

\section{$\mathrm{S}^{2} / \mathrm{X}$}

La agregación es definida por la magnitud de la diferencia entre la varianza $\left(\mathrm{S}^{2}\right)$ y la media $(X)$ de la población. Cuando la varianza es mayor al promedio de parásitos por hospedador, se trata de una distribución agregada $\left(S^{2} / X>1\right)$, en caso contrario la distribución es uniforme o regular $\left(\mathrm{S}^{2} / \mathrm{X}<1\right)$. Cuando la distribución es aleatoria o al azar, tanto la varianza como el promedio de parásitos por hospedador son iguales $\left(S^{2} / X=1\right)$. 


\section{Parámetros cuantitativos evaluados a nivel de comunidad}

Se calcularon los siguientes índices (Magurran, 1988):

- Riqueza Específica (S): número de especies presentes en la comunidad.

- Diversidad $\left(\boldsymbol{H}^{\prime}\right)$ : estima la relación entre la riqueza específica y la abundancia relativa de las especies -equitabilidad o uniformidad- en la comunidad. Se obtiene mediante el Índice de Diversidad de Shannon-Wiener:

$$
H^{\prime}=\sum(\pi) .(\ln \pi)
$$

Donde $\pi=$ proporción de los individuos de la especie i en la muestra.

Para obtener el índice de diversidad los datos de abundancia se transformaron a logaritmo decimal $\left(\log _{10}\right)$.

- Equitatividad (E): mide la diferencia entre la diversidad observada y la esperada (o diversidad máxima); varía entre 0 y 1 ; se aproxima a 0 cuando una especie es ampliamente dominante en el seno de la comunidad y a 1 cuando todas las especies tienen una abundancia similar:

$$
\mathrm{E}=\mathrm{H}^{\prime} / \mathrm{D} \text { máx }
$$

$H^{\prime}$ : índice de diversidad de Shannon-Wiener.

D máx: diversidad máxima. La diversidad máxima es aquel valor que se obtendría en una comunidad en la cual todas las especies tendrían una abundancia similar, y se expresa como: D' máx.= Ln S.

La Riqueza específica, la Diversidad y la Equitatividad se midieron a nivel de comunidad componente.

- Especie Dominante $(\boldsymbol{d})$ : se obtuvo utilizando el Índice no paramétrico de Berger- Parker, el cual permite conocer la proporción de la especie más abundante respecto del número total de parásitos en la muestra:

$$
d=\mathrm{Nmax} / \mathrm{Nt}
$$

Nmax= abundancia máxima

$\mathrm{Nt}=$ abundancia total.

- Coeficiente de similaridad (CSS): se utilizó el coeficiente de Sфrensen para expresar el grado de semejanza entre comunidades (Brower y Zar, 1977).

-Especies centrales, satélites y secundarias: se siguieron los criterios establecidos por Bush y Holmes (1986). 
Variables biológicas del hospedador (peso, longitud y sexo) en relación a la intensidad de infección y a la riqueza de especies:

- Se utilizó el Test-U de Mann-Whitney`s para comparar la abundancia de infección y la riqueza específica con el sexo de los hospedadores.

-Se utilizó el Test de Correlación por rangos de Spearman $\left(r_{s}\right)$ para determinar la relación entre el peso de los hospedadores y la riqueza específica.

-Se utilizó el Test de Correlación por rangos de Spearman $\left(r_{s}\right)$ para determinar la relación tanto del peso como de la longitud de los hospedadores y la intensidad de infección total y por cada taxón (a nivel específico). Cabe destacar que para calcular la relación con la intensidad de infección, sólo se consideraron aquellos taxones que infectaron a diez o más hospedadores ( $\mathrm{n} \geq 10$ ). Además, este test se utilizó para analizar la intensidad media con la prevalencia a nivel de comunidad de parásitos. 

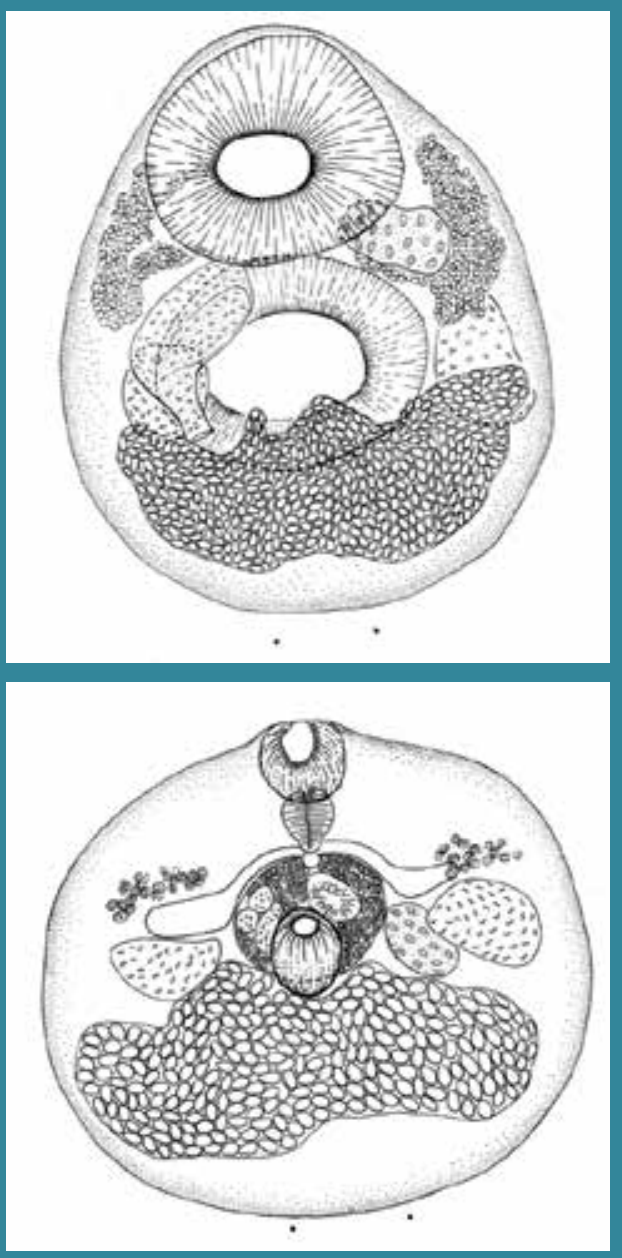

Capítulo III

RESULTADOS

ASPECTOS TAXONÓMICOS
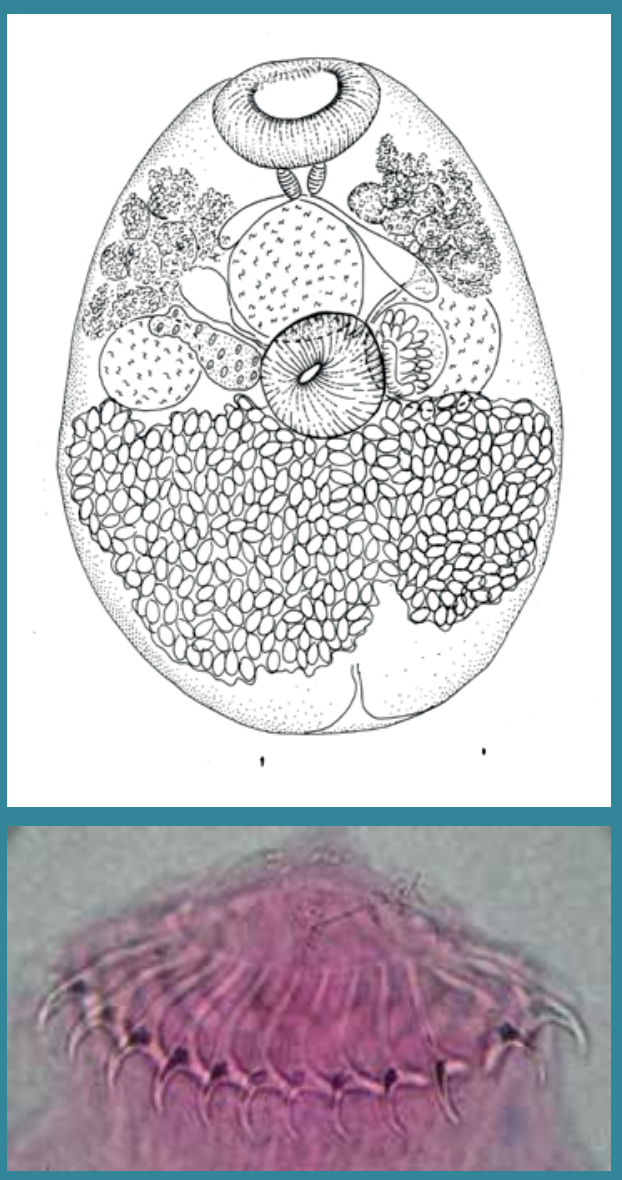


\section{CAPÍTULO III}

\section{ASPECTOS TAXONÓMICOS}

\section{1. Introducción}

Las primeras referencias sobre estudios de helmintos de murciélagos de la Región Neotropical provienen de Brasil y corresponden a Kolenati (1856) quien describió nematodes del género Capillaria Zeder, 1800 (Trichurida, Trichinellidae); posteriormente, Molin (1861) reporta y describe a Histiostrongylus coronatus Molin, 1861 (Strongylida, Molineidae). Más tarde, los trematodes fueron estudiados en Brasil por Travassos (1921, $1928,1955)$. Al mismo tiempo, desde inicios de la década de 1930, Pérez-Vigueras efectúa investigaciones sobre los helmintos de filostómidos de Cuba (1934, 1935, 1936, 1940, 1941a, 1941b, 1942). Simultáneamente, los nematodes de murciélagos de América tropical fueron estudiados exhaustivamente por Lent y Teixeira de Freitas (1936, 1940) y Lent et al. $(1945,1946)$.

La fauna de cestodes de murciélagos está relativamente bien estudiada en Europa, Noreste asiático y Norteamérica, con un registro de 117 especies. Si se considera que la diversidad de micromamíferos en áreas tropicales es mayor, podría predecirse una mayor diversidad de especies de cestodes, sin embargo la información para áreas tropicales es muy fragmentaria. En Argentina se conocen dos registros de cestodes en murciélagos: Vampirolepis dicipiens Spasskii, 1954 y V. elongatus Rego, 1962, parásitos de Eumops abrasus y Pygoderma bilabiatum Wagner (Boero y Delpietro, 1970). En términos generales el ciclo de vida de los cestodes es heteroxeno; los murciélagos cumplen el rol de hospedadores definitivos y los hospedadores intermediarios involucrados son insectos, ácaros, miriápodos y, en algunos casos, arácnidos. Los ciclos de vida de las especies que parasitan a murciélagos no son conocidos (Georgiev et al., 2006).

Los digeneos son parásitos con un complejo ciclo de vida y los micromamíferos son frecuentes hospedadores definitivos y están distribuidos en todo el mundo. A nivel mundial 15 familias de digeneos fueron halladas parasitando a 13 familias de quirópteros. Las familias Vespertilionidae y Phyllostomidae poseen la fauna más rica (Feliu et al., 2006). La fauna parasitaria referida a digeneos de murciélagos del Neotrópico fue bien documentada por Caballero (1940; 1960), Pérez-Ponce de León et al. (1996) y Guzmán-Cornejo et al. (2003) en México; por Bärtschi (2002) en Belice; Thatcher (1982), Castiblanco y Vélez (1982), Vélez y Thatcher (1990), Caro et al. (2003) en Colombia; Travassos (1928), Travassos et al. (1969), Foster y Mertins (1996), Portes Santos y Gibson (1998) y Pesenti et al. (2015) en Brasil; Marshall y Miller (1979) en Ecuador; Caballero y Brenes (1957) en Costa Rica; Pérez Vigueras (1940), (1960), Odening (1973), Zdzitowiecki y Rutkowska (1980) en Cuba; Caballero (1960) en Honduras; Caballero (1964) y Thatcher (1982) en Panamá; Lent et al. (1945), Vaucher (1981) en Paraguay; Dubois (1983) en Perú, Ma- 
ñé-Garzón y Telias (1965), Mañé-Garzón y González (1976) en Uruguay. En Argentina, hasta el año 2010 solo tres (Myotis nigricans Schinz, Myotis levis Geoffroy y Tadarida brasiliensis Geoffroy) de las más de 60 especies de murciélagos registradas para el país, fueron dadas a conocer como hospedadores de digeneos (Barquez et al., 2006; Lunaschi 2002a, 2002b, 2004, 2005, 2006; Lunaschi et al. 2003). A partir del trabajo de Lunaschi y Notarnicola (2010) se amplió la lista de especies hospedadoras al citar a Eumops bonariensis Peters y Molossops temminkii Burmeister.

La nematofauna que parasita a los murciélagos también es muy específica, incluye especies de ciclo directo e indirecto. A nivel mundial se reconocen 34 géneros de nematodes asociados a quirópteros (Ubelaker, 1970; Morand et al., 2006) y en el Neotrópico se registran 53 especies parasitando a murciélagos (Santos y Gibson, 2015). En Argentina los estudios son escasos, durante más de 20 años solo se tuvo el registro del tricostrongílido Allintoshius baudi Vaucher y Durette-Desset, 1980 parásito del vespertiliónido Myotis aelleni Baud en la provincia de Chubut (Vaucher y Durette-Desset, 1980). Posteriormente se registraron nuevos tricostrongílidos, además de tricúridos y fisaloptéridos en murciélagos de la provincia de Entre Ríos y a Tricholeiperia proencai Travassos, 1937, Cheiropteronema striatum Oviedo, Ramallo y Claps 2010 y Biacantha normaliae Oviedo, Ramallo, Claps y Miotti, 2012 en las provincias de Salta, Jujuy y Tucumán (Ramallo et al., 2007; Oviedo, 2009; Oviedo et al., 2009a; 2009b; 2009c; 2010; 2012).

En el presente trabajo se analiza la fauna de helmintos asociada a especies de murciélagos de las familias Molossidae, Phyllostomidae y Vespertilionidae que se distribuyen en 11 localidades de la provincia de Corrientes y una de la provincia de Misiones.

\section{III.2. Especificaciones metodológicas}

En el presente trabajo se describe la presencia y se efectúa la caracterización morfológica de 12 taxones de helmintos provenientes del análisis de 12 especies de murciélagos. Para cada taxón se provee una ficha taxonómica y se elaboró un mapa de distribución a fin de visualizar los registros previos y el aporte de este estudio. Las medidas de los helmintos expresan los valores mínimos -máximos y entre paréntesis están los promedios ( \pm desvío estándar). Para cada taxón se proveen datos de Prevalencia (\%) e Intensidad media (IM \pm desvío estándar) con sus valores mínimo y máximo. Los nematodes no fueron estudiados exhaustivamente debido al escaso material obtenido y su deficiente estado de conservación. La propuesta de actualización de la checklist de helmintos parásitos de murciélagos sudamericanos se basa en la reciente publicación de Santos y Gibson (2015), publicación que compendia los parásitos de las región neotropical. Además, en la sección Anexo, se adicionó información sobre las medidas de los helmintos, de acuerdo al hospedador en que fueron hallados, cuando estuvieron presentes en más de una especie de murciélago (Tablas A.2 a 8). Si bien estos últimos datos no fueron analizados en el presente trabajo, serán de utilidad para la preparación de publicaciones específicas. 


\section{III.3. Resultados}

Phyllum: Platyhelminthes

Clase: Cestoda

Orden: Cyclophyllidea van Beneden in Braun, 1900

Familia: Hymenolepididae Ariola, 1899

Género: Vampirolepis Spasskij, 1954

V. guarany Rego, 1961

V. cf macroti Zdzitwiecki y Rutkowska, 1980

Clase: Trematoda Rudolphi, 1808

Subclase: Digenea Carus, 1863:

Familia: Anenterotrematidae Yamaguti, 1958

Género: Anenterotrema Stunkard, 1938

A. liliputianum (Travassos, 1928) Caballero, 1964

A. eduardocaballeroi (Freitas, 1960) Caballero, 1960

Familia: Lecithodendriidae Lühe, 1901

Género: Gymnoacetabulum Lunaschi y Drago, 2007

G. talavarensis (Lunaschi, 2002)

Género: Ochoterenatrema Caballero y C, 1943

O. Iabda Caballero y C, 1943

Género: Paralecithodendrium Travassos, 1921

P. aranhai Lent, Freitas y Prença, 1945

Familia: Phaneropsolidae Mehra, 1935

Género: Limatulum Travassos, 1921

L. oklahomense Macy, 1932

Familia: Urotrematidae Posch, 1926

Género: Urotrema Braun, 1900

U. scabridum Braun, 1900

Phyllum: Nemathelminthes

Clase: Nematoda Rudolphi, 1808

Subclase: Adenophorea Chitwood, 1958 
Orden: Enoplida Schuurmans, Stethoven y Delenetz, 1933

Suborden: Trichinellina

Superfamilia: Trichinelloidea Hall, 1916

Familia: Trichuridae (Ransom, 1811) Raillet, 1915

Subfamilia: Capillariinae Raillet, 1915

Género: Capillaria Zeder, 1800

Subclase: Secernetea Linstow, 1905

Orden: Spirurida Chitwood, 1933

Suborden: Spirurina Railliet y Henry, 1915

Superfamilia: Rictularioidea Hall, 1913

Familia: Rictulariidae (Hall, 1915) Railliet, 1916

Género: Pterygodermatites Wedl, 1861

Orden: Strongylida Molin, 1861

Superfamilia: Trichostrongyloidea (Skrjabin y Schulz, 1937) Durette-Desset y Chabaud, 1993

Familia: Molineidae (Skrjabin y Schulz, 1937) Durette-Desset y Chabaud, 1993

Género: Anoplostrongylus Boulenger 1926

\section{Phyllum PLATYHELMINTHES \\ Clase CESTODA}

Orden Ciclophillydea van Beneden in Braun, 1900

Familia Hymenolepididae Ariola, 1899

Es la familia de cestodes con mayor riqueza específica, la mayoría de las especies son parásitos de aves. Para los himenolepídidos que parasitan murciélagos ningún ciclo de vida es conocido, no obstante existen referencias que revelan que diversos órdenes de insectos y anélidos participan como hospedadores intermediarios (Georgiev et al., 2006).

Vampirolepis Spasskij, 1954

Si bien se han utilizado distintas denominaciones genéricas desde la descripción original, actualmente la mayoría de los autores coinciden en la denominación Vampirolepis cuando se describen himenolepididos de murciélagos (Vaucher, 1992). La redefinición del género fue efectuada por Vaucher (1992) e incluye más de 50 especies, todas pa- 
rasitando a murciélagos. Es de distribución cosmopolita y en la región Neotropical se reconoce una docena de especies (Zdzitwiecki y Rutkowska, 1980).

\section{Vampirolepis guarany Rego, 1961}

(Figura III.3.2)

Descripción: Longitud total 41 a $48 \mathrm{~mm}(44 \pm 2,51 \mathrm{~mm})$; ancho máximo 1,7 a 2,1 (1,9 $\pm 0,13$

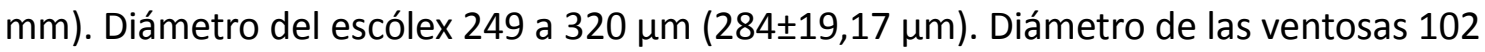
a $135 \mu \mathrm{m}(115 \pm 10,34 \mu \mathrm{m})$. Escólex armado, rostelo con 24 ganchos tipo fraternoide por poseer mango largo y delgado, lámina curvada y guarda no bifurcada y robusta, perpendicular al mango (Andreiko et al., 1969), de 49 a $51 \mu \mathrm{m}(50 \pm 0,93 \mu \mathrm{m})$ de largo. Proglótides craspédotas; proglótides maduras con tres testículos dispuestos en línea, situados en su región posterior. Ovario lobulado, situado en el centro de la proglótide, en posición anterotesticular. Glándula vitelógena maciza, postovariana. Útero transverso. Poro genital lateral en posición media. Huevos esféricos de 50 a $59 \mu \mathrm{m}(55,2 \pm 2,92 \mu \mathrm{m})$ de diámetro.

Material examinado: 8 especímenes ( 3 especímenes de E. patagonicus, 2 especímenes de $M$. rufus y 3 especímenes de $A$. lituratus).

Hospedadores y procedencia: Eumops patagonicus de Corrientes Capital, Mercedes y San Lorenzo, Provincia de Corrientes, Molossus rufus de Garabí y Puerto Valle Provincia de Corrientes y Artibeus lituratus de Garabí Provincia de Corrientes y Apóstoles Provincia de Misiones.

Localización: intestino delgado

\section{Prevalencia (P) e Intensidad Media $\pm D S$ (IM) (Min-Max):}

Eumops patagonicus: $\mathrm{P}=20,6 \%(13 / 66) ; \mathrm{IM}=3,92 \pm 6,1(1-23)$

Molossus rufus: $\mathrm{P}=10 \%(2 / 20) ; \mathrm{IM}=2$

Artibeus lituratus: $\mathrm{P}=50 \%$ (5/10); IM=69,2 $\pm 51,5$ (21-125)

Comentarios: En la Región Neotropical fueron descriptas dos especies de Vampirolepis caracterizadas por poseer un número de ganchos similar al de los especímenes aquí descriptos: Vampirolepis elongatus Rego, 1962 con 26-32 ganchos y V. guarany con 2227 ganchos (Zdzitwiecki y Rutkowska, 1980). Esta última especie se caracteriza por poseer los ganchos de mayor longitud que $V$. elongatus, alcanzando $50 \mu \mathrm{m}$ ( $V$. elongatus $18 \mu \mathrm{m})$. Las restantes características morfológicas de los ejemplares aquí estudiados son coincidentes con las aportadas oportunamente por Rego y Vaucher para V. guarany.

Vampirolepis guarany fue descrita por primera vez parasitando a Molossus crassicaudatus Geoffroy, Molossus sp. y una especie indeterminada, citada como Chiroptera sp., de Asunción del Paraguay (localidad tipo) y varias localidades de Brasil (Rego, 1961). Más tarde, Vaucher (1986) la redescribe como Hymenolepis guarany (Rego) asociada 
a Eumops bonariensis, Molossus rufus, M. molossus crassicaudatus (Molossidae), Lasiurus (Dasypterus) ega Gervais, 1856 y Eptesicus furinalis (Vespertilionidae) colectados en Paraguay. Posteriormente, Vaucher (1992) en su revisión del género Vampirolepis, la enumera como $V$. guarany. En este sentido, este hallazgo constituye la primera cita para Argentina y permite ampliar el rango de hospedadores al ser hallado parasitando a $E$. patagonicus y $A$. lituratus y ampliar su distribución hacia el sur, con cinco localidades en la provincia de Corrientes y una en Misiones. En la Figura III.3.1 se encuentran señalados los registros para esta especie, incluyendo los aportes del presente estudio.

Teniendo en cuenta que el aspecto condicionante para la transmisión de cestodes himenolepididos es la existencia de anélidos o artrópodos que actúen como hospedadores intermediarios en su ciclo de vida y que $A$. lituratus es una especie de hábitos frugívoros, es dable suponer que $V$. guarany, pueda desarrollar un ciclo de vida directo, tal como se presenta en otros Hymenolepididae. Una infestación accidental por ingestión de insectos, es poco probable dado que distintos estudios muestran que los murciélagos frugívoros son capaces de cumplir todas sus necesidades proteicas ingiriendo exclusivamente frutas (Delorme y Thomas 1999).

Figura III.3.1. Distribución geográfica de Vampirolepis guarany

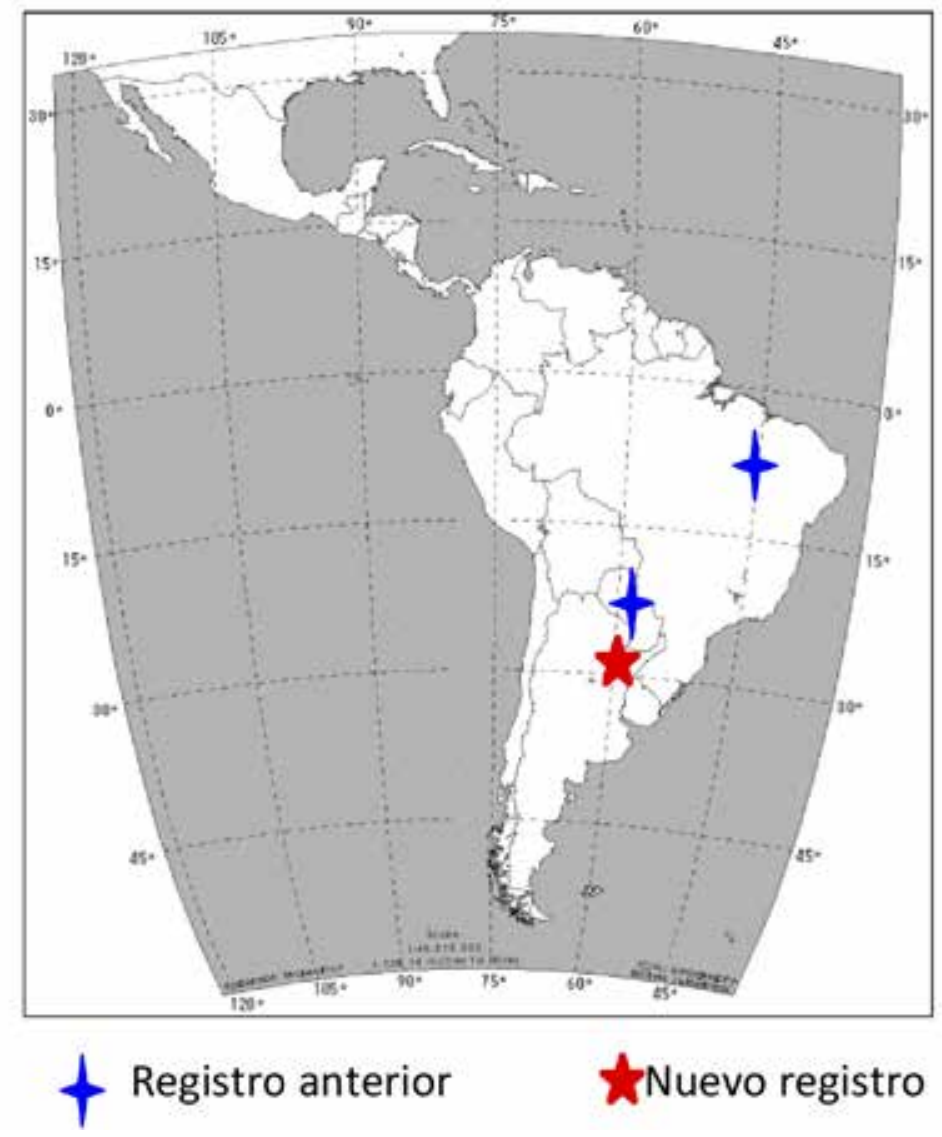




\section{Vampirolepis guarany}
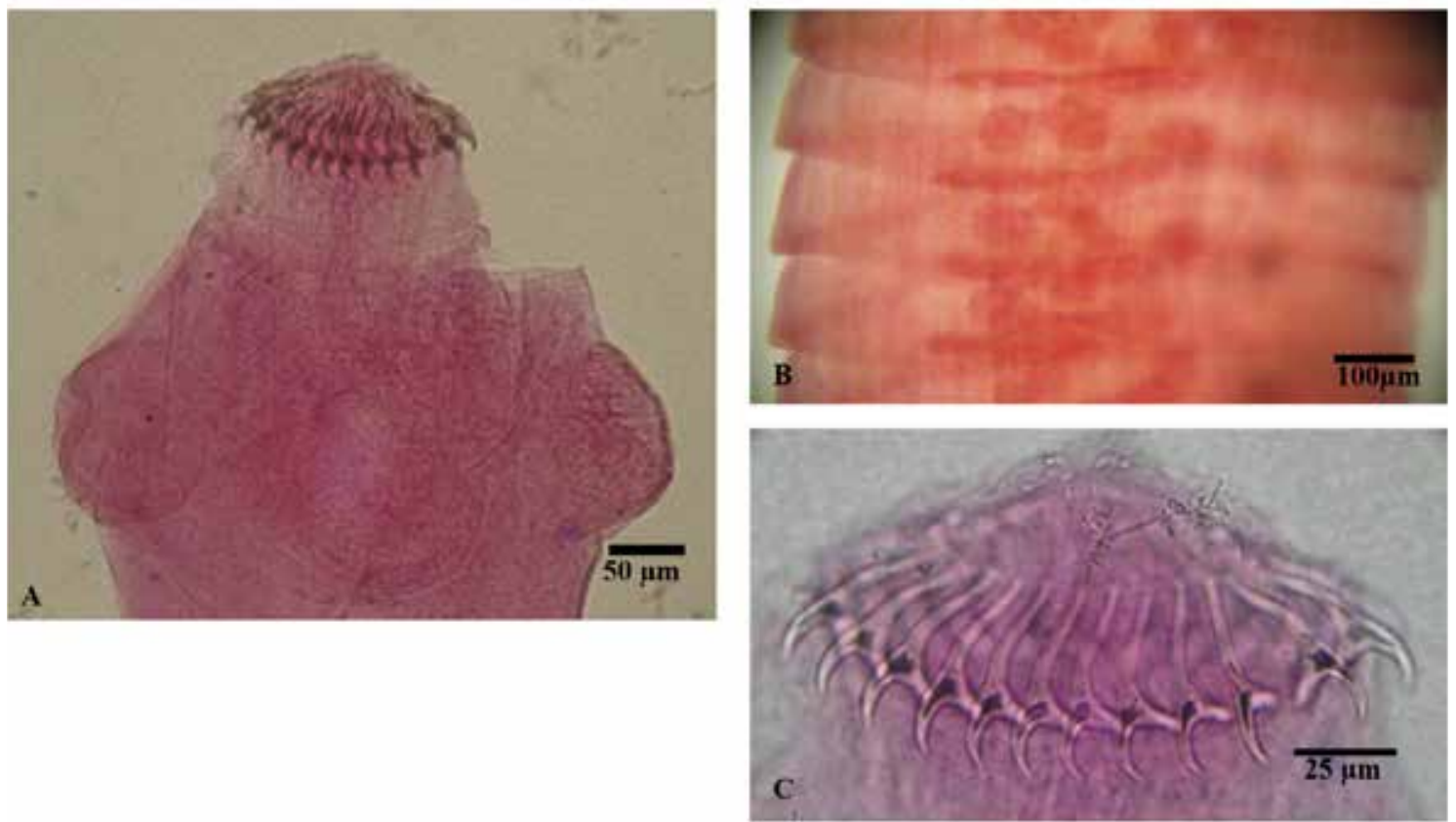

Figura III.3.2. Vampirolepis guarany. A- escolex. B- proglótides maduras. C- ganchos.

\section{Vampirolepis cf macroti Zdzitwiecki y Rutkowska, 1980}

(Figura III.3.4)

Descripción: Un individuo incompleto de 3, $5 \mathrm{~mm}$ de largo, constituido por el escólex y escasas proglótides inmaduras. Escólex armado de $228 \mu \mathrm{m}$ de diámetro. El rostelo posee 29 ganchos de 26 a $30 \mu \mathrm{m}$ de longitud, ubicados en círculo. El escólex porta cuatro ventosas de 88 a $101 \mu \mathrm{m}$ de diámetro.

Material examinado: 1 espécimen

Hospedadores y procedencia: Eptesicus furinalis (Garabí)

Localización: intestino delgado

\section{Prevalencia e Intensidad:}

Eptesicus furinalis: $\mathrm{P}=6,25 \%(1 / 16) \mathrm{I}=1$

Comentarios: Para los murciélagos del género Eptesicus (Vespertilionidae) del neotrópico se conocen cuatro especies de cestodes del género Vampirolepis: Vampirolepis dicipiens (Diesing, 1850), caracterizado por poseer entre 38 y 46 ganchos; Vampirolepis christensoni (Macy, 1931) que posee entre 35 y 41 ganchos y Vampirolepis roudabushi (Macy y Rausch, 1946) que presenta entre 41 y 48 ganchos y Vampirolepis macroti con 29 a 34 
ganchos. El número de ganchos hallado en el espécimen estudiado es significativamente menor que tres de las especies antes mencionadas. A su vez, comparando con los especímenes de $V$. guarany, el espécimen hallado en $E$. furinalis difiere en el número y en la longitud de los ganchos ( $V$. guarany: 24 ganchos de $50 \mu \mathrm{m}$ de largo). Las características morfométricas de los ganchos del espécimen de $E$. furinalis coinciden con aquellas de V. macroti, especie caracterizada por presentar entre 29 y 34 ganchos de 28 a $30 \mu \mathrm{m}$ de largo. Por este motivo, se considera que el espécimen estudiado pertenecería a la especie $V$. macroti, quedando pendiente la confirmación con el estudio de otros ejemplares que permitan observar la posición de los testículos que caracteriza a la especie, un testículo poral y dos antiporales. En este contexto, desde su descripción original (Zdzitwiecki y Rutkowska, 1980) no se conocen citas, por lo tanto existe un único registro de $V$. macroti en Cuba parasitando a Macrotus waterhousei minor (Phyllostomidae). Este trabajo constituiría la segunda cita de la especie y la primera cita para Argentina. Asimismo, E. furinalis ampliaría el listado de especies hospedadoras para este himenolepidido. En la Figura III.3.3 se encuentran señalados los registros para esta especie, incluyendo los aportes del presente estudio.

Figura III.3.3. Distribución geográfica de Vampirolepis cf macroti

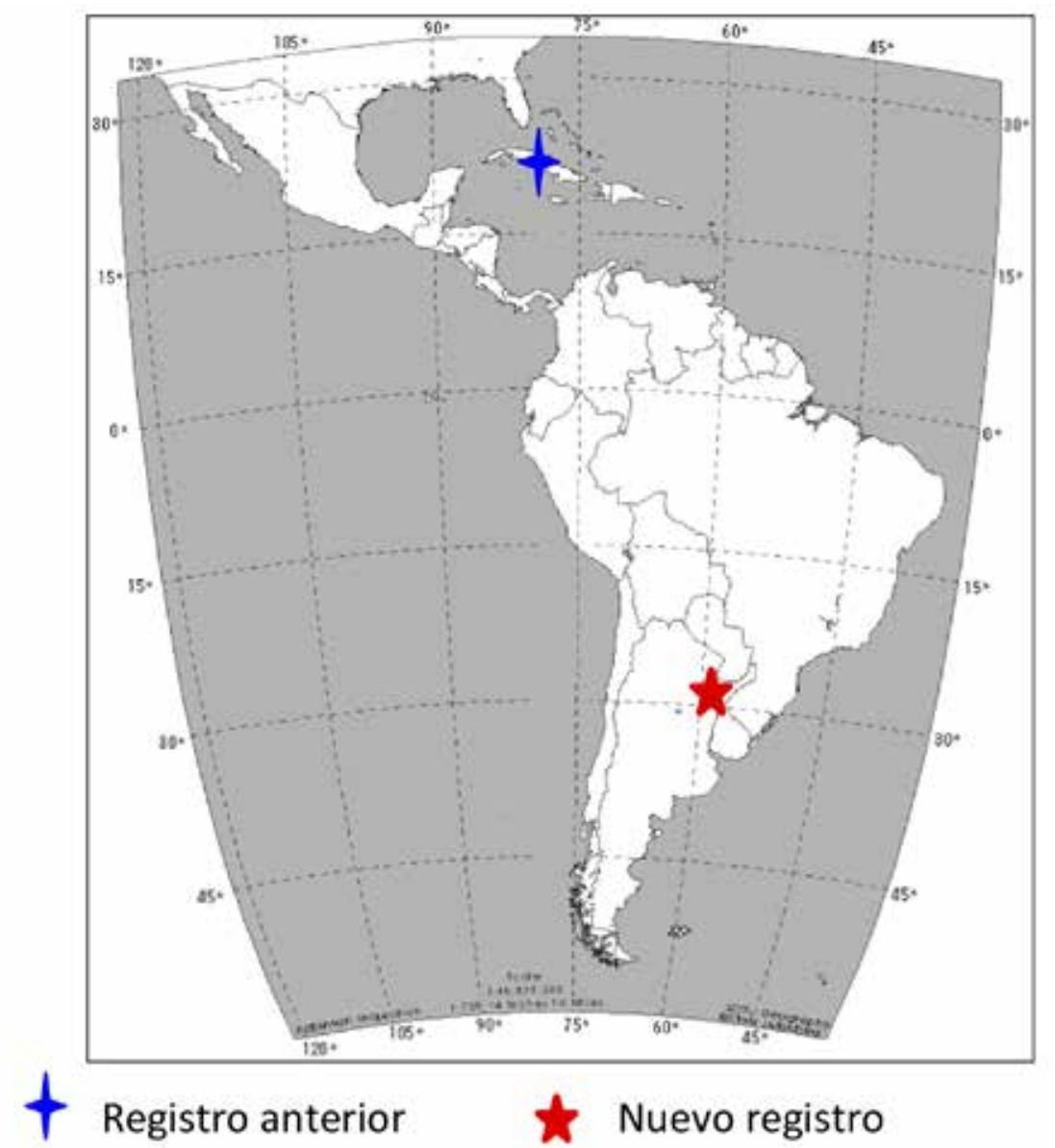




\section{Vampirolepis cf macroti}
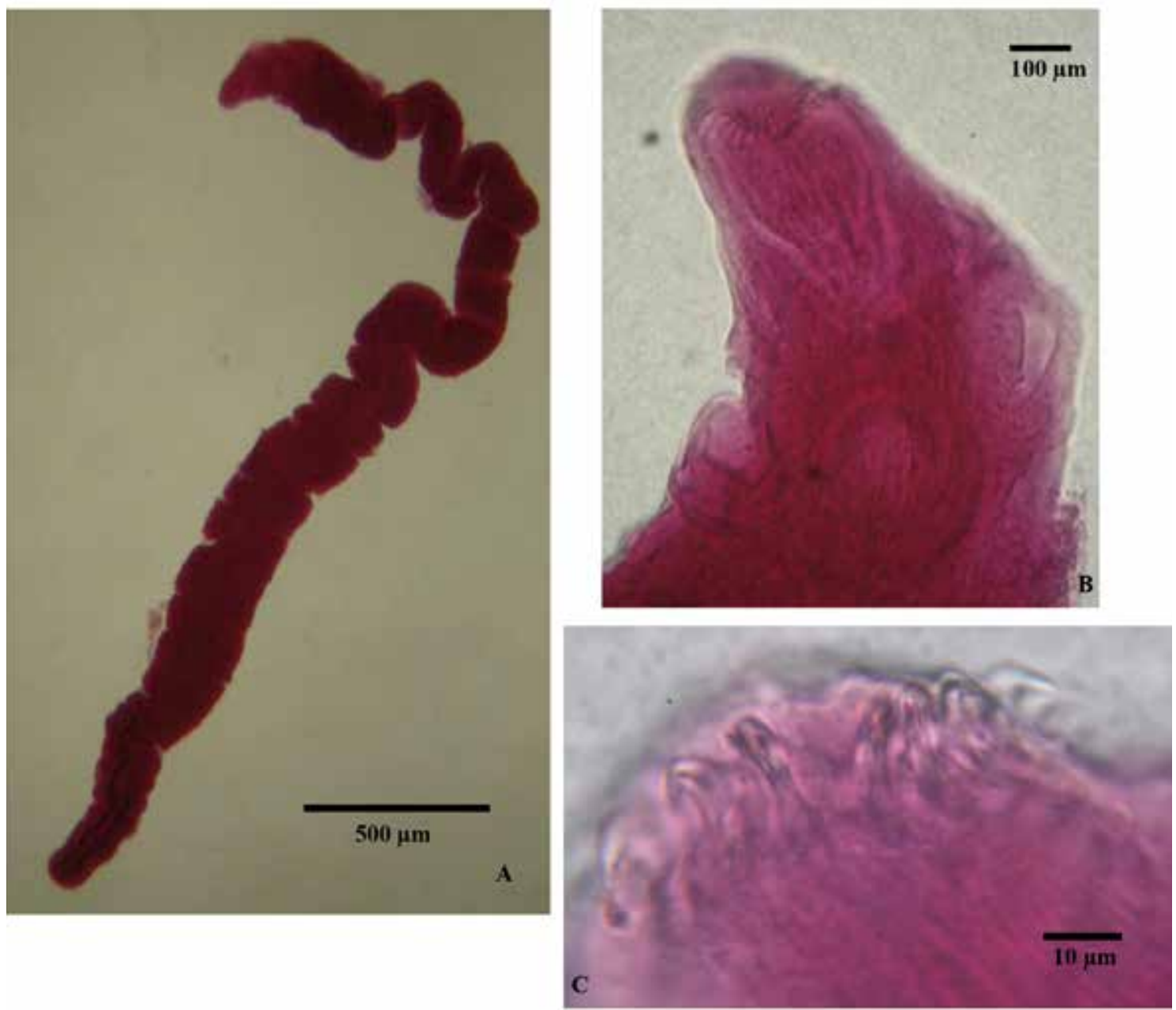

Figura III.3.4. Vampirolepis cf macroti. A- individuo completo. B- excolex. C- ganchos

Clase TREMATODA Rudolphi, 1808

Subclase Digenea Carus, 1863

Familia Anenterotrematidae Yamaguti, 1958

Los miembros de la familia Anenterotrematidae se caracterizan por la ausencia de sistema digestivo. Son parásitos del intestino delgado y ocasionalmente de la vesícula biliar de murciélagos de la región Neotropical. El ciclo de vida de los anenterotrematide es desconocido pero, acorde a los grupos de digeneos relacionados, los murciélagos adquirirían el parásito por consumo de artrópodos infectados con la metacercaria (Santos y Gibson, 2015). 


\section{Anenterotrema Stunkard, 1938}

Edcaballerotrema Freitas, 1960 fue considerado sinónimo de Anenterotrema Stunkard, 1938 (Caballero, 1960; Portes Santos y Gibson, 1998). Lunaschi (2002a; 2002b; 2004) y Lunaschi et al. (2003) re-describen y sinonimizan especies de Lecithodendriidae en base a la revisión de material tipo y nuevos especímenes provenientes de murciélagos de Argentina.

\section{Anenterotrema eduardocaballeroi (Freitas, 1960) Caballero, 1960}

(Figura III.3.6)

Descripción. Cuerpo pequeño, de 310 a $480 \mu \mathrm{m}$ x 152 a $225 \mu \mathrm{m}(341 \pm 57,6$ x 192 24 $\mu \mathrm{m})$. Tegumento liso. Ventosa oral subterminal, con dos proyecciones papiliformes en su pared, de 85 a $100 \mu \mathrm{m} \times 100$ a $112 \mu \mathrm{m}(93 \pm 5,9 \times 108 \pm 3,7 \mu \mathrm{m})$. Ventosa ventral pre-ecuatorial, de 85 a $97 \mu \mathrm{m} \times 85$ a $100 \mu \mathrm{m}(92 \pm 4,7 \times 93 \pm 4,8 \mu \mathrm{m})$. Relación ancho de ventosas $1: 1,15$. Faringe y ciegos intestinales ausentes. Poro genital mediano. Bolsa del cirro anterior a la ventosa ventral, de 38 a $44 \mu \mathrm{m}$ x 42 a $60 \mu \mathrm{m}(40 \pm 2,1 \times 50 \pm 6,1 \mu \mathrm{m})$, contiene la vesícula seminal plegada y un cirro corto. Testículos laterales, inmediatamente posteriores a la ventosa ventral, simétricos. Testículo derecho de 35 a $45 \mu \mathrm{m} \times 35$ a $38 \mu \mathrm{m}$ $(38 \pm 3,4 \times 36 \pm 1,3 \mu \mathrm{m})$. Testículo izquierdo de 39 a $47 \mu \mathrm{m} \times 35$ a $49 \mu \mathrm{m}(42 \pm 2,6 \times 43 \pm 4$ $\mu \mathrm{m})$. Ovario mediano, intertesticular, posterior a la ventosa ventral, de 30 a $37 \mu \mathrm{m} \times 32$ a $45 \mu \mathrm{m}(32 \pm 2,9 \times 41 \pm 4,3 \mu \mathrm{m})$. Glándulas vitelinas constituidas por folículos pequeños. Útero ocupando toda la región posterior del cuerpo. Huevos grandes, de 27 a $30 \mu \mathrm{m} x$ 15 a $17 \mu \mathrm{m}(27 \pm 1,1 \times 16 \pm 1 \mu \mathrm{m})$.

Material estudiado: 8 ejemplares maduros (4 especímenes de Molossus rufus, 4 especímenes de Molossops temminkii).

Hospedadores y procedencia: Molossus rufus (Puerto Valle), Molossops temminkii (Rincón del Socorro).

Localización: intestino delgado e intestino grueso.

Prevalencia (P) - Intensidad (I):

Molossus rufus: $\mathrm{P}=5 \%(1 / 20), \mathrm{I}=21$

Molossops temminkii: $\mathrm{P}=20 \%(1 / 5), \mathrm{l}=13$

Comentarios: Si bien fue inicialmente descrita con el género Eduardocaballerotrema Freitas, 1960, en el mismo año Caballero la sinonimiza con Anenterotrema, siendo confirmado luego por Yamaguti (1971). Anenterotrema eduardocaballeroi fue descrita para Brasil asociada a Eumops glaucinus (Wagner, 1943), Molossus rufus rufus, Molossus major crassicaudatus (Molossidae), Phyllostomus elongatus (Phyllostomidae) e Histiotus velatus (Vespertilionidae) y para Colombia parasitando a M. molossus (Lunaschi, 2002a; Caro et al., 2003). Las características morfológicas observadas en los especímenes estudiados 
concuerdan con las descripciones precedentes, aunque morfométricamente existe una similitud mayor con la descripción original de Freitas (1960), principalmente en el tamaño del cuerpo, testículos y huevos. En el presente trabajo se reporta a esta especie por primera vez para Argentina, se vuelve a mencionar a M. rufus como hospedador y se registra por primera vez a Molossops temminkii como nuevo hospedador. En la Figura III.3.5 se encuentran señalados los registros para esta especie, incluyendo los aportes del presente estudio.

Figura III.3.5. Distribución geográfica de Anenterotrema eduardocaballeroi

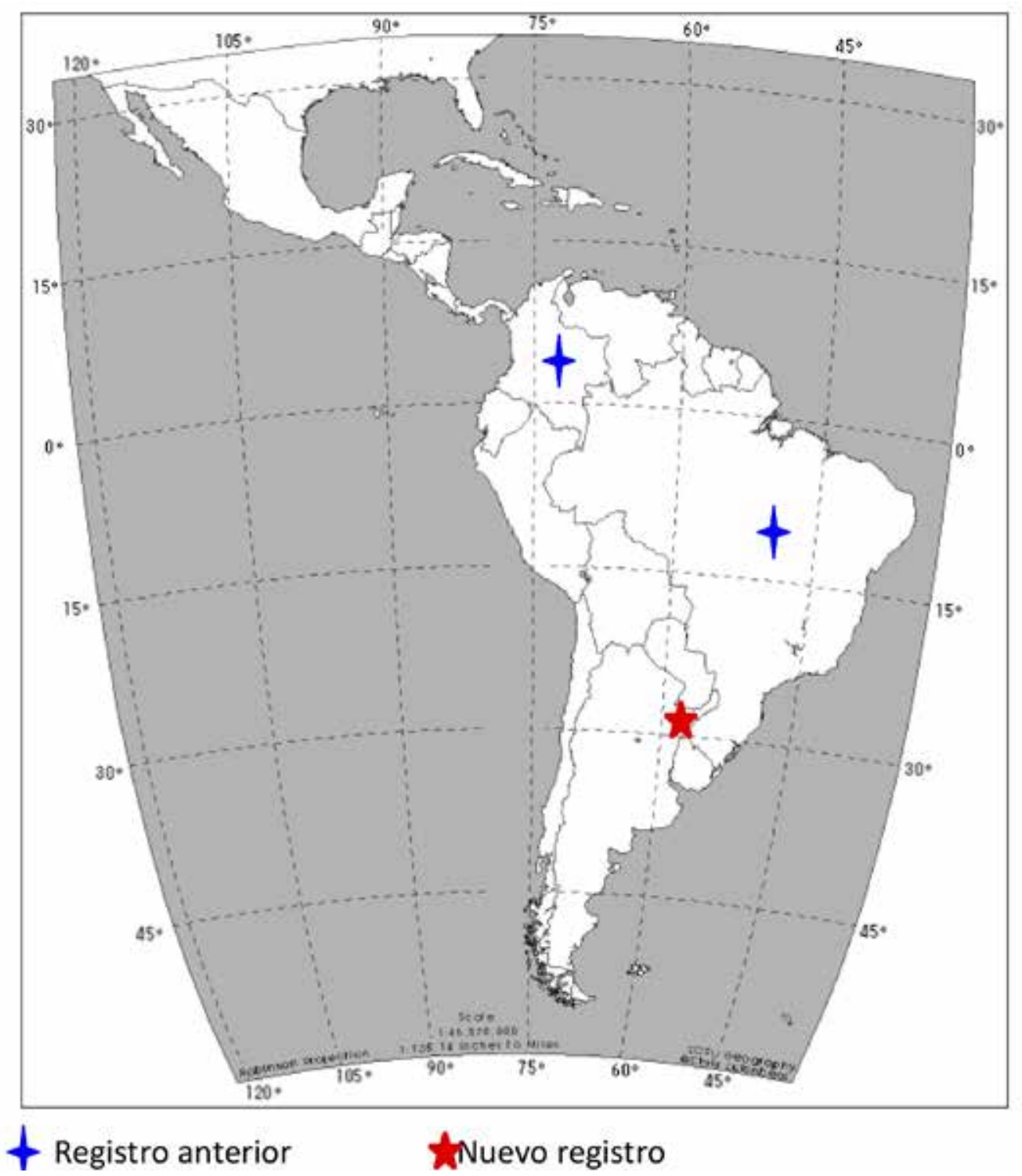




\section{Anenterotrema eduardocaballeroi}
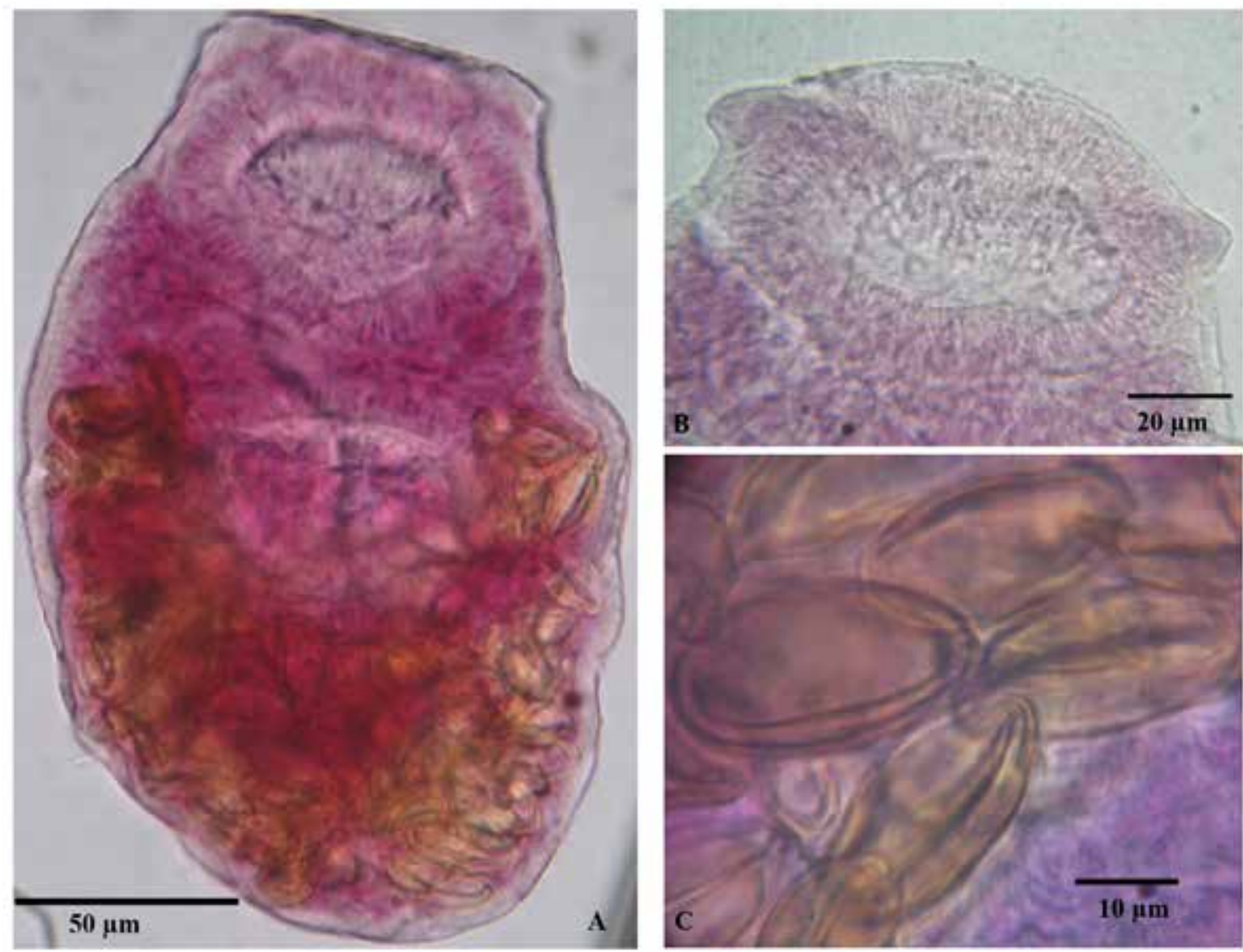

Figura III.3.6. Anenterotrema eduardocaballeroi. A- vista ventral, B- detalle del pliegue en ventosa oral, C- huevos

\section{Anenterotrema liliputianum (Travassos, 1928) Caballero, 1964}

(Figura III.3.8)

Descripción: Cuerpo muy pequeño, piriforme, con ancho máximo en la región media, de

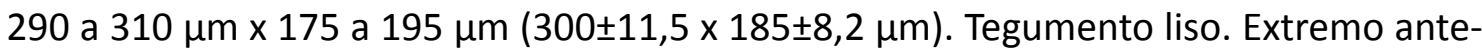
rior sin pliegue transversal de la pared del cuerpo a nivel de la ventosa oral. Ventosa oral esférica, grande, subterminal, de 80 a $107 \mu \mathrm{m} \times 100$ a $110 \mu \mathrm{m}(93 \pm 11,9 \times 105 \pm 5,8 \mu \mathrm{m})$. Ventosa ventral en el tercio medio del cuerpo, esférica, de tamaño similar a la ventosa

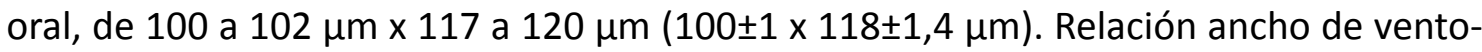
sas 1:0,9. Faringe, esófago y ciegos ausentes. Gónadas alrededor de la ventosa ventral. 
Testículos pequeños, simétricos o subsimétricos, enteros, laterales o posterolaterales a la ventosa ventral. Testículo derecho de 31 a $46 \mu \mathrm{m} \times 41$ a $43 \mu \mathrm{m}(39 \pm 6,2 \times 42 \pm 0,8 \mu \mathrm{m})$, testículo izquierdo de 43 a $50 \mu \mathrm{m} \times 39$ a $54 \mu \mathrm{m}(46 \pm 3,6 \times 46 \pm 7,6 \mu \mathrm{m})$. Bolsa del cirro anterior a la ventosa ventral, conteniendo la vesícula seminal interna enrollada a lo largo, complejo prostático, células prostáticas y cirro, de 40 a $48 \mu \mathrm{m}$ x 48 a $55 \mu \mathrm{m}(44 \pm 3,3 \times$ $50 \pm 3,4 \mu \mathrm{m}$ ). Ovario sumediano, posterolateral a la ventosa ventral, de 32 a $37 \mu \mathrm{m} \times 39$ a $49 \mu \mathrm{m}(34 \pm 2,4 \times 44 \pm 5,2 \mu \mathrm{m})$. Glándula de Mehlis mediana, lateral al ovario; receptáculo seminal no observado; canal de Laurer corto. Glándulas vitelinas foliculares, enmascaradas por el útero. Útero largo, extendiéndose lateralmente hacia la ventosa ventral. Huevos operculados, grandes en relación al tamaño del cuerpo, de 28 a $32 \mu \mathrm{m} \times 17$ a $18 \mu \mathrm{m}(30 \pm 1,6 \times 18 \pm 0,5 \mu \mathrm{m})$. Metatermo corto, escasamente desarrollado, en ubicación opuesta a la bolsa del cirro. Poro excretor y vesícula excretora no observados.

Material estudiado: 4 ejemplares maduros.

Hospedadores y procedencia: Molossus rufus (Puerto Valle)

Localización: intestino grueso.

\section{Prevalencia (P) - Intensidad (I):}

Molossus rufus: $\mathrm{P}=5 \%(1 / 20), \mathrm{I}=6$

Comentarios: En 1928, Travassos describe esta especie parasitando molósidos de Brasil. Posteriormente, se la registra en reiteradas ocasiones en el mismo país (Freitas, 1961; Freitas y Dobbin, 1962; Ubelaker et al., 1977). Recientemente, Lunaschi y Notarnicola (2010) la redescriben con base al material tipo depositado en la Colección Helmintologica del Instituto Oswaldo Cruz (CHIOC) proveniente de Molossus molossus, Molossus rufus y Phyllostomus elongatus (Geoffroy) (Phyllostomidae) y la registran por primera vez en Argentina, asociada a Molossops temminkii. En el presente trabajo se reporta por segunda vez para el país, asociada a M. rufus y se amplía su distribución geográfica. En la Figura III.3.7 se encuentran señalados los registros para esta especie, incluyendo los aportes del presente estudio. 
Figura III.3.7. Distribución geográfica de Anenterotrema liliputianum

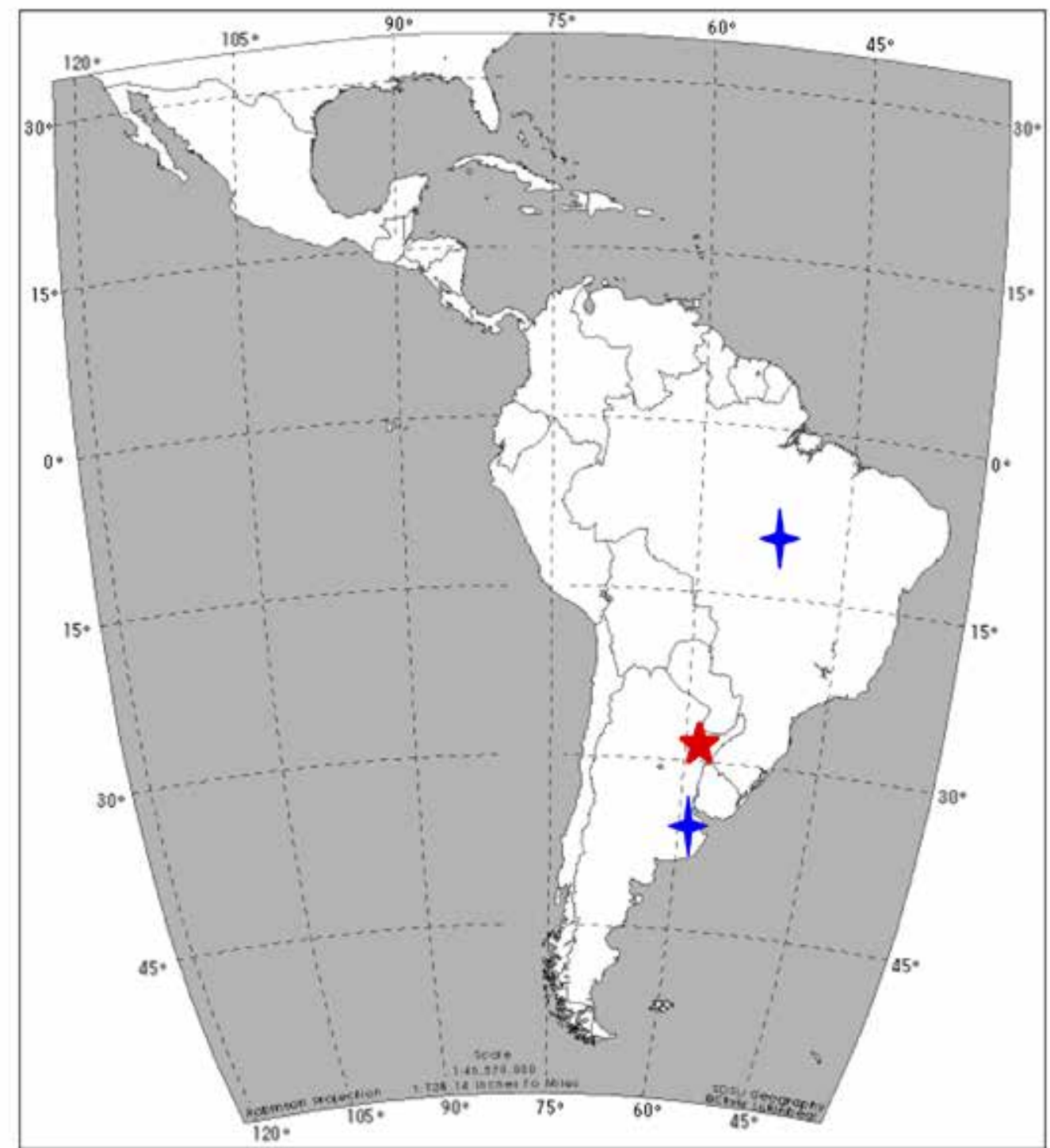

† Registro anterior $\quad$ Nuevo registro 


\section{Anenterotrema liliputianum}
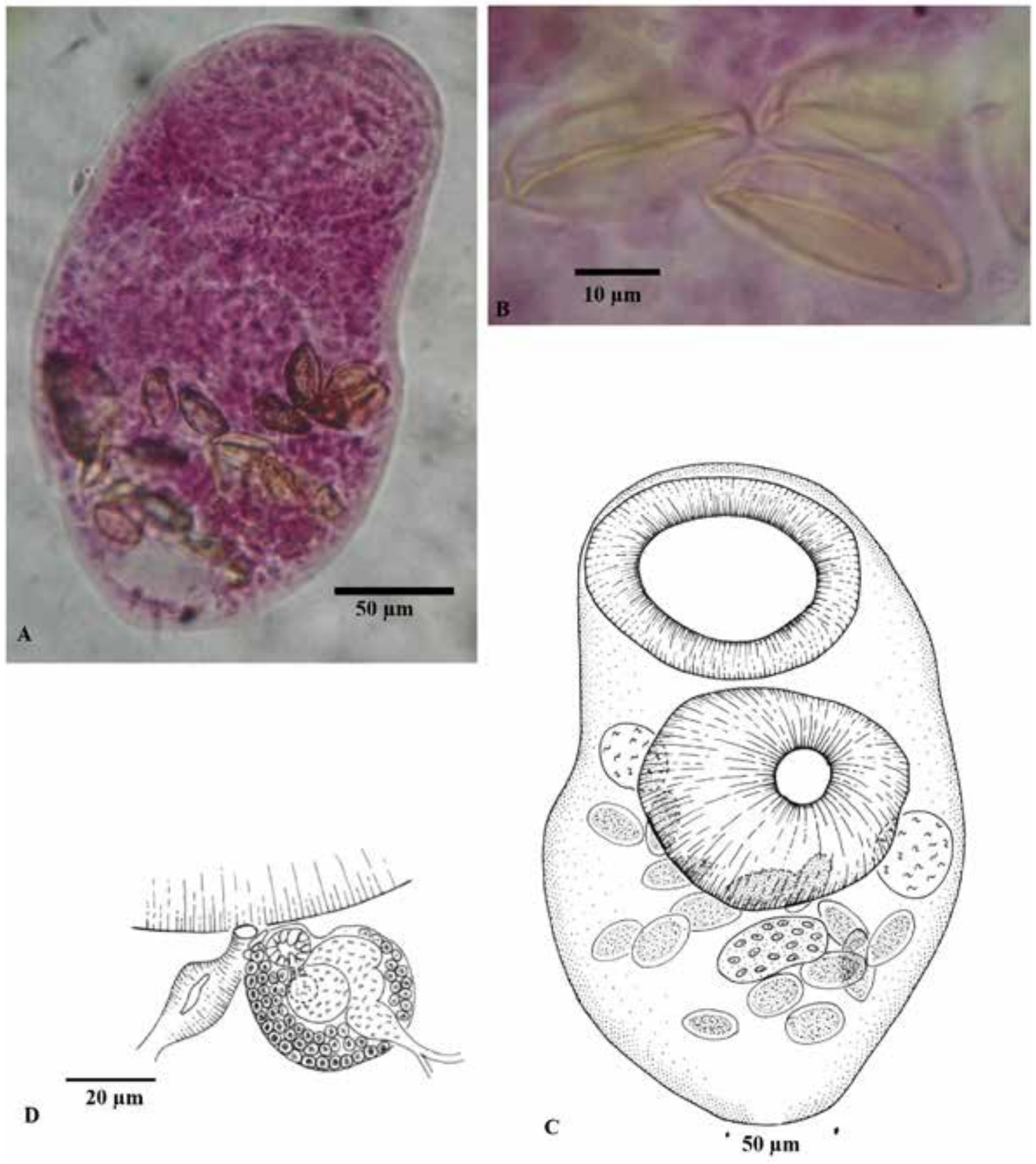

Figura III.3.8. Anenterotrema liliputianum. A- vista ventral, B- huevos, C- vista ventral, ubicación y proporción de las ventosas, D- detalle de la genitalia terminal 
Familia Lecithodendriidae Lühe, 1901

Los representantes de la familia Lecithodendriidae son parásitos de murciélagos y ocasionalmente de aves, caracterizados por poseer un poro genital mediano y ausencia de un verdadero saco del cirro y cirro y presencia de un pseudo saco del cirro. El desarrollo de las cercarias se da en prosbranquios de agua dulce. Las formas enquistadas fueron encontradas en insectos del orden Trichoptera (Yamaguti, 1975).

Gymnoacetabulum Lunaschi y Drago, 2007

El género Gymnoacetabulum es, hasta el presente, monoespecífico y la característica distintiva es la presencia de un saco acetábulo genital que aloja la pequeña ventosa ventral y los poros genitales, por lo que la identificación es inequívoca. Fue descrito originalmente como Suttonia por Lunaschi (2002a) y luego transferido a Gymnoacetabulum (Lunaschi y Drago, 2007) por haber estado pre-ocupado el nombre genérico.

\section{Gymnoacetabulum talavarensis (Lunaschi, 2002)}

(Figura III.3.10)

Descripción: Cuerpo pequeño, esférico, aplanado dorsoventralmente, de 500 a $750 \times 810$ a $1000 \mu \mathrm{m}(645 \pm 89,7 \times 895 \pm 70,5 \mu \mathrm{m})$. Tegumento espinoso. Ventosa oral subterminal, de 60 a 85 x 55 a $92 \mu \mathrm{m}(74 \pm 8,6 \times 76,2 \pm 11,7 \mu \mathrm{m})$. Ventosa ventral en posición ecuatorial, débilmente desarrollada, incluida en un pequeño saco acetábulo- genital, cercana a su margen posterior, de 90 a $200 \times 150$ a $200 \mu \mathrm{m}(136,8 \pm 39,5 \times 180,7 \pm 16,6 \mu \mathrm{m})$. Saco acetábulo-genital conteniendo la ventosa ventral y el poro genital. Esófago corto. Ciegos cortos, que alcanzan el margen anterior de los testículos. Testículos postcecales ecuatoriales y laterales al saco acetábulo-genital. Testículo derecho de 100 a 175 x 110 a $235 \mu \mathrm{m}$ $(133,4 \pm 23 \times 180,4 \pm 41,7 \mu \mathrm{m})$; testículo izquierdo de 102 a 162 × 95 a $175 \mu \mathrm{m}(131,2 \pm 24,4$ $x 1123 \pm 29 \mu \mathrm{m})$. Saco del pseudocirro bien desarrollado, en posición media, intercecal y dorsal a la ventosa ventral, de 87 a 105 × 92 a $112 \mu \mathrm{m}(92,1 \pm 6 \times 99,5 \pm 6,6 \mu \mathrm{m})$; contiene una masa compacta de células prostáticas, pars prostática bien desarrollada, vesícula seminal y un corto conducto eyaculador. Poros genitales abiertos independientemente dentro del saco acetábulo-genital, poro genital masculino mediano; poro femenino sinistral. Ovario en posición mediana o submediana e intertesticular, de 87 a 147 x 80 a $167 \mu \mathrm{m}$ $(121,1 \pm 22,5$ x 117,4 $\pm 27,4 \mu \mathrm{m})$. Glándulas de Mehlis y canal de Laurer presentes. Glándulas vitelinas compuestas por folículos grandes dispuestos en región prececal. Útero ocupando toda la región posterior a la ventosa ventral. Huevos pequeños y operculados, de 15 a $20 \times 9$ a $10 \mu \mathrm{m}(17,8 \pm 1,6 \times 9,6 \pm 0,5 \mu \mathrm{m})$. Vesícula excretora en forma de $\mathrm{V}$.

Material estudiado: 8 ejemplares maduros, (4 especímenes de Eumops patagonicus, 4 especímenes de Myotis albescens). 
Hospedadores y procedencia: Eumops patagonicus (Capital, San Lorenzo, Mercedes) y Myotis albescens (San Isidro).

Localización: intestino delgado e intestino grueso.

Prevalencia (P) - Intensidad Media $\pm D S$ (IM) (Min-Max):

Eumops patagonicus: $\mathrm{P}=60,6 \%(40 / 66), \mathrm{IM}=47,3 \pm 76,7$ (2-494)

Myotis albescens: $P=17,2 \%(6 / 35), I M=4 \pm 4,1(1-12)$

Comentarios: Fue mencionado como parásito de Molossus molossus, Tadarida brasiliensis (Mollosidae) y Myotis levis (Vespertilionidae) en la provincia de Buenos Aires (Lunaschi, 2002a; Lunaschi y Drago, 2007; Lunaschi y Notarnicola, 2010). En el presente estudio se agregan dos nuevos hospedadores, Eumops patagonicus y Myotis albescens y se amplía su distribución geográfica, citándola primera vez para el Nordeste argentino. En la Figura III.3.9 se encuentran señalados los registros para esta especie, incluyendo los aportes del presente estudio.

Figura III.3.9. Distribución geográfica de Gymnoacetabulum talavarensis

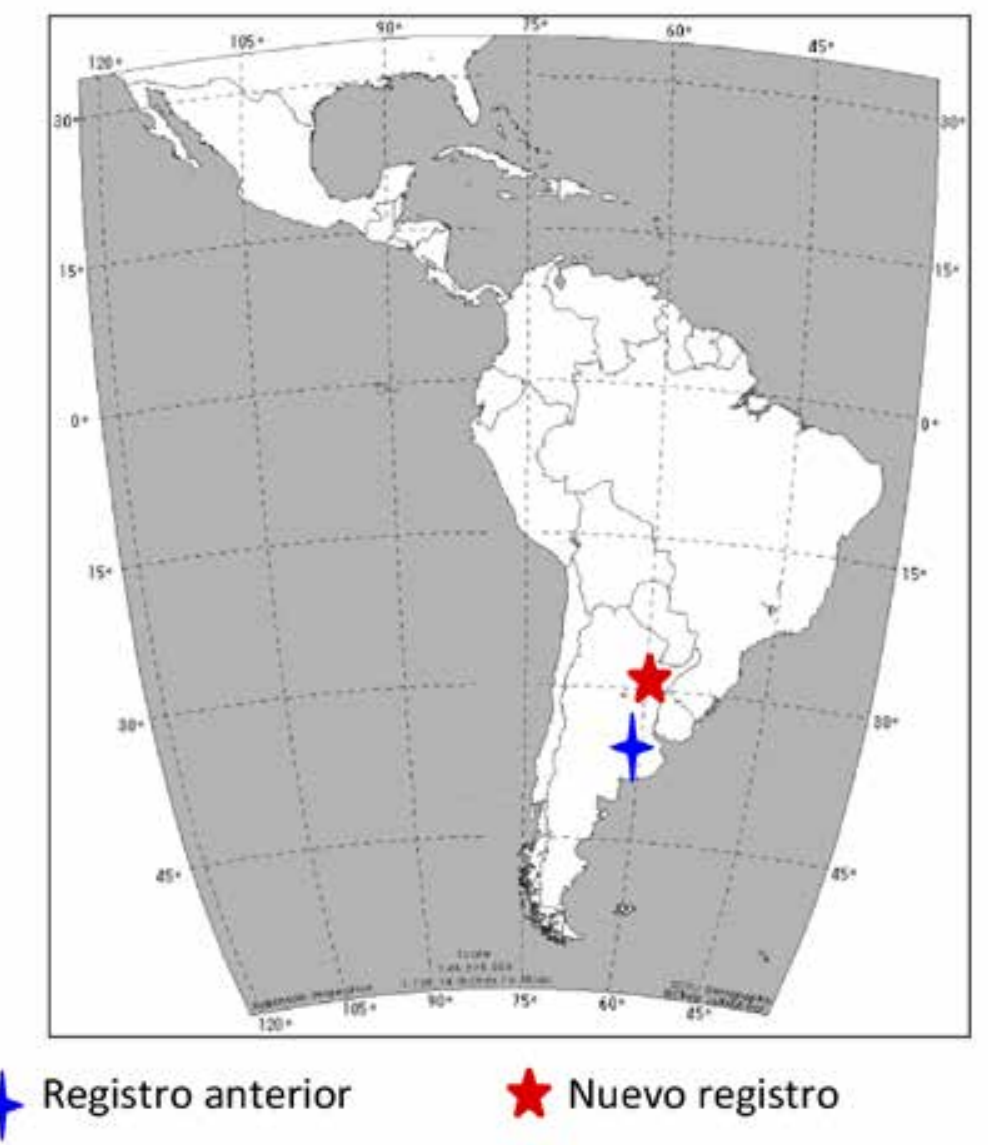




\section{Gymnoacetabulum talavarensis}
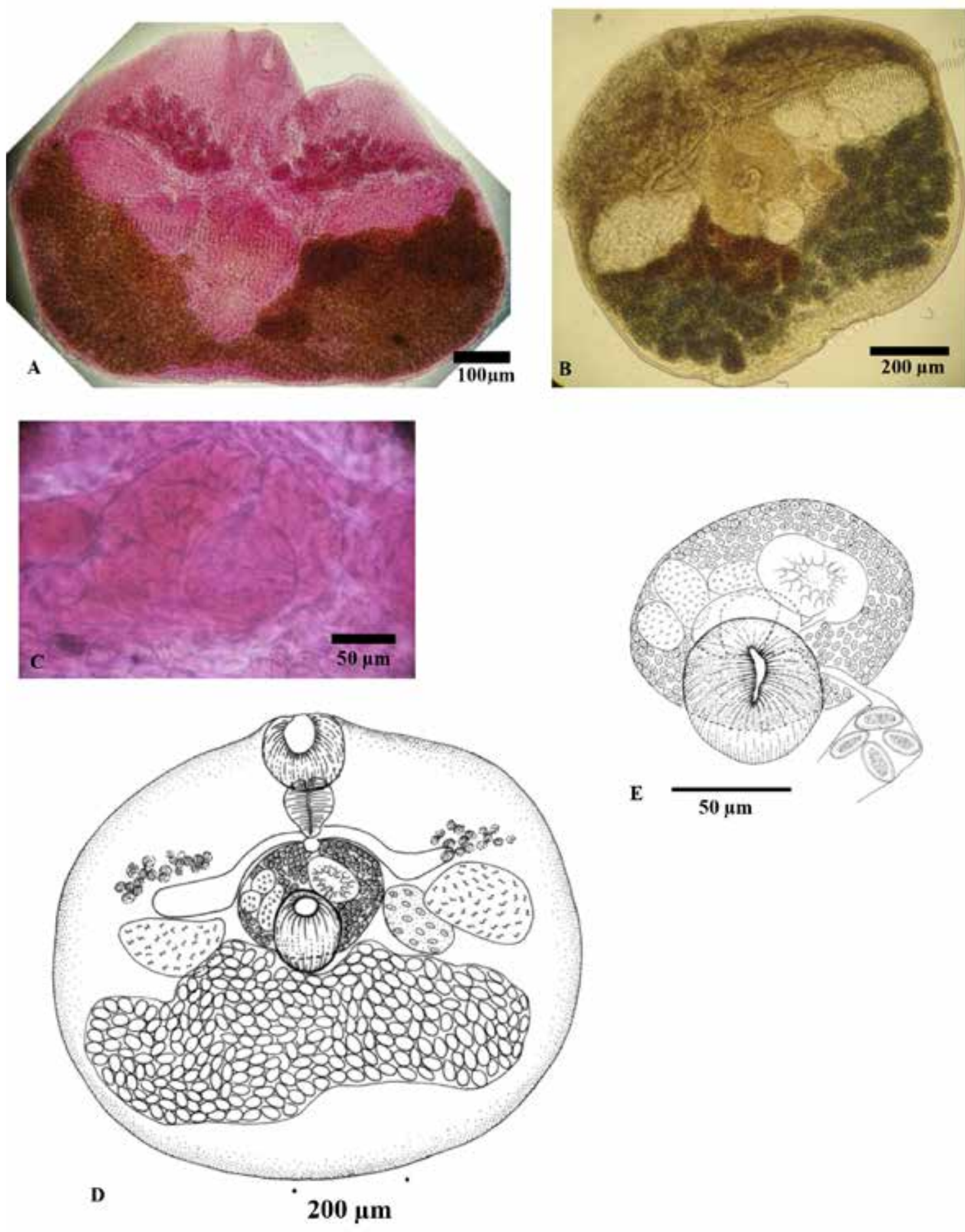

Figura III.3.10. Gymnoacetabulum talavarensis. A- vista ventral especimen in toto coloreado; $\mathrm{B}$ - vista ventra espécimen in toto en freso; C- saco acetábulo-genital; D- detalle de las estructuras internas; E- detalle del saco acetábulo-genital 


\section{Ochoterenatrema Caballero y C, 1943}

Los ejemplares de este género se caracterizan fundamentalmente por la presencia de un poro sexual muy desarrollado situado en el lado izquierdo del acetábulo y dentro de un área poral muy notoria. La masa prostática es voluminosa y contiene una vesícula seminal grande. El ovario tiene posición ecuatorial sobre el lado derecho del acetábulo.

\section{Ochoterenatrema labda Caballero y C., 1943}

(Figura III.3 12)

Descripción: Cuerpo pequeño, piriforme u oval, de 380 a $490 \mu \mathrm{m}$ de largo y 290 a 469 $\mu \mathrm{m}$ de ancho $(434 \pm 24,9 \times 359 \pm 36,2 \mu \mathrm{m})$. Tegumento liso. Ventosa oral subterminal, de 80 a 95 x 82 a $100 \mu \mathrm{m}(86 \pm 4,5 \times 91 \pm 4,2 \mu \mathrm{m})$ de largo y ancho, respectivamente. Ventosa ventral preecuatorial, de 80 a 102 × 87 a $105 \mu \mathrm{m}(93 \pm 5,9 \times 97 \pm 5,1 \mu \mathrm{m})$ de largo y ancho. Relación ancho de las ventosas 1: 0,93. Con pseudogonocotilo sobre el margen izquierdo de la ventosa ventral. Prefaringe ausente; faringe pequeña; esófago corto; ciegos digestivos cortos y divergentes, alcanzan la región testicular o pretesticular. Poro genital próximo al borde anterior de la ventosa ventral. Atrio genital pequeño. Falsa bolsa del cirro grande y ubicada entre la bifurcación cecal y la ventosa ventral; encierra una vesícula seminal voluminosa, pars prostática corta y un muy corto conducto eyaculador que se relaciona con el atrio genital. Testículos simétricos, preecuatoriales y laterales a la ventosa ventral; testículo derecho de 67 a $120 \mu \mathrm{m}$ x 65 a $135 \mu \mathrm{m}(104 \pm 9,8 \times 129 \pm 13,7$ $\mu \mathrm{m})$; testículo izquierdo de 70 a 120 × 86 a $140 \mu \mathrm{m}(105 \pm 11,1 \times 121 \pm 15,9 \mu \mathrm{m})$. Ovario, de contorno irregular, de 90 a $120 \times 115$ a $135 \mu \mathrm{m}(106 \pm 8,9 \times 125 \pm 7,5 \mu \mathrm{m})$, ocupa, en la región derecha del cuerpo, el espacio limitado por el aparato digestivo, el testículo y la falsa bolsa del cirro. Glándula de Mehlis grande y bien delimitada, ubicada entre la ventosa ventral y el testículo derecho. Receptáculo seminal difuso. Canal de Laurer no observado. Glándulas vitelínicas constituidas por folículos grandes laterales y de posición prececal y pretesticular. Útero ocupando toda la región posterior del cuerpo; termina en un metatremo corto. Huevos operculados, ovoides, de 20 a 22 x 11 a $12 \mu \mathrm{m}(20,1 \pm 0,4 \mathrm{x}$ $11 \pm 0,2 \mu \mathrm{m})$. Vesícula excretora en forma de "V"; poro excretor subterminal.

Material estudiado: 28 ejemplares maduros, (10 especímenes de Eumops patagonicus, 7 especímenes de Molossops temminkii, 1 especimen de Molossus rufus, 2 especimenes de Myotis albescens y 8 especimenes de Myotis cf nigricans).

Hospedadores y procedencia: Eumops patagonicus (Capital, Carlos Pellegrini, Mercedes, San Lorenzo, Rincón del Socorro), Molossops temminkii (Rincón del Socorro), Molossus rufus (Puerto Valle), Myotis albescens (San Isidro), Myotis cf nigricans (Isla Apipé).

Localización: intestino delgado e intestino grueso. 


\section{Prevalencia (P) - Intensidad Media $\pm D S$ (IM) (Min-Max):}

Eumops patagonicus: $\mathrm{P}=25,8 \%(17 / 66), \mathrm{IM}=14,6 \pm 13,1(1-45)$

Molossops temminckii: $\mathrm{P}=40 \%(2 / 5), \mathrm{IM}=14 \pm 15,6(3-25)$

Molossus rufus: $\mathrm{P}=5 \%(1 / 20), \mathrm{I}=4$

Myotis albescens: $\mathrm{P}=5,7 \%(2 / 35), \mathrm{IM}=4,5 \pm 3,5(2-7)$

Myotis cf nigricans: $\mathrm{P}=3,2 \%(1 / 31), \mathrm{I}=56$

Comentarios: 0 . labda fue descripta y registrada por primera vez en Tadarida brasiliensis y Natalus mexicanus de México (Caballero y C, 1943). Posteriormente fue citada para Panamá en Myotis nigricans (Caballero y C, 1964) y nuevamente para México en T. brasiliensis (Cain, 1966; Guzmán Cornejo et al., 2003). Recientemente, Lunaschi y Notarnícola (2010) la citan por primera vez para Argentina, parasitando a T. brasiliensis y Myotis levis de la provincia de Buenos Aires. En el presente trabajo se revela su hallazgo en M.cf nigricans de Argentina y se registra por primera vez en cuatro nuevas especies hospedadoras (Eumops patagonicus, Molossops temminkii, Molossus rufus y Myotis albescens) y se amplía su distribución geográfica al Nordeste del país. En la Figura III.3 11 se encuentran señalados los registros para esta especie, incluyendo los aportes del presente estudio. 
Figura III.3.11. Distribución geográfica de Ochoterenatrema labda

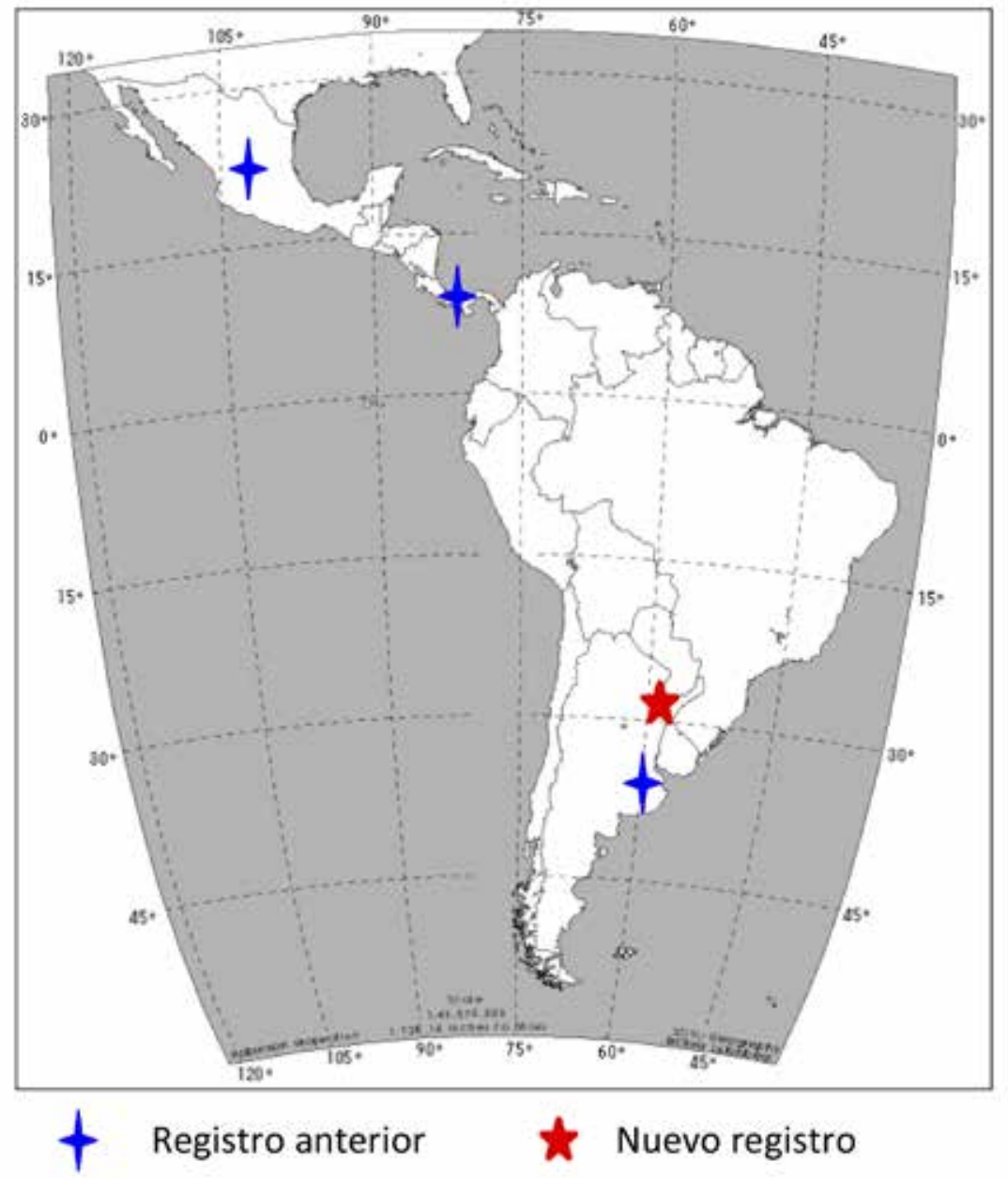




\section{Ochoterenatrema labda}
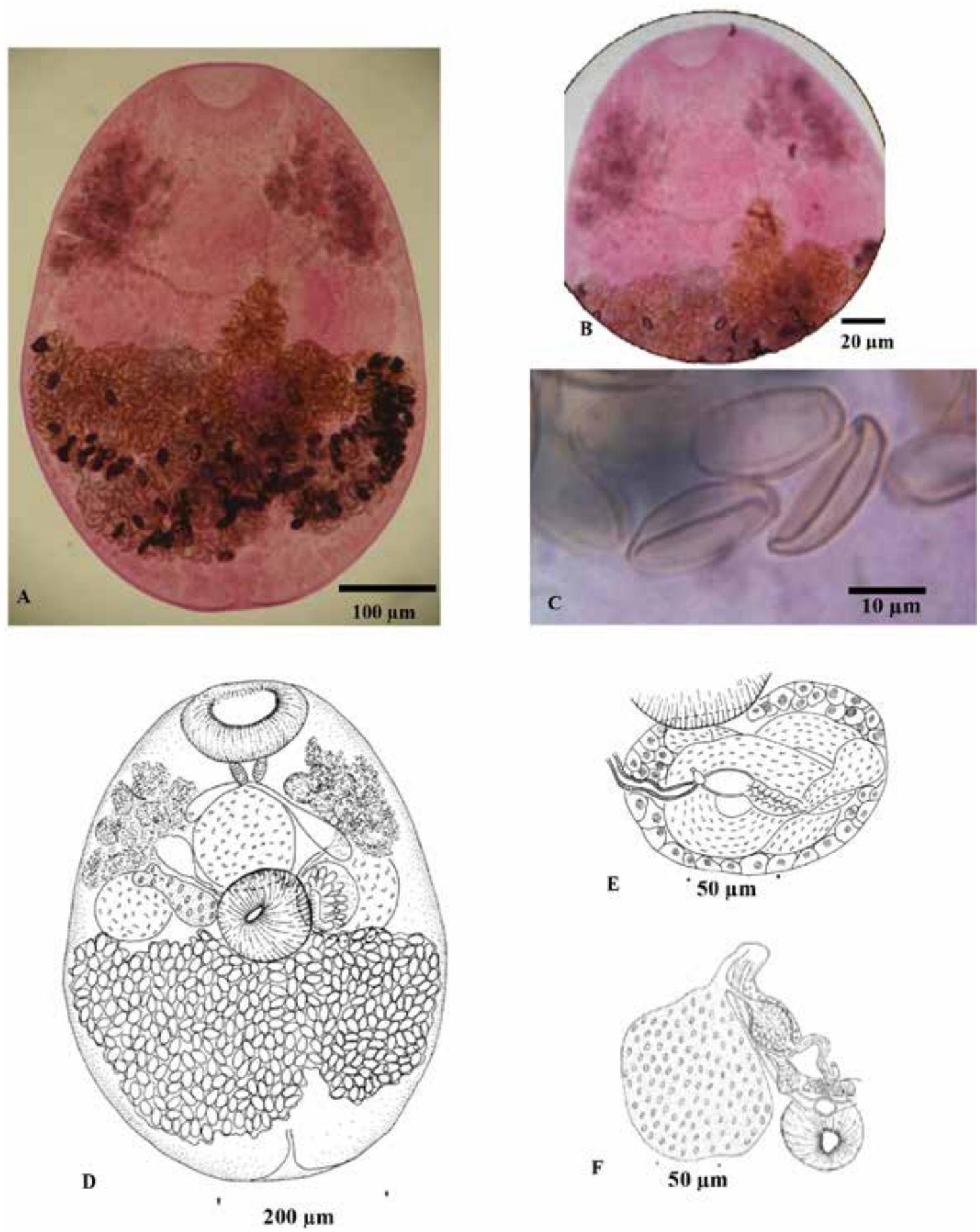

Figura III.3.12. Ochoterenatrema labda. A y D- especímen in toto vista ventral; B- detaIle del pseudogonocotilo; C-huevos; E- detalle del pseudosaco del cirro; F- detalle del complejo ovárico. 
Paralecithodendrium Travassos, 1921

Los ejemplares de este género se caracterizan principalmente por poseer los testículos cercanos a los extremos cecales.

\section{Paralecithodendrium aranhai Lent, Freitas y Proença, 1945}

(Figura III.3.14)

Descripción: Cuerpo pequeño, piriforme, 420 a $690 \mu \mathrm{m}$ de largo y 360 a $750 \mu \mathrm{m}$ de ancho $(535 \pm 75,2 \times 580 \pm 109,1 \mu \mathrm{m})$. Tegumento liso. Ventosa oral subterminal, de 55 a 75 $\mu \mathrm{m} \times 50$ a $87 \mu \mathrm{m}(65 \pm 5,8 \times 68 \pm 11,1 \mu \mathrm{m})$. Ventosa ventral postecuatorial, de 57 a $95 \mu \mathrm{m}$

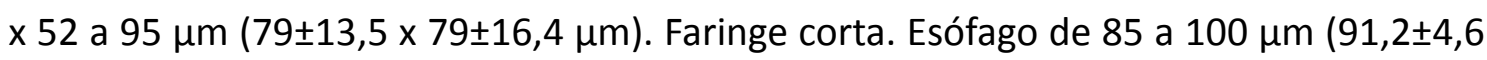
$\mu \mathrm{m})$ de largo. Ciegos cortos, divergentes, típicamente extendidos hasta la región testicular. Testículos enteros, en la zona de la ventosa ventral, cercanos al extremo cecal; testículo derecho 85 a $105 \mu \mathrm{m} \times 75$ a $165 \mu \mathrm{m}(99 \pm 5,4 \times 114 \pm 32,6 \mu \mathrm{m})$, testículo izquierdo 77 a $112 \mu \mathrm{m}$ x 75 a $135 \mu \mathrm{m}(94 \pm 11,2 \times 105 \pm 15,7 \mu \mathrm{m})$. Saco del pseudocirro voluminoso, esférico, mediano, entre la bifurcación intestinal y la ventosa ventral, 90 a $195 \mu \mathrm{m} \times 92$ a $200 \mu \mathrm{m}(130 \pm 34,9 \times 148 \pm 30,2 \mu \mathrm{m})$. Poro genital mediano, ecuatorial. Ovario lobulado, oval, submediano, en la zona testicular y de la ventosa ventral, 65 a $130 \mu \mathrm{m}$ x 82 a 112 $\mu \mathrm{m}(92 \pm 25,5 \times 95 \pm 11,7 \mu \mathrm{m})$. Útero ocupando la mayor parte de la región postesticular. Huevos pequeños, $20 \times 10 \mu \mathrm{m}$. Vitelarium folicular, en dos espacios laterales, anteriores a los testículos, superpuestos a los ciegos. Vesícula excretora en forma de $\mathrm{V}$.

Material estudiado: 10 ejemplares maduros, (4 especímenes de Eumops patagonicus, 6 especímenes de Myotis cf nigricans).

Hospedadores y procedencia: Eumops patagonicus (Capital, San Lorenzo y Mercedes) y Myotis cf nigricans (Isla Apipé).

Localización: intestino delgado

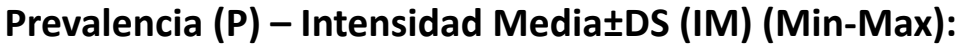

Eumops patagonicus: $\mathrm{P}=28,8 \%(19 / 66), \mathrm{IM}=22,6 \pm 21,2(3-72)$

Myotis cf nigricans: $\mathrm{P}=6,5 \%(2 / 31), \mathrm{IM}=33 \pm 15,6(26-40)$

Comentarios: distintas especies de Paralecithodendrium han sido citadas en la Región Neotropical registrando como hospedadores a murciélagos de Cuba (Groschaft y Valle, 1969; Zdzitowiecki y Rutkowska, 1980), Brasil (Travassos, 1921; 1928; Foster y Mertins, 1996) y Paraguay (Lent et al. 1945; Caballero y Caballero, 1960). Paralecithodendrium aranhai fue descripta asociada a los molósidos Nyctinomops laticaudatus y Molossus molossus de Paraguay (Lent et al., 1945). Travassos et al. (1969) supone que también debe estar presente en Brasil. En Argentina, Boero y Led (1971) mencionan a Paralecithodendrium 
conturbatum Freitas 1960, parasitando a Tadarida brasiliensis de la ciudad de La Plata. Paralecithodendrium conturbatum se diferencia de $P$. aranhai por poseer la ventosa oral de mayor tamaño que la ventral, mientras que en los ejemplares de $P$. aranhai la ventosa oral es más pequeña que la ventral. En el presente trabajo se cita por primera vez a Paralecithodendrium aranhai en Argentina, extendiendo su distribución geográfica hacia el SE y se amplía el registro de hospedadores al hallarlo parasitando a Eumops patagonicus y Myotis cf nigricans. En la Figura III.3.13 se encuentran señalados los registros para esta especie, incluyendo los aportes del presente estudio.

Figura III.3.13. Distribución geográfica de Paralecithodendrium aranhai

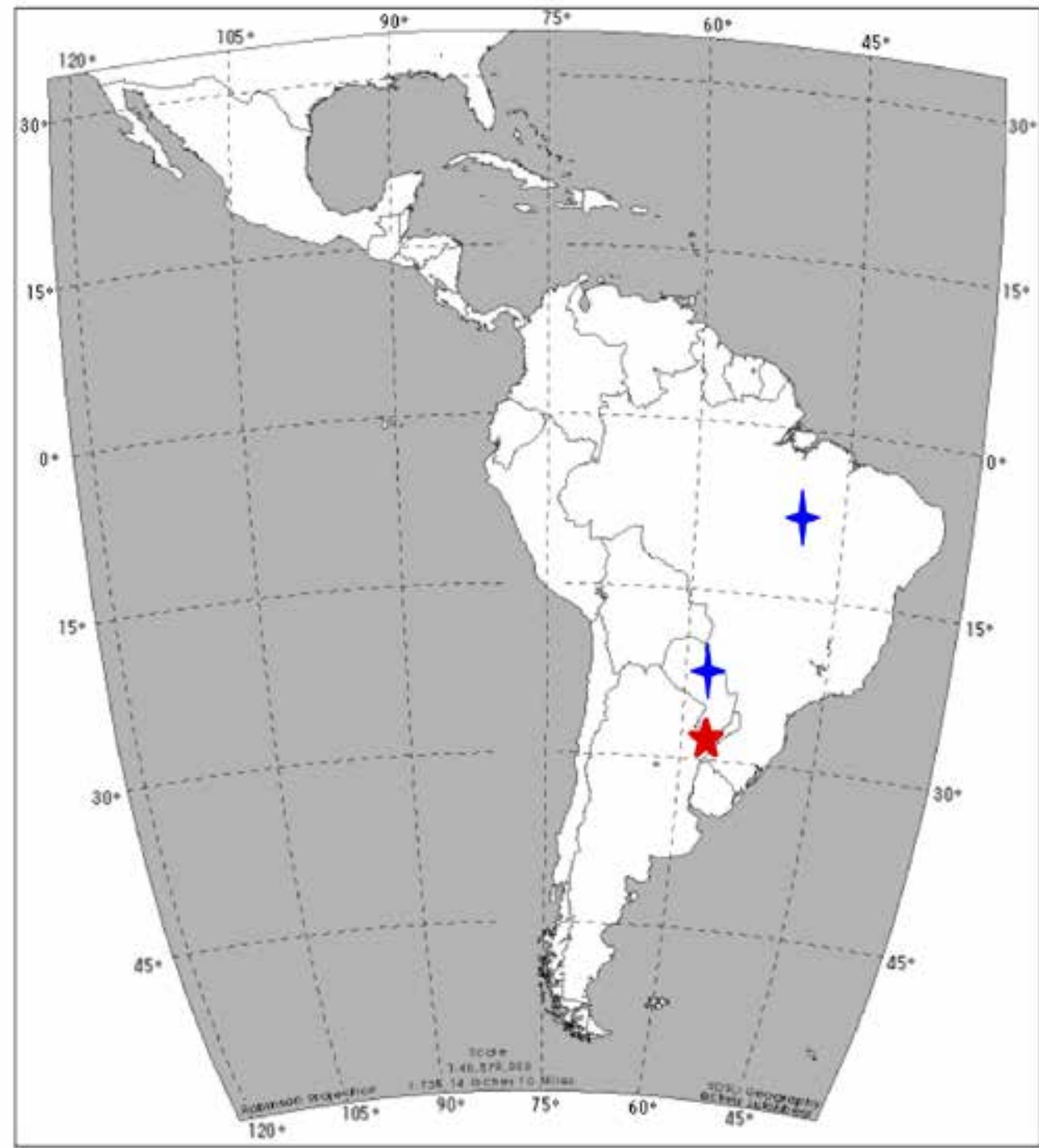

Registro anterior

Nuevo registro 


\section{Paralecithodendrium aranhai}
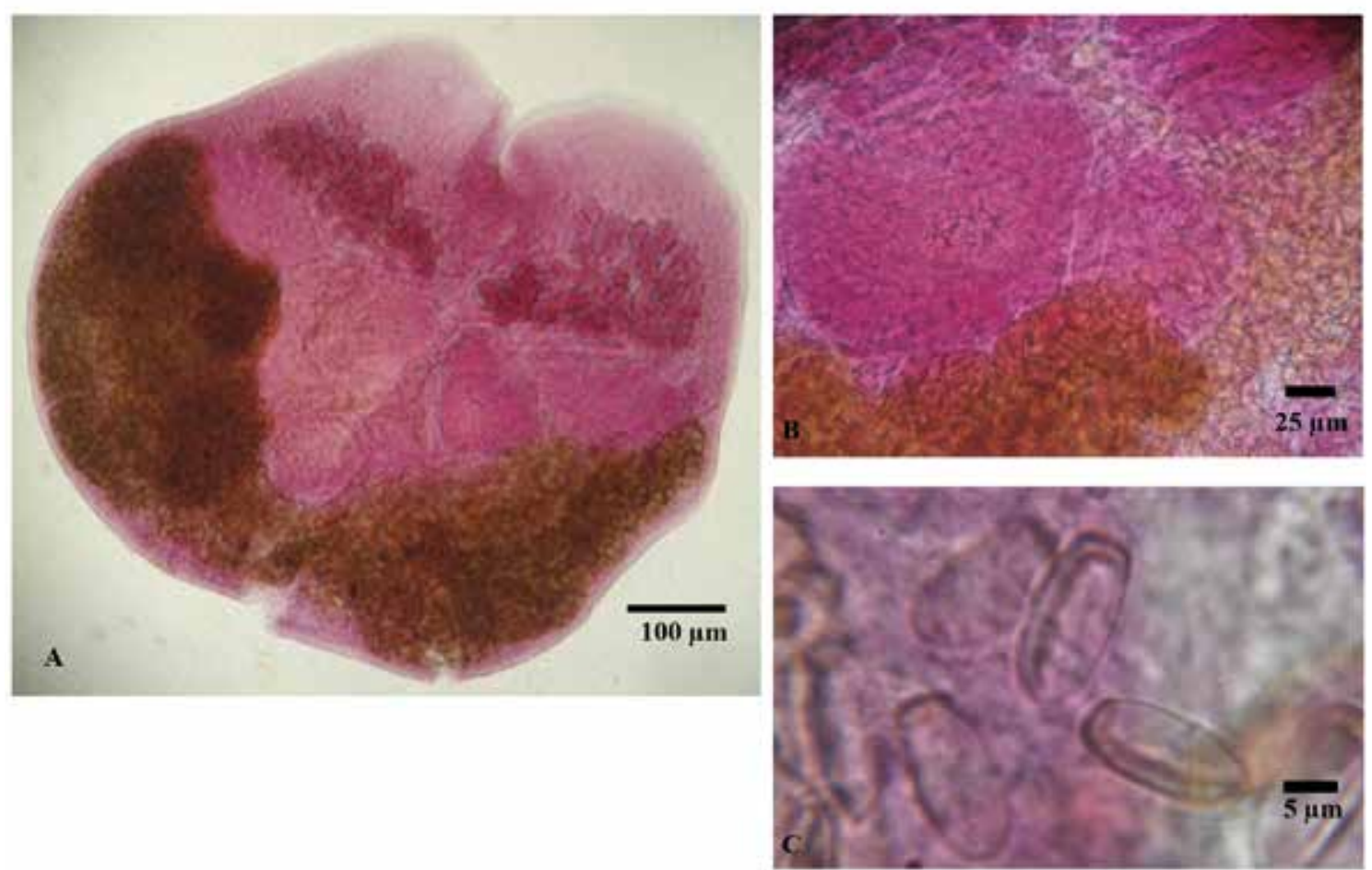

Figura III.3.14. Paralecithodendrium aranhai. A- espécimen in toto coloreado; B- detalle del acetábulo; C- huevos.

\section{Familia Phaneropsolidae Mehra, 1935}

Los representantes de la familia Phaneropsolidae son de distribución cosmopolita y parasitan a mamíferos, aves y raramente a reptiles. Se caracterizan por poseer tegumento con espinas, por poseer la ventosa ventral en posición tipicamente ecuatorial y por la presencia o ausencia de saco del cirro (Lotz y Font, 2008).

\section{Limatulum Travassos, 1921}

Los indivíduos de este género se caracterizan por poseer la ventosa ventral en zona ecuatorial, saco del cirro orientado posteriormente y el poro genital masculino abierto en posición posterolateral a la ventosa ventral. Son parásitos del intestino y estómago de murciélagos de Norte y Sudamérica (Lotz y Font, 2008). 


\section{Limatulum oklahomense Macy, 1932}

(Figura III.3.16)

Descripción: Cuerpo de forma oval alargado, de 510 a $610 \mu \mathrm{m}$ x 330 a $550 \mu \mathrm{m}(562 \pm 28,3$ $x 460 \pm 59,3 \mu \mathrm{m}$ ) de largo y ancho respectivamente. Tegumento espinoso. Ventosa oral

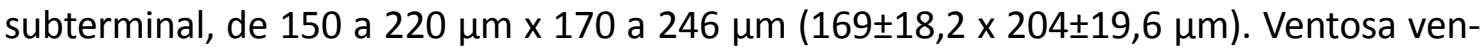
tral ubicada en el tercio medio del largo del cuerpo, 172 a $222 \mu \mathrm{m}$ x 200 a $304 \mu \mathrm{m}(196 \mathrm{x}$ $230 \mu \mathrm{m})$. Relación Vo/Vv 1:1 - 1,2 (1:1,1). Esófago corto. Bifurcación intestinal anterior a la ventosa ventral. Ciegos cortos, que se entiende hasta la región anterior de la ventosa ventral. Testículos enteros, esféricos, simétricos a ligeramente oblicuos, ubicados en el tercio medio del cuerpo. Testículo derecho 80 a $117 \mu \mathrm{m}$ x 83 a $100 \mu \mathrm{m}(102 \pm 12,1$ x 90 $\pm 4,8$ $\mu \mathrm{m})$, testículo izquierdo 92 a $95 \mu \mathrm{m} \times 98$ a $117 \mu \mathrm{m}(93 \pm 1,4 \times 106 \pm 5,5 \mu \mathrm{m})$. Saco del cirro grande, conteniendo una vesícula seminal larga plegada sobre si misma; pars prostática

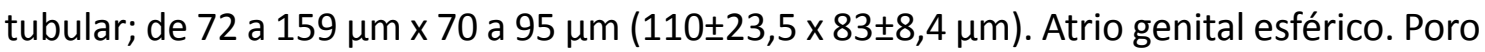
genital ubicado a la izquierda de la línea media, lateral a la ventosa ventral. Ovario redondeado, entero, submediano, en contacto con el margen anterior del testículo derecho, de

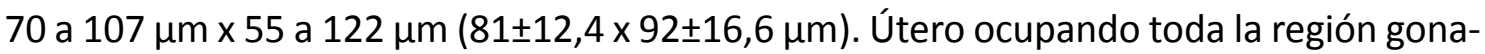
dal, metratermo de pared gruesa. Huevos ovoides y operculados, de 18 a $22 \mu \mathrm{m} \times 9$ a 11 $\mu \mathrm{m}(20 \pm 0,8 \times 10 \pm 0,6 \mu \mathrm{m})$. Glándulas vitelinas foliculares, folículos grandes distribuidos en dos campos laterales entre la faringe y la región anterior de la ventosa ventral; ocupando las regiones extracecal y cecal. Vesícula excretora no observada. Poro excretor terminal.

Material estudiado: 12 ejemplares maduros, (1 especímen de Molossus rufus, 6 especímenes de Myotis albescens, 5 especímenes de Myotis of nigricans).

Hospedadores y procedencia: Molossus rufus (Santa María), Myotis cf nigricans (Isla Apipé), Myotis albescens (Cabred, San Isidro).

Localización: estómago.

Prevalencia (P) - Intensidad Media \pm DS (IM) (Min-Max):

Molossus rufus: $\mathrm{P}=5 \%(1 / 20), \mathrm{I}=4$

Myotis albescens: $P=60 \%(21 / 35), I M=3,9 \pm 5,1$ (1-22)

Myotis cf nigricans: $\mathrm{P}=9,7 \%(3 / 31), \mathrm{IM}=13,7 \pm 12,6(6-25)$

Comentarios: En América, especies del género Limatulum fueron halladas en el estómago e intestino de murciélagos de USA, México, Cuba, Costa Rica, Colombia, Nicaragua, Brasil, Paraguay y Uruguay (Lunaschi et al., 2003). Las características morfológicas y morfométricas de los especímenes estudiados son acordes a $L$. oklahomense registrada en Tadarida brasiliensis de México, USA y Paraguay (Ubelaker et al., 1977) y en Tadarida brasiliensis cynocephala de Brasil (Foster y Mertins, 1996). Dicha especie fue citada por primera vez para Argentina por Lunaschi et al. (2003) asociada a Myotis nigricans de la 
Provincia de Formosa. En el presente trabajo se la vuelve a encontrar asociada a $M$. cf nigricans y se registra por primera vez a $M$. rufus y $M$. albescens como hospedadores. Asimismo se amplía la distribución geográfica con los nuevos registros para la provincia de Corrientes (Figura III.3.15).

Figura III.3.15. Distribución geográfica de Limatulum oklahomense

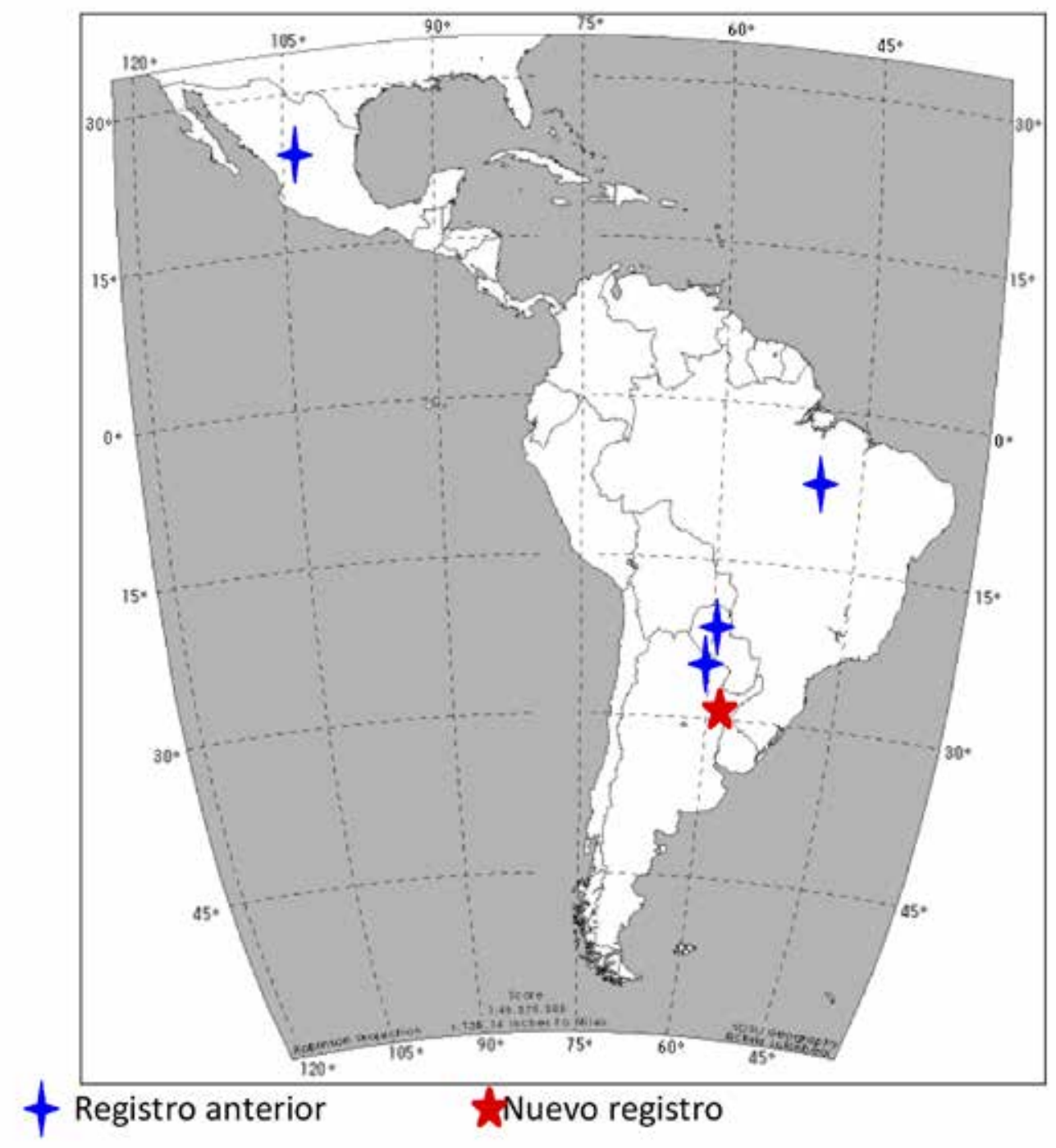




\section{Limatulum oklahomense}
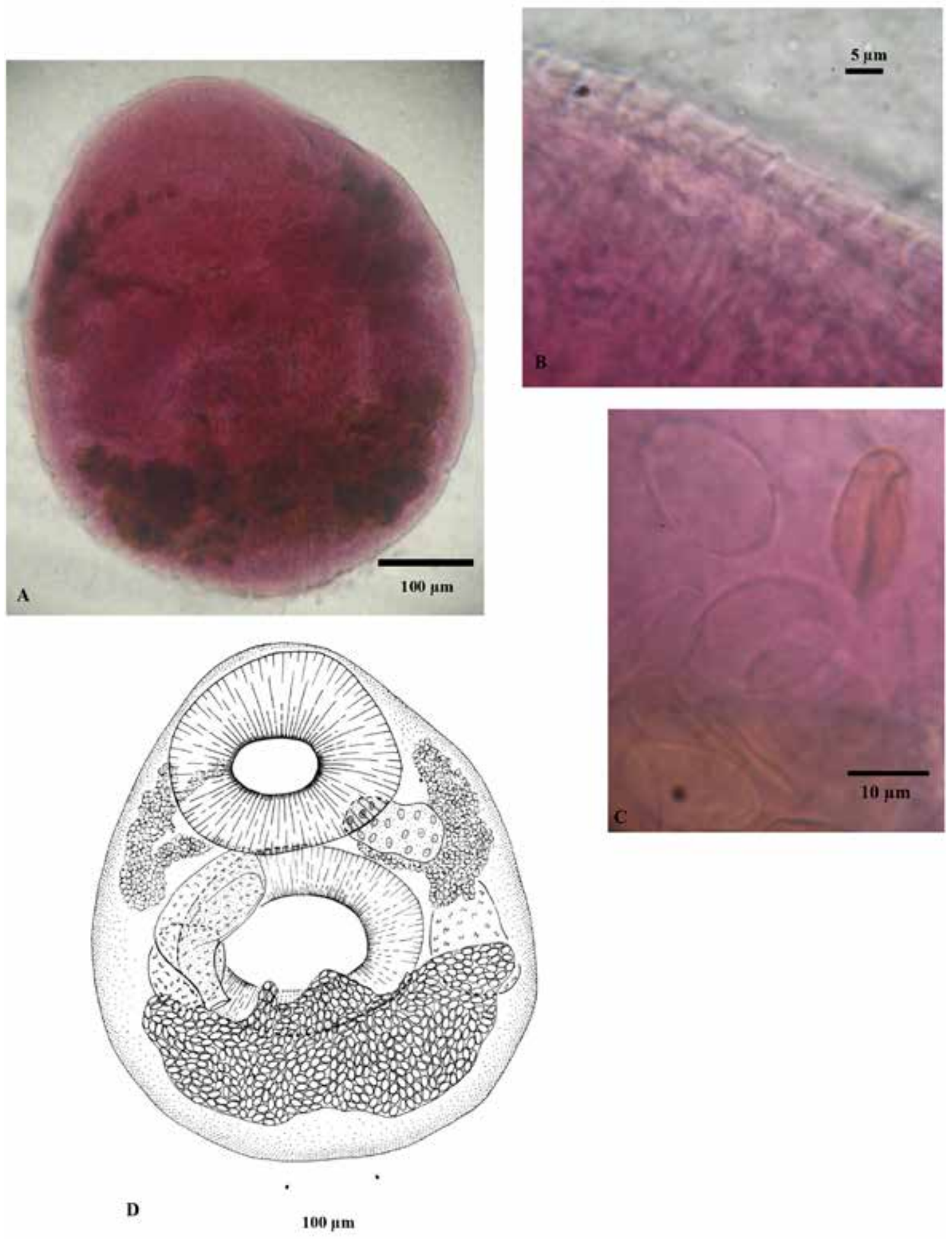

Figura III.3.16. Limatulum oklahomense. A- espécimen in toto vista ventral; B- detalle de las espinas tegumentarias; C- huevos; D- vista ventral 


\section{Familia Urotrematidae Posch, 1926}

Se registran dos géneros parasitando murciélagos, Urotrematulum Macy, 1933 y Urotrema Braun, 1900. El primero se caracteriza por poseer el ovario y los testículos lobulados, el ovario ubicado lejos de la ventosa ventral y las glándulas vitelinas que no se extienden hasta la ventosa ventral. Contrariamente, los representantes del género Urotrema poseen el ovario y los testículos macizos, el ovario cercano a la ventosa ventral y las glándulas vitelinas extendidas hasta la ventosa ventral (Font y Lotz, 2008).

\section{Urotrema Braun, 1900}

Los miembros de éste género poseen el ovario posterior a la ventosa ventral y los testículos en tándem y esféricos en el hindbody; además las ramas vitelinas anteriores están a nivel de la ventosa ventral. El género Urotrema es el que posee el mayor número de especies y de mayor distribución geográfica. La mayoría de las especies son parásitos de murciélagos aunque fueron también reportadas en la rata almizclera y lagartos del género Anolis (Goldberg et al., 1994; Mañé-Garzón y Telias, 1965).

\section{Urotrema scabridum Braun, 1900}

(Figura III.3.18)

Descripción: Cuerpo alargado, voluminoso y de extremos redondeados; de 570 a $1750 \mu \mathrm{m}$ y 270 a $725 \mu \mathrm{m}(1093 \pm 240,6 \times 507 \pm 96,3 \mu \mathrm{m})$ de largo y ancho, respectivamente. Tegumento espinoso. Ventosa oral subterminal, subesférica, de 60 a $18 \mu \mathrm{m}$ y 60 a $162 \mu \mathrm{m}(100 \pm 14,9 \mathrm{x}$ $116 \pm 22,5 \mu \mathrm{m})$. Ventosa ventral subigual a la ventosa oral y ubicada en el tercio anterior del cuerpo, de 72 a $210 \mu \mathrm{m}$ y 75 a $226 \mu \mathrm{m}(130 \pm 30,3$ x 132 $232,8 \mu \mathrm{m})$. Prefaringe corta. Faringe bien desarrollada, subelíptica. Esófago corto. Ciegos digestivos largos, alcanzando la región testicular o postesticular. Testículos de contorno liso, medianos, en tándem a ligeramente en diagonal e intercecales; testículo anterior de 52 a $148 \mu \mathrm{m}$ y 80 a $240 \mu \mathrm{m}(103 \pm 24,9 \mathrm{x}$ $153 \pm 36,8 \mu \mathrm{m})$; testículo posterior de 65 a $152 \mu \mathrm{m}$ y 85 a $220 \mu \mathrm{m}(116 \pm 25,4 \times 150 \pm 28,3 \mu \mathrm{m})$. Ovario anterior, de borde liso, intercecal, inmediatamente post-acetabular y ubicado a la derecha de la línea media, de 38 a $115 \mu \mathrm{m}$ y 43 a $136 \mu \mathrm{m}$ (75 $\pm 20,3$ x 95 $\pm 28,1 \mu \mathrm{m})$. Glándula de Mehlis postovariana. Receptáculo seminal y canal de Laurer no observados. Glándulas vitelínicas foliculares extendidas desde la ventosa ventral hasta el testículo anterior. Útero con numerosas asas transversales y descendentes, que sobrepasando lateralmente a los ciegos se distribuyen masivamente desde el área postovariana hasta el extremo posterior, pudiendo cubrir parcialmente a los testículos. Metratermo paralelo a la bolsa del cirro. Saco del cirro de 41 a 125 y 30 a $112 \mu \mathrm{m}(86 \pm 26,9$ x 65 $\pm 21,3 \mu \mathrm{m})$. Poro genital subterminal, cerca del extremo posterior del cuerpo. Huevos pequeños, ovoides, operculados, de color pardo, de 21 a 23 y 10 a $12 \mu \mathrm{m}(22 \pm 0,7 \times 11 \pm 0,5 \mu \mathrm{m})$. Vesícula excretora en forma de $\mathrm{V}$. Poro excretor mediano, ventral, terminal, posterior y próximo al poro genital. 
Material estudiado: 37 ejemplares maduros (17 especímenes de Eumops patagonicus, 7 especímenes de Molossus rufus, 4 especímenes de Molossops temminkii, 5 especímenes de Myotis albescens, 4 especímenes de Myotis cf nigricans).

Hospedadores y procedencia: Eumops patagonicus (Santa María, Rincón del Socorro, Capital, Mercedes, San Lorenzo); Molossus molossus (Mercedes), Molossus rufus (Puerto Valle); Molossops temminkii (Rincón del Socorro); Myotis albescens (Cabred, San Isidro); Myotis cf nigricans (Carlos Pellegrini, Isla Apipé).

Localización: intestino delgado e intestino grueso.

\section{Prevalencia (P) - Intensidad Media $\pm D S$ (IM) (Min-Max):}

Eumops patagonicus: $\mathrm{P}=87,9 \%(58 / 66), \mathrm{IM}=56,9 \pm 59,6(3-322)$

Molossops temminckii: $\mathrm{P}=80 \%(4 / 5), \mathrm{IM}=13 \pm 10,5$ (4-28)

Molossus rufus: $\mathrm{P}=20 \%(4 / 20), \mathrm{IM}=18,7 \pm 24,8(10-54)$

Molossus molossus: $\mathrm{P}=16,6 \%(1 / 6), \mathrm{I}=1$

Myotis albescens: $\mathrm{P}=14,3 \%(5 / 35), \mathrm{IM}=5,4 \pm 4,3(1-11)$

Myotis cf nigricans: $\mathrm{P}=9,7 \%(3 / 31), \mathrm{IM}=12,3 \pm 11,9(5-26)$

Comentarios: El estatus taxonómico de las especies del género Urotrema está cuestionado. Ya Caballero (1942) reconoció dos especies de las cinco consideradas originalmente por Macy (1933): U. scabridum Braun, 1900, especie parásita de mamíferos y U. shirleyae de lagartos (Zamparo et al., 2005). Bray et al. (1999) propusieron agrupar en un "complejo Urotrema scabridum" a las especies U. shillingeri Price, 1931; U. lasiurensis Alicata, 1932; U. aelleni Baer, 1957; U. macrotestis Mañé-Garzón y Telias, 1965; U. minuta Macy, 1933.

Urotrema scabridum es una especie frecuentemente hallada en murciélagos de América (Braun, 1900; Chandler, 1938; Pérez Vigueras, 1940; Marshall y Miller, 1979; Lamothe-Argumedoet al., 1997; Castiblanco y Vélez, 1982; Caro et al., 2003). También fue encontrada parasitando reptiles de República Dominicana y roedores de Uruguay (Goldberg et al., 1994; Mañé-Garzón y Telias, 1965). En Argentina, fue reportada en Holochilus brasiliensis vulpinus (Rodentia) (Sutton y Lunaschi, 1990) y fue registrada por primera vez para murciélagos (Molossus rufus) de la ciudad de La Plata por Led y Boero (1973). En estudios recientes Lunaschi y Notarnicola (2010) la citan como parásito de los molósidos Eumops bonariensis, Tadarida brasiliensis y Molossops temminkii y el vespertiliónido Myotis levis, de las provincias de Buenos Aires y Misiones. El presente trabajo amplía la distribución geográfica de $U$. scabriduma citándola por primera vez para la provincia de Corrientes y se agregan como nuevos hospedadores a Eumops patagonicus, Molossus molossus y Myotis albescens, Myotis cf nigricans.

Respecto a las características morfométricas se observó una gran variabilidad intraespecífica, probablemente debida al estado de desarrollo del espécimen parásito y no al hospedador en que se encuentre, el análisis de estas variaciones será motivo de futuras 
investigaciones (Anexo Tabla A.8). De acuerdo a la primera clasificación de Macy (1933), que tiene en cuenta las características morfométricas, los ejemplares examinados se ajustan a la descripción de Urotrema minuta. No obstante, hasta tanto se dilucide con precisión, se decidió adoptar la propuesta de Bray et al. (1999) utilizando la denominación "complejo Urotrema scabridum". En la Figura III.3.17 se muestran los registros para esta especie, incluyendo los aportes del presente estudio.

Figura III.3.17. Distribución geográfica de Urotrema scabridum

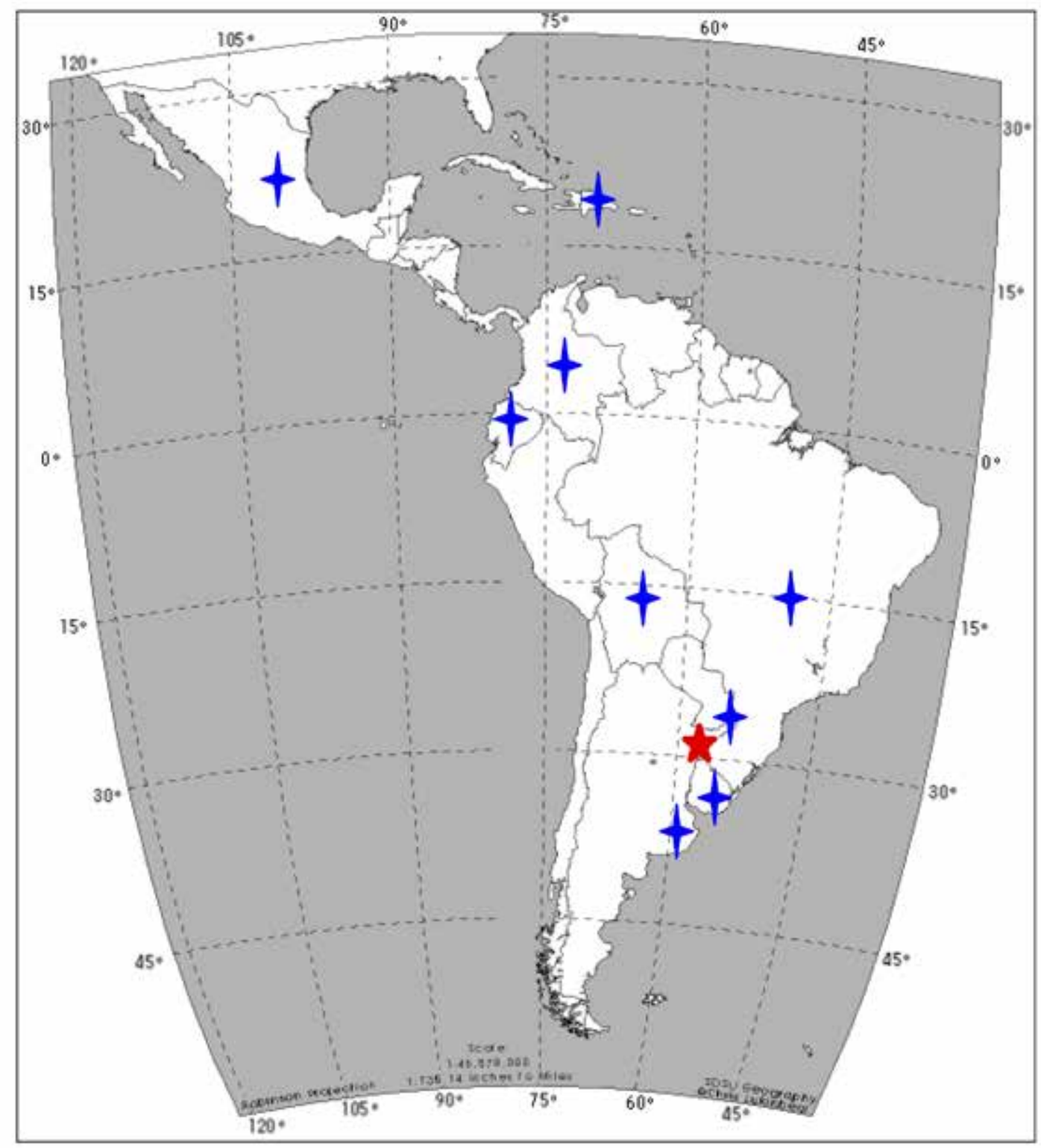

Registro anterior

Nuevo registro 


\section{Urotrema scabridum}
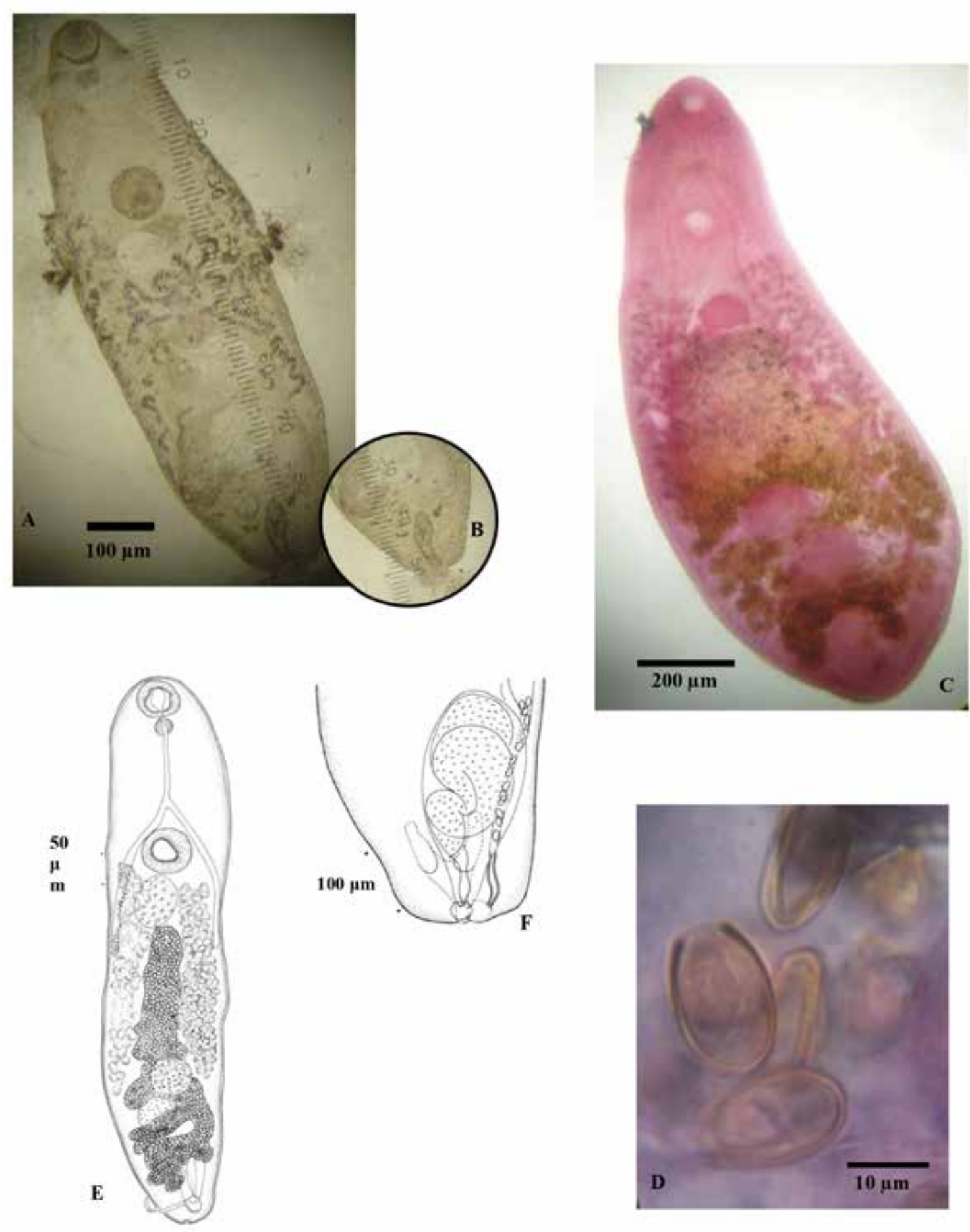

Figura III.3.18. Urotrema scabridum. A- vista ventral espécimen in toto en fresco; B y F- detalle del extremo posterior; C- espécimen coloreado; D- huevos; E- esquema del espécimen completo. 


\section{Phyllum NEMATHELMINTHES}

Clase NEMATODA Rudolphi, 1808

Subclase Adenophorea Chitwood, 1958

Orden Enoplida Schuurmans, Stethoven y Delenetz, 1933

Superfamilia Trichinelloidea Hall, 1916

Los representantes de esta superfamilia se diferencian por la forma del esófago, el cual consta de una porción anterior, muscular y corta y una porción posterior, glandular y larga. Incluye a las familias Trichinellidae, Cystoopsidae y Trichuridae (Anderson, 2000).

Familia Trichuridae (Ransom, 1811) Raillet, 1915

Como rasgo particular se menciona a los huevos, ovales, de cáscara gruesa y refringente, envuelta en otra capa delgada y un opérculo en cada extremo (López Neira, 1947). La vulva se halla ubicada al final del esófago. Incluye tres subfamilias y alrededor de 22 géneros parásitos de todos los órdenes de vertebrados, distribuidos en todo el mundo. Las especies de la subfamilia Trichurinae se localizan en el intestino grueso de mamíferos; las de Capillarinae son comunes en el intestino, tracto urinario y respiratorio y menos comunes en el hígado, bazo y piel de todos los grupos vertebrados, especialmente aves y mamíferos; las especies de Trichosomoidinae están asociadas a las mucosas bucal, nasal, intestinal y de la vejiga de mamíferos (Anderson, 2000).

\section{Subfamilia Capillariinae Raillet, 1915}

Los representantes de esta subfamilia son extremadamente diversos morfológicamente, aunque están incluidos en un solo género. Son fundamentalmente ovíparos. Respecto al ciclo de vida presentan tanto ciclos directos como indirectos, en la mayoría de los casos el huevo se encuentra embrionado en el útero. En el caso de ciclos heteroxenos el huevo no embrionado es ingerido por el hospedador intermediario, en el cual se desarrolla la larva infectiva (Anderson, 2000).

\section{Capillaria Zeder, 1800}

Los individuos del género Capillaria se caracterizan por poseer el cuerpo diferenciado en dos porciones de similar diámetro, una porción anterior o esofageal y una porción posterior o reproductiva. Son comunes en el intestino, especialmente de aves y mamíferos. Los individuos introducen todo el cuerpo en la mucosa intestinal (Anderson, 2000). 


\section{Capillaria sp.}

(Figura III.3.20)

Descripción: no se obtuvieron espécimenes completos, la caracterización fue únicamente morfológica, quedando pendiente el análisis morfométrico. Individuo largo y delgado; cuerpo diferenciado en una parte anterior o esofageal y una posterior o reproductiva, la vulva es no protrusiva y se encuentra ubicada al final del área esofágica. Huevos ovoides operculados.

Material estudiado: 2 individuos hembra.

Hospedadores y procedencia: Molossops temminckii (Rincón del Socorro), Molossus rufus (Puerto Valle, Santa María), Sturnira lilium (Puerto Valle).

Localización: intestino delgado.

Prevalencia (P) - Intensidad Media $\pm D S$ (IM) (Min-Max):

Molossops temminckii: $\mathrm{P}=20 \%(1 / 5), \mathrm{IM}=3$

Molossus rufus: $\mathrm{P}=30 \%(6 / 20), \mathrm{IM}=3,5 \pm \mathbf{2 , 9}(\mathbf{1 - 9})$

Sturnira lilium: $P=55,5 \%(5 / 9), I M=4,4 \pm 3,5(1-9)$

Comentarios: Diversas especies de Capillaria han sido descriptas y registradas para murciélagos del Neotrópico, tales como C. angrese Travassos 1934, C. diesingii (Kolenati 1856), C. pulchra Freitas 1934, C. rivarolai Lent, Freitas y Cavalcanti Proeca 1946, asociadas principalmente a molósidos de Brasil y Paraguay (Freitas Texeira, 1934; Freitas Texeira y Lent, 1936; Lent et al., 1946; Barus y del Valle, 1967). Únicamente con el epíteto genérico, Capillaria sp. fue registrada en Brasil, Colombia y Venezuela, con localización estomacal y principalmente en filostómidos (Guerrero, 1985; Cuartas-CaIle y Muñoz-Arango, 1999; Noronha et al., 2002; Nogueira et al., 2004). En Argentina solo se conoce un registro en Buenos Aires, aunque sin especificar hospedador y localización (Drago et al., 2007). El presente hallazgo permite confirmar la presencia de Capillaria sp. en nuestro país y adjudicar el rol de hospedadores a dos molósidos ( $M$. temminckii y $M$. rufus) y un filostómido (S. lilium). Los caracteres relevantes para la identificación específica se encuentran en los machos, en el presente estudio no se hallaron machos por lo que no pudo realizarse la determinación específica. En la Figura III.3.19 se observa la distribución geográfica de este taxón. 
Figura III.3.19. Distribución geográfica de Capillaria sp.

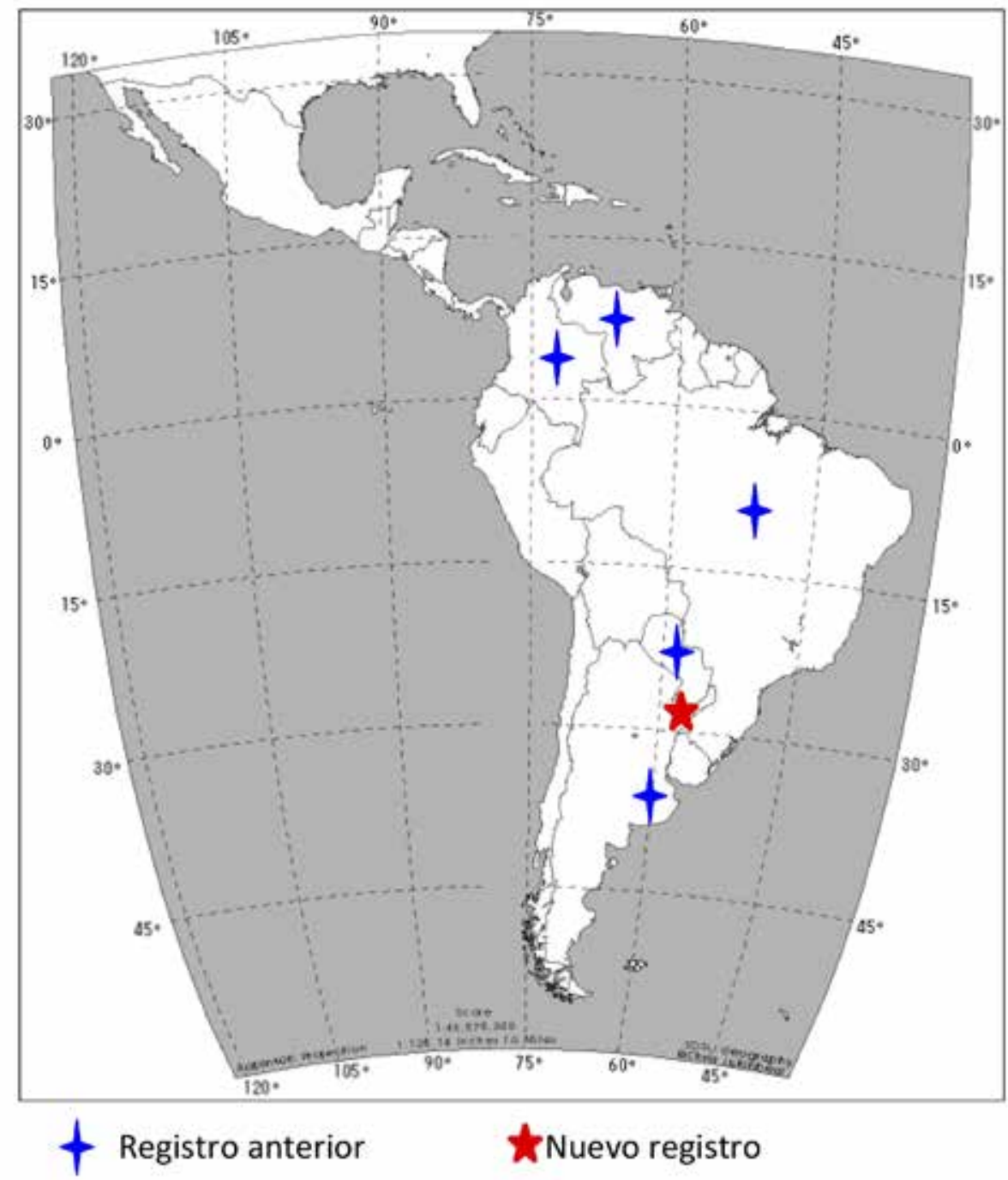




\section{Capillaria sp.}
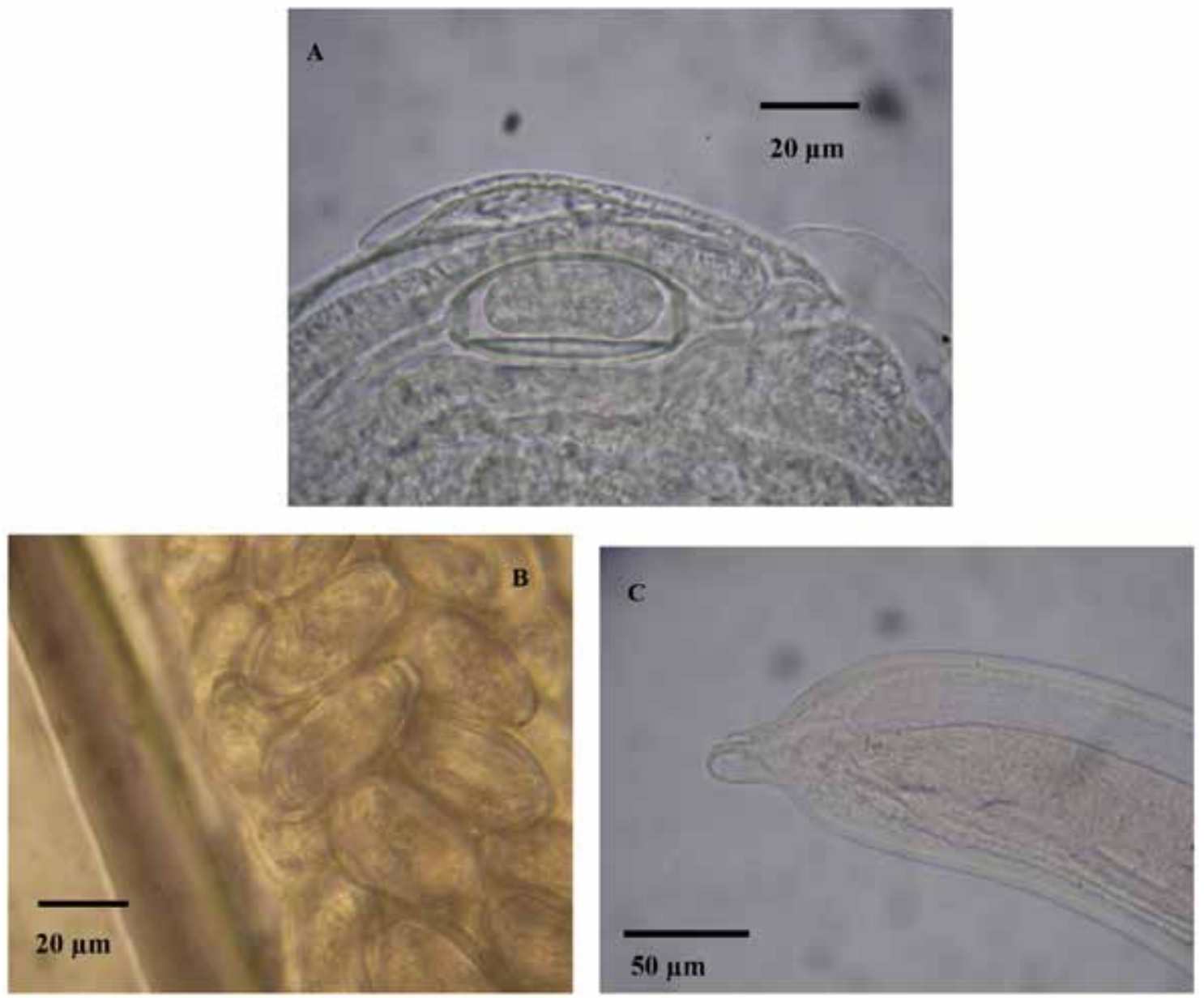

Figura III.3.20. Capillaria sp. hembra. A- detalle de vulva, B- huevos, C- extremo posterior.

Subclase Secernetea Linstow, 1905

Orden Spirurida Chitwood, 1933

Suborden Spirurina Railliet y Henry, 1915

Superfamilia Rictularoidea Hall, 1913

Familia Rictulariidae (Hall, 1915) Railliet, 1916

La familia Rictulariidae constituye un grupo homogéneo que incluye dos géneros y más de 50 especies. Los representantes de este grupo se caracterizan por carecer de pseudolabio y presentar una abertura bucal grande con dientes y espinas quitinosas dispuestas en hileras a lo largo del cuerpo o en la parte anterior del mismo. Son parásitos heteroxenos y un insecto actúa como hospedador intermediario (Anderson, 2000). 


\section{Pterygodermatites Wedl, 1861}

Los nematodes del género Pterygodermatites se caracterizan por la presencia de una boca subterminal a terminal, una cápsula bucal con tres dientes esofágicos y dos hileras de espinas cuticulares. Este género se divide en cinco subgéneros basando sus diferencias en la posición de la abertura oral, el número de espinas cuticulares prevulvares y la presencia de una papila caudal en los machos (Quentin, 1969).

\section{Pterygodermatites sp.}

(Figura III.3.22)

Descripción: no se obtuvieron espécimenes completos, la caracterización fue únicamente morfológica, quedando pendiente el análisis morfométrico. Individuos de tamaño medio. Abertura bucal apical, con tres dientes esofágicos. Presencia de dos hileras de espinas cuticulares ventrales, vulva postecuatorial. Extremidad posterior de la hembra aguzada.

Material estudiado: 2 individuos hembra

Hospedadores y procedencia: Eumops patagonicus (Capital)

Localización: intestino delgado

\section{Prevalencia (P) - Intensidad Media (IM) (Min-Max):}

Eumops patagonicus: $3 \%(2 / 66), \mathrm{IM}=3$ (3)

Comentarios: En la región Neotropical han sido reportados tres subgéneros Pterygodermatites (Paucipectines), Pterygodermatites (Multipectines) y Pterygodermatites (Pterygodermatites), de todos únicamente el primer subgénero ha sido reportado en murciélagos (Caspeta-Mandujano et al., 2013). En Sudamérica solo existen registros para Brasil, Pterygodermatites (Paucipectines) elegans fue hallada parasitando a Eumops perotis (Vicente et al., 1997) y recientemente Pterygodermatites (Paucipectines) andyraicola fue encontrada en Eumops perotis, E. auripendulus, E. glaciunus y Promops nasutus (Cardias et al., 2015). Recientes investigaciones informan acerca de su hallazgo en Molossops temminkii del noroeste de Argentina (Oviedo, 2009). En el presente trabajo se cita por primera vez parasitando a $E$. patagonicus y se amplía su distribución geográfica al nordeste de Argentina. En la Figura III.3.21 se observa la distribución geográfica de este taxón. 
Figura III.3.21. Distribución geográfica de Pterygodermatites sp.

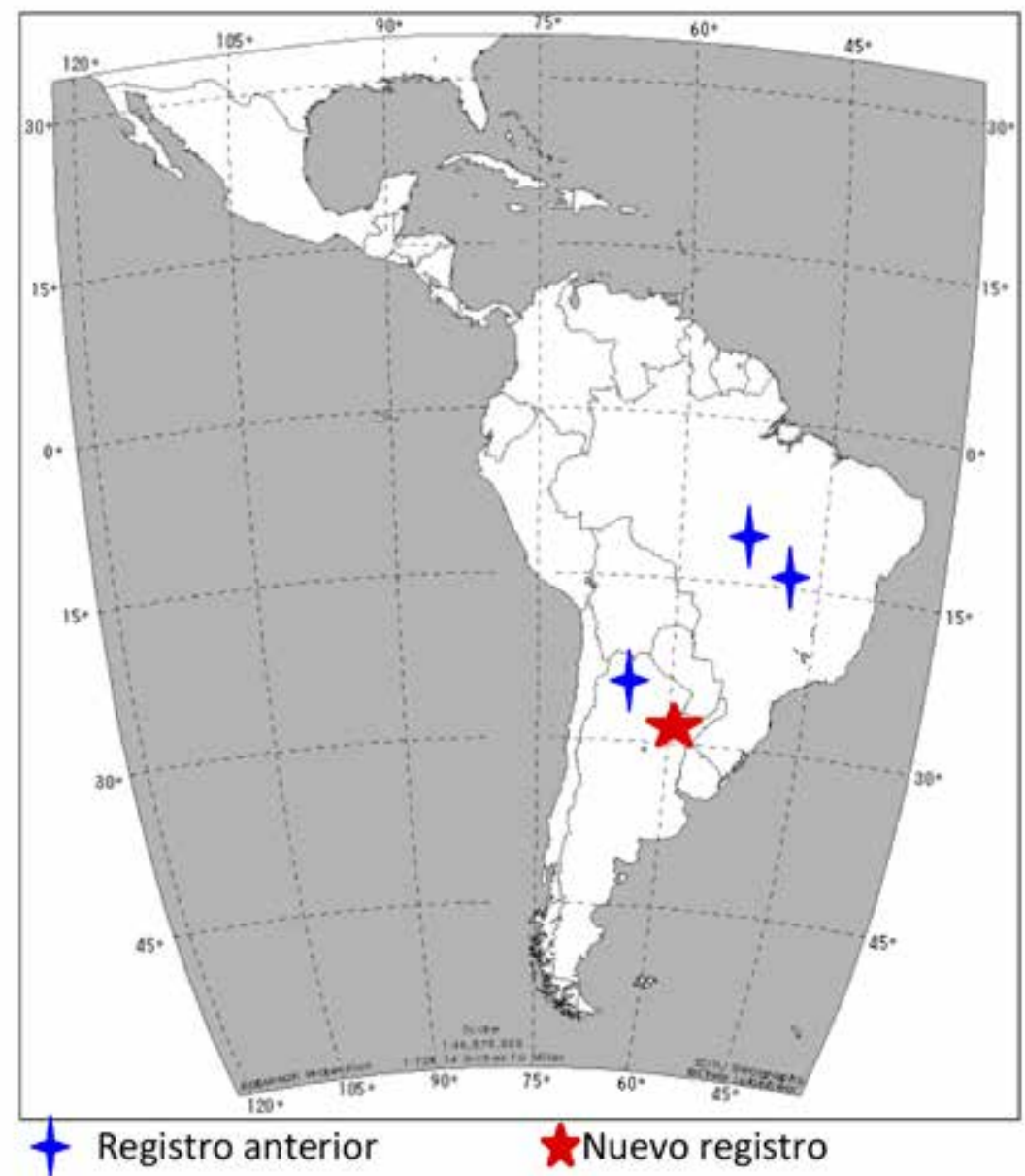


Pterygodermatites sp.
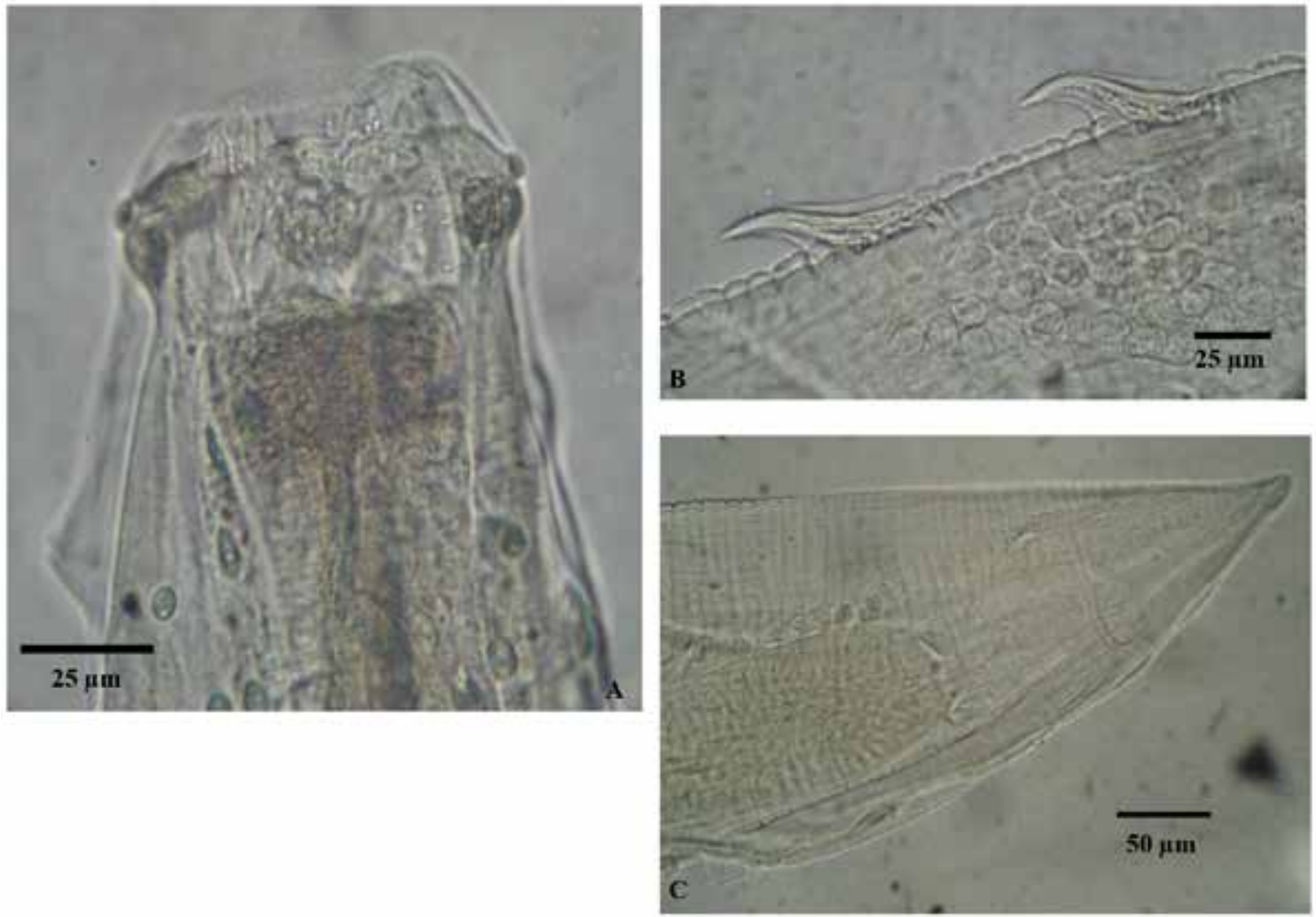

Figura III.3.22. Pterygodermatites sp. hembra. A- extremidad anterior, B-espinas cuticulares, C-extremidad posterior.

Orden Strongylida Molin, 1861

\section{Superfamilia Trichostrongyloidea}

(Skrjabin y Schulz, 1937) Durette-Desset y Chabaud, 1993

Es la superfamilia con mayor número de géneros y especies parásitas, incluidos en 14 familias y 24 subfamilias (Durette Desset y Chabaud, 1977; 1981; Durette Desset, 1983). El estudio de su taxonomía se ve dificultado no solo por el gran número de especies sino además por ser de pequeño tamaño y externamente similares. Los individuos se caracterizan por poseer el cuerpo enrollado, los labios y la cápsula bucal están reducidos, generalmente poseen synlophe; los machos presentan una bolsa caudal y las hembras son didélficas (Durette Desset, 1983; Gibbons, 2010). Presentan un ciclo de vida monoxeno, se localizan principalmente en el tracto digestivo y el rango de hospedadores es amplio. Su diversidad es extrema como parásitos de mamíferos, principalmente murciélagos, roedores y rumiantes (Anderson, 2000). En la Región Neotropical se registran diversos estudios referidos a 
tricostrongílidos de murciélagos, destacándose Brasil como el país en que se llevaron a cabo numerosas investigaciones (Freitas Texeira y Mendonca, 1963; Vicente et al., 1997; Nogueira et al., 2004). En Argentina los trabajos son escasos (Oviedo et al., 2010).

\section{Familia Molineidae}

(Skrjabin y Schulz, 1937) Durette-Desset y Chabaud, 1993

Anoplostrongylus Boulenger 1926

Los individuos del género Anoplostrongylus se caracterizan por poseer una vesícula cefálica dividida en tres porciones, distintas entre machos y hembras. Poseen alas laterales y bursa caudal bilobada. Synlophe presente, de orientación ventrodorsal (Travassos, 1937; Falcón Ordaz et al., 2006).

\section{Anoplostrongylus sp.}

(Figura III.3.24)

Descripción: solo se consideraron dos individuos hembras para realizar la caracterización que fue únicamente cualitativa. Solo uno de ellos se encontraba completo, presentando una longitud total $8,9 \mathrm{~mm}$. Synlophe presente, con crestas en orientación dorso-ventral. Con vesícula cefálica dividida en tres porciones, la tercera porción levemente más ancha que las anteriores. Alas laterales presentes. Presencia de una espina delgada en el extremo posterior de la hembra, la cual posee una protuberancia rodeada por una espina dorsal robusta y dos lateroventrales más pequeñas.

Material estudiado: 2 individuos hembra

Hospedadores y procedencia: Eumops patagonicus (Capital, Mercedes, San Lorenzo, Rincón del Socorro), Eumops perotis (Capital), Molossus rufus (Puerto Valle), Eptesicus furinalis (Carlos Pellegrini, Isla Apipé).

Localización: intestino delgado.

\section{Prevalencia (P) - Intensidad Media $\pm D S$ (IM) (Min-Max):}

Eumops patagonicus: $\mathrm{P}=31,8 \%(21 / 66), \mathrm{IM}=3,33 \pm 1,8(1-7)$

Eumops perotis: $\mathrm{P}=100 \%(1 / 1), \mathrm{I}=5$

Molossus rufus: $\mathrm{P}=10 \%(2 / 20), \mathrm{IM}=2,5 \pm 0,7$ (2-3)

Eptesicus furinalis: $\mathrm{P}=12,5 \%(2 / 16), \mathrm{IM}=3,3 \pm 1,4(2-4)$

Comentarios: Para la Región Neotropical es conocida una sola especie, Anoplostrongylus paradoxus (Travassos, 1918) y fue hallada en Tadarida brasiliensis y Eumops perotis de Chile y Brasil, en T. laticaudata y T. macrotis de Paraguay y Cuba (Muñoz et al., 2011; Travassos, 1918; Vicente et al., 1997; Lent et al., 1946; Rutkowska, 1980; Barus y del Valle, 1967). Los especímenes estudiados en el presente trabajo se diferencian de $A$. paradoxus por la orientación dorso-ventral de las crestas del synlophe (en A. paradoxus es ven- 
tro-dorsal) y por poseer las hembras una espina cuticular a nivel de la vulva (ausente en A. paradoxus). En este sentido, un reciente estudio en el Noroeste de Argentina menciona estas características en individuos asociados a Eumops patagonicus y E. bonariensis (Oviedo, inéd). En la Figura III.3.23 se observa la distribución de Anoplostrongylus paradoxus y Anoplostrongyus sp. En el presente trabajo se registra a E. patagonicus, E. perotis, Molossus rufus y Eptesicus furinalis como especies hospedadoras. Si bien el material biológico obtenido para el presente trabajo consistió únicamente en ejemplares hembras y estuvo en mal estado de conservación, estudios en proceso sobre nematodes de murciélagos de Corrientes colectados con posterioridad permitieron observar las características mencionadas (González, com. pers.); hecho que permitirá un estudio más profundo con el fin de llegar a la identificación taxonómica y su eventual nuevo estatus específico.

Figura III.3.23. Distribución geográfica de Anoplostrongylus sp.

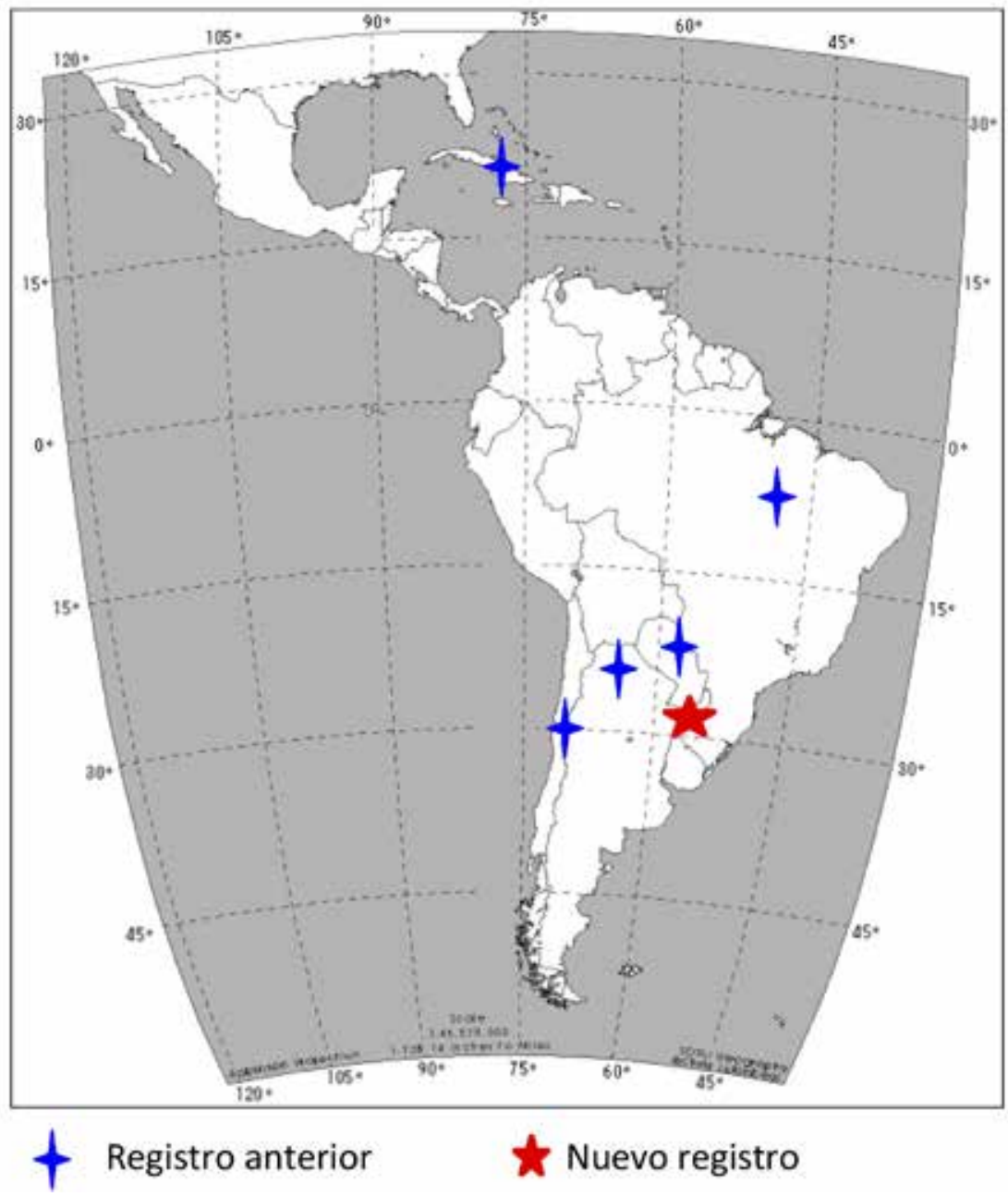




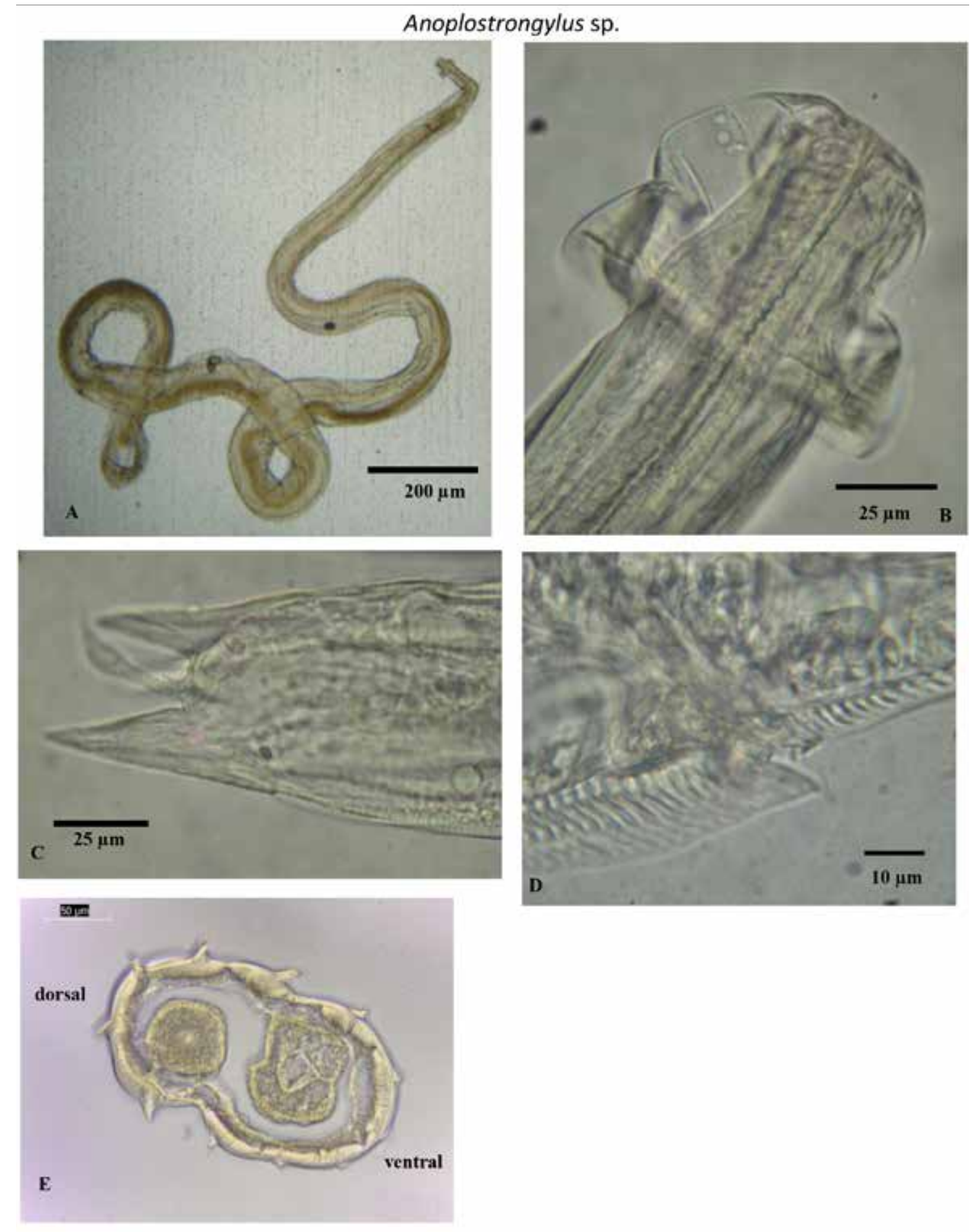

Figura III.3.24. Anoplostrongylus sp. hembra. A- especimen completo, B- extremidad anterior, C extremidad posterior, D- espina cuticular a nivel de la vulva, E-synlophe, corte a nivel medio del cuerpo. 


\section{III.4. Integración de los datos}

En la Tabla III.4.1 se observan los hospedadores registrados para cada taxón parásito y se resaltan las nuevas asociaciones. Se aprecia que Urotrema scabridum es la especie con mayor distribución hospedatoria, estando presente en seis especies hospedadoras, mientras que Anenterotrema liliputianum y Pterygodermatites sp. solo estuvieron presentes en una especie hospedadora. A excepción de A. liliputianum para todos los taxones se registran nuevas especies hospedadoras.

Tabla III.4.1. Lista de taxones parásitos y especies hospedadoras.

\begin{tabular}{|c|c|c|c|}
\hline \multicolumn{3}{|l|}{ Parásito } & \multirow{2}{*}{$\begin{array}{l}\text { Hospedador } \\
\text { Especie }\end{array}$} \\
\hline Clase & Familia & Especie & \\
\hline \multirow[t]{4}{*}{ Cestoda } & Hymenolepididae & Vampirolepis guarany & Eumops patagonicus \\
\hline & & & Molossus rufus \\
\hline & & & Artibeus lituratus* \\
\hline & & Vampirolepis of macroti & Eptesicus furinalis* \\
\hline \multirow[t]{21}{*}{ Digenea } & Urotrematidae & Urotrema scabridum & Eumops patagonicus* \\
\hline & & & Molossus Molossus \\
\hline & & & Molossus rufus \\
\hline & & & Molossops temminkii \\
\hline & & & Myotis albescens* \\
\hline & & & Myotis cf nigricans \\
\hline & Lecithodendriidae & Gymnoacetabulum talavarensis & Eumops patagonicus* \\
\hline & & & Myotis albescens* \\
\hline & & Ochoterenatrema labda & Eumops patagonicus* \\
\hline & & & Molossus rufus* \\
\hline & & & Molossops temminkii* \\
\hline & & & Myotis of nigricans \\
\hline & & & Myotis albescens* \\
\hline & & Paralecithodendrium aranhai & Eumops patagonicus* \\
\hline & & & Myotis cf nigricans* \\
\hline & Phaneropsolidae & Limatulum oklahomense & Molossus rufus* \\
\hline & & & Myotis albescens* \\
\hline & & & Myotis of nigricans \\
\hline & Anenterotrematidae & Anenterotrema liliputianun & Molossus rufus \\
\hline & & Anenterotrema eduardocaballeroi & Molossus rufus \\
\hline & & & Molossops temminkii* \\
\hline \multirow[t]{8}{*}{ Nematoda } & Rictulariidae & Pterygodermatites sp. & Eumops patagonicus* \\
\hline & Molineidae & Anoplostrongylus sp. & Eumops patagonicus* \\
\hline & & & Eumops perotis* \\
\hline & & & Molossus rufus* \\
\hline & & & Eptesicus furinalis* \\
\hline & Trichuridae & Capillaria sp. & Molossus rufus* \\
\hline & & & Sturnira lilium* \\
\hline & & & Molossops temminkii* \\
\hline
\end{tabular}

*Nueva especie hospedadora 
En la Tabla III.4.2 se listan las especies hospedadoras estudiadas y las especies de helmintos registradas. La mayor riqueza específica se observa en Molossus rufus, con un registro de ocho especies de helmintos, cinco trematodes, dos nematodes y un cestode. En Eumops perotis, Artibeus lituratus y Sturnira lilium solo pudo observarse una especie parásita presente, no obstante, en los tres casos son registros novedosos (Anoplostrongylus sp., Vampirolepis guarany y Capillaria sp. respectivamente). En los filostómidos Platyrrhinus lineatus y Desmodus rotundus no se hallaron helmintos.

Tabla III.4.2. Lista de murciélagos y sus helmintos parásitos.

\begin{tabular}{|c|c|c|c|}
\hline Familia & Especie & Familia & Especie \\
\hline \multirow[t]{21}{*}{ Mollosidae } & Eumops patagonicus & Hymenolepididae & Vampirolepis guarany \\
\hline & & Lecithodendriidae & Gymnoacetabulum talavarensis* \\
\hline & & & Ochoterenatrema labda* \\
\hline & & & Paralecithodendrium aranhai* \\
\hline & & Urotrematidae & Urotrema scabridum* \\
\hline & & Trichostrongylidae & Anoplostrongylus sp.* \\
\hline & & Rictulariidae & Pterygodermatites sp.* \\
\hline & Eumops perotis & Molineidae & Anoplostrongylus sp.* \\
\hline & Molossops temminkii & Anenterotrematidae & Anenterotrema eduardocaballeroi* \\
\hline & & Lecithodendriidae & Ochoterenatrema labda* \\
\hline & & Urotrematidae & Urotrema scabridum \\
\hline & & Trichuridae & Capillaria sp.* \\
\hline & Molossus molossus & Urotrematidae & Urotrema scabridum \\
\hline & Molossus rufus & Hymenolepididae & Vampirolepis guarany \\
\hline & & Anenterotrematidae & Anenterotrema liliputianum \\
\hline & & & Anenterotrema eduardocaballeroi \\
\hline & & Lecithodendriidae & Ochoterenatrema labda* \\
\hline & & Phaneropsolidae & Limatulum oklahomense* \\
\hline & & Urotrematidae & Urotrema scabridum \\
\hline & & Trichuridae & Capillaria sp.* \\
\hline & & Trichostrongylidae & Anoplostrongylus sp.* \\
\hline \multirow[t]{4}{*}{ Phyllostomidae } & Artibeus lituratus & Hymenolepididae & Vampirolepis guarany* \\
\hline & Desmodus rotundus & \multicolumn{2}{|c|}{ no se observaron helmintos } \\
\hline & Platyrrhinus lineatus & \multicolumn{2}{|c|}{ no se observaron helmintos } \\
\hline & Sturnira lilium & Trichuridae & Capillaria sp.* \\
\hline \multirow[t]{10}{*}{ Vespertilionidae } & Eptesicus furinalis & Hymenolepididae & Vampirolepis cf macroti* \\
\hline & & Trichostrongylidae & Anoplostrongylus sp.* \\
\hline & Myotis albescens & Lecithodendriidae & Gymnoacetabulum talavarensis* \\
\hline & & & Ochoterenatrema labda* \\
\hline & & Phaneropsolidae & Limatulum oklahomense* \\
\hline & & Urotrematidae & Urotrema scabridum* \\
\hline & Myotis cf nigricans & Lecithodendriidae & Ochoterenatrema labda \\
\hline & & & Paralecithodendrium aranhai* \\
\hline & & Phaneropsolidae & Limatulum oklahomense \\
\hline & & Urotrematidae & Urotrema scabridum \\
\hline
\end{tabular}

* Nuevo registro de helminto parásito para la especie hospedadora 


\section{III.5. Meta-análisis de datos}

En un trabajo reciente Santos y Gibson (2015) recopilan en una checklist, información proveniente de 120 publicaciones sobre los helmintos de murciélagos, poniendo de relieve que se conocen reportes de helmintos de 92 especies de murciélagos lo que representa un tercio de las 275 especies conocidas en Sud América. Santos y Gibson (2015) reportan 370 registros de 114 taxones (especies nominales) de helmintos parásitos, que incluyen 53 especies de nematodes, 40 de trematodes, 18 de cestodes y tres de acantocéfalos. En el listado no se incluye a Vampirolepis guarany, $V$. cf macroti y Limatulum oklahomense, taxones que se adicionan en el presente trabajo.

En este contexto, considerando los helmintos hallados en el presente trabajo, se propone efectuar un meta-análisis de la información de modo de actualizar la checklist publicada por Santos y Gibson (2015) (Tabla III.5.1). Asimismo, teniendo en cuenta que los datos para Argentina se encuentran muy dispersos, incluso algunos solo en resúmenes de reuniones científicas, se propone la integración de los resultados del presente trabajo y la información pre-existente en una checklist de helmintos parásitos de murciélagos de Argentina (Tabla III.5.2). De este modo, se pretende actualizar la información y reposicionar los estudios sobre helmintos parásitos de murciélagos en nuestro país. 


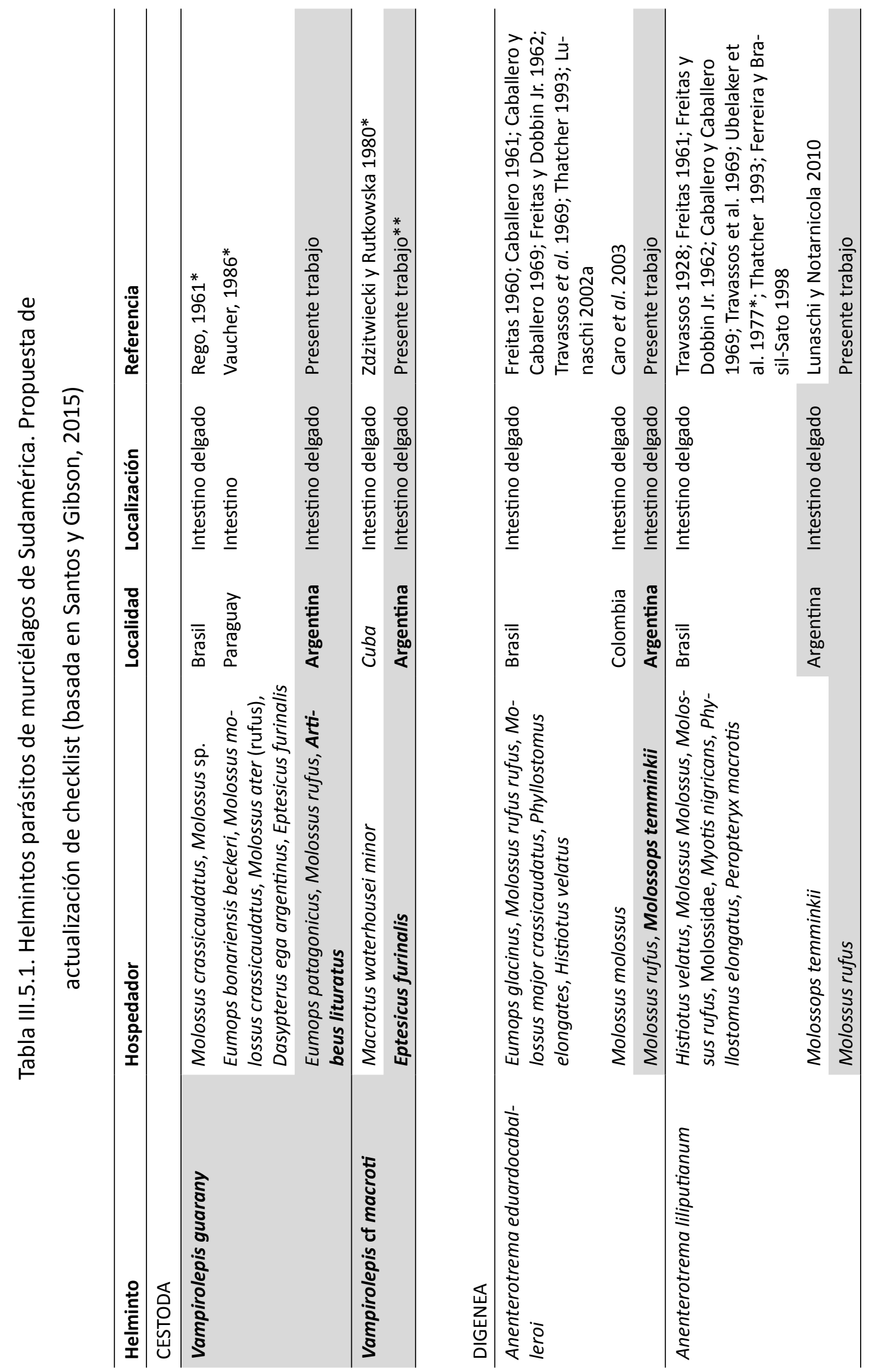




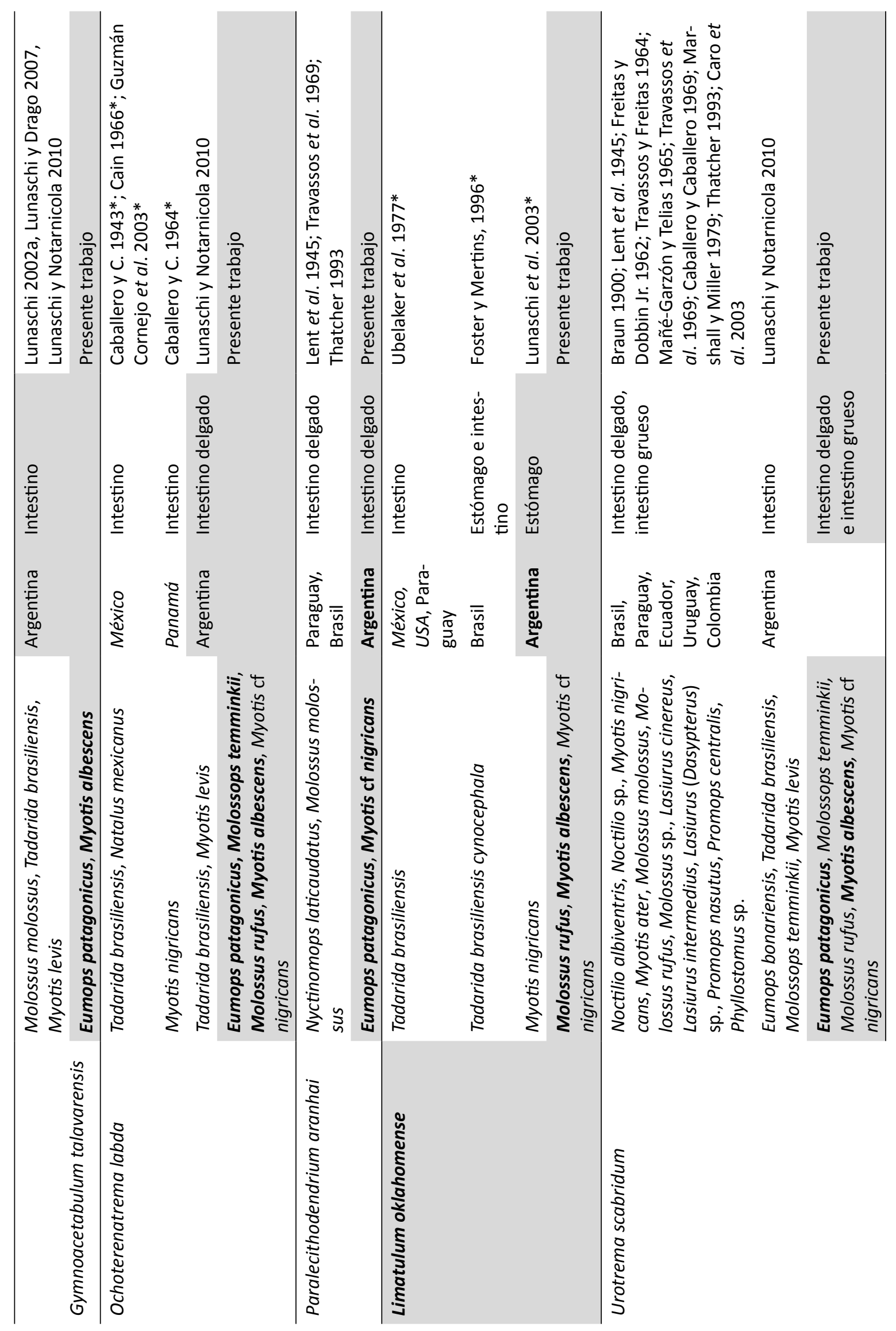




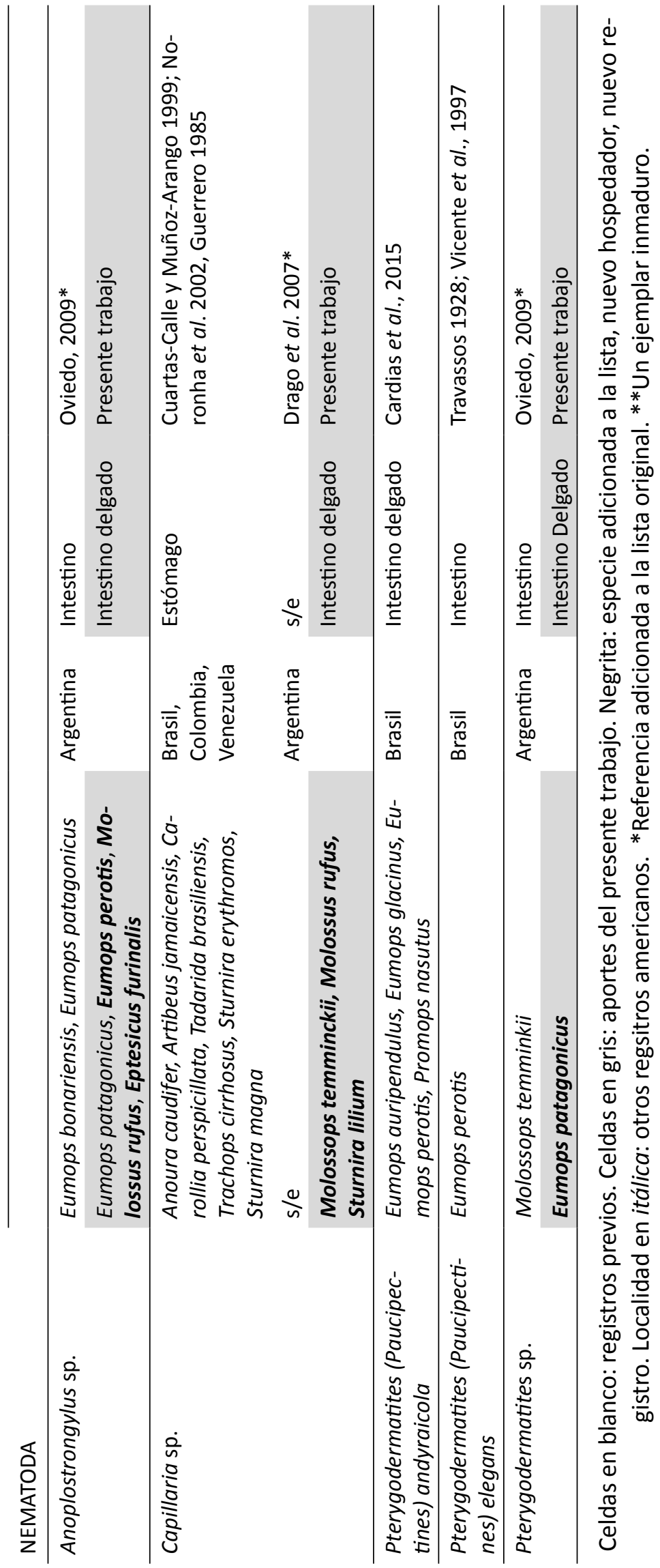




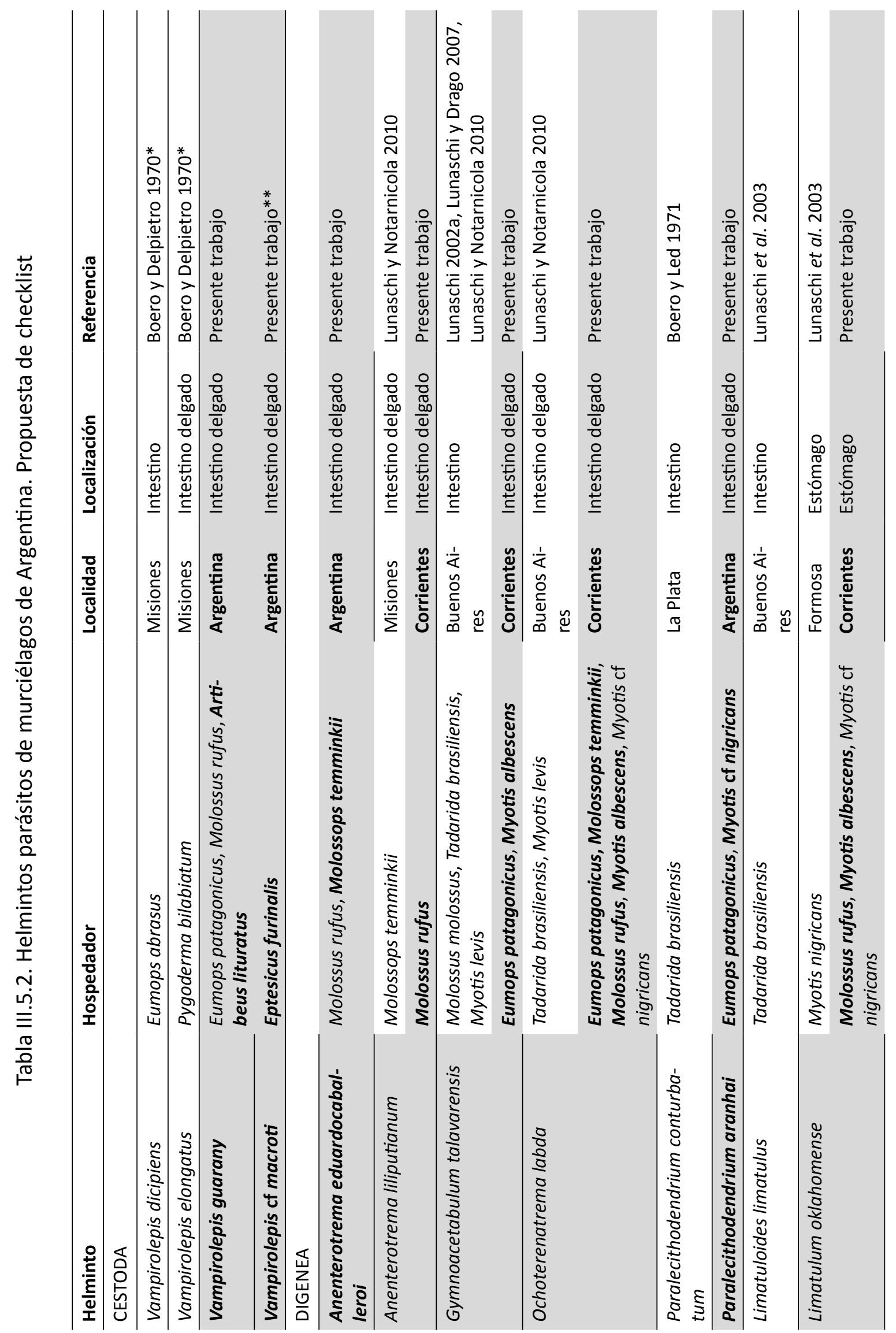




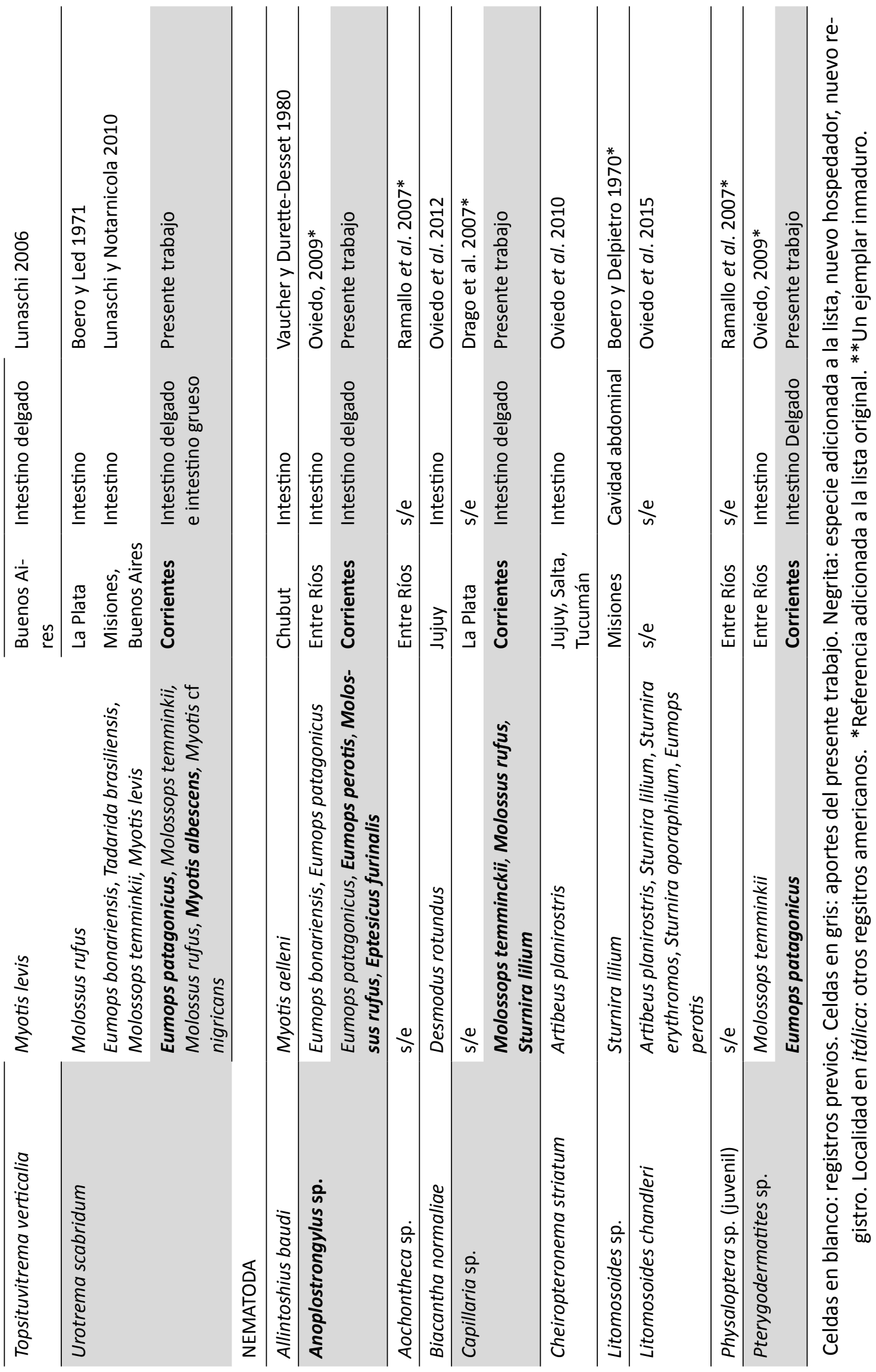




\section{III.6. Discusión y conclusiones}

Los primeros estudios sobre helmintos de murciélagos en Argentina datan de los años 70 (Boero y Delpietro, 1970; Boero y Led, 1971) y desde estas investigaciones existe un hiato de 30 años (a excepción del hallazgo de Vaucher y Durette-Desset, 1980). Las investigaciones de Lunaschi (2002) reabren el campo de estudio y comienzan importantes aportes (ver Tabla III.5.2). De acuerdo a la información pre-existente un total de 20 taxones de helmintos asociados a murciélagos han sido registrados en nuestro país. En el presente trabajo se reportan 12 taxones de helmintos parásitos asociados a diez especies de murciélagos. De los cuales cinco (Vampirolepis guarany, Vampirolepis cf macroti, Anenterotrema eduardocaballeroi, Paralecithodendrium aranhai y Anoplostrongylus sp.) son nuevos registros para Argentina, incrementando la lista de helmintos a 25 taxones.

Así, se identificaron dos taxones representantes de la Clase Cestoda, que son nuevos registros para Argentina. En cuanto a la certeza taxonómica, no se tienen dudas respecto a Vampirolepis guarany ya que el material analizado permitió observar las características que definen al taxón y su presencia en Paraguay alentaría la posibilidad de hallarla en nuestro país. Respecto a Vampirolepis cf macroti, se obtuvo solo un ejemplar por lo que resulta necesario ampliar la muestra y profundizar en su estudio, más aun considerando que el único registro hasta el momento es Cuba.

La Clase Trematoda es la mejor representada, identificándose siete taxones. Urotrema scabridum es la especie con mayor distribución hospedatoria, estando presente en seis (Eumops patagonicus, Molossops temminckii, Molossus molossus, Molossus rufus, Myotis albescens y Myotis cf nigricans) de las 12 especies de murciélagos evaluadas en el presente trabajo. Este rango hospedatorio está acompañado de una elevada prevalencia (9,7-87,9\%) e intensidad media $(5,4-56,9)$, además de una amplia distribución geográfica y de la capacidad de infectar otros grupos de mamíferos como roedores y reptiles (Mañé-Garzón y Telias, 1965; Sutton y Lunaschi, 1990; Goldberg et al., 1994). El escenario planteado refuerza la afirmación que podría tratarse de un "complejo" que involucraría varias especies (Bray et al., 1999), lo que hace evidente la necesidad de profundizar en el estudio de este taxón.

Entre los Lecithodendriidae, Ochoterenatrema labda fue la especie con mayor amplitud de hospedadores, estando presente en cinco especies de murciélagos (E. patagonicus, $M$. temminckii, $M$. rufus, $M$. albescens y $M$. cf nigricans), con prevalencia e intensidad media variables (5,7-40\% y 4,5-14,6 respectivamente); su distribución geográfica abarca México y Panamá en América Central y la provincia de Buenos Aires en Argentina. A diferencia, Gymnoacetabulum talavarensis y Paralecithodendrium aranhai estuvieron presentes solo en dos especies de murciélagos (E. patagonicus y $M$. albescens y E. patagonicus y $M$. cf nigricans respectivamente), ambas especies de helmintos presentaron mayor prevalencia en E. patagonicus que en las especies de Myotis ( $P=60,6 \%$ vs. $\mathrm{P}=17,2 \%$ para $G$. talavarensis y $\mathrm{P}=28,8 \%$ vs. $\mathrm{P}=6,5 \%$ para $P$. aranhai). Cabe resaltar que la distribución geográfica de $G$. talavarensis se encuentra restringida a Argentina, sin embargo $P$. aranhai fue registrada también en Paraguay y Brasil. 
Limatulum oklahomense, único representante de la familia Phaneropsolidae, estuvo presente en tres hospedadores (Molossus rufus, Myotis albescens y Myotis cf nigricans) y fue la única especie con localización en estómago, hecho que coincide con hallazgos de trabajos similares (Lunaschi et al., 2003). Es de amplia distribución geográfica y en uno de los hospedadores (Myotis albescens) presentó una elevada prevalencia, aunque baja intensidad media (60,0\% y 3,9 respectivamente).

Entre los Nematodes, Anoplostrongylus sp., fue el taxón de mayor amplitud de hospedadores, estando presente en cuatro especies de murciélagos (Eumops patagonicus, Eumops perotis, Molossus rufus y Eptesicus furinalis). La infección en E. patagonicus alcanzó un $31,8 \%$ de prevalencia aunque en baja intensidad.

Por otra parte, Anenterotrema liliputianum (Trematoda) y Pterygodermatites sp. (Nematoda) solo estuvieron presentes en una especie hospedadora (Molossus rufus y Eumops patagonicus respectivamente), ambos helmintos presentaron baja prevalencia e intensidad media, $\mathrm{P}=5 \%, \mathrm{IM}=6$ en el primer caso y $\mathrm{P}=3 \%, \mathrm{IM}=3$ en el segundo caso. Siendo ambos taxones de ciclo indirecto se plantea la posibilidad de una escasa presencia o baja abundancia de los hospedadores intermediarios en el área de estudio.

A excepción de Anenterotrema liliputianum el resto de los taxones registran nuevas especies hospedadoras. En este sentido, se registran 23 nuevas asociaciones parásito-hospedador. Respecto a los cestodes se registran una nueva asociación para Vampirolepis guarany con Artibeus lituratus y una para Vampirolepis of macroti con Eptesicus furinalis, aunque en el últmo caso es necesario profundizar el estudio ya que solo se observó un ejemplar inmaduro.

Entre los digeneos se registran cuatro nuevas asociaciones para Ochoterenatrema labda con E. patagonicus, Molossops temminckii, Molossus rufus y Myotis albescens, dos para Urotrema scabridum con E. patagonicus y M. albescens, dos para Gymnoacetabulum talavarensis con E. patagonicus y M. albescens, dos para Paralecithodendrium aranhai con E. patagonicus y Myotis cf nigricans y dos para Limatulum oklahomense con M. rufus y M. albescens y una para Anenterotrema eduardocaballeroi con M. temminckii.

En cuanto a los nematodes se registran cuatro nuevas asociaciones para Anoplostrongylus sp. con Eumops patagonicus, E. perotis, M. rufus y E. furinalis, tres nuevas asociaciones para Capillaria sp. con M. temminckii, M. rufus y Sturnira lilium y una para Pterygodermatites sp. con E. patagonicus. Además, se menciona la posibilidad de una nueva especie de Anoplostrongylus, lo cual sumaría una nueva asociación. Por otra parte la mayoría de las especies de helmintos halladas en el presente trabajo representan nuevos registros para la especie hospedadora, destacándose Eumops patagonicus y Myotis albescens para los cuales todos los hallazgos resultaron novedosos; incluso mencionándose por primera vez a los nematodes asociados a E. patagonicus y a los trematodes hallados en $M$. albescens. 
Respecto a la distribución geográfica, se citan por primera vez dos especies de cestodes asociados a murciélagos argentinos: Vampirolepis guarany y $V$. cf macroti. Por primera vez se registran en Argentina los digeneos Paralecithodendrium aranhai y Anenterotrema eduardocaballeroi. Además se amplía la distribución de los helmintos citados para Argentina, adicionando nuevas localidades.

Cabe resaltar que, debido al escaso y deteriorado material y a la ausencia de machos no fue posible la determinación específica de los tres taxones de nematodes, quedando pendiente esta tarea para futuras investigaciones.

A excepción de Anoplostrongylus sp., todos los helmintos hallados presentan ciclos indirectos que involucran artrópodos como hospedadores intermediarios. Ello está en relación a que la mayoría de los murciélagos analizados son insectívoros y la diversidad de helmintos hallados se restringe por la especificidad de la dieta. Por otra parte, si se considera el hecho de que los quirópteros son el segundo orden más abundante entre los mamíferos, estimando solo en América del Sur unas 275 especies de murciélagos y que, hasta el momento, solo un tercio de ellas (92) han sido evaluadas parasitológicamente, la diversidad de helmintos parásitos está claramente subestimada, más aun teniendo en cuenta la rica fauna de ectoparásitos reportados por Frank et al. (2014), estimada en 273 especies vs 114 especies de helmintos, lo que implica una diversidad de helmintos solo ligeramente mayor a la de sus hospedadores estudiados. En el presente trabajo se menciona la posibilidad de una especie nueva del género Anoplostrongylus y se sugiere la revisión exhaustiva del complejo Urotrema scabridum, lo que podría significar nuevos taxones de helmintos asociados a murciélagos.

Los resultados presentados en el presente capítulo dan cuenta de la importancia de los estudios taxonómicos de parásitos en un grupo de especies hospedadoras que explotan diferentes ambientes y estas adaptados a diversos nichos tróficos. Estas contribuciones intentan avanzar en el conocimiento de nuevas asociaciones parasitarias las cuales permitirán hacer una mejor interpretación de las relaciones hospedador, parásito, ambiente en un contexto ecológico. 

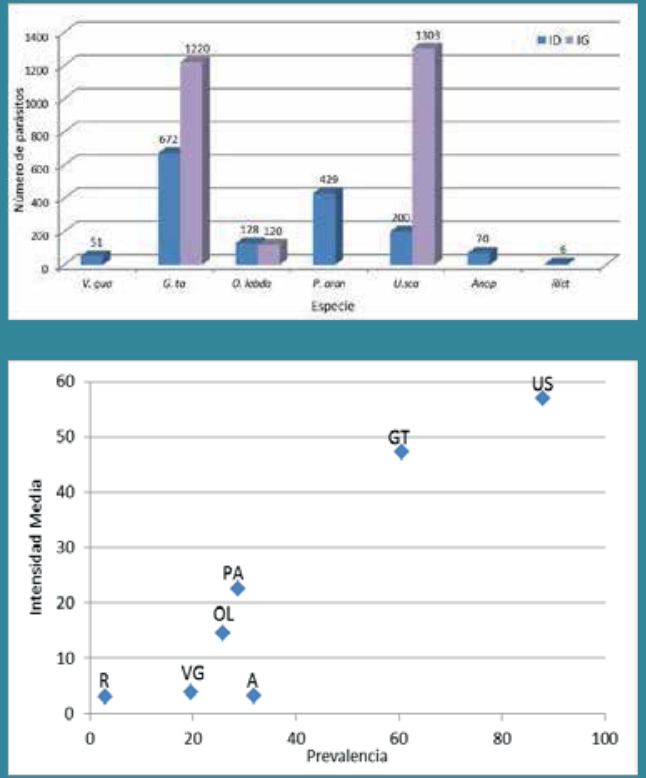

Capítulo IV

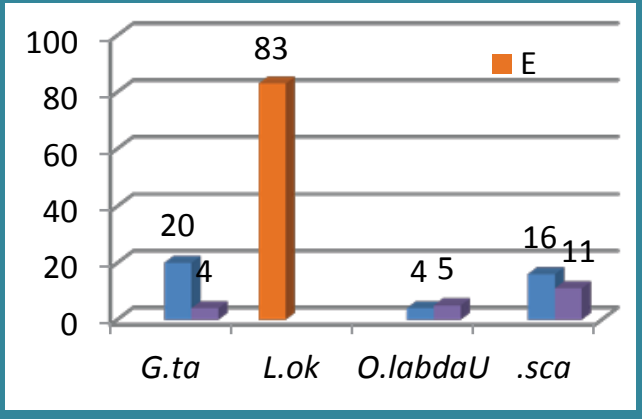

RESULTADOS

ASPECTOS ECOLÓGICOS
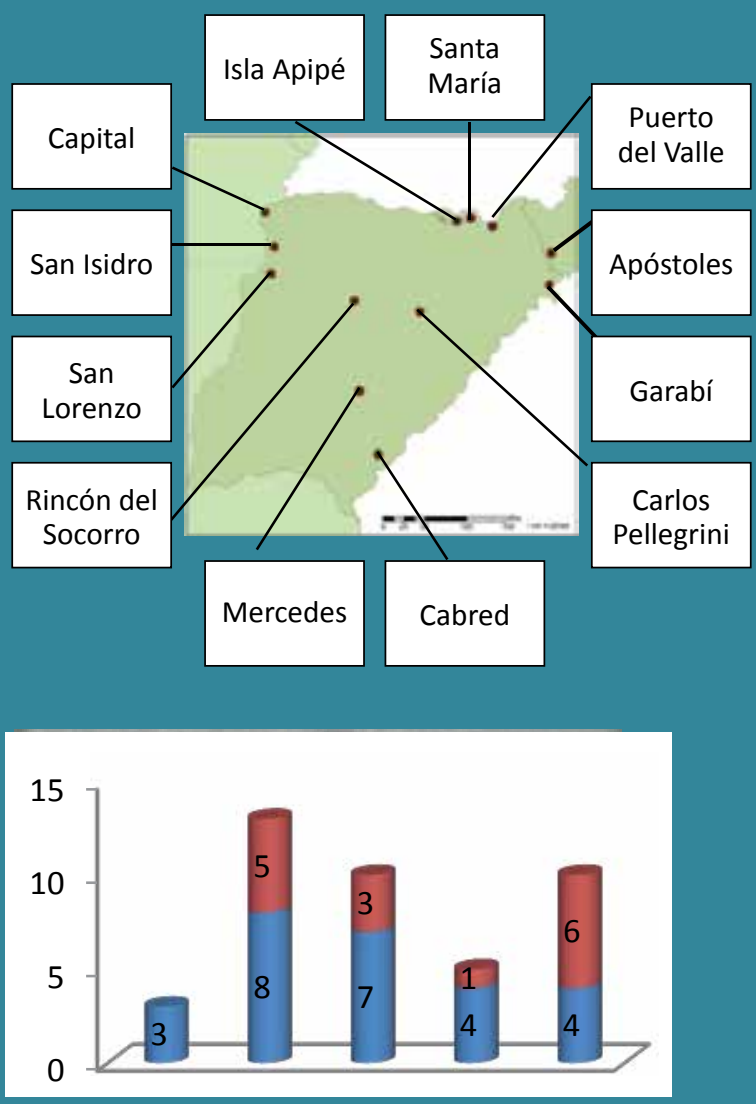


\section{CAPÍTULO IV}

\section{ASPECTOS ECOLÓGICOS}

\section{IV.1. Introducción}

La organización de las comunidades parasitarias de helmintos es distinta según se desarrollen sobre hospedadores ectotérmicos o endotérmicos. Los hospedadores endotérmicos al poseer tractos digestivos diferenciados y consumir una elevada cantidad de alimento por su alta tasa de metabolismo, presentan una mayor diversidad de especies en las comunidades de enteroparásitos (Kehr y Hamann, 1995). En este contexto, debido a su acelerado metabolismo, es de esperar que los murciélagos presenten una elevada riqueza de especies. A su vez, cada especie hospedadora alberga una fauna de parásitos que le es propia y esta puede ser utilizada como marcador de especificidad y contribuir a la comprensión de las áreas de distribución y de la filogenia de sus hospedadores (Navone et al., 2010). En este sentido, la especificidad puede analizarse relacionando una población de parásitos con el número de hospedadores, definiendo el grado de restricción que tiene un taxón parásito en el número de especies capaz de utilizar durante su ciclo de vida; así, se consideran especialistas a aquellos taxones que restringen su distribución, desarrollo y/o reproducción a una única especie, género o familia de hospedadores o a un grupo de hospedadores filogenéticamente relacionados. Mientras que una especie generalista se desarrolla en diferentes familias de hospedadores no relacionados filogenéticamente, aun cuando pueden mostrar preferencia por una familia en particular (Holmes y Price, 1986; Esch y Fernández, 1993; Kennedy, 1975; Poulin, 1998).

Por otra parte, para establecer la riqueza específica en una comunidad es necesario medir la composición de especies en término del número de especies presentes y sus abundancias relativas y no proporcionar simplemente el número de especies presentes, sin tener en cuenta las diferencias que puedan existir entre las abundancias de cada una de ellas (Begon et al., 1996). En ecología parasitaria esta medida se denomina diversidad específica y se aplica tanto para la infracomunidad como para la comunidad componente $y$, en ambos casos es posible relacionarla con variables que dependen del hospedador tal como el sexo o tamaño de los mismos.

Por otra parte, para medir la representatividad de las especies se las puede agrupar en especies centrales, especies secundarias y especies satélites (Bush y Holmes, 1986); en la primera categoría están incluidas las que se encuentran mejor representadas en la comunidad logrando un equilibrio al interactuar entre sí y en general son escasas. Las especies satélites son las que se presentan ocasionalmente y en general más numerosas. Las especies con características intermedias entre los dos grupos anteriormente descritos son consideradas especies secundarias. 
Al analizar a nivel de comunidad de parásitos hay que considerar que mientras que las infracomunidades están dadas sobre escalas de tiempo ecológicas por la infección y los procesos demográficos, las comunidades componentes se relacionan con escalas de tiempo evolutivo y con procesos como invasiones, especiaciones, extinciones y colonizaciones de "switches" ó parches de hospedadores (Poulin, 1998). La riqueza de especies disminuye cuando algunas especies de parásitos se extinguen localmente y aumentan cuando colonizan poblaciones cercanas de otros hospedadores. La semejanza en la composición de especies entre las comunidades componentes de diferentes pero coespecíficas poblaciones de hospedadores dependerá de su proximidad geográfica y de la posibilidad de cambios de parásitos entre ellas (Poulin y Morand, 2004). Como en otros tipos de comunidades ecológicas la semejanza entre las comunidades componentes de parásitos a menudo tiende a disminuir exponencialmente con la distancia geográfica. Varias comunidades componentes de diferentes poblaciones de una especie de hospedador son todas subconjuntos del set entero de especies de parásitos que afecta a dicha especie hospedadora en toda su distribución geográfica. Este gran conjunto de parásitos corresponde a la fauna parasitaria. El término comunidad no puede aplicarse a la fauna parasitaria porque por lo general una sola población de hospedador no incluirá todas las especies de parásitos. La fauna parasitaria representa el nivel jerárquico más alto de organización de asociaciones parasitarias para un hospedador dado; este es un nivel más bien artificial que una entidad biológica, pero sin embargo la fauna parasitaria ha sido el objeto de muchos estudios macroecológicos de diversidad de parásitos (Poulin, 1998; Poulin y Morand, 2004). En este contexto, la mayoría de los estudios referidos a helmintofauna de murciélagos comprenden aspectos taxonómicos, con descripciones de nuevas especies, listados y nuevos registros, mientras que los estudios de corte ecológico sobre poblaciones y comunidades de helmintos parásitos son escasos y se refieren únicamente a los indicadores parasitológicos (Foster y Mertins, 1996; Nogueira et al., 2004; Pesenti et al., 2015).

Por otra parte, la dieta alimenticia tiene mucha importancia para explicar el parasitismo de los quirópteros, porque muchos de sus componentes como artrópodos, moluscos y pequeños vertebrados intervienen en el desarrollo del ciclo biológico de los helmintos, actuando como hospedadores intermediarios o paraténicos (Esteban et al., 1990). De este modo por ejemplo los digeneos presentan estadios larvales que se desarrollan en hospedadores intermediarios asociados a cuerpos de agua, los cuales deben ser ingeridos por el hospedador definitivo para que continúe el ciclo. Entre los nematodes se distinguen los de ciclo directo y los de ciclo indirecto y, a su vez, especies heteroxenas presentan alternativas de ciclo directo, por lo tanto se amplía la posibilidad de transmisión (Anderson, 2000).

Finalmente, uno de los grandes desafíos de la parasitología actual es entender cómo los procesos modeladores de la biodiversidad se desarrollaron en el escenario evolutivo que proponen los hospedadores y los parásitos (Poulin y Morand, 2000; Poulin y Mou- 
Iliot, 2004). En este sentido, la teoría biogeográfica de islas es utilizada para generar predicciones acerca de los factores involucrados en la diversificación de los ensambles parasitarios (MacArthur y Wilson, 1967; Kuris et al., 1980). Bajo esta teoría se presume que las características del hospedador, tales como tamaño corporal y distribución geográfica, promueven altas tasas de especiación o colonización de nuevas especies y estarían asociadas con una alta diversidad de parásitos. De este modo, se esperaría que los hospedadores más grandes alberguen los ensambles de parásitos más ricos, dado que proporcionan una variedad espacial mayor para la diversificación de nichos (Gregory et al., 1996; Arneberg, 2002; Morand y Harvey, 2000; Vitone et al., 2004). Asimismo, una mayor distribución geográfica del hospedador permitiría alojar una mayor diversidad de parásitos, debido a que su distribución se superpondría con otras especies hospedadoras, promoviendo la adquisición de nuevas especies parásitas (Gregory et al., 1990; Feliu et al., 1997; Krasnov et al., 2004). Así, en escalas espaciales pequeñas y períodos cortos de tiempo, el solapamiento entre especies hospedadoras puede facilitar la transferencia de parásitos e incrementar la riqueza de especies de parásitos en las comunidades amparadas por la especie hospedadora individual y en escalas espaciales mayores, las especies hospedadoras con amplias distribuciones geográficas se superpondrán con las de otras especies hospedadoras de las cuales pueden adquirir nuevos parásitos en una escala de tiempo más larga. Es de esperar entonces, que especies hospedadoras con distribuciones geográficas más amplias posean una riqueza de especies más elevada que aquellas con distribuciones más restringidas (Poulin y Morand, 2004).

En el presente capítulo se analizan las poblaciones y comunidades de parásitos de cada especie hospedadora, expresadas en los distintos niveles de análisis ecológicos y relacionando con variables biológicas del hospedador. A continuación se integran los análisis a nivel de Familia de hospedadores. Finalmente se exponen los resultados en relación a la distribución geográfica de los helmintos parásitos y se analiza la helmintofauna de acuerdo a la distribución geográfica de los hospedadores, aludiendo a los conceptos de Fauna Parásita Local y Fauna Parásita Regional (Esch y Fernandez, 1993; Poulin, 2014).

\section{IV.2. Especificaciones metodológicas}

\section{Curva de acumulación de especies}

Se confeccionó una curva de acumulación de especies a fin de estimar el esfuerzo de muestreo requerido para lograr datos fiables. Se consideró cada murciélago como unidad de muestreo, sobre la base de 199 individuos. Se aplicó la ecuación de Clench como función descriptiva de la curva, ajustada mediante el algoritmo de Gauss-Newton. Se obtuvo un valor de 11,98 para la riqueza de especies (S). El modelo ajustado arrojó un coeficiente de determinación $\mathrm{R}^{2}=0,953107$, los valores obtenidos indican que el inventario observado es altamente fiable (Figura IV.2). 


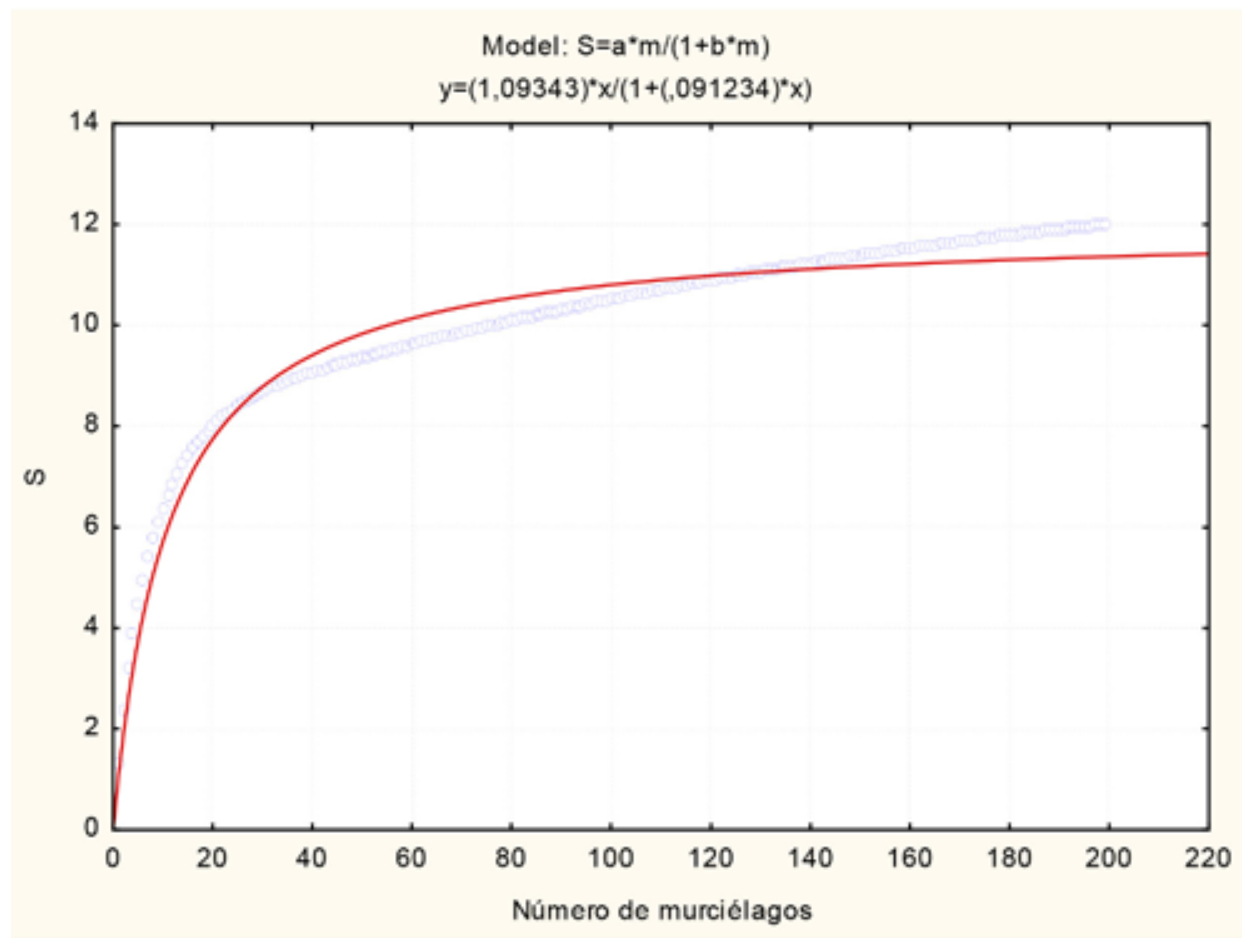

Figura IV.2. Curva de acumulación de especies.

\section{Análisis estadísticos}

Para cada taxón parásito se calcularon los indicadores parasitológicos Prevalencia (P), Intensidad Media (IM) y Abundancia Media (AM). Para evaluar diferencias a nivel de sexo y tamaño (peso y longitud) se seleccionaron las especies de hospedadores cuyo número de individuos examinados fue $\geq 20$. De este modo, la relación de la infección parasitaria con dichas variables biológicas se estimó para dos especies de molósidos: Eumops patagonicus y Molossus rufus y dos especies de vespertiliónidos: Myotis albescens y Myotis cf nigricans. Dado que la distribución de la abundancia y de la intensidad de parásitos en los murciélagos no se ajusta a la distribución normal, para probar si existen diferencias significativas en la abundancia media e intensidad media según el sexo de los hospedadores, se utilizó el test $U$ de Mann Whitney Wilcoxon y la correlación de Spearman para el peso y la longitud. Se efectuó el agrupamiento de especies por familia a fin de evaluar si las diferencias se presentan en este nivel taxonómico. Se comparó la prevalencia a nivel de familia de hospedadores, utilizando el test de chi cuadrado $\left(\chi^{2}\right)$. A fin de evaluar la interacción parasitaria, se tuvo en cuenta únicamente a Eumops patagonicus por brindar datos suficientes. Para analizar diferencias en la abundancia media e intensidad media de Vampirolepis guarany entre murciélagos insectívoros y frugívoros se utilizó el análisis de variancia no paramétrico de Kruskal Wallis (K). Para relacionar la riqueza de especies parásitas con la distribución geográfica de los hospedadores se construyó un gráfico representativo, integrando los resultados obtenidos en el presente estudio con los antecedentes existentes, de modo que confluyeran en la caracterización de la parasitofauna de cada especie de murciélago evaluada. 


\section{IV.3. Resultados}

Se evaluó un total de 212 murciélagos pertenecientes a 12 especies de tres familias: Molossidae $(n=98)$, Phyllostomidae $(n=32)$ y Vespertilionidae $(n=82)$. Del total de murciélagos examinados 130 estuvieron parasitados y en 82 no se observaron helmintos parásitos, siendo la Prevalencia general 61,3\%. En la Figura IV.3.1 se observa el total de ejemplares evaluados de las especies estudiadas y los individuos parasitados y no parasitados. En dos especies de la familia Phyllostomidae (Desmodus rotundus y Platyrrhynus lineatus) ninguno de los individuos examinados presentó endoparásitos.

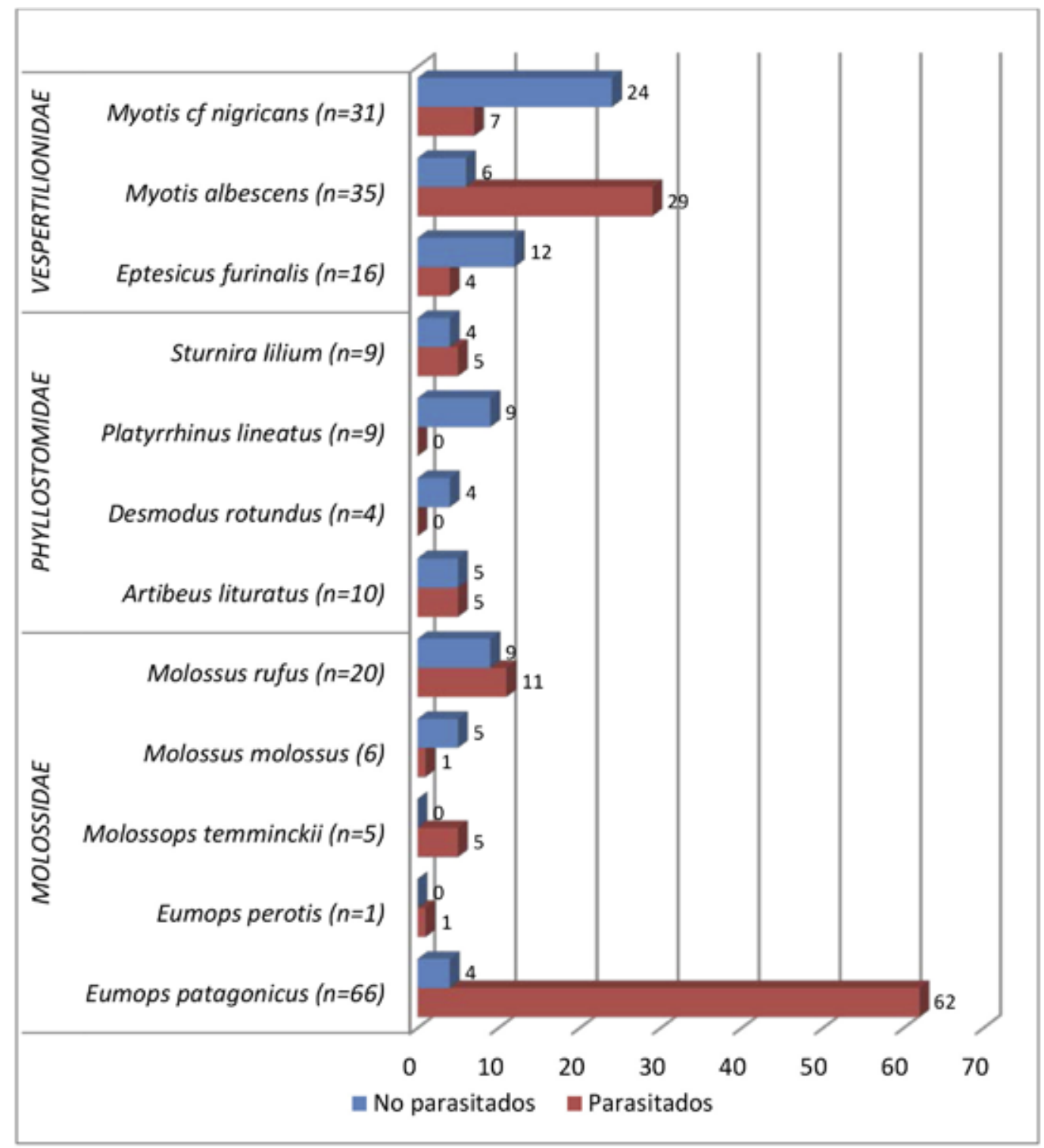

Figura IV.3.1. Individuos parasitados y no parasitados de las especies de murciélagos examinadas (N=212). 


\section{Prevalencia y Número de Parásitos}

Los grupos de helmintos hallados representan a cestodes, trematodes y nematodes. En la Tabla IV.3.1 se observa la representatividad de los taxones hallados en los distintos hospedadores. El taxón más prevalente fue Trematoda, en el que se observó que el 50,9\% de los murciélagos examinados presentó al menos un espécimen de este grupo. Asimismo, los digeneos fueron los mejor representados en términos de abundancia, observándose 6446 ejemplares sobre un total de 6990 helmintos. Si bien los nematodes tuvieron una prevalencia mayor que los cestodes (19,3\% y $10,4 \%$ respectivamente), fue más numeroso el grupo de los cestodes, en el que se contabilizaron 402 individuos, mientras que entre los nematodes se contabilizaron 142 ejemplares. Respecto a los hospedadores, la familia Molossidae presentó la mayor prevalencia de infección, con 81,6\% de los individuos parasitados. Entre los molósidos y vespertiliónidos se encontraron representantes de los tres grupos de helmintos, sin embargo no se observaron digeneos entre los filostómidos estudiados. Se observó una riqueza de 12 taxones de helmintos parásitos. La mayor riqueza se observó en la familia Molossidae y la menor en Phyllostomidae.

Tabla IV.3.1. Infección parasitaria en murciélagos

\begin{tabular}{|c|c|c|c|c|c|c|c|}
\hline \multirow{3}{*}{ Hospedador } & \multirow{3}{*}{$\begin{array}{c}P \% \\
(P / E)\end{array}$} & \multicolumn{4}{|c|}{ Plathyhelminthes } & \multirow{2}{*}{\multicolumn{2}{|c|}{$\frac{\text { Nematoda }}{\text { Adenophorea y Sercenetea }}$}} \\
\hline & & \multicolumn{2}{|c|}{ Cestoda } & \multicolumn{2}{|c|}{ Trematoda } & & \\
\hline & & $P \%(P / E)$ & NTP & P\% (P/E) & NTP & P\% (P/E) & NTP \\
\hline MOLOSSIDAE & $81,6(80 / 98)$ & $16,3(16 / 98)$ & 55 & $73,5(72 / 98)$ & 6103 & 33,7 (33/98) & 110 \\
\hline E. patagonicus & $93,9(62 / 66)$ & $21,2(14 / 66)$ & 51 & $92,4(61 / 66)$ & 5872 & $34,8(23 / 66)$ & 76 \\
\hline E. perotis & $100,0(1 / 1)$ & - & - & - & - & $100,0(1 / 1)$ & 5 \\
\hline M. temminckii & $100,0(5 / 5)$ & - & - & $100,0(5 / 5)$ & 93 & $20,0(1 / 5)$ & 3 \\
\hline M. molossus & $16,7(1 / 6)$ & - & - & $16,7(1 / 6)$ & 1 & - & - \\
\hline M. rufus & $55,0(11 / 20)$ & $10,0(2 / 20)$ & 4 & $25,0(5 / 20)$ & 137 & $40,0(8 / 20)$ & 26 \\
\hline PHYLLOSTOMIDAE & $31,3(10 / 32)$ & $15,6(5 / 32)$ & 346 & - & - & $15,6(5 / 32)$ & 22 \\
\hline A. lituratus & $50,0(5 / 10)$ & $50,0(5 / 10)$ & 346 & - & - & - & - \\
\hline D. rotundus & $(0 / 4)$ & - & - & - & - & - & - \\
\hline P. lineatus & $(0 / 9)$ & - & - & - & - & - & - \\
\hline S. Iilium & $55,5(5 / 9)$ & - & - & - & - & $55,5(5 / 9)$ & 22 \\
\hline VESPERTILIONIDAE & $48,8(40 / 82)$ & $1,2(1 / 82)$ & 1 & $43,9(36 / 82)$ & 343 & $3,7(3 / 82)$ & 10 \\
\hline E. furinalis & $25,0(4 / 16)$ & $6,3(1 / 16)$ & 1 & - & - & $18,8(3 / 16)$ & 10 \\
\hline M. albescens & $82,9(29 / 35)$ & - & - & $82,9(29 / 35)$ & 143 & - & - \\
\hline M. cf nigricans & $22,6(7 / 31)$ & - & - & $22,6(7 / 31)$ & 200 & - & - \\
\hline TOTAL & $61,3(130 / 212)$ & $10,4(22 / 212)$ & 402 & $50,9(108 / 212)$ & 6446 & $19,3(41 / 212)$ & 142 \\
\hline
\end{tabular}

$\mathrm{P}$ \%: Prevalencia; (P/E): número de murciélagos parasitados/número de murciélagos examinados; NTP: número total de parásitos.

A continuación se efectúa el análisis de la helmintofauna asociada a cada una de las especies hospedadoras. 


\section{IV.3.1. Familia Molossidae}

\section{Eumops patagonicus (Thomas, 1924)}

\section{Infección parasitaria}

Se evaluaron 66 individuos de esta especie hospedadora, de los cuales 62 (93,9\%) presentaron helmintos parásitos. Los valores de infección parasitaria discriminados por sexo del hospedador se expresan en la Tabla IV.3.1.1.

Tabla IV.3.1.1. Infección parasitaria en Eumops patagonicus

\begin{tabular}{|c|c|c|c|c|c|}
\hline Sexo & $n$ & $\mathrm{P} \%$ & NP & IM $\pm D S$ (rango) & $\mathrm{AM} \pm \mathrm{DS}$ \\
\hline$\hat{0}$ & 19 & 84,2 & 2294 & $\begin{array}{c}143,4 \pm 118,2 \\
(3-440)\end{array}$ & $120,7 \pm 120,5$ \\
\hline$q$ & 47 & 97,9 & 3705 & $\begin{array}{c}80,5 \pm 119,2 \\
(4-799)\end{array}$ & $78,8 \pm 118,5$ \\
\hline Total & 66 & 93,9 & 5999 & $\begin{array}{c}102,7 \pm 131,7 \\
(3-799)\end{array}$ & $90,9 \pm 119,7$ \\
\hline
\end{tabular}

Si bien los valores de prevalencia y número de parásitos son superiores en las hembras, se observa que la intensidad y abundancia medias son mayores en los machos, resultando la diferencia en la intensidad media estadísticamente significativa ( $W=645$; $\left.P_{0,05 ; 2}=0,02\right)$.

\section{Análisis de las poblaciones componentes}

Indicadores parasitológicos, localización y dispersión de helmintos

La riqueza en E. patagonicus fue igual a siete especies: Vampirolepis guarany (Cestoda), Gymnoacetabulum talavarensis, Ochoterenatrema labda, Paralecithodendrium aranhai, Urotrema scabridum (Digenea), Anoplostrongylus sp. y Pterygodermatites sp. (Nematoda).

En la Tabla IV.3.1.2 se observan los indicadores parasitológicos, la localización y el índice de dispersión de cada población parásita. Urotrema scabridum fue la especie de mayor prevalencia y número de individuos, siendo la especie dominante $(d=0,55)$. Asimismo, fue la especie con mayor intensidad y abundancia media. En todas las especies se observa una distribución agregada. 
Tabla IV.3.1.2. Helmintos parásitos de Eumops patagonicus

\begin{tabular}{|c|c|c|c|c|c|c|}
\hline & P \% & NP & $\begin{array}{l}\text { IMEDS } \\
\text { (rango) }\end{array}$ & $A M \pm D S$ & SI & iD \\
\hline \multicolumn{7}{|l|}{ CESTODA } \\
\hline V. guarany & $19,7(13 / 66)$ & 51 & $\begin{array}{c}3,9 \pm 6,1 \\
(1-23)\end{array}$ & $0,8 \pm 3,1$ & ID & 12,3 \\
\hline \multicolumn{7}{|l|}{ TREMATODA } \\
\hline G. talavarensis & $60,6(40 / 66)$ & 1892 & $\begin{array}{c}47,3 \pm 76,7 \\
(2-494)\end{array}$ & $28,7 \pm 67,9$ & ID-IG & 161,1 \\
\hline O. labda & $25,8(17 / 66)$ & 248 & $\begin{array}{c}14,6 \pm 13,1 \\
(1-45)\end{array}$ & $3,7 \pm 9,1$ & ID-IG & 22,3 \\
\hline P. aranhai & $28,8(19 / 66)$ & 429 & $\begin{array}{c}22,6 \pm 21,2 \\
(3-72)\end{array}$ & $6,5 \pm 15,4$ & ID & 36,7 \\
\hline U. scabridum & $87,9(58 / 66)$ & 3303 & $\begin{array}{c}56,9 \pm 59,6 \\
(3-322)\end{array}$ & $50,0 \pm 57,7$ & ID-IG & 66,6 \\
\hline \multicolumn{7}{|l|}{ NEMATODA } \\
\hline Anoplostrongylus sp. & $31,8(21 / 66)$ & 70 & $\begin{array}{c}3,3 \pm 1,8 \\
(1-7)\end{array}$ & $1,1 \pm 1,9$ & ID & 3,2 \\
\hline Pterygodermatites sp. & $3,0(2 / 66)$ & 6 & 3 & $0,1 \pm 0,5$ & ID & 2,9 \\
\hline
\end{tabular}

P: prevalencia; NP: número de parásitos; IM: intensidad media; AM: abundancia media; DS: desvío standard; SI: sitio de infección; iD: índice de dispersión; ID: intestino delgado; IG: intestino grueso

Todos los helmintos se localizaron en el tracto intestinal. En la Figura IV.3.1.1 se aprecia el número de individuos parásitos de cada especie hallado en el intestino delgado y grueso. En todas las especies se encontraron localizaciones en intestino delgado; tres de ellas (digeneos) también se localizaron en intestino grueso, observándose en G. talavarensis una mayor proporción en esta última localización.

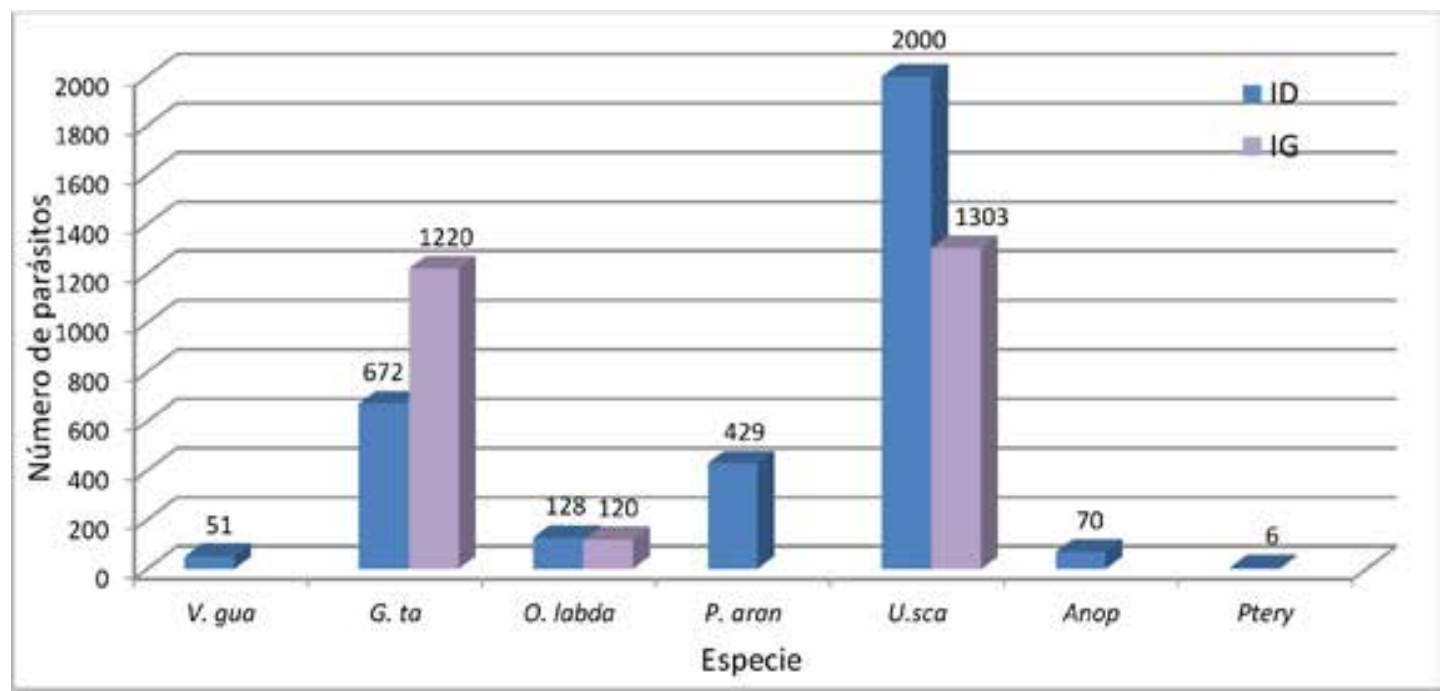

Figura. IV.3.1.1 Número de helmintos parásitos intestinales de E. patagonicus. ID: intestino delgado; IG: intestino grueso. V.gua: Vampirolepis guarany, G.ta: Gymnoacetabulum talavarensis, P.aran: Paralecithodendrium aranhai, U.sca: Urotrema scabridum, Anop: Anoplostrongylus sp., Ptery: Pterygodermatites sp. 


\section{Relación entre el tamaño del hospedador y los helmintos parásitos}

Respecto a las variables relacionadas con el tamaño del hospedador (peso y longitud) se observó una relación inversa estadísticamente significativa entre el peso del hospedador y la intensidad de infección $\left(r_{s}=-0,35 ; p<0,01\right)$ y no se verificó relación estadísticamente significativa con la longitud $\left(r_{s}=-0,21 ; p=0,3\right)$. A su vez, al analizar cada una de las especies parásitas se observó una relación inversa estadísticamente significativa entre el peso del hospedador y la intensidad de infección de $V$. guarany, G. talavarensis y $U$. scabridum ( $r_{s}=-0,24, p=0,05 ; r_{s}=-0,2, p=0,05 ; r_{s}=-0,41, p=0,0006$ respectivamente), mientras que no se observó una relación estadísticamente significativa con la longitud $\left(r_{s}=-0,15, p=1 ; r_{s}=-0,1, p=0,4 ; r_{s}=-0,06, p=0,6\right.$, respectivamente). Las relaciones entre peso y longitud y la intensidad de infección de $O$. labda, P. aranhai y Anoplostrongylus sp., resultaron estadísticamente no significativas $\left(r_{s}=-0,3, p=0,9\right.$ y $r_{s}=0,08, p=0,5 ; r_{s}$ $=-0,15, p=0,2$ y $r_{s}=0,1, p=0,4 ; r_{s}=-0,06 ; p=0,6$ y $r_{s}=-0,17, p=0,2$, respectivamente).

\section{Análisis de la Infracomunidad}

\section{Riqueza específica}

La riqueza media fue $2,6 \pm 1,2$. Se hallaron solo siete casos de infecciones monoespecíficas, mientras que la mayoría de los murciélagos estuvo parasitado por más de una especie de helminto. En la Figura IV.3.1.2 se observa la distribución de frecuencias de la riqueza específica. Se observa que el $64 \%$ de los hospedadores estuvo parasitado por entre 2 y 3 especies de helmintos, solo el 11\% presentaron infecciones monoespecíficas, y un $25 \%$ infecciones múltiples de entre 4 y 5 especies parásitas.

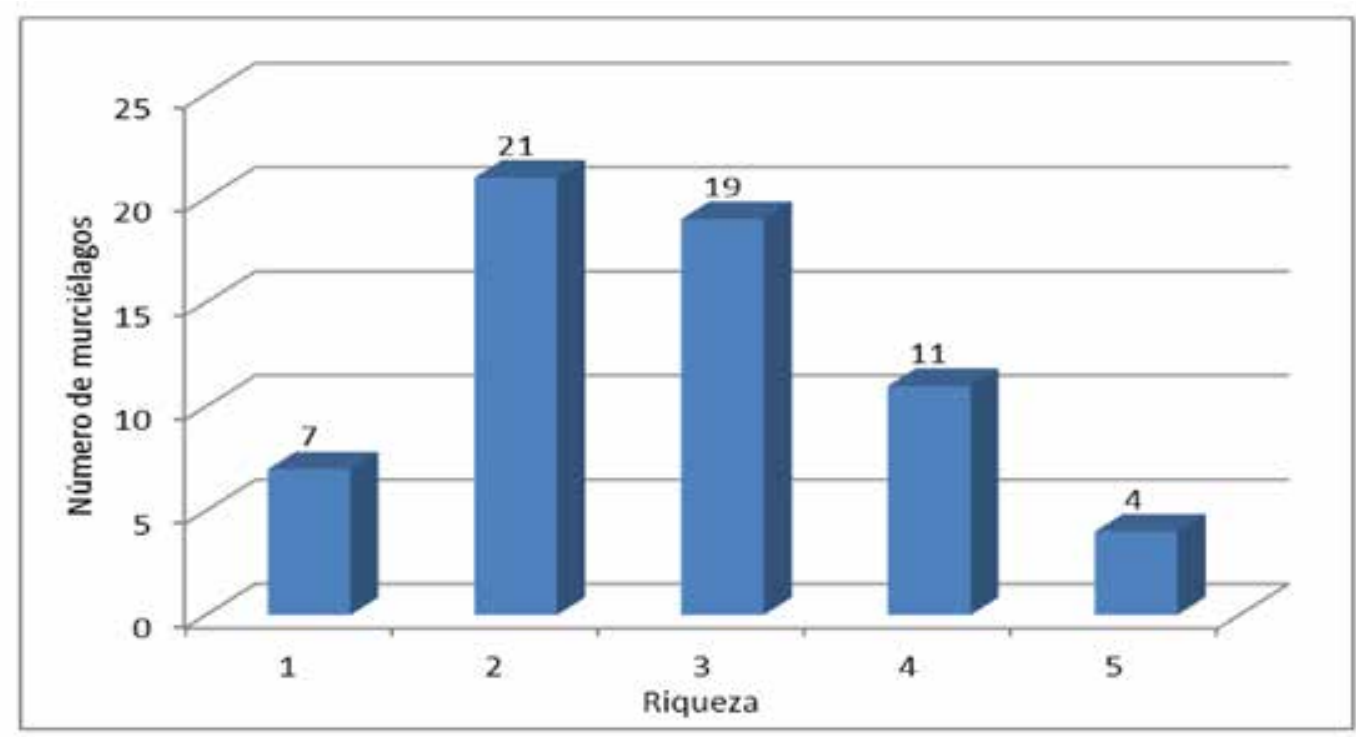

Figura IV.3.1.2. Número de individuos de E. patagonicus parasitados con 1 a 5 especies de helmintos. 
En cuanto a la intensidad, la mayoría de los murciélagos $(n=60)$ presentaron intensidades entre 1 y 100 y en solo dos individuos se registraron más de 400 helmintos parásitos (Figura IV.3.1.3).

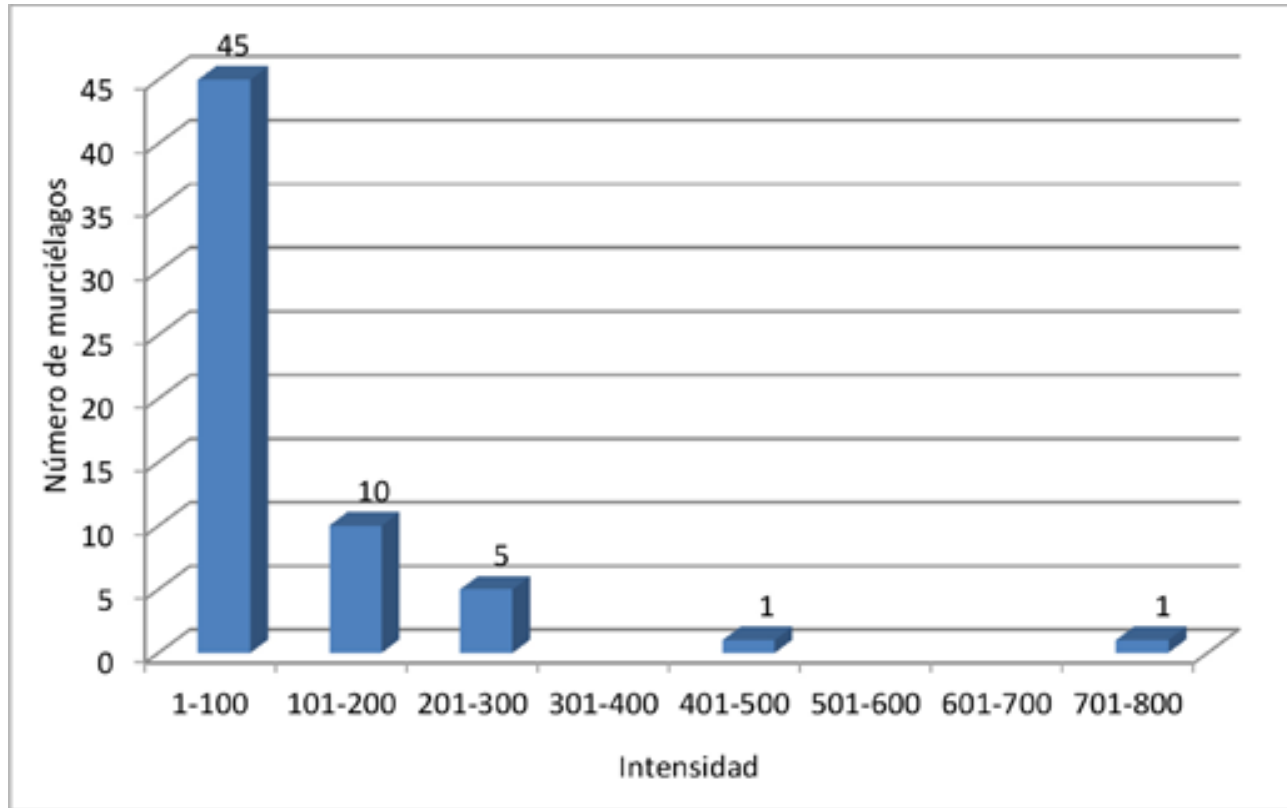

Figura IV.3.1.3. Distribución de frecuencia de intensidad de helmintos parásitos de E. patagonicus.

\section{Interacción parasitaria}

Se comprobaron interacciones positivas entre Gymnoacetabulum talavarensis/Vampirolepis guarany, G. talavarensis/Urotrema scabridum, G. talavarensis/Palacithodendrium aranhai y entre $P$. aranhai/Ochoterenatrema labda. En la Tabla IV.3.1.4 se observan los valores de los índices de co-variación para cada caso, basados en el coeficiente de correlación de Spearman $\left(r_{s}\right)$.

Tabla IV.3.1.4. Co-variación entre helmintos parásitos de Eumops patagonicus.

\begin{tabular}{|l|l|l|l|l|l|l|l|l|}
\hline \multicolumn{1}{|c|}{ Helminto } & & 1 & 2 & 3 & 4 & 5 & 6 & 7 \\
\hline Anoplostrongylus sp. (1) & $\mathrm{r}_{\mathrm{s}}$ & 1,000 & & & & & & \\
\hline Pterygodermatites sp. (2) & $\mathrm{r}_{\mathrm{s}}$ & $-0,116$ & 1,000 & & & & & \\
\hline V. guarany (3) & $\mathrm{r}_{\mathrm{s}}$ & $-0,083$ & $-0,090$ & 1,000 & & & & \\
\hline U. scabridum (4) & $\mathrm{r}_{\mathrm{s}}$ & $-0,160$ & 0,017 & 0,104 & 1,000 & & & \\
\hline G. talavarensis (5) & $\mathrm{r}_{\mathrm{s}}$ & 0,049 & $-0,120$ & $0,325^{*}$ & $0,374^{*}$ & 1,000 & & \\
\hline O. Iabda (6) & $\mathrm{r}_{\mathrm{s}}$ & $-0,229$ & $-0,100$ & 0,173 & 0,035 & 0,114 & 1,000 & \\
\hline P. aranhai (7) & $\mathrm{r}_{\mathrm{s}}$ & $-0,153$ & $-0,112$ & 0,200 & 0,159 & $0,314^{*}$ & $0,289^{*}$ & 1,000 \\
\hline
\end{tabular}

*Significativo $p<0,05$. 


\section{Análisis de la Comunidad Componente}

La riqueza específica de E. patagonicus fue igual a siete. En la Tabla IV.3.1.4 se presentan los valores de los índices ecológicos.

Tabla IV.3.1.4. Índices ecológicos de E. patagonicus.

\begin{tabular}{lc}
\hline \multicolumn{1}{c}{ Índices } \\
\hline Número total de parásitos & 5999 \\
Riqueza (S) & 7 \\
Índice de Shannon ( $\left.\mathrm{H}^{\prime}\right)$ & 1,112 \\
Equitabilidad (J) & 0,572 \\
Dominancia Berger-Parker & 0,550 \\
\hline
\end{tabular}

Se aprecia que los valores de diversidad y equitabilidad sugieren que no existe una especie dominante dentro de la comunidad de helmintos parásitos (confirmado por el índice de dominancia) y que las especies no poseen una abundancia similar, aunque se encuentran en un punto intermedio.

\section{Especies centrales, secundarias y satélites}

La distribución de frecuencias de los helmintos parásitos respecto a la prevalencia muestra una leve trimodalidad, una especie presentó una prevalencia menor a 10\%, cuatro especies presentaron prevalencias entre 20 y $40 \%$ y dos especies prevalencias mayores a 60\% (Figura IV.3.1.4). Asimismo, se obtuvo una correlación estadísticamente significativa $\left(r_{s}=0,79 ; p<0,05\right)$ entre la prevalencia y la intensidad media. De este modo se puede distinguir $U$. scabridum como especie central, a Pterygodermatites sp. como especie satélite y las demás como especies secundarias (Figura IV.3.1.5).

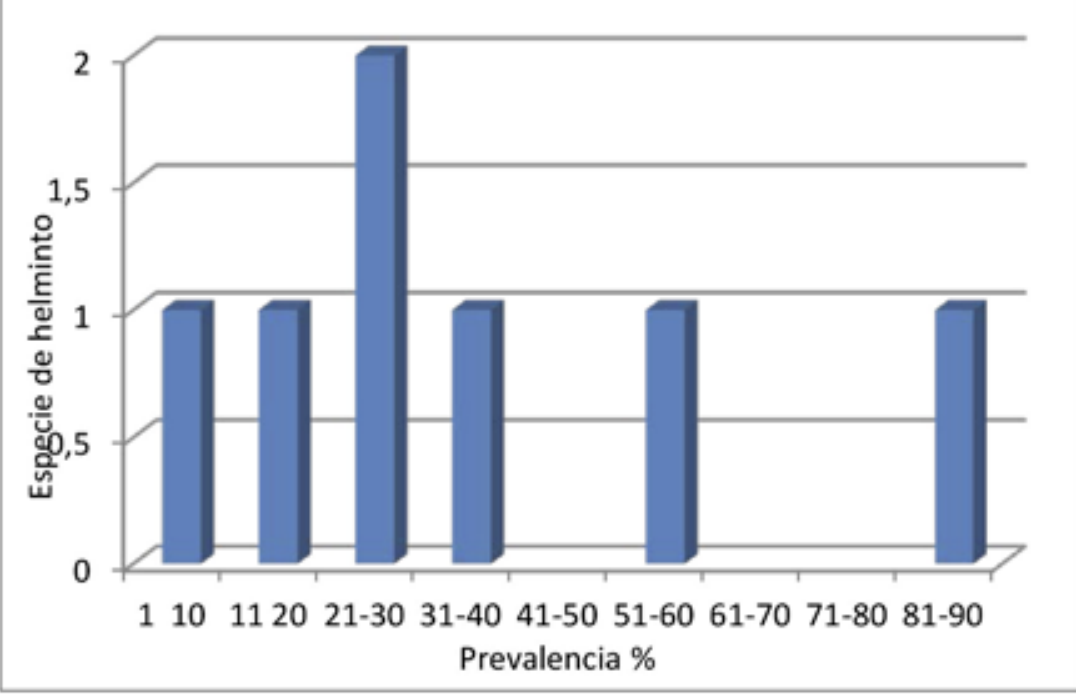

Figura IV.3.1.4. Distribución de frecuencias de las prevalencias específicas de helmintos parásitos de $E$. patagonicus. 


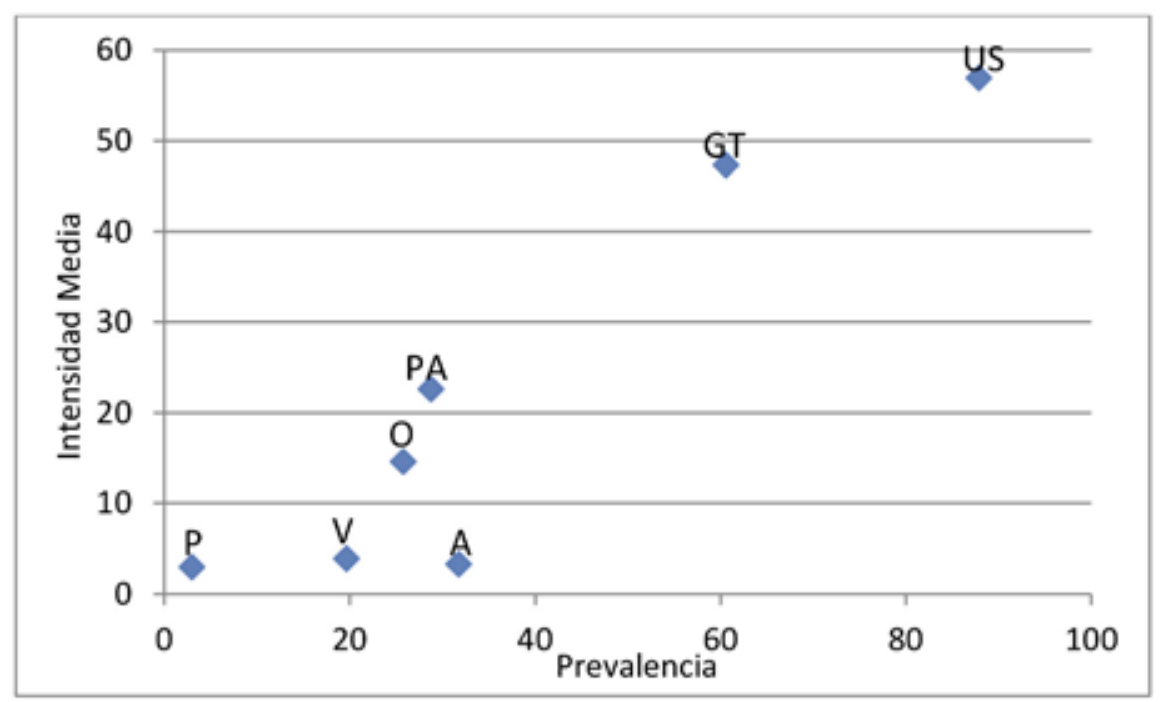

Figura IV.3.1.5. Prevalencia e intensidad media de las especies parásitas de E. patagonicus. A: Anoplostrongylus sp., GT: Gymnoacetabulum talavarensis, OL: Ochoterenatrema labda, PA: Paralecithodendrium aranhai, P: Pterygodermatites sp., US: Urotrema scabridum, VG: Vampirolepis guarany

\section{Eumops perotis (Schinz, 1821)}

Se evaluó un único ejemplar de esta especie, en el que se observaron cinco individuos de Anoplostrongylus sp., localizados en el intestino delgado. El análisis de la infrapoblación se incorporó al análisis a nivel de Familia.

\section{Molossops temminckii (Burmaister, 1854)}

\section{Infección parasitaria}

Se evaluaron cinco individuos de esta especie, la totalidad de ellos estuvo parasitado. En la Tabla IV.3.1.5 se aprecian los valores de infección parasitaria discriminados por sexo del hospedador, se observan valores superiores en los machos respecto a todos los indicadores.

Tabla IV.3.1.5. Infección parasitaria en Molossops temminckii

\begin{tabular}{|c|c|c|c|c|c|}
\hline Sexo & $\mathrm{n}$ & $\mathrm{P} \%$ & NP & $\mathrm{IM} \pm \mathrm{DS}$ (rango) & $\mathrm{AM} \pm \mathrm{DS}$ \\
\hline \multirow[t]{2}{*}{$\hat{0}$} & 3 & 100 & 77 & $25,7 \pm 11,0$ & $25,7 \pm 11,0$ \\
\hline & & & & $(3-33)$ & \\
\hline \multirow[t]{2}{*}{ q } & 2 & 100 & 19 & $9,5 \pm 7,8$ & $9,5 \pm 7,8$ \\
\hline & & & & $(4-15)$ & \\
\hline \multirow[t]{2}{*}{ Total } & 5 & 100 & 96 & $19,2 \pm 12,4$ & $19,2 \pm 12,4$ \\
\hline & & & & (3-33) & \\
\hline
\end{tabular}

$\mathrm{n}=$ número de murciélagos examinados, $\mathrm{P}=$ prevalencia, $\mathrm{NP}=$ número de parásitos, $\mathrm{IM}=$ intensidad media, $\mathrm{AM}=$ abundancia media, $\mathrm{DS}=$ desvío standard. 


\section{Análisis de las poblaciones componentes}

Indicadores parasitológicos, localización y dispersión de helmintos

La riqueza en M. temminckii fue igual a cuatro especies: Anenterotrema eduardocaballeroi, Ochoterenatrema labda, Urotrema scabridum (Digenea) y Capillaria sp. (Nematoda). No se observaron representantes de la Clase Cestoda. Si bien el número de murciélagos examinados fue escaso, la prevalencia de infección de $100 \%$ y el hallazgo de cuatro especies de helmintos motivó el cálculo de los indicadores parasitológicos en los distintos niveles de análisis, aunque no se efectuaron pruebas estadísticas. En la Tabla IV.3.1.6 se aprecian los indicadores parasitológicos, la localización y el índice de dispersión de cada población parásita.

Tabla IV.3.1.6. Helmintos parásitos de Molossops temminckii

\begin{tabular}{|c|c|c|c|c|c|c|}
\hline & P \% & NP & $\begin{array}{l}\text { IM } \pm D S \\
\text { (rango) }\end{array}$ & $A M \pm D S$ & SI & iD \\
\hline TREMATODA & & 93 & & & & \\
\hline A.eduardocaballeroi & $20(1 / 5)$ & 13 & 13 & $2,6 \pm 5,8$ & ID & 13 \\
\hline O. labda & $40(2 / 5)$ & 28 & $\begin{array}{c}14 \pm 15,6 \\
(3-25)\end{array}$ & $5,6 \pm 10,9$ & ID-IG & 21,3 \\
\hline U. scabridum & $80(4 / 5)$ & 52 & $\begin{array}{c}13 \pm 10,5 \\
(4-28)\end{array}$ & $10,4 \pm 10,8$ & ID & 11,2 \\
\hline NEMATODA & & 3 & & & & \\
\hline Capillaria sp. & $20(1 / 5)$ & 3 & 3 & $0,6 \pm 1,3$ & ID & 3 \\
\hline
\end{tabular}

P: prevalencia; NP: número de parásitos; IM: intensidad media; AM: abundancia media;

DS: desvío standard; SI: sitio de infección; iD: índice de dispersión; ID: intestino delgado; IG: intestino grueso

Urotrema scabridum fue la especie de mayor prevalencia y número de individuos, siendo la especie dominante $(d=0,54)$. En todas las especies se observa una distribución agregada. 


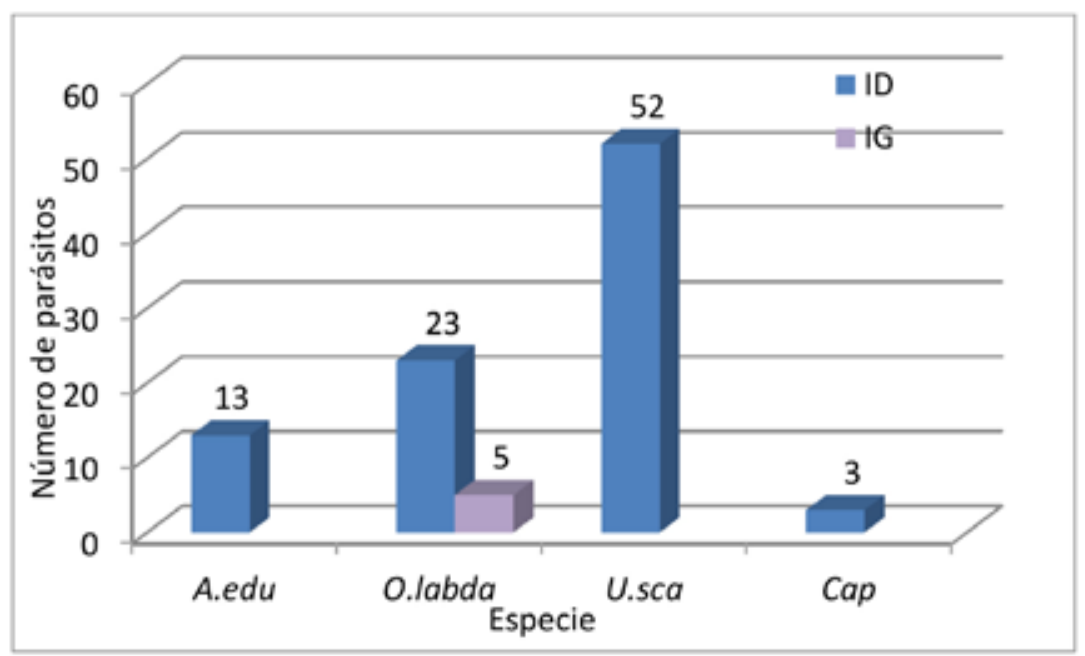

Figura. IV.3.1.6. Número de helmintos parásitos intestinales de M. temminckii. ID: intestino delgado; IG: intestino grueso. A.edu: Anenterotrema eduardocaballeroi, O.labda: Ochoterenatrema labda, U.sca: Urotrema scabridum, Cap: Capillaria sp.

Las especies parásitas se localizaron en el tracto intestinal, ocupando exclusivamente el intestino delgado, a excepción de $O$. labda que además se la encontró en intestino grueso. En la Figura IV.3.1.6 se observa el número de individuos parásitos presentes en cada porción intestinal.

\section{Análisis de la Infracomunidad}

\section{Riqueza específica}

La riqueza media fue $1,6 \pm 0,54$. Dos de los murciélagos presentaron infecciones monoespecíficas mientras que en los tres restantes se encontraron dos especies de helmintos conviviendo en el intestino.

\section{Análisis de la Comunidad Componente}

La riqueza específica de M. temminckii fue 4. En la Tabla IV.3.1.7 se presentan los valores de los índices ecológicos, los cuales muestran que no existe una especie dominante dentro de la comunidad de helmintos parásitos (confirmado por el índice de dominancia) y que las especies no poseen una abundancia similar, aunque se encuentran en punto intermedio. 
Tabla IV.3.1.7. Índices ecológicos de M. temminckii.

\begin{tabular}{lc}
\hline \multicolumn{1}{c}{ Índices } \\
\hline Número total de parásitos & 96 \\
Riqueza (S) & 4 \\
Índice de Shannon $\left(\mathrm{H}^{\prime}\right)$ & 1,071 \\
Equitabilidad (J) & 0,772 \\
Dominancia Berger-Parker & 0,541 \\
\hline
\end{tabular}

\section{Especies centrales, secundarias y satélites}

Respecto a la distribución de frecuencia de las prevalencias específicas se observó que tres de las especies de helmintos presentaron prevalencias entre 20 y $40 \%$, mientras una, U. scabridum alcanzó el $80 \%$ de prevalencia. No se verificó una correlación estadísticamente significativa entre la prevalencia e intensidad media $\left(r_{s}=0,50 ; p=0,5\right)$, de modo que no es posible distinguir entre especies centrales, secundarias y satélites. En la Figura IV.3.1.7 se aprecia la dispersión de los helmintos respecto a la prevalencia e intensidad media.

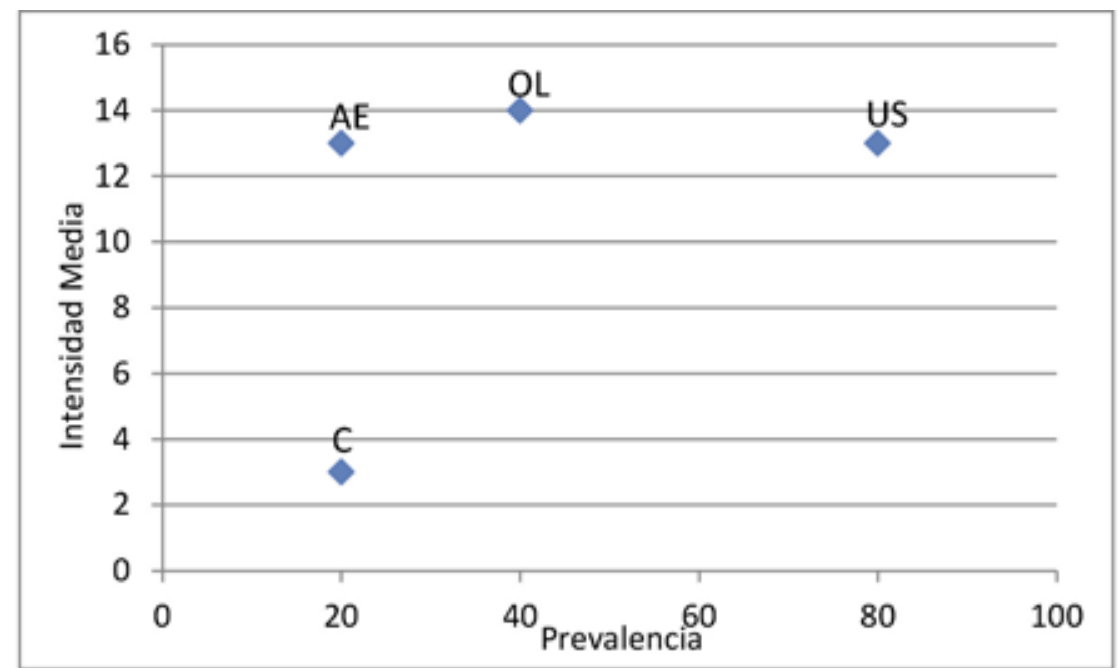

Figura IV.3.1.7. Prevalencia e Intensidad Media de las especies parásitas de M. temminckii. AE: Anenterotrema eduardocaballeroi, OL: Ochoterenatrema labda, T: Trichuridae sp., US: Urotrema scabridum 


\section{Molossus molossus (Pallas, 1776)}

Se evaluaron seis individuos de esta especie y solo se encontró un ejemplar de $U$. scabridum en el intestino delgado de uno de ellos. Este dato se incorporó al análisis a nivel de Familia.

Molossus rufus (É. Goeffroy Saint-Hilaire, 1806)

\section{Infección parasitaria}

Se evaluaron 20 individuos de esta especie hospedadora, de los cuales 11 se encontraban parasitados. Los valores de infección parasitaria discriminados por sexo del hospedador se observan en la Tabla IV.3.1.8.

Tabla IV.3.1.8. Infección parasitaria en Molossus rufus

\begin{tabular}{|c|c|c|c|c|c|}
\hline Sexo & $n$ & $\mathrm{P} \%$ & NP & 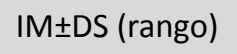 & $A M \pm D S$ \\
\hline$\hat{\sigma}$ & 8 & 50 & 20 & $\begin{array}{c}5,0 \pm 4,1 \\
(1-9)\end{array}$ & $2,5 \pm 3,7$ \\
\hline q & 12 & 58,3 & 147 & $\begin{array}{c}21,0 \pm 17,2 \\
(2-54)\end{array}$ & $12,2 \pm 17$ \\
\hline Total & 20 & 55 & 167 & $\begin{array}{c}15,2 \pm 15,7 \\
(1-54)\end{array}$ & $8,4 \pm 13,8$ \\
\hline
\end{tabular}

Tanto los valores de prevalencia como de intensidad y abundancia medias son mayores en las hembras, aunque las diferencias no resultaron estadísticamente significativas $\left(W=14,5 ; P_{0,05 ; 2}=0,08\right.$ y $W=70,5 ; P_{0,05 ; 2}=0,27$ respectivamente).

\section{Análisis de las poblaciones componentes}

Indicadores parasitológicos, localización y dispersión de helmintos

La riqueza de $M$. rufus fue igual a ocho especies: un cestode Vampirolepis guarany, cinco digeneos Anenterotrema educardocaballeroi, A. liliputianun, Limatulum oklahomense, Ochoterenatrema labda y Urotrema scabridum y dos nematodes Anoplostrongylus sp. y Capillaria sp. La prevalencia de infección fue 55 \% (11/20). En la Tabla IV.3.1.9 se aprecian los indicadores parasitológicos, la localización y el índice de dispersión de cada población parásita. Urotrema scabridum fue la especie de mayor prevalencia y número de individuos, siendo la especie dominante $(d=0,61)$. En todas las especies se observa una distribución agregada. 
Tabla IV.3.1.9. Helmintos parásitos de Molossus rufus

\begin{tabular}{|c|c|c|c|c|c|c|}
\hline & P \% & NP & $\begin{array}{l}\text { IMEDS } \\
\text { (rango) }\end{array}$ & $A M \pm D S$ & SI & iD \\
\hline \multicolumn{7}{|l|}{ CESTODA } \\
\hline V. guarany & $10(2 / 20)$ & 4 & 2 & $0.2 \pm 0,6$ & ID & 1,8 \\
\hline \multicolumn{7}{|l|}{ TREMATODA } \\
\hline A.eduardocaballeroi & $5(1 / 20)$ & 21 & 21 & $1,1 \pm 4,7$ & IG & 21 \\
\hline A. liliputianun & $5(1 / 20)$ & 6 & 6 & $0,3 \pm 1,3$ & IG & 6 \\
\hline L. oklahomense & $5(1 / 20)$ & 4 & 4 & $0,2 \pm 0,9$ & $E$ & 4 \\
\hline O. labda & $5(1 / 20)$ & 4 & 4 & $0,2 \pm 0,9$ & IG & 4 \\
\hline U. scabridum & $20(4 / 20)$ & 102 & $\begin{array}{c}18,7 \pm 24,8 \\
(10-54) \\
\end{array}$ & $5,1 \pm 13$ & ID-IG & 33,3 \\
\hline \multicolumn{7}{|l|}{ NEMATODA } \\
\hline Anoplostrongylus sp. & $10(2 / 20)$ & 5 & $\begin{array}{c}2,5 \pm 0,7 \\
(2-3)\end{array}$ & $0,3 \pm 0,8$ & ID & 2,5 \\
\hline Capillaria sp. & $30(6 / 20)$ & 21 & $\begin{array}{c}3,5 \pm 2,9 \\
(1-9)\end{array}$ & $1,1 \pm 2,2$ & ID & 4,7 \\
\hline
\end{tabular}

P: prevalencia; NP: número de parásitos; IM: intensidad media; AM: abundancia media; DS: desvío standard; SI: sitio de infección; iD: índice de dispersión; E: estómago; ID: intestino delgado; IG: intestino grueso.

Las especies de helmintos se localizaron en el tracto digestivo; todos los helmintos se distribuyeron entre el intestino delgado y grueso a excepción de $L$. oklahomense que se localizó únicamente en el estómago. En la Figura IV.3.1.8 se observa el número de individuos parásitos en sus distintas localizaciones. 


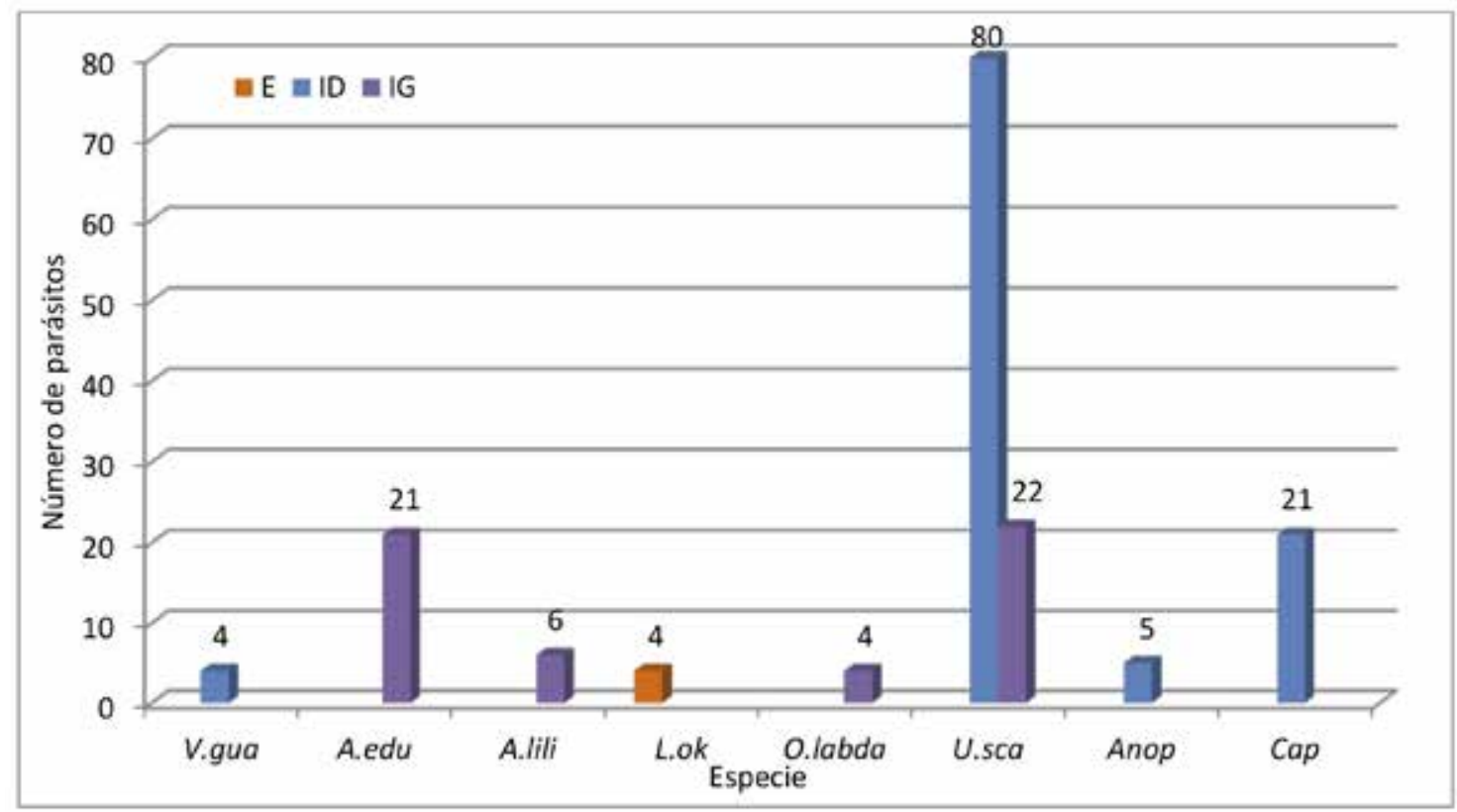

Figura. IV.3.1.8. Número de helmintos parásitos intestinales de $M$. rufus. E: estómago; ID: intestino delgado; IG: intestino grueso. A.edu: Anenterotrema eduardocaballeroi, A.lili: A. liliputianun, L.ok: Limatulum oklahomense, O.labda: Ochoterenatrema labda, U.sca: Urotrema scabridum, Anop: Anoplostrongylus sp., Cap: Capillaria sp.

Relación entre el tamaño del hospedador y los helmintos parásitos

Respecto a las variables relacionadas con el tamaño del hospedador (peso y longitud) no se observaron relaciones estadísticamente significativas con la intensidad total de infección ( $r_{s}=0,01 ; p=0,98$ y $r_{s}=0,22 ; p=0,36$ respectivamente). No se efectuó el análisis de cada una de las especies debido a que ninguna estuvo presente en 10 o más individuos.

\section{Análisis de la Infracomunidad}

\section{Riqueza específica}

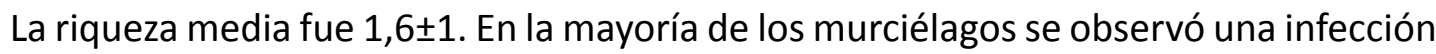
monoespecífica y solo un individuo hospedador presentó cuatro especies de helmintos conviviendo. En la Figura IV.3.1.9 se observa la distribución de frecuencias de la riqueza específica. 


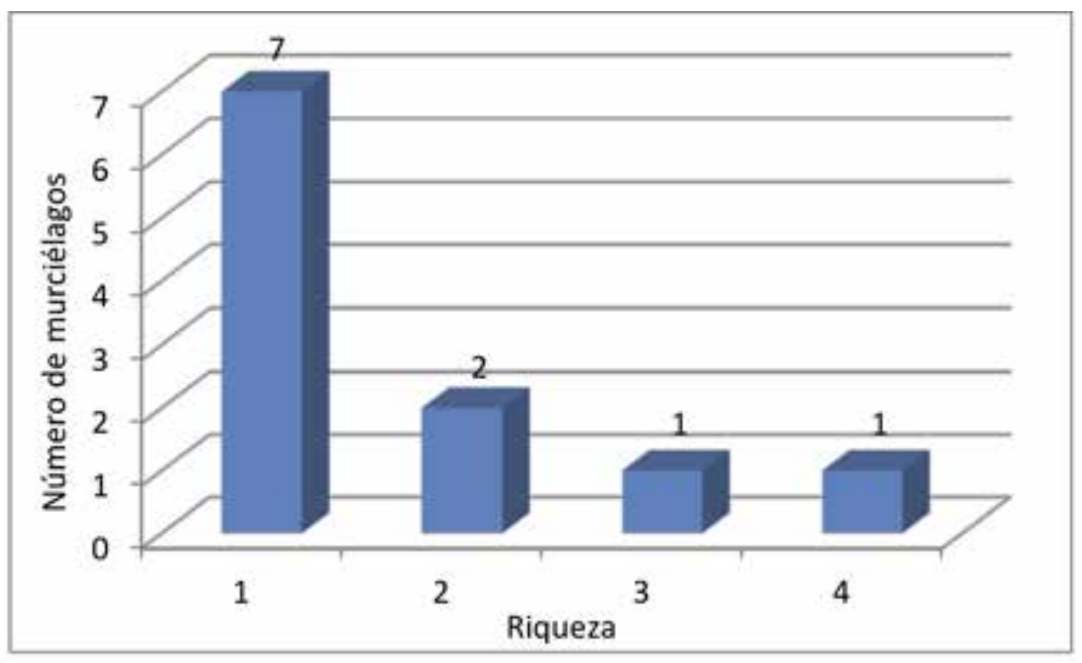

Figura IV.3.1.9. Número de individuos de $M$. rufus parasitados con 1 a 4 especies de helmintos

Respecto a la intensidad de infección parasitaria, la mayoría de los murciélagos ( $n=9$ ) presentaron intensidades entre 1 y 20 individuos y en solo dos individuos se registraron valores mayores (Figura IV.3.1.10).

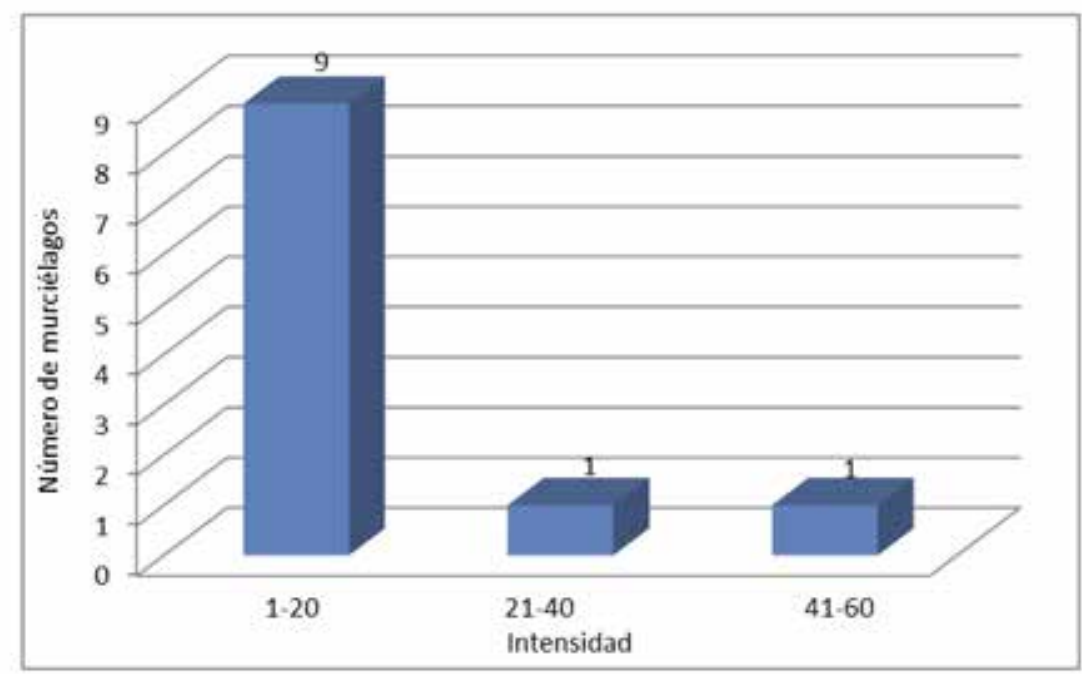

Figura IV.3.1.10. Distribución de frecuencia de intensidad de helmintos parásitos de $M$. rufus

\section{Análisis de la Comunidad Componente}

La riqueza específica de M. rufus fue igual a ocho. En la Tabla IV.3.1.10 se presentan los valores de los índices ecológicos. 
Tabla IV.3.1.10. Índices ecológicos de Molossus rufus.

\begin{tabular}{lc}
\hline \multicolumn{1}{c}{ Índices } \\
\hline Número total de parásitos & 167 \\
Riqueza $(\mathrm{S})$ & 8 \\
Índice de Shannon $\left(\mathrm{H}^{\prime}\right)$ & 1,315 \\
Equitabilidad $(\mathrm{J})$ & 0,633 \\
Dominancia Berger-Parker & 0,610 \\
\hline
\end{tabular}

Los valores de diversidad y equitabilidad sugieren que no existe una especie dominante dentro de la comunidad de helmintos parásitos (confirmado por el índice de dominancia) y que las especies no poseen una abundancia similar.

\section{Especies centrales, secundarias y satélites}

La mayoría de las especies de helmintos presentes en $M$. rufus mostraron baja prevalencia e intensidad media; solo $U$. scabridum y Capillaria sp. presentaron prevalencias entre 20 y $30 \%$ aunque la intensidad media fue baja (Figura IV.3.1.11). La correlación entre prevalencia e intensidad media no mostró un valor estadísticamente significativo $\left(r_{s}=0,27 ; p=0,51\right)$. En este sentido, no es posible distinguir entre especies centrales, secundarias y satélites.

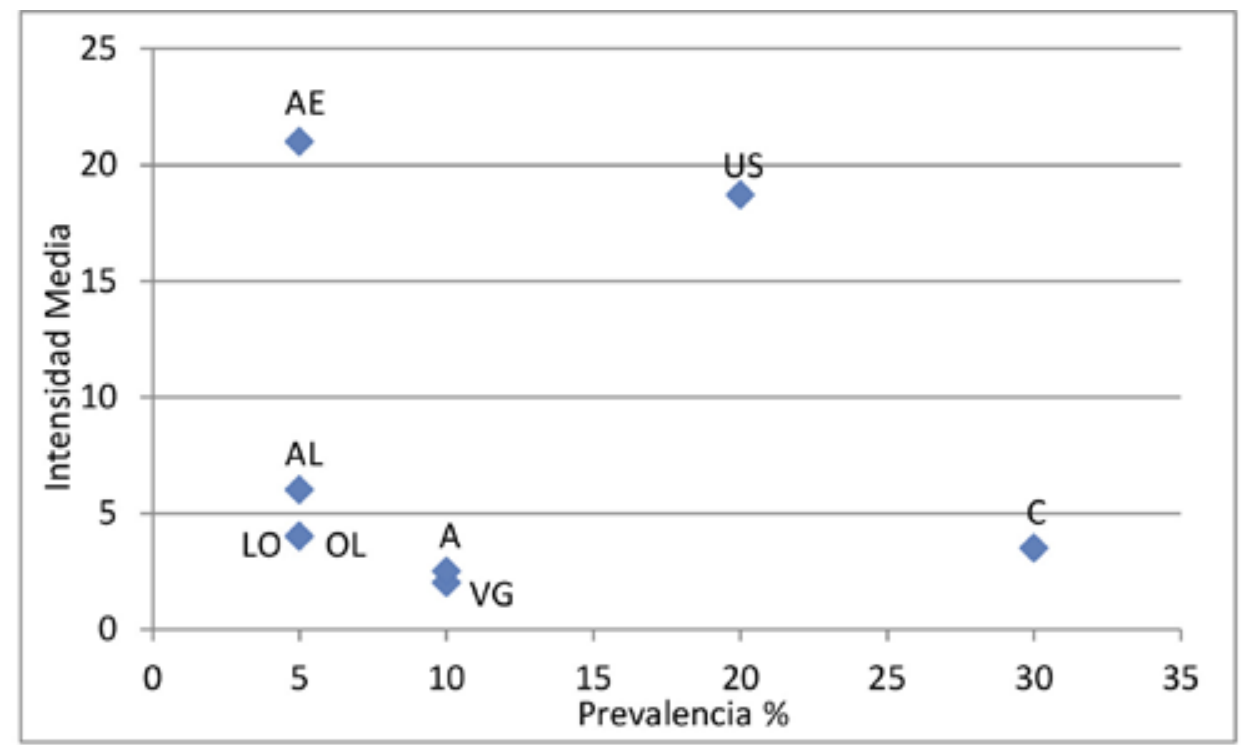

Figura IV.3.1.11. Prevalencia e Intensidad Media de las especies parásitas de M. rufus. A: Anoplostrongylus sp., AE: Anenterotrema eduardocaballeroi, AL: A. liliputianum, LO: Limatulum oklahomense, OL:

Ochoterenatrema labda, C: Capillaria sp., US: Urotrema scabridum, VG: Vampirolepis guarany. 


\section{Análisis de la Familia Molossidae}

Se estudiaron 98 ejemplares de cinco especies de murciélagos de la Familia Molossidae. La riqueza de helmintos parásitos en esta familia fue de 11 especies.

En la Figura IV.3.1.12 se aprecia el solapamiento de los helmintos parásitos respecto a las especies hospedadoras de la Familia Molossidae. Se observa que Urotrema scabridum está presente en todas las especies de murciélagos estudiadas pertenecientes a esta familia, a excepción de E. perotis; mientras que G. talavarensis, P. aranhai y Pterygodermatites sp. solo están presentes en E. patagonicus y A. liliputianum y L. oklahomense solo están presentes en $M$. rufus.

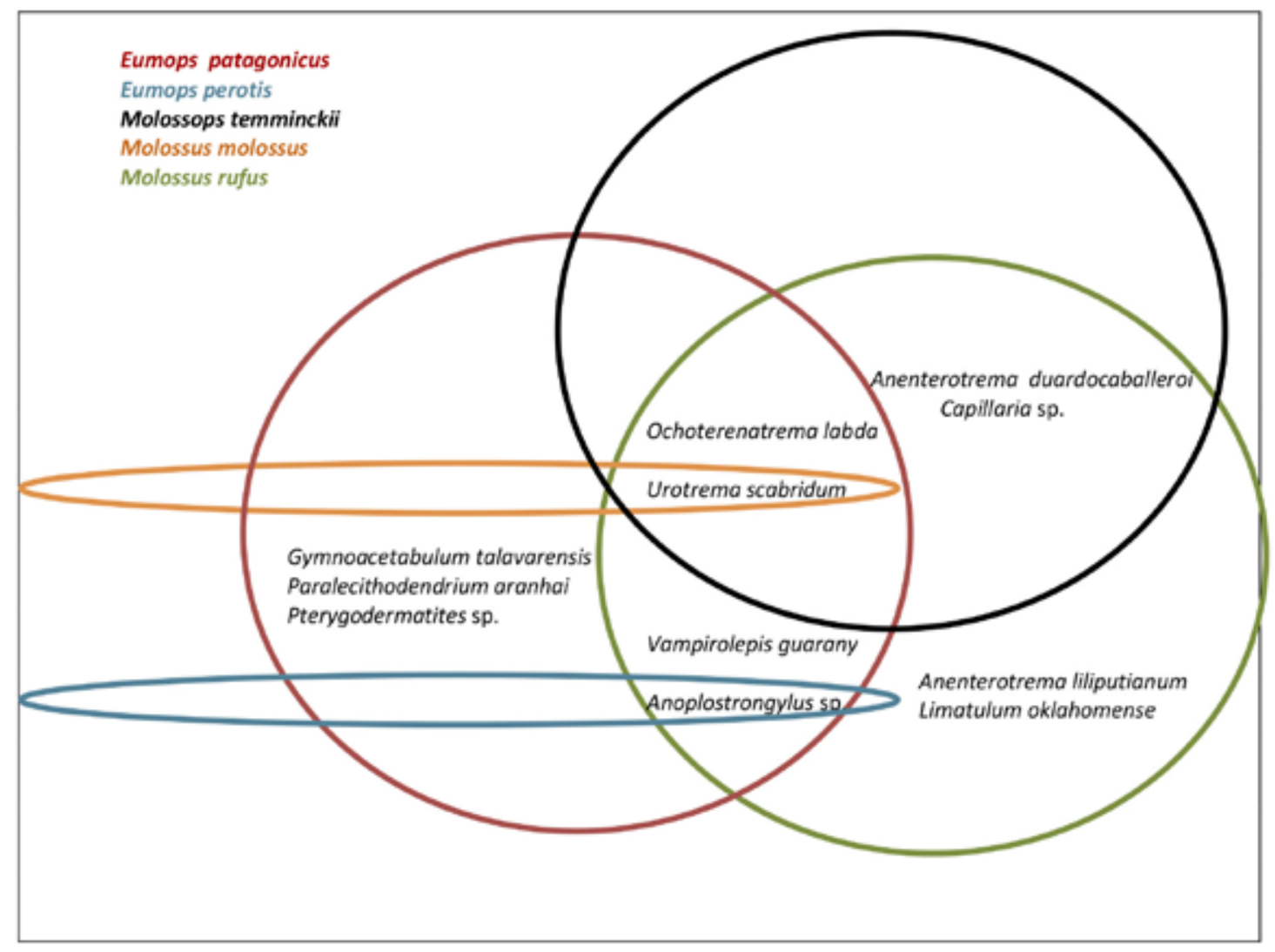

Figura IV.3.1.12. Helmintos parásitos presentes en las distintas especies hospedadoras de la Familia Molossidae

Por otra parte, E. perotis y $M$. molossus presentaron un solo taxón y un escaso número de parásitos. En la primera especie hospedadora, en el único individuo evaluado, se contabilizaron cinco ejemplares de Anoplostrongylus sp. y en la segunda especie, solo un murciélago presentó un único ejemplar del digeneo U. scabridum.

Cada especie hospedadora presentó distintos valores de infección parasitaria. En la Tabla IV.3.1.11 se observa la comparación entre las especies hospedadoras, respecto a la infección parasitaria, riqueza de especies y especie dominante. 
Tabla IV.3.1.11. Infección parasitaria de la familia Molossidae.

\begin{tabular}{lcccc}
\hline \multicolumn{1}{c}{ Hospedador } & P\% (P/E) & NP & S & $\begin{array}{c}\text { Especie dominante } \\
\text { Índice de Berger-Parker }\end{array}$ \\
\hline MOLOSSIDAE & $81,6(80 / 98)$ & 6268 & 11 & U. scabridum; $d=0,55$ \\
\hline E. patagonicus & $93,9(62 / 66)$ & 5999 & 7 & U. scabridum; $d=0,55$ \\
E. perotis & $100(1 / 1)$ & 5 & 1 & U. scabridum; $d=0,54$ \\
M. temminckii & $100(5 / 5)$ & 96 & 4 & - \\
M. molossus & $16,7(1 / 6)$ & 1 & 1 & U. scabridum; $d=0,61$ \\
M. rufus & $55(11 / 20)$ & 167 & 8 &
\end{tabular}

$\mathrm{P} \%$ : prevalencia; $(\mathrm{P} / \mathrm{E})$ : parasitados/examinados; NP: número de parásitos; S: riqueza

Se observa que M. rufus fue el hospedador con mayor riqueza específica (ocho especies) y E. patagonicus el de mayor intensidad. En todos los casos la especie dominante es U. scabridum, siéndolo también para toda la familia Molossidae.

Los índices ecológicos se presentan en las especies de hospedadores en las que fueron calculados y en la totalidad de los miembros de la familia Molossidae (Tabla IV.3.1.12).

Tabla IV.3.1.12. Índices ecológicos de los helmintos parásitos de la familia Molossidae.

\begin{tabular}{lcccc}
\hline \multicolumn{1}{c}{ Índices } & $\begin{array}{c}\text { Eumops } \\
\text { patagonicus }\end{array}$ & $\begin{array}{c}\text { Molossops } \\
\text { temminckii }\end{array}$ & $\begin{array}{c}\text { Molossus } \\
\text { rufus }\end{array}$ & Molossidae \\
\hline Índice de Shannon $\left(\mathrm{H}^{\prime}\right)$ & 1,112 & 1,071 & 1,315 & 1,292 \\
Equitabilidad $(\mathrm{J})$ & 0,572 & 0,772 & 0,633 & 0,538 \\
Dominancia Berger-Parker & 0,550 & 0,541 & 0,610 & 0,524 \\
\hline
\end{tabular}

Se aprecia que la diversidad de helmintos parásitos fue mayor en $M$. rufus. Respecto al índice de equitabilidad se observa que en $M$. temminckii y $M$. rufus todos los parásitos tienen la misma representatividad, lo que se confirma con los valores intermedios del índice de Berger-Parker. Sin embargo en E. patagonicus y en la totalidad de la familia estos valores son cercanos a 0,5 lo que también sugiere que no existe una especie que domine sobre el resto.

Al evaluar el grado de similaridad se obtuvo que las comunidades de helmintos de $E$. patagonicus y $M$. rufus son similares en menos de un $50 \%$ (CSS= $44 \%$ ). 


\section{IV.3.2. Familia Phyllostomidae}

\section{Artibeus lituratus (Olfers, 1818)}

\section{Infección parasitaria}

Se evaluaron 10 individuos de esta especie, en cinco de los cuales se observaron helmintos parásitos (50\%). En la Tabla IV.3.2.1 se aprecian los valores de infección parasitaria discriminados por sexo del hospedador, se observan valores superiores en las hembras respecto a los machos, en todos los indicadores.

Tabla IV.3.2.1. Infección parasitaria en Artibeus lituratus

\begin{tabular}{cccccc}
\hline Sexo & $n$ & P\% & NP & $\begin{array}{c}\text { IM } \pm \text { DS } \\
\text { (rango) }\end{array}$ & AM \pm DS \\
\hline ^ & 5 & 20 & 53 & $\begin{array}{c}26,5 \pm 7,8 \\
(21-32)\end{array}$ & $10,6 \pm 15,0$ \\
9 & 5 & 60 & 293 & $\begin{array}{c}97,7 \pm 47,3 \\
(43-125)\end{array}$ & $58,6 \pm 63,1$ \\
\hline Total & 10 & 50 & 346 & $69,2 \pm 51,5$ & $34,6 \pm 50,1$ \\
& & & & $(21-125)$ & \\
\hline
\end{tabular}

$\mathrm{n}=$ número de murciélagos examinados, $\mathrm{P}=$ prevalencia, $\mathrm{NP}=$ número de parásitos, $\mathrm{IM}=$ intensidad media, $\mathrm{AM}=$ abundancia media, $\mathrm{DS}=$ desvío standard.

Se identificó un único taxón de helminto parásito: Vampirolepis guarany (Cestoda). En todos los casos los individuos se localizaron en intestino delgado. No se efectuaron análisis ecológicos para esta especie de murciélago. Los datos se incorporaron al análisis entre Familias y gremio trófico de los hospedadores. Se observó el registro de un elevado número de individuos de $V$. guarany; en este sentido, cabe aclarar que se contabilizaron escólex con estróbilo escasamente desarrollado.

\section{Desmodus rotundus (É. Goeffroy Saint-Hilaire, 1810)}

Se evaluaron cuatro individuos de ésta especie, en ninguno de los cuales se observaron helmintos parásitos.

\section{Platyrrhinus lineatus (É. Goeffroy Saint-Hilaire, 1810)}

Se evaluaron nueve individuos de ésta especie, en ninguno de los cuales se observaron helmintos parásitos.

\section{Sturnira lilium (É. Goeffroy Saint-Hilaire, 1810)}

\section{Infección parasitaria}

Se estudiaron nueve individuos de ésta especie hospedadora, de los cuales 5 presentaron helmintos parásitos. Los valores de infección discriminados por sexo se observan en la Tabla IV.3.2.2. 
Tabla IV.3.2.2. Infección parasitaria en Sturnira lilium

\begin{tabular}{cccccc}
\hline Sexo & $\mathrm{n}$ & $\mathrm{P} \%$ & $\mathrm{NP}$ & $\begin{array}{c}\mathrm{IM} \pm \mathrm{DS} \\
\text { (rango) }\end{array}$ & $\mathrm{AM} \pm \mathrm{DS}$ \\
\hline 0 & 3 & 33,3 & 4 & 4 & $1,3 \pm 2,3$ \\
+ & 6 & 66,6 & 18 & $\begin{array}{c}4,5 \pm 4,1 \\
(1-9)\end{array}$ & $3,0 \pm 3,9$ \\
\hline Total & 9 & 55,5 & 22 & $\begin{array}{c}4,4 \pm 3,5 \\
(1-9)\end{array}$ & $2,4 \pm 3,4$ \\
\hline
\end{tabular}

$\mathrm{n}=$ número de murciélagos examinados, $\mathrm{P}=$ prevalencia, $\mathrm{NP}=$ número de parásitos, $\mathrm{IM}=$ intensidad media, $\mathrm{AM}=$ abundancia media, $\mathrm{DS}=$ desvío standard

Se observó un único taxón de helminto: Capillaria sp. (Nematoda). En todos los casos los individuos se localizaron en intestino delgado. No se efectuaron análisis ecológicos para esta especie de murciélago. Los datos se incorporaron al análisis entre Familias y gremio trófico de los hospedadores.

\section{Análisis de la Familia Phyllostomidae}

Se evaluaron 32 individuos de cuatro especies de murciélagos de la Familia Phyllostomidae. En dos de las especies analizadas (Desmodus rotundus y Platyrrhinus lineatus) no se observaron helmintos parásitos, mientras que en las otras dos (Artibeus lituratus y Sturnira lilium) se registraron dos especies de helmintos: Vampirolepis guarany y CapiIlaria sp., respectivamente. Debido a la escasez de datos cuantitativos no se efectuaron análisis estadísticos y los resultados correspondientes a la presente familia de murciélagos fueron integrados al análisis entre familias y gremio trófico de los hospedadores.

\section{IV.3.3. Familia Vespertilionidae}

\section{Eptesicus furinalis (d’Orbigny y Gervais, 1847)}

\section{Infección parasitaria}

Se evaluaron 16 individuos de esta especie hospedadora, de los cuales cuatro se encontraban parasitados. Los valores de infección parasitaria discriminados por sexo del hospedador se observan en la Tabla IV.3.3.1. Las hembras presentaron intensidad y abundancia medias mayores que los machos. 
Tabla IV.3.3.1. Infección parasitaria en Eptesicus furinalis

\begin{tabular}{|c|c|c|c|c|c|}
\hline Sexo & $n$ & $\mathrm{P} \%$ & NP & $\begin{array}{l}\text { IM } \pm D S \\
\text { (rango) }\end{array}$ & $A M \pm D S$ \\
\hline$\sigma^{1}$ & 2 & 100 & 3 & $\begin{array}{c}1,5 \pm 0,7 \\
(1-2)\end{array}$ & $1,5 \pm 0,7$ \\
\hline$q$ & 14 & 14,3 & 8 & $\begin{array}{c}4 \\
(4-4)\end{array}$ & $0,6 \pm 1,4$ \\
\hline Total & 16 & 25 & 11 & $\begin{array}{c}2,7 \pm 1,5 \\
(1-4)\end{array}$ & $0,7 \pm 1,4$ \\
\hline
\end{tabular}

Debido al escaso número de helmintos parásitos hallados $(n=11)$ no se efectuaron análisis estadísticos. Los datos se incorporaron al análisis a nivel de la Familia Vespertilionidae.

\section{Análisis de las poblaciones componentes}

Indicadores parasitológicos, localización y dispersión de helmintos

La riqueza de $E$. furinalis fue igual a dos especies: un cestode Vampirolepis cf macroti y un nematode Anoplostrongylus sp. La prevalencia fue 25\% (4/16). En la Tabla IV.3.3.2 se aprecian los indicadores parasitológicos, la localización y el índice de dispersión de cada especie parásita.

Tabla IV.3.3.2. Helmintos parásitos de E. furinalis

\begin{tabular}{lcccccc}
\hline & P \% & NP & $\begin{array}{c}\text { IM } \pm \text { DS } \\
\text { (rango) }\end{array}$ & AM \pm DS & SI & iD \\
\hline $\begin{array}{l}\text { CESTODA } \\
\text { Vampirolepis cf macroti }\end{array}$ & $6,3(1 / 16)$ & 1 & 1 & $0,06 \pm 0,2$ & ID & 1 \\
\hline $\begin{array}{l}\text { NEMATODA } \\
\text { Anoplostrongylus sp. }\end{array}$ & $18,8(3 / 16)$ & 10 & $\begin{array}{c}3,3 \pm 1,4 \\
(2-4)\end{array}$ & $0,6 \pm 2,1$ & ID & 3,2 \\
\hline
\end{tabular}

P: prevalencia; NP: número de parásitos; IM: intensidad media; AM: abundancia media; DS: desvío standard; SI: sitio de infección; iD: índice de dispersión; ID: intestino delgado.

Se contabilizaron diez especímenes de Anoplostrongylus sp. en tres individuos de $E$. furinalis y solo se observó un ejemplar de Vampirolepis cf macroti en un único individuo de esta especie hospedadora. La especie dominante fue Anoplostrongylus sp. $(d=0,85)$. Ambas especies de helmintos se localizaron en intestino delgado y presentaron una distribución agregada. 


\section{Myotis albescens (É. Goeffroy Saint-Hilaire, 1806)}

Se evaluaron 35 individuos de esta especie hospedadora, de los cuales 29 (82,9\%) presentaron helmintos parásitos. Los valores de infección parasitaria discriminados por sexo del hospedador se expresan en la Tabla IV.3.3.3.

Tabla IV.3.3.3. Infección parasitaria en Myotis albescens

\begin{tabular}{|c|c|c|c|c|c|}
\hline Sexo & $\mathrm{n}$ & $\mathrm{P} \%$ & NP & $\begin{array}{l}\mathrm{IM} \pm \mathrm{DS} \\
\text { (rango) }\end{array}$ & $\mathrm{AM} \pm \mathrm{DS}$ \\
\hline 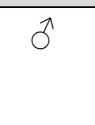 & 4 & 100 & 54 & $\begin{array}{c}13,5 \pm 13,8 \\
(1-32)\end{array}$ & $13,5 \pm 13,8$ \\
\hline q & 31 & 80,6 & 89 & $\begin{array}{c}3,6 \pm 3,2 \\
(1-12)\end{array}$ & $2,9 \pm 3,2$ \\
\hline Total & 35 & 82,9 & 143 & $\begin{array}{c}4,9 \pm 6,5 \\
(1-32)\end{array}$ & $4,1 \pm 6,1$ \\
\hline
\end{tabular}

Se observa que la prevalencia, intensidad y abundancia medias son mayores en los machos, aunque las diferencias entre las últimas dos variables no resultaron estadísticamente significativas ( $W=83,0 ; P_{0,05 ; 2}=0,13$ y $W=107,0 ; P_{0,05 ; 2}=0,06$, respectivamente).

\section{Análisis de las poblaciones componentes}

Indicadores parasitológicos, localización y dispersión de helmintos

La riqueza de helmintos en $M$. albescens fue igual a cuatro especies, todas digeneos: Gymnoacetabulum talavarensis, Limatulum oklahomense, Ochoterenatrema labda y Urotrema scabridum. En la Tabla IV.3.3.4 se observan los indicadores parasitológicos, la localización y el índice de dispersión de cada población parásita.

Tabla IV.3.3.4. Helmintos parásitos de $M$. albescens

\begin{tabular}{lcccccc}
\hline & P $\%$ & NP & $\begin{array}{c}\text { IM } \pm \text { DS } \\
\text { (rango) }\end{array}$ & AM \pm DS & SI & iD \\
\hline $\begin{array}{l}\text { TREMATODA } \\
\text { G. talavarensis }\end{array}$ & $17,1(6 / 35)$ & 24 & $4 \pm 4,1$ & $0,7 \pm 2,2$ & ID-IG & 7,0 \\
L. oklahomense & $60(21 / 35)$ & 83 & $3,9 \pm 5,1$ & $2,4 \pm 4,4$ & E & 8,1 \\
& & & $(1-12)$ & & \\
O.labda & $5,7(2 / 35)$ & 9 & $4,5 \pm 3,5$ & $0,3 \pm 1,2$ & ID-IG & 5,8 \\
& & & $(2-7)$ & & & \\
U. scabridum & $14,3(5 / 35)$ & 27 & $5,4 \pm 4,3$ & $0,8 \pm 2,5$ & ID-IG & 8,3
\end{tabular}

P: prevalencia; NP: número de parásitos; IM: intensidad media; AM: abundancia media; DS: desvío standard; SI: sitio de infección; iD: índice de dispersión; E: estómago; ID: intestino delgado; IG: intestino grueso. 
Limatulum oklahomense fue la especie de mayor prevalencia, número de individuos y abundancia media, resultando la especie dominante $(d=0,58)$. Las cuatro poblaciones mostraron una distribución agregada. Las poblaciones de helmintos se localizaron en intestino delgado y grueso, a excepción de L. oklahomense que se localizó únicamente en estómago (Figura IV.3.3.1).

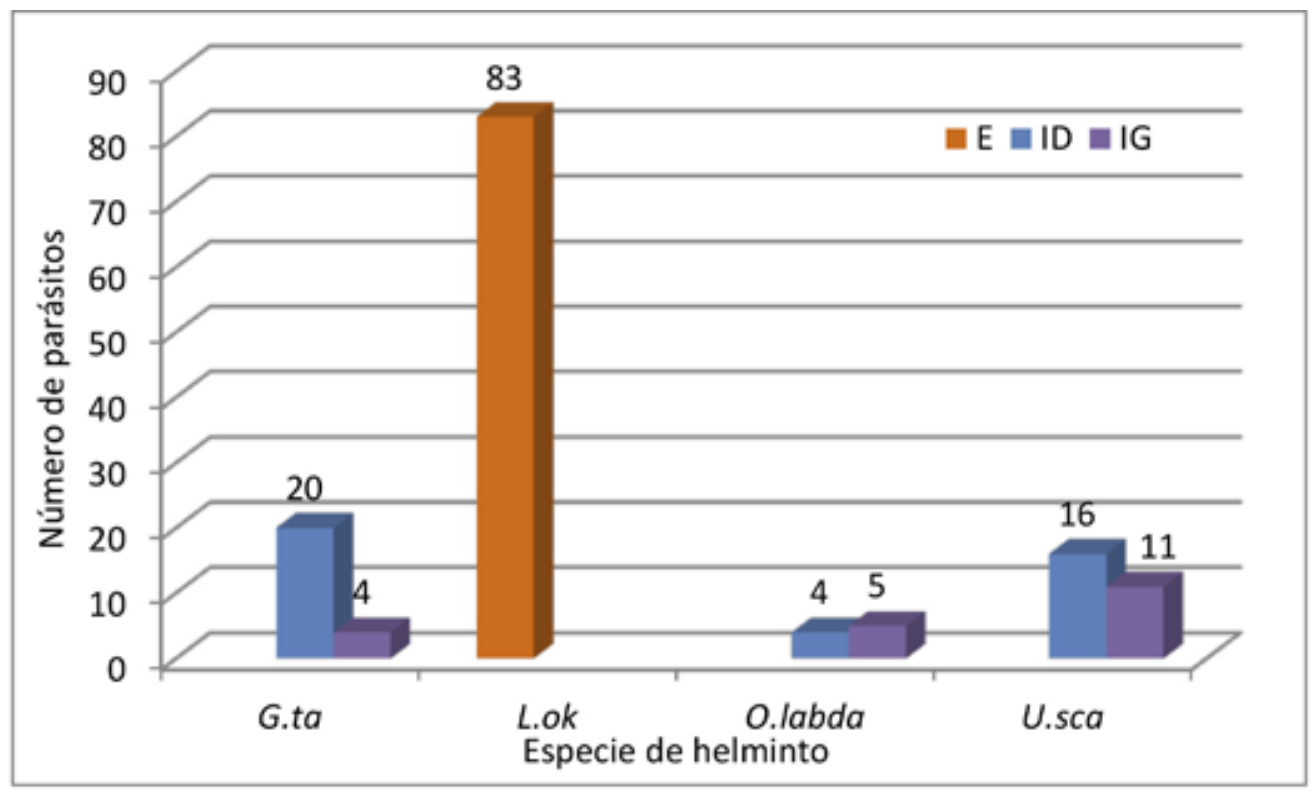

Figura. IV.3.3.1. Número de helmintos parásitos intestinales de M. albescens. E: estómago; ID: intestino delgado; IG: intestino grueso. G.ta: Gymnoacetabulum talavarensis, L.ok: Limatulum oklahomense,

O.labda: Ochoterenatrema labda, U.sca: Urotrema scabridum.

Relación entre el tamaño del hospedador y los helmintos parásitos

Respecto a las variables relacionadas con el tamaño del hospedador (peso y longitud) no se observaron relaciones estadísticamente significativas con la intensidad total de infección ( $r_{s}=0,02 ; p=0,89$ y $r_{s}=-0,13 ; p=0,45$ respectivamente). Al analizar dichas variables respecto a $L$. oklahomense no se observó una relación estadísticamente significativa entre la longitud del hospedador y la intensidad de infección $\left(r_{s}=0,04, p=0,8\right.$ y $r_{s}=-0,07$, $p=0,7$, respectivamente).

\section{Análisis de la Infracomunidad}

\section{Riqueza específica}

La riqueza media fue $1,2 \pm 0,4$. En la mayoría de los murciélagos se observaron infecciones monoespecíficas, mientras que solo en cinco casos se registraron infecciones biespecíficas. En la Figura IV.3.3.2 se observa la distribución de frecuencias de la riqueza específica. 


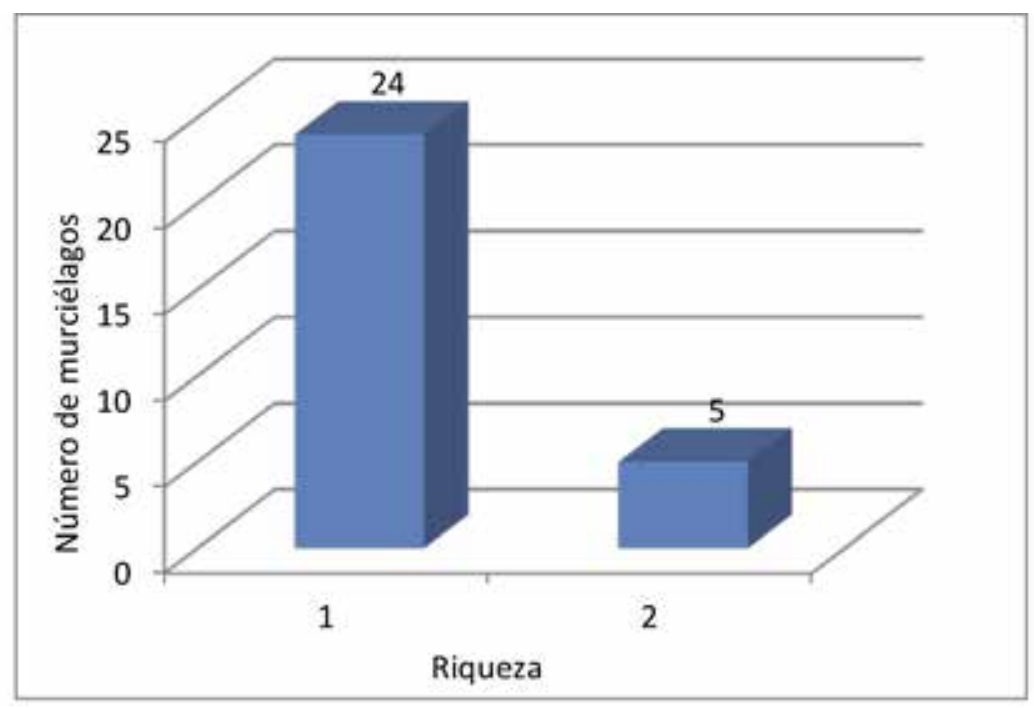

Figura IV.3.3.2. Número de individuos de $M$. albescens parasitados con 1 y 2 especies de helmintos.

Respecto a la intensidad de infección parasitaria, la mayoría de los murciélagos ( $n=28)$ presentaron intensidades entre 1 y 20 especímenes parásitos y en solo un individuo se registró un valor mayor (Figura IV.3.3.3).

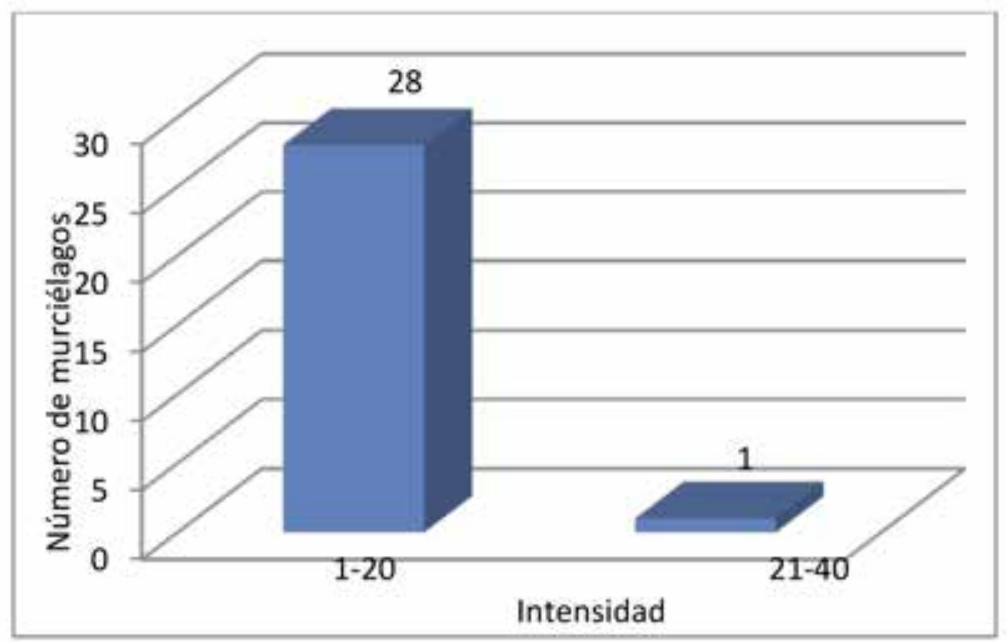

Figura IV.3.3.3. Distribución de frecuencia de intensidad de helmintos parásitos de $M$. albescens

\section{Análisis de la Comunidad Componente}

La riqueza específica de $M$. albescens fue igual a cuatro. En la Tabla IV.3.3.5 se presentan los valores de los índices ecológicos. 
Tabla IV.3.3.5. Índices ecológicos de M. albescens.

\begin{tabular}{lc}
\hline \multicolumn{1}{c}{ Índices } \\
\hline Número total de parásitos & 143 \\
Riqueza (S) & 4 \\
Índice de Shannon $\left(\mathrm{H}^{\prime}\right)$ & 1,10 \\
Equitabilidad $(\mathrm{J})$ & 0,79 \\
Dominancia Berger-Parker & 0,58 \\
\hline
\end{tabular}

Los valores de diversidad y equitabilidad sugieren que no existe una especie dominante dentro de la comunidad de helmintos parásitos (confirmado por el índice de dominancia) y que las especies no poseen una abundancia similar.

\section{Especies centrales, secundarias y satélites}

La distribución de frecuencias de la prevalencia de los helmintos parásitos muestra tres especies ubicadas en el intervalo 1 a $20 \%$ y una cuarta especie que alcanza el 60 \% (Figura IV.3.3.4). La correlación entre la prevalencia y la intensidad media no fue estadísticamente significativa $\left(r_{s}=0,80 ; p>0,05\right)$. En este caso, las especies centrales, secundarias y satélites son indistinguibles. Limatulum oklahomense mostró una elevada prevalencia aunque la intensidad media fue similar a las otras especies de helmintos (Figura IV.3.3.4).

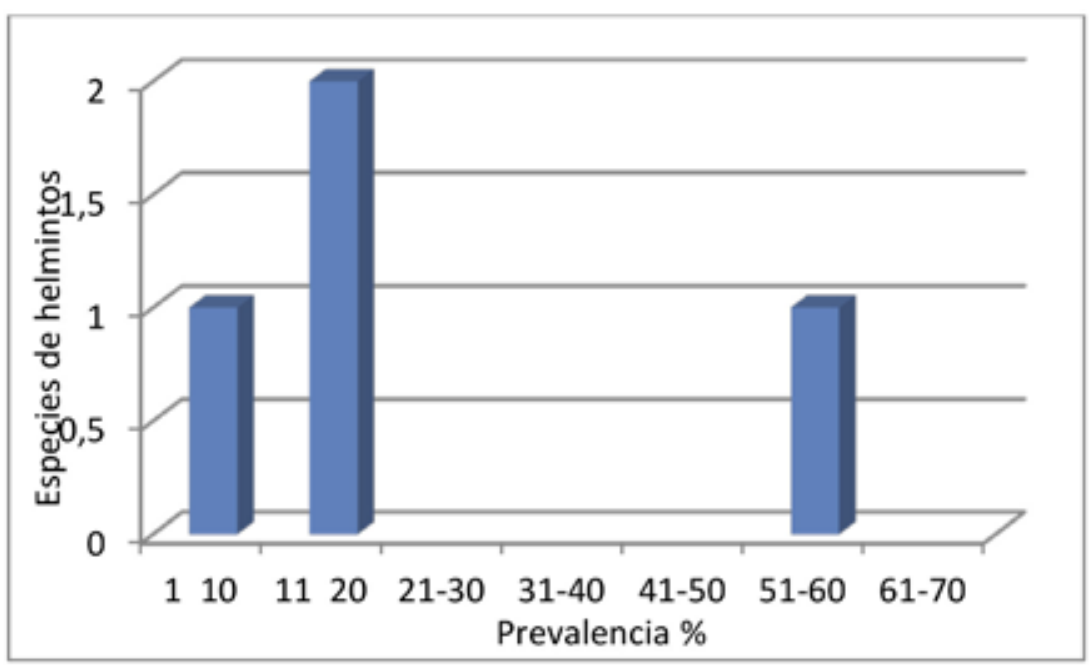

Figura IV.3.3.4. Distribución de frecuencias de las prevalencias específicas de helmintos parásitos de $M$. albescens. 


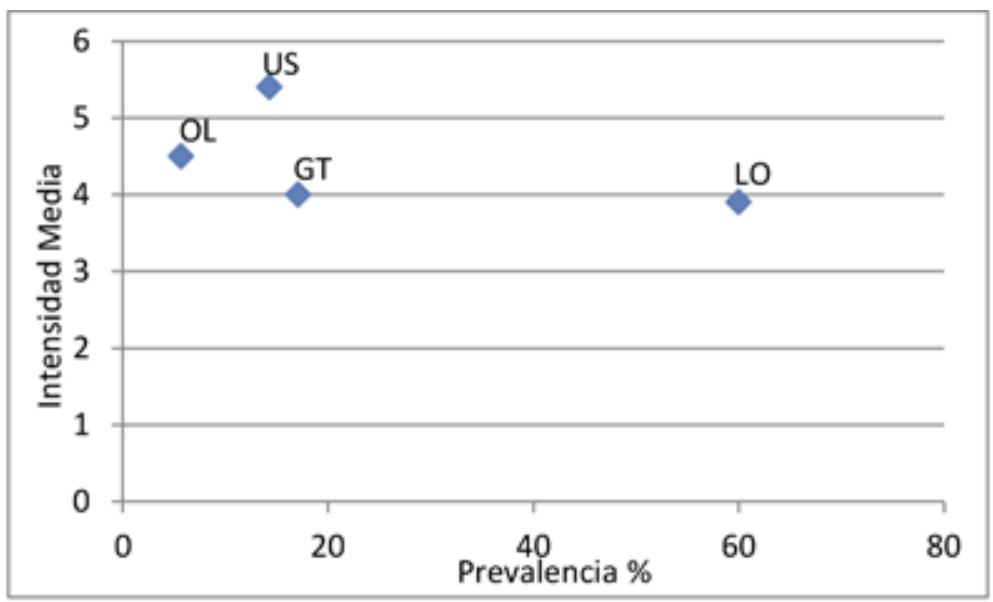

Figura IV.3.3.5. Prevalencia e intensidad media de las especies parásitas de M. albescens. GT: Gymnoacetabulum talavarensis, LO: Limatulum oklahomense, OL: Ochoterenatrema labda, US: Urotrema scabridum.

\section{Myotis cf nigricans (Schinz, 1821)}

Se evaluaron 31 individuos de esta especie hospedadora, de los cuales siete $(22,6 \%)$ estuvieron parasitados. Los valores de infección parasitaria discriminados por sexo del hospedador se expresan en la Tabla IV.3.3.6.

Tabla IV.3.3.6. Infección parasitaria en Myotis cf nigricans

\begin{tabular}{|c|c|c|c|c|c|}
\hline Sexo & $\mathrm{n}$ & $\mathrm{P} \%$ & NP & $\mathrm{IM} \pm \mathrm{DS}$ (rango) & $\mathrm{AM} \pm \mathrm{DS}$ \\
\hline$\hat{0}$ & 13 & 15,4 & 32 & $\begin{array}{c}16 \pm 14,1 \\
(6-26)\end{array}$ & $2,5 \pm 7,2$ \\
\hline q & 18 & 16,7 & 168 & $\begin{array}{c}33,6 \pm 19,3 \\
(10-56)\end{array}$ & $9,3 \pm 18,1$ \\
\hline Total & 31 & 22,6 & 200 & $\begin{array}{c}28,6 \pm 18,9 \\
(6-56)\end{array}$ & $6,5 \pm 14,8$ \\
\hline
\end{tabular}

$\mathrm{n}=$ número de murciélagos examinados, $\mathrm{P}=$ prevalencia, $\mathrm{NP}=$ número de parásitos, $\mathrm{IM}=$ intensidad media, $\mathrm{AM}=$ abundancia media, $\mathrm{DS}=$ desvío standard.

Se observa que todos los indicadores son mayores en las hembras, particularmente la intensidad y abundacia media, aunque no se verificaron diferencias estadísticamente significativas entre estas variables y el sexo del hospedador $\left(W=5,5 ; P_{0,05 ; 2}=0,4\right.$ y $W=$ 191,$0 ; P_{0,052}=0,3$ respectivamente). 


\section{Análisis de las poblaciones componentes}

Indicadores parasitológicos, localización y dispersión de helmintos

La riqueza en Myotis cf nigricans fue igual a cuatro especies, todas digeneos: Limatulum oklahomense, Ochoterenatrema labda, Paralecithodendrium aranhai y Urotrema scabridum. En la Tabla IV.3.3.7 se observan los indicadores parasitológicos, la localización y el índice de dispersión de cada población parásita.

Tabla IV.3.3.7. Helmintos parásitos de Myotis cf nigricans

\begin{tabular}{|c|c|c|c|c|c|c|}
\hline & P \% & NP & $\begin{array}{l}\text { IMEDS } \\
\text { (rango) }\end{array}$ & $A M \pm D S$ & SI & iD \\
\hline \multicolumn{7}{|l|}{ TREMATODA } \\
\hline L. oklahomense & $9,7(3 / 31)$ & 41 & $\begin{array}{c}13,7 \pm 12,6 \\
(6-25)\end{array}$ & $1,3 \pm 4,9$ & $E$ & 17,8 \\
\hline O. labda & $3,2(1 / 31)$ & 56 & 56 & $1,8 \pm 10,1$ & ID-IG & 56 \\
\hline P. aranhai & $6,5(2 / 31)$ & 66 & $\begin{array}{l}33 \pm 15,6 \\
(26-40)\end{array}$ & $2,1 \pm 8,4$ & ID & 33,4 \\
\hline U. scabridum & $9,7(3 / 31)$ & 37 & $\begin{array}{c}12,3 \pm 11,9 \\
(5-26)\end{array}$ & $1,2 \pm 4,8$ & ID & 19,3 \\
\hline
\end{tabular}

P: prevalencia; NP: número de parásitos; IM: intensidad media; AM: abundancia media; DS: desvío standard; SI: sitio de infección; iD: índice de dispersión; E: estómago; ID: intestino delgado; IG: intestino grueso.

Se observa que Paralecithodendrium aranhai presentó los mayores valores de intensidad media y abundancia media y resultó ser la especie dominante $(d=0,33)$. Todas las especies mostraron una distribución agregada y se localizaron en el tracto digestivo. Limatulum oklahomense se localizó únicamente en estómago mientras que el resto lo hizo en intestino delgado y grueso. En la Figura IV.3.3.6 se aprecia la distribución de los helmintos en las distintas localizaciones.

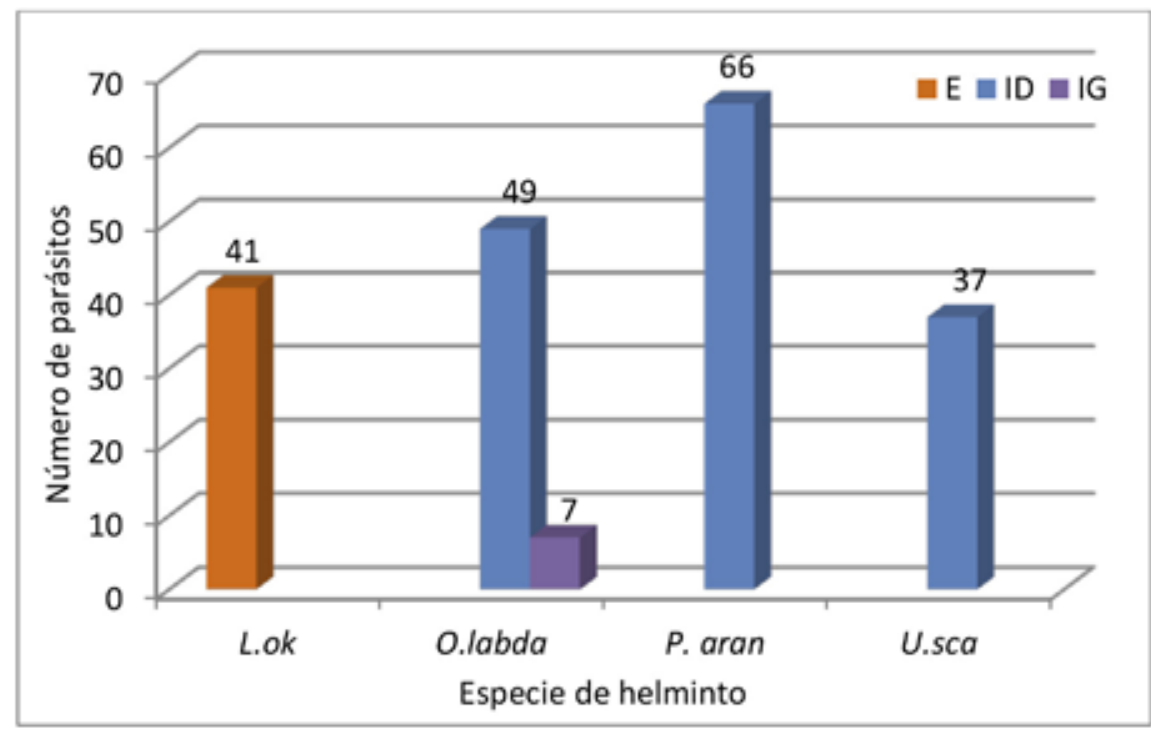

Figura. IV.3.3.6. Número de helmintos parásitos intestinales de Myotis cf nigricans. E: estómago; ID: intestino delgado; IG: intestino grueso. L.ok: Limatulum oklahomense, O.labda: Ochoterenatrema labda, P. aran: Paralecithodendrium aranhai, U.sca: Urotrema scabridum. 
Relación entre el tamaño del hospedador y los helmintos parásitos

Respecto a las variables relacionadas con el tamaño del hospedador (peso y longitud) no se observaron relaciones estadísticamente significativas con la intensidad de infección ( $r_{s}=-0,04 ; p=0,83$ y $r_{s}=0,05 ; p=0,78$ respectivamente).

\section{Análisis de la Infracomunidad}

\section{Riqueza específica}

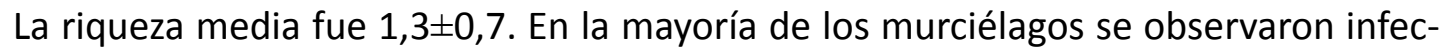
ciones monoespecíficas, mientras que solo en un caso se observó la presencia simultánea de tres especies de helmintos (Figura IV.3.3.7).

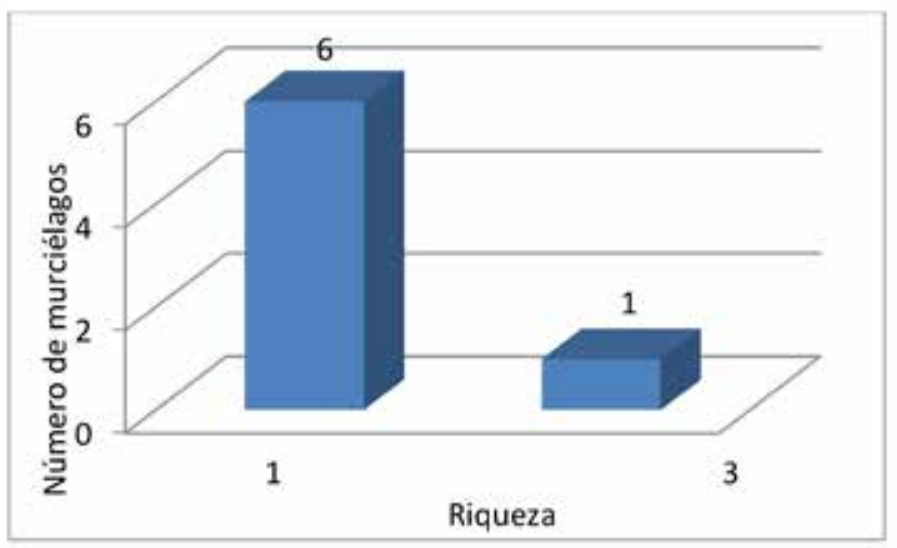

Figura IV.3.3.7. Número de individuos de Myotis cf nigricans parasitados con 1 y 3 especies de helmintos

Respecto a la intensidad de infección parasitaria, se observan tres grupos distribuidos en los valores de intensidad entre 1 y 60 individuos parásitos (Figura IV.3.3.8).

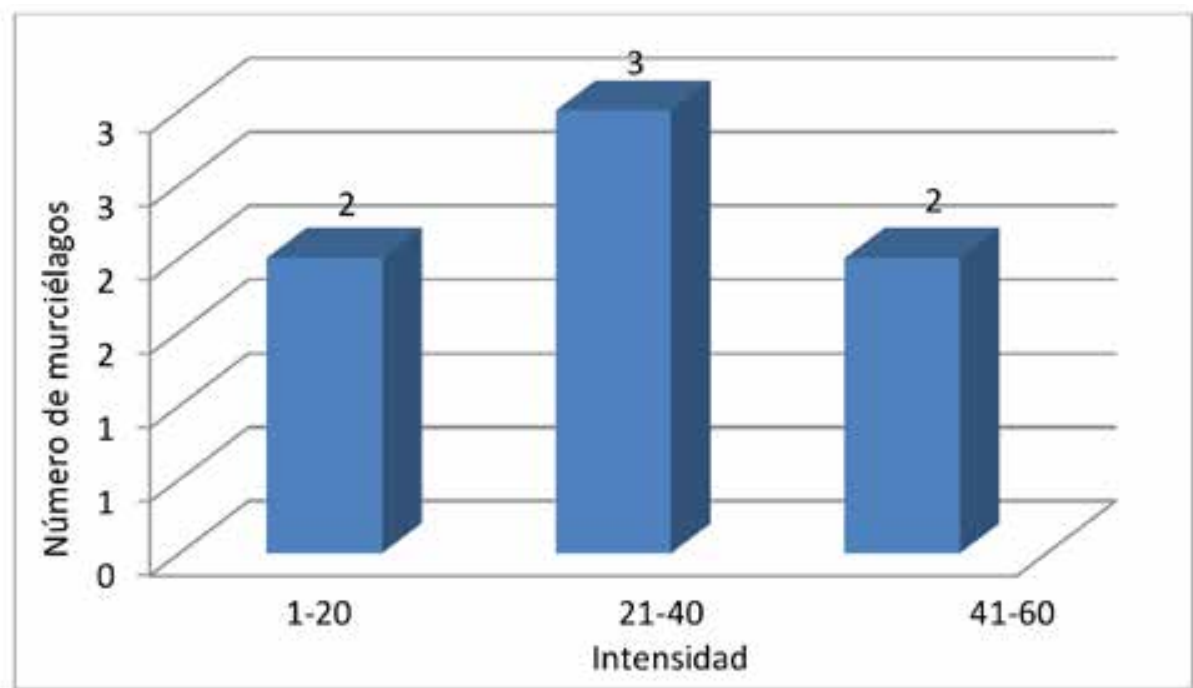

Figura IV.3.3.8. Distribución de frecuencia de intensidad de helmintos parásitos de Myotis cf nigricans. 


\section{Análisis de la Comunidad Componente}

La riqueza específica de Myotis of nigricans fue igual a cuatro. En la Tabla IV.3.3.5 se presentan los valores de los índices ecológicos.

Tabla IV.3.3.5. Índices ecológicos de Myotis cf nigricans.

\begin{tabular}{lc}
\hline \multicolumn{1}{c}{ Índices } \\
\hline Número total de parásitos & 200 \\
Riqueza (S) & 4 \\
Índice de Shannon $\left(\mathrm{H}^{\prime}\right)$ & 1,36 \\
Equitabilidad (J) & 0,98 \\
Dominancia Berger-Parker & 0,33 \\
\hline
\end{tabular}

El índice de Shannon resultó 1,36 y la equitabilidad alcanzó un valor muy cercano a 1 , lo que indica la ausencia de una especie dominante en la comunidad de helmintos parásitos.

\section{Especies centrales, secundarias y satélites}

Ninguna de las especies de helmintos alcanzó el $10 \%$ de prevalencia. Ochoterenatrema labda fue la especie de helmintos con mayor intensidad, aunque con la menor prevalencia (Figura IV.3.3.9).

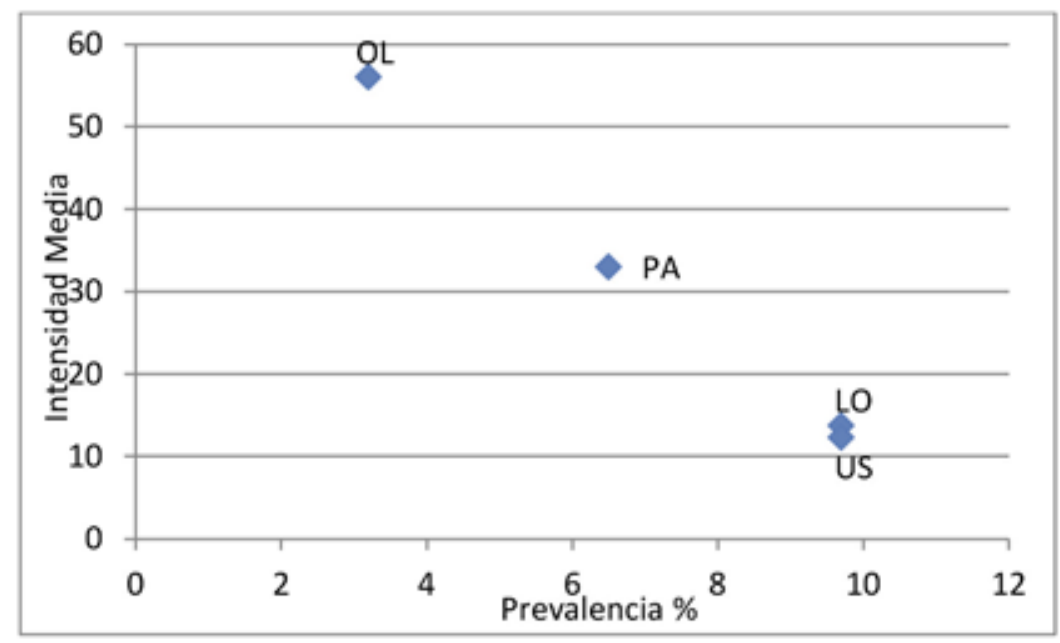

Figura IV.3.3.9. Prevalencia e intensidad media de las especies parásitas de M. cf nigricans. LO: Limatulum oklahomense, OL: Ochoterenatrema labda, PA: Paralecithodendrium aranhai, US: Urotrema scabridum. 


\section{Análisis de la Familia Vespertilionidae}

Se estudiaron un total de 82 ejemplares de tres especies de murciélagos de la familia Vespertilionidae. La riqueza de helmintos parásitos en esta familia fue de siete especies. En la Figura IV.3.3.10 se aprecia el solapamiento de helmintos parásitos respecto a las tres especies hospedadoras evaluadas.

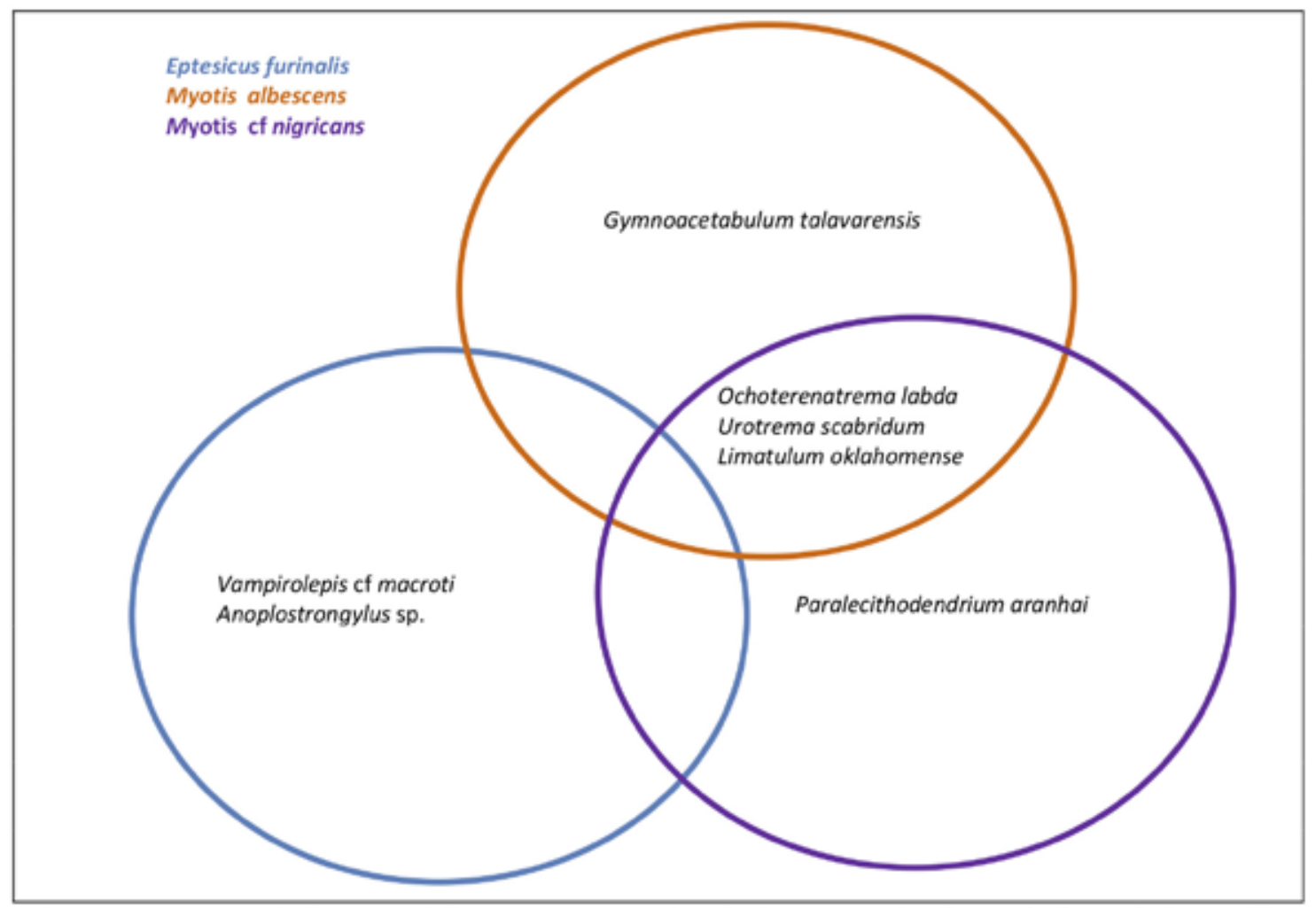

Figura IV.3.3.10. Helmintos parásitos presentes en las distintas especies hospedadoras de la Familia Vespertilionidae.

Se observa que no hay una especie de helminto compartida por las tres especies hospedadoras y que, a su vez, los helmintos presentes en $E$. furinalis no se encuentran en las dos especies de Myotis, que si comparten tres especies de digeneos. Asimismo, $G$. talavarensis está presente solo en $M$. albescens y $P$. aranhai solo en Myotis cf nigricans.

En cada especie hospedadora se registraron distintos valores de infección parasitaria (Tabla IV.3.3.6). 
Tabla IV.3.3.6. Infección parasitaria de la familia Vespertilionidae.

\begin{tabular}{lcccc}
\hline \multicolumn{1}{c}{ Hospedador } & P\% (P/E) & NP & S & $\begin{array}{c}\text { Especie dominante } \\
\text { Índice de Berger-Parker }\end{array}$ \\
\hline VESPERTILIONIDAE & $48,8(40 / 82)$ & 354 & 7 & L. oklahomense; $d=0,35$ \\
\hline E. furinalis & $25(4 / 16)$ & 11 & 2 & Anoplostrongylus sp; $d=0,85$ \\
M. albescens & $82,9(29 / 35)$ & 143 & 4 & L. oklahomense; $d=0,58$ \\
M. cf nigricans & $22,6(7 / 31)$ & 200 & 4 & P. aranhai; $d=0,33$ \\
\hline
\end{tabular}

$\mathrm{P} \%$ : prevalencia; $(\mathrm{P} / \mathrm{E})$ : parsitados/examinados; NP: número de parásitos; S: riqueza

Se aprecia que $M$. albescens fue el hospedador que presentó la mayor prevalencia de infección. A su vez, la especie de helminto dominante fue distinta en cada una de las tres especies de murciélagos, resultando $L$. oklahomense la especie dominante para la totalidad de la familia. Los índices ecológicos se presentan en las especies de hospedadores en las que fueron calculados y en la totalidad de los miembros de la familia Vespertilionidae (Tabla IV.3.3.7).

Tabla IV.3.3.7. Índices ecológicos de los helmintos parásitos de la familia Vespertilionidae.

\begin{tabular}{lccc}
\hline \multicolumn{1}{c}{ Índices } & $\begin{array}{c}\text { Myotis albes- } \\
\text { cens }\end{array}$ & $\begin{array}{c}\text { Myotis cf } \\
\text { nigricans }\end{array}$ & Vespertilionidae \\
\hline Índice de Shannon $\left(\mathrm{H}^{\prime}\right)$ & 1,104 & 1,359 & 1,576 \\
Equitabilidad $(\mathrm{J})$ & 0,796 & 0,980 & 0,809 \\
Dominancia Berger-Parker & 0,580 & 0,330 & 0,354 \\
\hline
\end{tabular}

Entre los hospedadores se aprecia que la diversidad de helmintos parásitos fue levemente mayor en Myotis of nigricans, elevándose el valor en la totalidad de la familia Vespertilionidae. Tanto en las especies hospedadoras como en la totalidad de la familia la equitabilidad fue cercana a 1 lo que indica la ausencia de una especie dominante en la comunidad de helmintos parásitos de Vespertilionidae.

Al evaluar el grado de similaridad se obtuvo que las comunidades de helmintos de las dos especies de Myotis son similares en más de un $50 \%$ (CSS= $75 \%$ ). 


\section{IV.3.4 Análisis de la helmintofauna a nivel Familia}

En la Figura IV.3.4.1 se aprecia el ensamble de helmintos parásitos de las tres familias analizadas. No se observan especies de helmintos comunes a las tres familias de murciélagos. Los murciélagos de la familia Molossidae comparten especies parásitas tanto con filostómidos como con vespertiliónidos, sin embargo no hay especies compartidas entre estas dos últimas familias. Se observa que las dos especies del género Anenterotrema son exclusivas de la familia Molossidae, mientras que Vampirolepis cf macroti lo es de la familia Vespertilionidae.

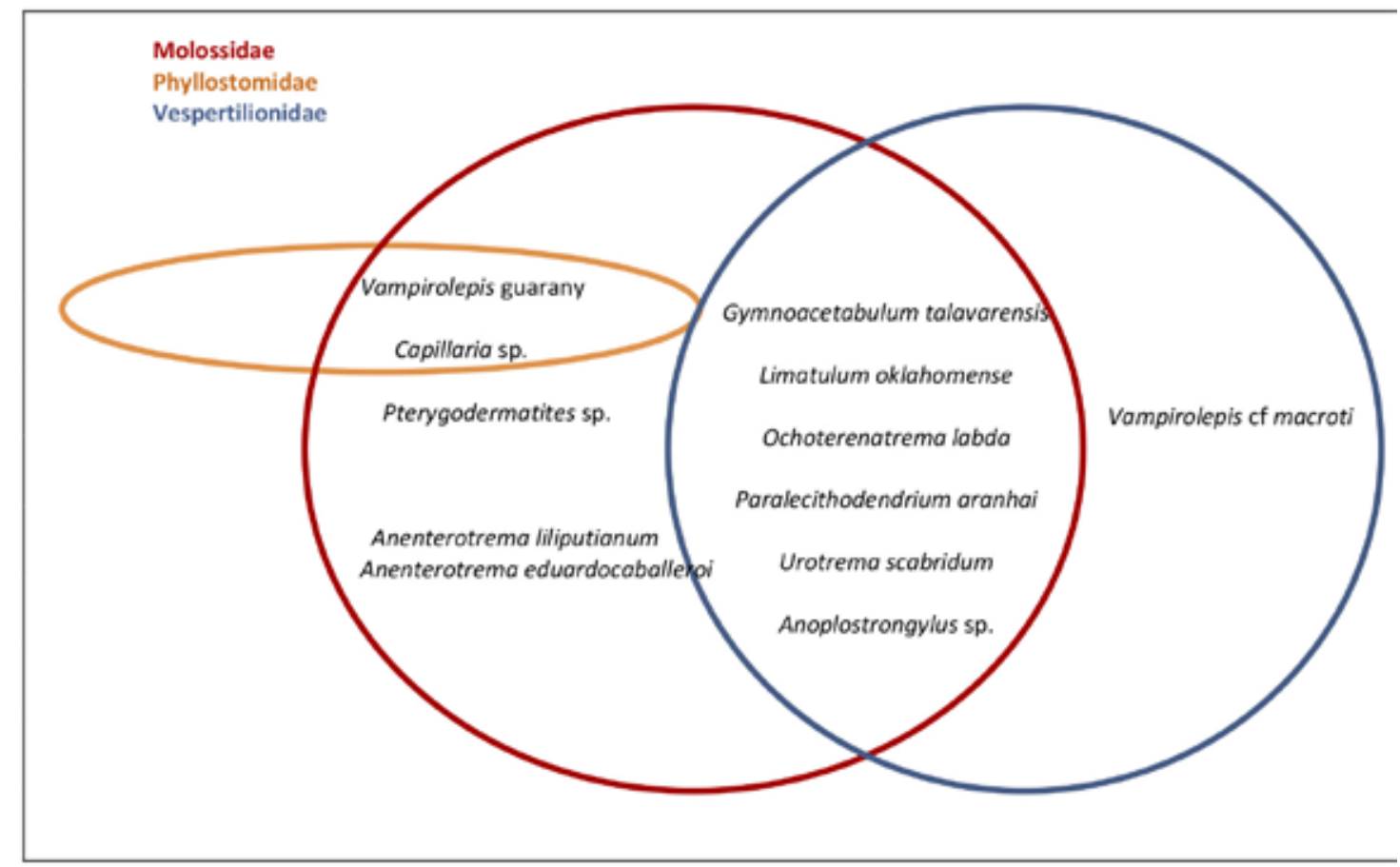

Figura IV.3.4.1. Helmintos parásitos presentes en las distintas familias de murciélagos.

Por otra parte, al comparar la prevalencia de infección de cada especie de helminto parásito se observa una marcada diferencia respecto a L. oklahomense, siendo mayor en Vespertilionidae. A su vez, $V$. guarany y Capillaria sp. presentan valores mayores en Phyllostomidae y G. talavarensis, O. labda, P. aranhai, U. scabridum y Anoplostrongylus sp. en Molossidae (Tabla IV.3.4.1). 
Tabla IV.3.4.1. Prevalencia específica de acuerdo a la familia de hospedadores

\begin{tabular}{|c|c|c|c|}
\hline & & $P \%(P / E)$ & \\
\hline Helminto & Molossidae & Phyllostomidae & Vespertilionidae \\
\hline \multicolumn{4}{|l|}{ CESTODA } \\
\hline V. guarany & $15,31(15 / 98)$ & $26,31(5 / 19)$ & - \\
\hline V. cf macroti & - & - & $1,21(1 / 82)$ \\
\hline \multicolumn{4}{|l|}{ TREMATODA } \\
\hline A. eduardocaballeroi & $2,04(2 / 98)$ & - & - \\
\hline A. liliputianun & $1,02(1 / 98)$ & - & - \\
\hline G. talavarensis & $40,81(40 / 98)$ & - & $7,31(6 / 82)$ \\
\hline L. oklahomense & $1,02(1 / 98)$ & - & $29,26(24 / 82)$ \\
\hline O. labda & $29,59(29 / 98)$ & - & $3,65(3 / 82)$ \\
\hline P. aranhai & $19,38(19 / 98)$ & - & $2,43(2 / 82)$ \\
\hline U. scabridum & $68,36(67 / 98)$ & - & $9,75(8 / 82)$ \\
\hline \multicolumn{4}{|l|}{ NEMATODA } \\
\hline Anoplostrongylus sp. & $24,48(24 / 98)$ & - & $3,7(3 / 82)$ \\
\hline Capillaria sp. & $7,14(7 / 98)$ & $26,31(5 / 19)$ & - \\
\hline Pterygodermatites sp. & $2,04(2 / 98)$ & - & - \\
\hline TOTAL & $81,63(80 / 98)$ & $52,63(10 / 19)$ & $50,0(41 / 82)$ \\
\hline
\end{tabular}

$\mathrm{P} \%$ : prevalencia; $(\mathrm{P} / \mathrm{E})$ : parasitados/examinados

Respecto a la prevalencia general de cada una de las familias se encontraron diferencias estadísticamente significativas, siendo mayor en Molossidae $\left(x^{2}=22,7 ; p<0,0001\right)$.

\section{IV.3.5 Ensamble de la helmintofauna de acuerdo al gremio trófico del hospedador}

Considerando que la parasitofauna está condicionada por el hábito alimenticio se efectuó una comparación entre el grupo de murciélagos insectívoros y el de frugívoros; no se consideró el grupo hematófago por estar representado solo por cuatro individuos en los que no se observaron helmintos. Asimismo, cabe resaltar que el número de individuos evaluados en un caso y otro fue considerablemente distinto (Insectívoros $n=180$ vs. Frugívoros $n=28$ ).

En la Figura IV.3.5.1 se aprecian los taxones registrados para ambos grupos. En el grupo frugívoro solo se detectaron dos especies de helmintos parásitos, las que a su vez, estuvieron presentes entre los insectívoros, no registrándose especies de helmintos exclusivas del grupo frugívoro. 


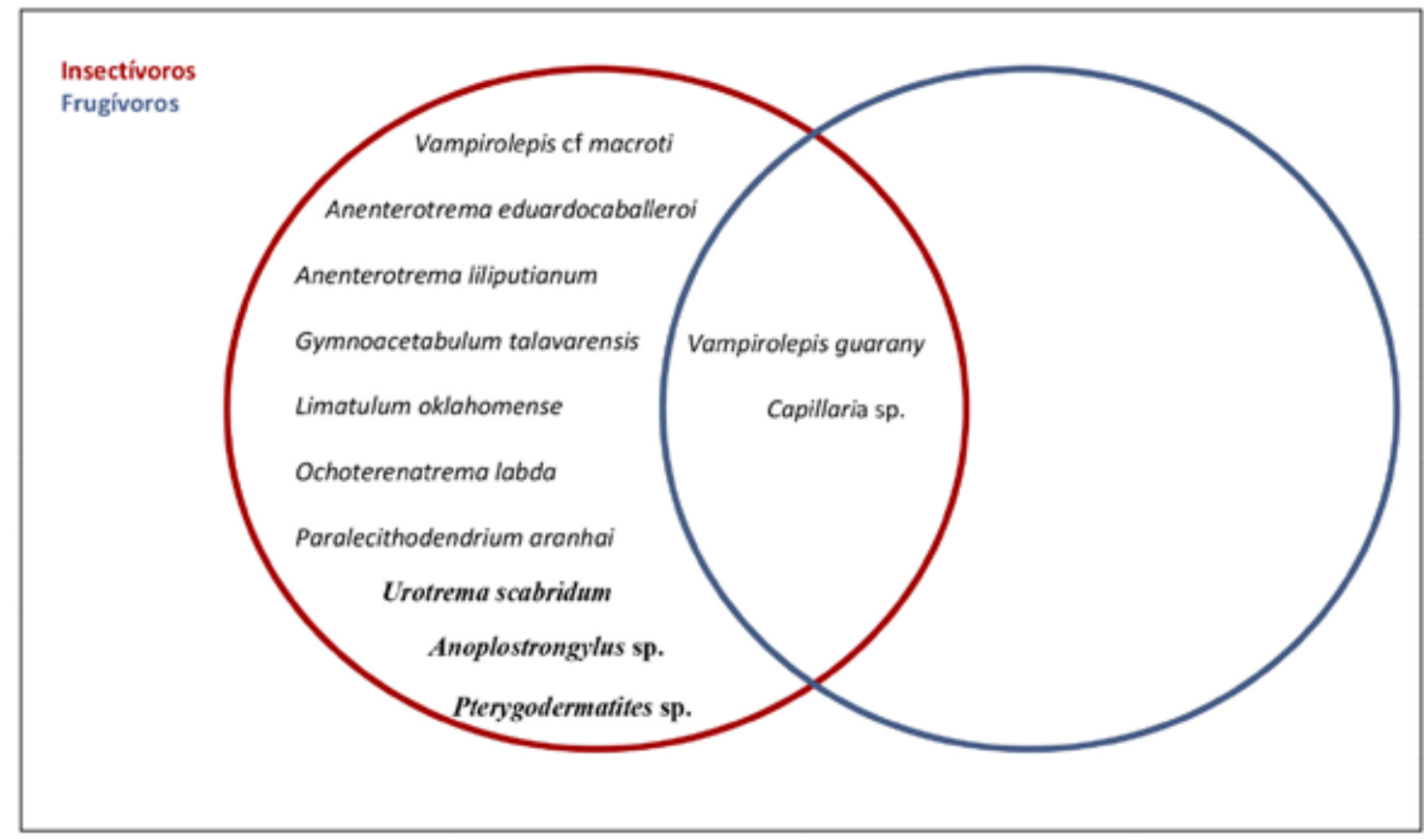

Figura IV.3.5.1. Helmintos parásitos de especies murciélagos insectívoras y frugívoras. Insectívoros: Eumops patagonicus, E. perotis, Molossops temminckii, Molossus molossus, M. rufus, Eptesicus furinalis, Myotis albescens, Myotis cf nigricans. Frugívoros: Artibeus lituratus (no se observaron helmintos parásitos), Platyrrhinus lineatus (no se observaron helmintos parásitos), Sturnira lilium.

En los murciélagos insectívoros estuvieron representados los 12 taxones de helmintos parásitos hallados en el presente estudio, mientras que en los frugívoros solo se observaron dos taxones: V. guarany (Cestoda) y Capillaria sp. (Nematoda). Respecto a las especies de helmintos registradas en los murciélagos insectívoros, salvo Anoplostrongylus sp., todas son heteroxenas, aunque los taxones observados en los murciélagos insectívoros presentan una alternativa de ciclo directo. Si bien los ciclos de vida de los helmintos que parasitan murciélagos son escasamente conocidos, está estudiado que los cestodes y digeneos desarrollan sus estadios larvales en artrópodos que formarían parte de la dieta de los murciélagos como hospedadores definitivos. Cabe resaltar que en el Capítulo III se hizo referencia a cada uno de los ciclos biológicos de los helmintos. En el caso $V$. guarany se registró su presencia en dos especies insectívoras (Molossidae) y una frugívora (Phyllostomidae), observándose que los indicadores parasitológicos fueron diferentes (Tabla IV.3.5.1). 
Tabla IV.3.5.1. Indicadores parasitológicos de Vampirolepis guarany.

\begin{tabular}{lccc}
\hline Especie Hospedadora & $\mathrm{P} \%$ & $\mathrm{IM} \pm \mathrm{DS}$ (rango) & AM $\pm \mathrm{DS}$ \\
\hline Insectívora & & 2 & $0,8 \pm 3,1$ \\
Eumops patagonicus & $19,8(13 / 66)$ & $3,9 \pm 6,1(1-23)$ & $0,2 \pm 0,6$ \\
Molossus rufus & $10,0(2 / 20)$ & 2 & \\
\hline Frugívora & & & $34,6 \pm 50,1$ \\
Artibeus lituratus & $50,0(5 / 10)$ & $69,2 \pm 51,5(21-125)$ & \\
\hline \multicolumn{1}{c}{ P: prevalencia; AM: abundancia media; DS: desvío standard; IM: intensidad media }
\end{tabular}

Es notoria la diferencia existente en todos los valores en $A$. lituratus, resultando una diferencia estadísticamente significativa en la abundancia media entre $A$. lituratus y $E$. patagonicus $(\mathrm{K}=56,3 ; \mathrm{p}=0,01)$ y en la intensidad media entre $A$. lituratus y $M$. rufus (K= $54,02 ; p=0,02)$. No obstante, mientras que en los murciélagos insectívoros se observaron individuos completos, en los frugívoros solo se hallaron escólex con el estróbilo escasamente desarrollado.

\section{IV.3.6. Fauna Parásita Local y Fauna Parásita Regional}

\section{Fauna Parásita Local}

En el presente apartado se efectúa una descripción cualitativa de los helmintos parásitos registrados en las doce localidades relevadas en el presente estudio. En la Figura IV.3.6.1 se aprecia la distribución de las especies de helmintos. Capital y Puerto Valle son las localidades con mayores registros, en ambas localidades se registraron siete especies, que incluyeron cestodes, digeneos y nematodes. Al contrario, en Apóstoles solo se observó una especie de cestode. 


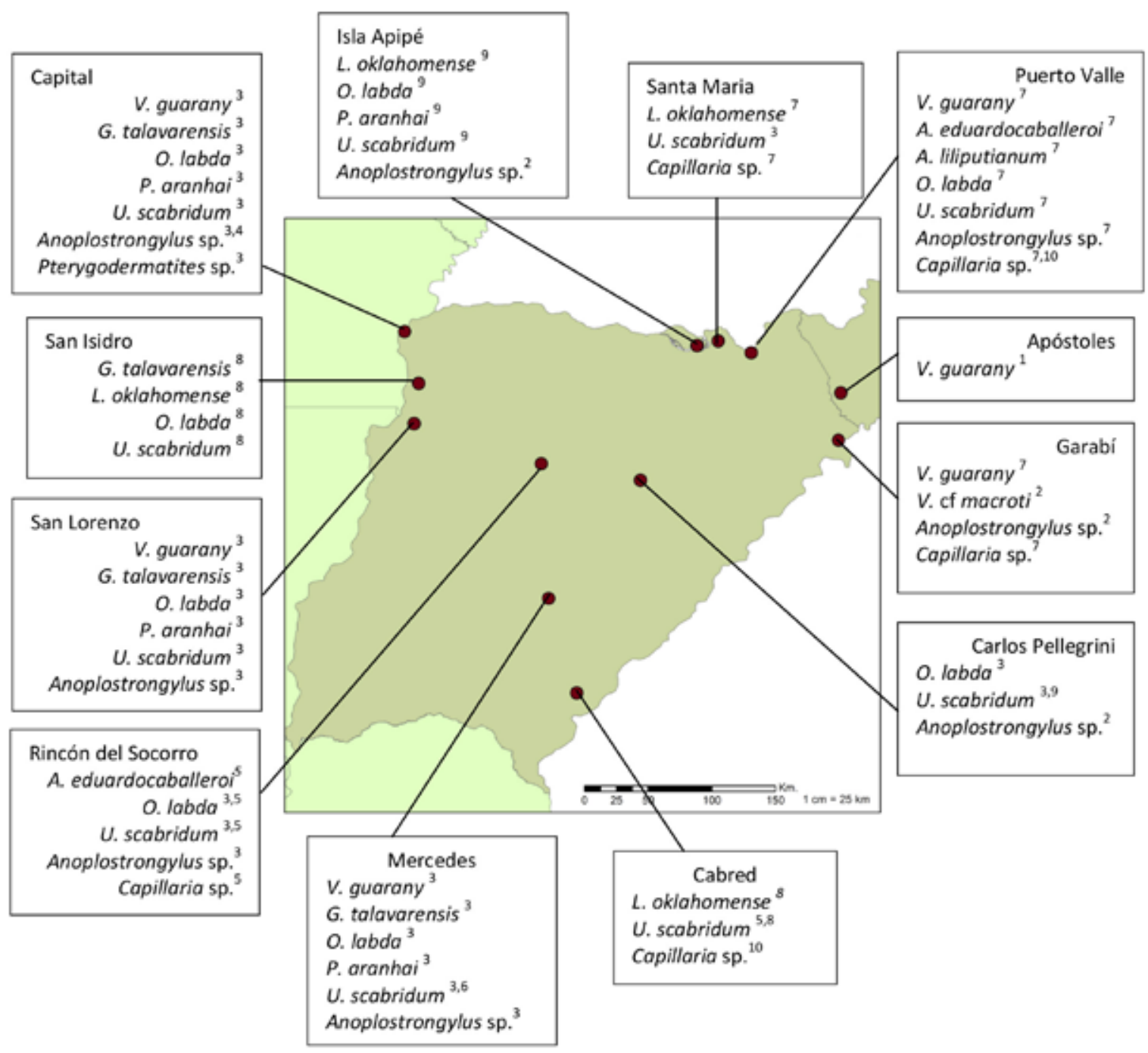

Figura IV.3.6.1. Distribución de las especies de helmintos parásitos de murciélagos de Corrientes y Misiones. Hospedadores: ${ }^{1}$ A. lituratus, ${ }^{2}$ E. furinalis, ${ }^{3}$ E. patagonicus, ${ }^{4}$ E. perotis, ${ }^{5}$ M. temminckii, ${ }^{6}$ M. molossus, ${ }^{7}$ M. rufus, ${ }^{8}$ M. albescens, ${ }^{9}$ M. cf nigricans, ${ }^{10}$ S. lilium.

Urotrema scabridum es la especie mejor representada, presente en diez de las doce localidades evaluadas, seguida por 0 . labda presente en ocho localidades. A excepción de $V$. cf macroti y Ptrygodermatites sp., presentes solo en Garabí y Capital respectivamente, todas las especies fueron halladas en distintas localidades de la extensión relevada. Todos los registros representan nuevas localidades, ampliando la distribución geográfica de los helmintos parásitos. 


\section{Fauna Parásita Regional}

\section{Riqueza de especies y distribución geográfica del hospedador}

Respecto a las especies de helmintos en molósidos se observa que Molossus molossus presenta 24 especies de helmintos como registro previo y en el presente estudio se halló una de ellas y además se cita por primera vez para Argentina la asociación Urotrema scabridum-M. molossus. Para Molossus rufus están registradas nueve especies de helmintos, en el presente trabajo se hallaron cuatro de ellas y además se adicionaron cuatro nuevas asociaciones, elevando a 13 la riqueza específica de este hospedador; a excepción de $U$. scabridum, todos las asociaciones parásito-hospedador halladas en este trabajo son novedades para Argentina. Para Molossops temminckii están registradas siete especies de helmintos, en el presente trabajo se halló una de ellas y se adicionaron tres nuevos registros, elevando a 10 la riqueza específica de este hospedador; Anenterotrema eduardocaballeroi y Ochoterenatrema labda representan nuevas asociaciones para este hospedador y nuevo registro para Argentina. En el caso de Eumops perotis se registra una nueva asociación con Anoplostrongylus sp., elevando a 5 la riqueza específica, siendo además un registro novedoso para Argentina. Respecto a E. patagonicus se registró una de las cuatro especies previamente citadas para este hospedador y se adicionaron seis nuevos registros, elevando a 10 su riqueza específica, todos representan registros novedosos para Argentina.

En relación a la distribución geográfica se espera una mayor riqueza de parásitos en los hospedadores de mayor distribución, hecho que se verifica en $M$. molossus, $M$. rufus y $M$. temminckii. Entre las dos especies de Eumops se observan diferencias en sentido contrario, probablemente debido a los escasos estudios en estos hospedadores (Figura IV.3.6.2). 


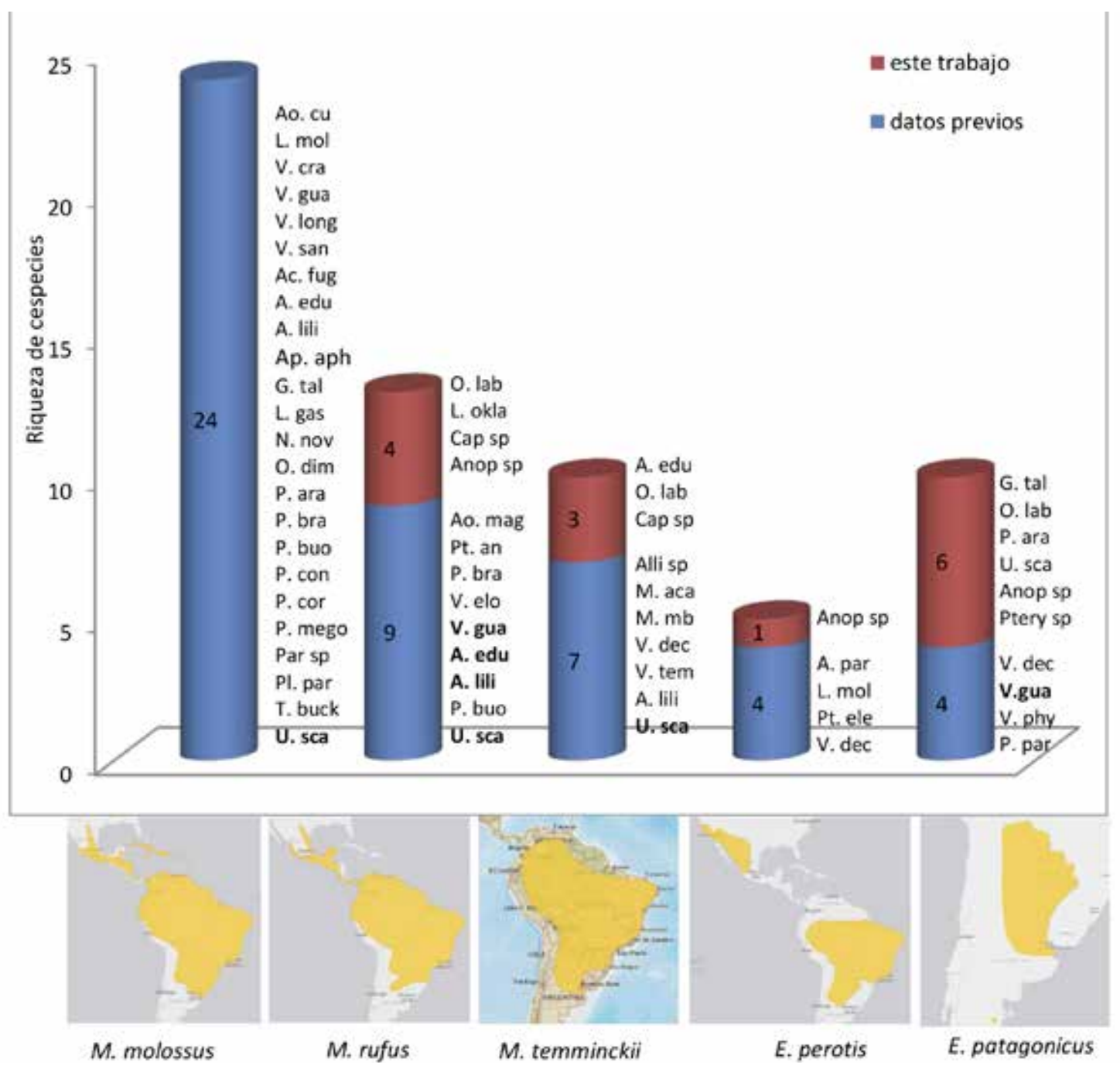

Figura IV.3.6.2. Riqueza de especies de helmintos parásitos en relación a la distribución geográfica de los molósidos estudiados. Negrita: registros coincidentes. Ac. fug: Acanthatrium fugleri, A. edu: Anenterotrema eduardocaballeroi, A. lili: Anenterotrema liliputianun, Alli sp.: Allintoshius sp., Anop sp: Anoplostrongylus sp., A. par: Anoplostrongylus paradoxus, Ao. cu: Aonchotheca cubana, Ao. mag: Aonchotheca magnifica, Ap. aph: Apharyngotrema apharyngotrema, Cap sp: Capillaria sp., G. tal: Gymnoacetabulum talavarensis, L. mol: Litomosoides molossi, L. okla: Limatulum oklahomense, L. gas: Limatulum gastroides, M. aca: Molostrongylus acantholpos, M. mb: Molostrongylus mbopi, N. nov: Nudacotyle novicia, O. dim: Ochoterenatrema diminutum, O. lab: Ochoterenatrema labda, P. ara: Paralecithodendrium aranhai, P. bra: Paralecithodendrium brachycolon, P. buo: Paralecithodendrium buongerminni, P. con: Paralecithodendrium conturbatum, P. cor: Paralecithodendrium cordiforme, P. mego: Paralecithodendrium megovarium, Par sp.: Paralecithodendrium sp., P. par: Postorchigenes paraguayensis, PI. par: Plagiorchis parumbursatus, Pt. an: Pterothomix angrensis, Pt. ele: Pterygodermatites elegans, Ptery sp: Pterygodermatites sp., T. buck: Tremajoannes buckleyi, U. sca: Urotrema scabridum, V. cra: Vampirolepis crassihamata, V. dec: Vampirolepis decipiens, V. elo: Vampirolepis elongatus, V. gua: Vampirolepis guarany, V. long: Vampirolepis longisaccata, V. phy: Vampirolepis phyllostomi, V. san: Vampirolepis santacruzensis, V. tem: Vampirolepis temminckii. 
En cuanto a la fauna de helmintos asociada a murciélagos de la familia Phyllostomidae, en la Figura IV.3.6.3 se aprecian los registros previos y los aportes del presente estudio.

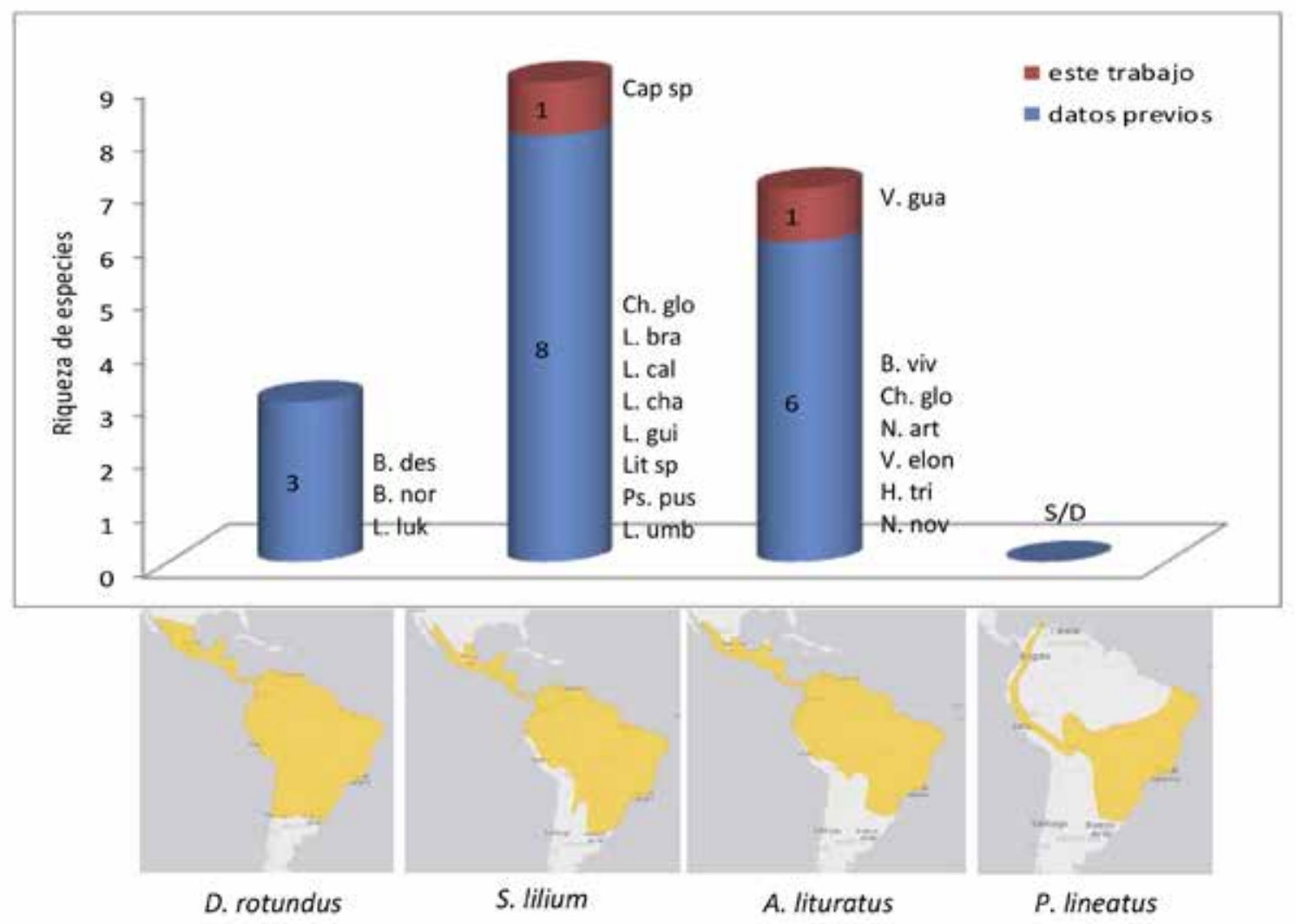

Figura IV.3.6.3. Riqueza de especies de helmintos parásitos en relación a la distribución geográfica de los filostómidos estudiados. S/D sin datos. B. des: Biacantha desmoda, B. nor: Biacantha normaliae, B. viv: Bidigiticauda vivípara, Cap sp: Capillaria sp., Ch. glo: Cheiroptema globocephala, H. tri: Hasstilesia tricolor, L. bra: Litomosoides brasiliensis, L. cal: Litomosoides caliensis, L. cha: Litomosoides chandleri, Lit sp: Litomosoides sp., L. luk: Lukonema lokoschusi, L. umb: Limatulum umbilicatum, N. art: Neoncicola artibei, N. nov: Nudacotyle novicia, Ps. pus: Pseudocapillaria pusilla, V. elo: Vampirolepis elongata, V. gua: Vampirolepis guarany

Se observan dos aportes que se adicionan a la riqueza de Sturnira lilium y Artibeus lituratus, los mismos son nuevos registros para Argentina y elevan la riqueza específica de estas especies de murciélagos a 9 y 7 , respectivamente. Respecto a la única especie hematófaga evaluada ( $D$. rotundus) se registran tres especies de helmintos que, en relación a la distribución del hospedador, resulta un número bajo, probablemente debido a las restricciones provenientes del hábito alimenticio; en el presente estudio no se observaron helmintos parásitos. En cuanto a Platyrrhinus lineatus no existen registros previos y en el presente estudio no se hallaron helmintos parásitos; al respecto se presenta un interrogante que deberá ser resuelto en futuras investigaciones. 
La fauna de helmintos asociados a murciélagos de la familia Vespertilionidae se aprecia en la Figura IV.3.6.4.

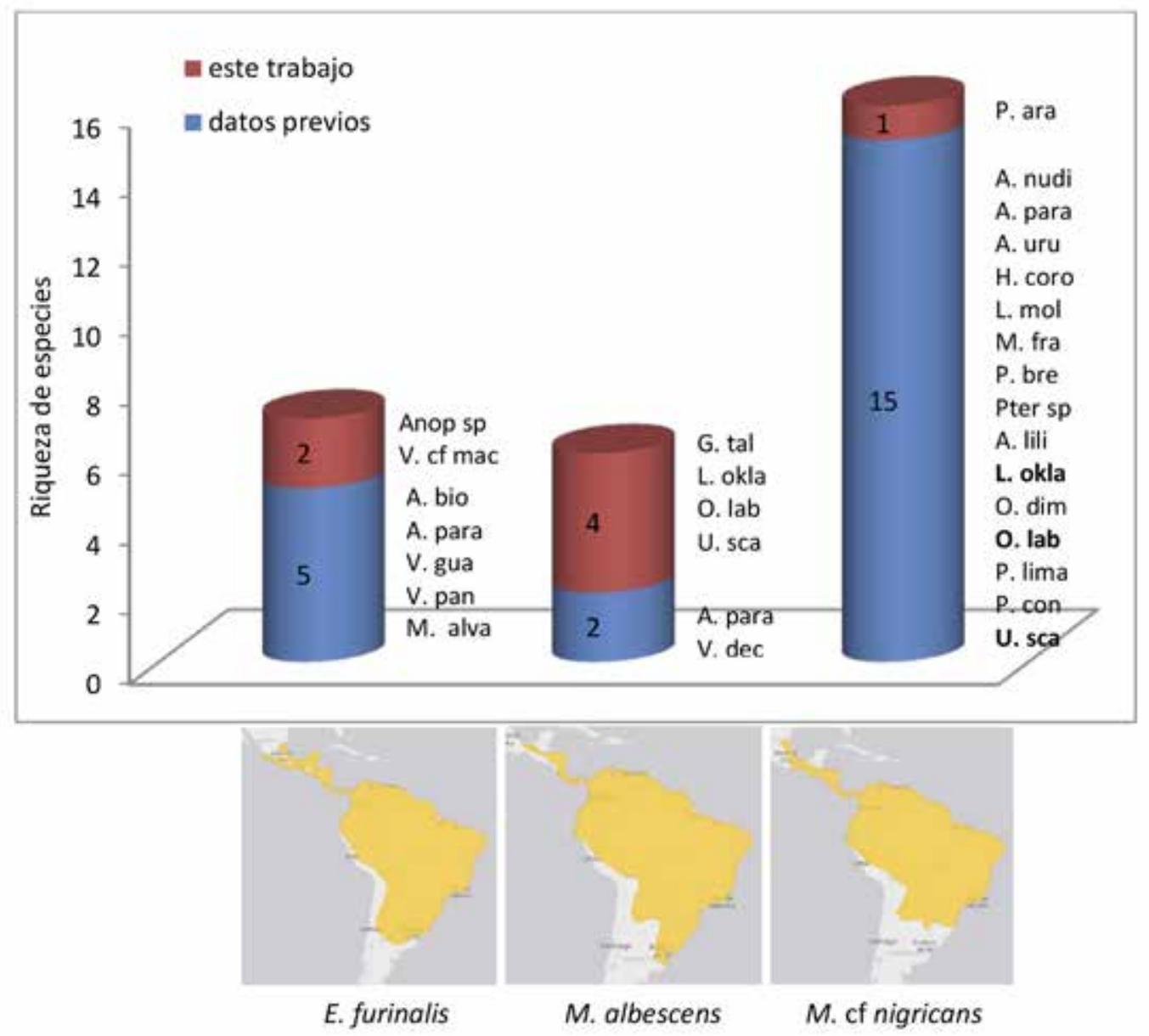

Figura IV.3.6.4. Riqueza de especies de helmintos parásitos en relación a la distribución geográfica de los vespertiliónidos estudiados. A. bio: Allintoshius bioccai, A. lili: Anenterotrema liliputianum, Anop sp: Anoplostrongylus sp., A. nuri: Allintoshius nudicaudatus, A. para: Allintoshius parallintoshius, A. uru: Allintoshius urumiac, G.tal: Gymnoacetabulum talavarensis, H. coro: Histiostrongylus coronatus, L. mol: Litomosoides molossi, L. okla: Limatulum oklahomense, M. alva: Metadelphis alvarengai, M. fra: Migonella fracchiai, $\mathrm{O}$. dim: Ochoterenatrema diminutum, O. lab: Ochoterenatrema labda, P. ara: Paralecithodendrium aranhai, P. bre: Pterothominx brevidelphis, P. con: Paralecithodendrium conturbatum, P. lima: Parabascus limatulum, Pter sp: Pterygodermatites sp., V. dec: Vampirolepis decipiens, V. gua: Vampirolepis guarany, V. cf mac:

Vampirolepis of macroti, V. pan: Vampirolepis pandonensis, U. sca: Urotrema scabridum. 
Entre los verpertiliónidos se observan cinco especies de helmintos parásitos registradas previamente para Eptesicus furinalis, en el presente trabajo se identificaron dos taxones que aumentan la riqueza específica de esta especie hospedadora a siete. Ambos hallazgos representan nuevas asociaciones hospedador/parásito y representan nuevos registros para Argentina. En el caso de Myotis albescens, en el presente trabajo se registraron cuatro taxones de helmintos parásitos, todos nuevas asociaciones hospedador/ parásito y nuevos registros para Argentina, los mismos se suman a las dos especies de helmintos previamente citadas para este hospedador, elevando la riqueza de dos a seis especies. Respecto a Myotis of nigricans se observan registros previos de 15 taxones de helmintos parásitos. En el presente trabajo se registran tres de los taxones previamente mencionados y se adiciona uno nuevo, elevando la riqueza específica de este hospedador a 16 taxones. A excepción de U. scabridum, las otras tres especies encontradas son nuevos registros para Argentina.

Teniendo en cuenta la distribución geográfica del hospedador se observa que el mayor número de helmintos parásitos corresponde a la especie hospedadora de menor distribución geográfica. Hecho que podría adjudicarse a un mayor caudal de investigaciones al respecto.

\section{IV.4. Discusión y conclusiones}

Ciento treinta de los 212 murciélagos evaluados presentaron helmintos parásitos, lo que representa una prevalencia general de $61,3 \%$, siendo Trematoda el grupo más prevalente y abundante, hecho que coincide con estudios similares sobre murciélagos de hábitos insectívoros, como lo son la mayoría de los especímenes evaluados en el presente trabajo (Foster y Mertins, 1996; Esteban et al., 2001; Pesenti et al., 2015). Dicho grupo de helmintos estuvo ausente en los murciélagos frugívoros, lo que nos lleva a realizar una primera distinción cualitativa condicionada por el hábito alimenticio.

En este sentido, se establecieron diferencias entre murciélagos insectívoros y frugívoros. Todos los trematodes son de ciclo heteroxeno, lo que implica la participación de invertebrados que actúan como hospedadores intermediarios que sirven de alimento a los mamíferos insectívoros, por lo que es de esperar que la fauna de helmintos sea distinta entre ambos grupos. Así, se comprobó que los frugívoros no presentaron trematodes; se identificaron un cestode ( $V$. guarany) y un nematode (Capillaria sp.), ambos de ciclo heteroxeno con alternativa de ciclo directo, lo que posibilita la transmisión sin mediar el consumo de insectos y explica su presencia. Aunque, por otra parte, es de destacar el hecho de que es conocido el consumo de insectos como complemento de proteínas en la dieta de los murciélagos frugívoros (Gardner, 1977; Thomas, 1984), lo que posibilitaría una transmisión indirecta, aunque también encontraríamos trematodes tal como lo reporta Nogueira et al. (2004) en murciélagos frugívoros de Brasil, hecho que, al no ocurrir, refuerza la hipótesis de una transmisión directa de los helmintos hallados en el presente 
trabajo. Asimismo, llama la atención la elevada intensidad de infección que se observó para $V$. guarany en los individuos frugívoros, no obstante los helmintos presentaron un escaso o nulo desarrollo del estróbilo por lo que se sugiere una baja adaptación del cestode al hospedador.

Por otra parte, al analizar la riqueza de especies a nivel de las dos familias de murciélagos insectívoros, cuyo número de individuos evaluados permite una comparación válida, se esperarían resultados similares ya que comparten el mismo gremio trófico. Sin embargo, se observa que en los molósidos se hallaron 11 de los 12 taxones de helmintos registrados en el presente trabajo vs. siete taxones en los vespertiliónidos. Los componentes diferenciales entre ambas familias se observan en las dos especies de Anenterotrematidae (Trematoda), en V. guarany (Cestoda) y en Capillaria sp. y Pterygodermatites sp. (Nematoda) que aparecen como exclusivas de los molósidos. Los helmintos mencionados presentan ciclo heteroxenos. En este sentido, la diferencia podría deberse a que los artrópodos que actúan como hospedadores intermediarios son diferencialmente consumidos entre ambas familias de murciélagos. Estudios efectuados en Molossus molossus (Molossidae) de Colombia dan cuenta de que los coleópteros son el principal componente en su dieta, representando el $46,1 \%$ del total de las presas; en contraposición estudios realizados en Rhogessa minutilla (Vespertilionidae) de Venezuela mencionan a los dípteros como presa principal representando el 42,5\% del total (Ramírez-Chaves et al., 2008; Sosa et al., 1996). No obstante, el recurso disponible en el área sería un condicionante en la selección de las presas por lo que son necesarios estudios locales para dilucidar este aspecto.

Del presente trabajo surge que $A$. eduardocaballeroi, A. liliputianum y Pterygodermatites sp. son exclusivas de la familia Molossidae, mientras $V$. cf macroti lo es de la familia Vespertilionidae. En este sentido, si consideramos el nivel familia de hospedadores como punto de corte para definir especies de helmintos generalistas o especialistas, Limatulum oklahomense, U. scabridum, los Lecithodendriidae (G. talavarensis, O. labda y $P$. aranhai), Vampirolepis guarany, Anoplostrongylus sp. y Capillaria sp. serían generalistas y los Anenterotrematidae (A. liliputianun y A. eduardocaballeroi), Vampirolepis of macroti y Pterygodermatites sp. serían especialistas.

Al comparar las especies de helmintos compartidas entre las familias, se observa que todas presentan mayores valores de prevalencia, abundancia e intensidad en la familia Molossidae, a excepción de Limatulum oklahomense, que parecería tener mayor afinidad con los vespertiliónidos. En coincidencia, en Argentina se la encontró asociada únicamente a Myotis nigricans (Vespertilionidae) (Lunaschi et al., 2003). Sin embargo, en Florida (USA) y Brasil L. oklahomense ha sido reportada en molósidos con prevalencias que varían entre 22,5 y 67\%, aunque con intensidades bajas (Foster y Mertins, 1996; Pesenti et al., 2015). En este sentido se remarca la necesidad de ampliar la muestra de estudio a fin de dilucidar este aspecto con mayor precisión. 
Entre los molósidos, el hospedador con mayor riqueza específica fue Molossus rufus $(S=8)$ seguido de Eumops patagonicus $(S=7)$; si bien se trata de poca diferencia cuantitativa, cualitativamente existen solo cuatro taxones compartidos, hecho que se refleja en un grado de similaridad menor a 50\%. Asimismo, si comparamos los indicadores parasitológicos de los helmintos compartidos en cada hospedador, se observa que los valores observados en E. patagonicus superan ampliamente a los observados en $M$. rufus, no obstante la diversidad fue mayor en este último hospedador. En ambos hospedadores, al igual que en las otras especies de molósidos la especie de helminto de mayor prevalencia, abundancia e intensidad media y dominante fue $U$. scabridum, alcanzando un valor cercano al $70 \%$ de prevalencia a nivel de familia Molossidae, en coincidencia con lo verificado por Lunaschi y Notarnicola (2010) para dos especies de molósidos de Argentina. Sin embargo, estudios en otro molósido muestra que los valores de prevalencia para Tadarida brasiliensis, no superan el $27 \%$ y la abundancia e intensidad media son bajas (Foster y Mertins, 1996; Pesenti et al., 2015). Teniendo en cuenta que U. scabridum posee una amplia distribución geográfica y de hospedadores es probable que las variaciones estén relacionadas con condiciones locales que favorecen la presencia y abundancia de los hospedadores intermediarios. Por otra parte, tal como se resalta en el capítulo III, es necesario profundizar en la taxonomía de este taxón.

Entre los vespertiliónidos se verificó una marcada diferencia entre Eptesicus furinalis y las dos especies de Myotis, de modo que no comparten ninguna especie de helminto. Ambas especies de Myotis presentaron solo trematodes mientras que en $E$. furinalis se observaron cestodes y nematodes. En estudios previos se registraron nematodes y cestodes para $M$. albescens y $M$. cf nigricans y trematodes para $E$. furinalis por lo tanto es posible que aumentando el tamaño de la muestra se hallen nuevos taxones de helmintos (Thatcher, 1993; Santos y Gibson, 2015). No obstante, cabe resaltar que E. furinalis pertenece a la subfamilia Vespertilioninae, distinta a la de Myotis (Myotinae) de modo que podría pensarse en la existencia de una barrera filogenética, aunque existen registros de helmintos en común entre ambas subfamilias, por lo tanto se descartaría esa posibilidad.

Asimismo, las dos especies del género Myotis comparten tres de las cuatro especies de helmintos. No obstante, estas tres especies de trematodes fueron halladas también entre los molósidos por lo que no es posible definirlas como específicas, más aun teniendo en cuenta que dichos helmintos poseen un amplio rango de hospedadores y distribución geográfica (Santos y Gibson, 2015). Por otra parte, la especie dominante fue diferente en cada especie hospedadora, resultando L. oklahomense la dominante a nivel de familia.

La localización de los helmintos fue predominantemente intestinal, a excepción de $L$. oklahomense con localización exclusivamente estomacal. Al analizar la localización intestinal se observa que la distribución fue distinta para cada taxón. Así, como se esperaba los cestodes se ubican exclusivamente en el intestino delgado; los nematodes (cuya localización es diversa) también se ubicaron exclusivamente en el intestino delgado mientras que los trematodes lo hicieron tanto en el intestino delgado como grueso, a excepción 
de Anenterotrema liliputianum que se localizó únicamente en la última porción intestinal. Se observa, además, que $P$. aranhai tiene una preferencia por el intestino delgado.

A nivel de infracomunidad se observaron infecciones mono y biespecíficas como predominantes, salvo en Eumops patagonicus cuya proporción de infecciones múltiples (tres a cinco especies) fue elevada. Todos los helmintos presentaron distribución agregada, reflejada en la intensidad de infección que fue elevada en unos pocos individuos hospedadores, hecho esperable ya que responde al comportamiento de las poblaciones parásitas que afectan en mayor medida a individuos más susceptibles (Esch y Fernández, 1993). En E. patagonicus se comprobó una interacción parasitaria positiva principalmente entre Gymnoacetabulum talavarensis con una especie de cestode (Vampirolepis guarany) y otras dos especies de trematodes (Paralecithodendrium aranhai y Urotrema scabridum), lo que sugiere que este taxón puede convivir y desarrollarse exitosamente en presencia de otros helmintos y que, a su vez, no sería competencia para el desarrollo de sus convivientes.

Respecto a la relación entre el sexo y los indicadores parasitológicos se observó diferencia significativa respecto a la intensidad media registrada únicamente en los machos de E. patagonicus. Hecho que podría explicarse porque los machos recorren mayores distancias que las hembras por lo tanto poseen un home range más amplio, lo que aumenta la posibilidad de consumo de presas portadoras de estadios infectantes (en virtud de que la mayoría de los helmintos hallados presentan ciclo heteroxeno) y su consecuente posibilidad de infección (Kunz y Fenton, 2003).

En cuanto a la relación entre el tamaño y los indicadores parasitológicos se observaron relaciones inversas significativas tanto con la intensidad de infección general como con algunas específicas en $E$. patagonicus y solamente con la intensidad de infección de U. scabridum en Molossus rufus y Myotis albescens. Era de esperar que los individuos más grandes reflejen mayores intensidades, sin embargo en el presente estudio se observó lo contrario, en este sentido se hace necesario profundizar en el análisis de las variables estudiadas para lograr resultados concluyentes.

Solo se pudo establecer especies centrales, secundarias y satélites al analizar la comunidad de helmintos de E. patagonicus, definiendo a U. scabridum como especie central a Pterygodermatites sp. como satélite y el resto (Vampirolepis guarany, Gymnoacetabulum talavarensis, Ochoterenatrema labda, Paralecithodendrium aranhai y Anoplostrongylus sp.) resultaron especies secundarias. Si bien, no se conocen trabajos con análisis similares por lo que resulta dificultoso comparar, se podrían tomar como referencia los valores de prevalencia e intensidad y abundancia media aportados por algunos autores para molósidos. Así, entre los trematodes, U. scabridum no presenta valores elevados, sin embargo Ochoterenatrema labda se presenta con prevalencias entre 61,3 y $71,8 \%$ y abundancias medias entre 14,2 y 29,3, posicionándose como una posible especie central en Tadarida brasiliensis (Molossidae) de México y Brasil (Guzmán-Cornejo et al., 2003; Pesenti et al., 2015); ente los nematodes la baja prevalencia e intensidad de Pterygodermatites sp. coincide con lo reportado para Eumops perotis de las Yungas argentinas (Oviedo inéd.). 
La presencia de la mayoría de los helmintos en distintas localidades de la provincia de Corrientes estaría indicando que el factor condicionante sería el hospedador y no el ambiente, hecho que se confirma al conocer otros registros en distintas áreas del neotrópico. No obstante, es necesario efectuar un análisis más completo y profundo que permita diferenciar los ambientes locales y obtener conclusiones sobre este aspecto.

Al integrar los resultados de esta investigación con la información previa y contextualizar en la distribución geográfica del hospedador, considerando la teoría de islas (MacArthur y Wilson, 1967), se esperaba que las especies de murciélagos de mayor distribución posean una fauna de helmintos más rica, hecho que se verificó entre los molósidos en Molossus molossus, Molossus rufus y Molossops temminckii y entre los filostómidos en Sturnira lilium. Al contrario, entre los vespertiliónidos Myotis cf nigricans es el que mayor riqueza de helmintos posee siendo el murciélago de menor distribución geográfica entre los estudiados en el presente trabajo. Al respecto, cabe señalar que la mayoría de la información proviene de registros aislados y los trabajos sistematizados para el estudio de helmintos de quirópteros son escasos, lo que impide un análisis concluyente.

A nivel de Neotrópico, los resultados obtenidos en el presente trabajo permiten ampliar el espectro de helmintos de nueve especies de murciélagos, elevando la riqueza de helmintos específica de cuatro especies de molósidos (Eumops patagonicus, E. perotis, Molossops temminckii y Molossus rufus), dos especies de filostómidos (Artibeus lituratus y Sturnira lilium) y tres especies de vespertiliónidos (Eptesicus furinalis, Myotis albescens y Myotis of nigricans).

Entre los aportes del presente trabajo se destaca la mención de 23 nuevas asociaciones hospedador/parásito. Respecto a los molósidos: se adicionan a la lista seis taxones a E. patagonicus (Gymnoacetabulum talavarensis, Ochoterenatrema labda, Paralecithodendrium aranhai, Urotrema scabridum (Trematoda), Anoplostrongylus sp. Pterygodermatites sp. (Nematoda), cuatro a M. rufus (Limatulum oklahomense, Ochoterenatrema labda (Trematoda), Anoplostrongylus sp., Capillaria sp. (Nematoda), tres a M. temminckii (Anenterotrema eduardocaballeroi, O. labda (Trematoda), Capillaria sp.) y uno a E. perotis (Anoplostrongylus sp.) Respecto a los filostómidos: se adiciona un taxón a Artibeus lituratus (V. guarany) y uno a S. Iilium (Capillaria sp.). En referencia a los vespertiliónidos se adicionan cuatro taxones a Myotis Albescens (G. talavarensis, L. oklahomense, $O$. labda, U. scabridum (Trematoda), una a Myotis cf nigricans (P. aranhai) y dos a Eptesicus furinalis (Vampirolepis of macroti (Cestoda), Anoplostrongylus sp.).

Al enfocar estos resultados con una perspectiva a nivel local, se pone de relieve la contribución del presente estudio al conocimiento de los murciélagos de Argentina, ya que albergando el 49,18\% (unas 30 especies) de la diversidad de murciélagos del país, Corrientes es una de las provincias de la Mesopotamia con menos estudios realizados sobre estos mamíferos (Barquez, 2004) y la helmintofauna asociada a ellos era desconocida hasta el presente. Por primera vez se mencionan helmintos asociados a murciélagos de Corrientes y se analizan características ecológicas de la asociación parásito/hospedador. 


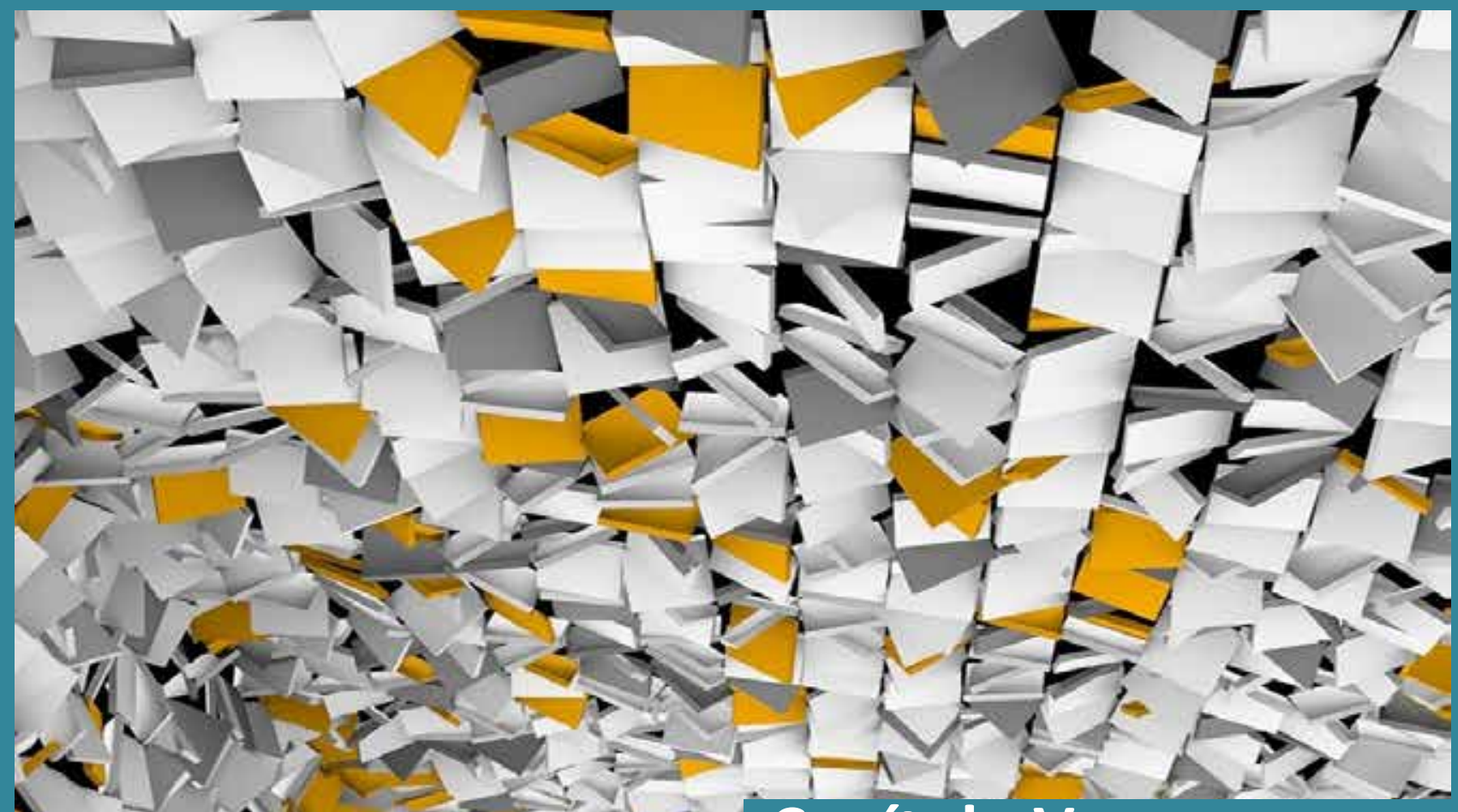

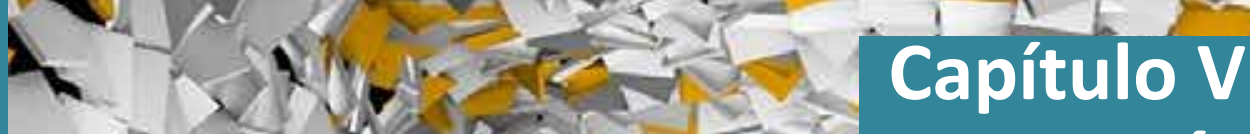

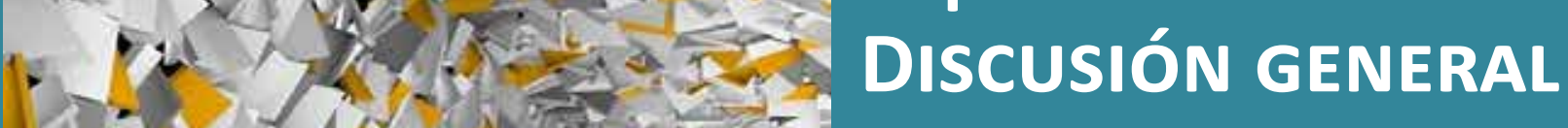
$1.1,7$ N Y Y CONCLUSIONES

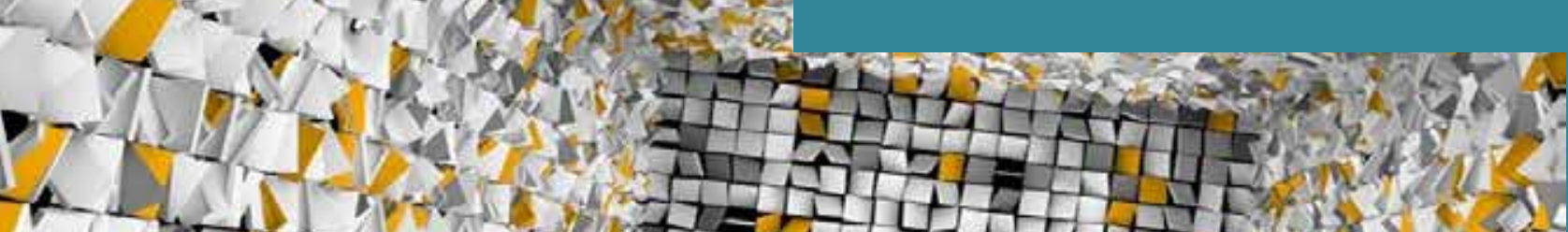
A-tur $21-3 \mathrm{~m}$ की

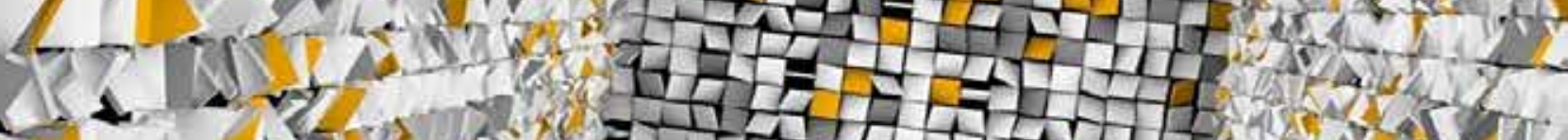

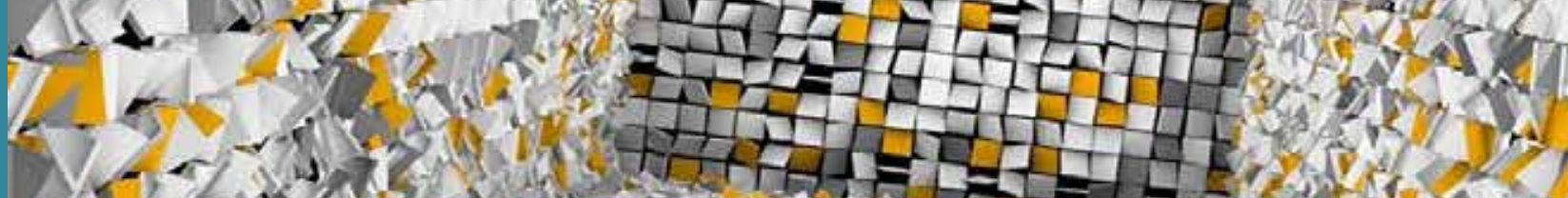

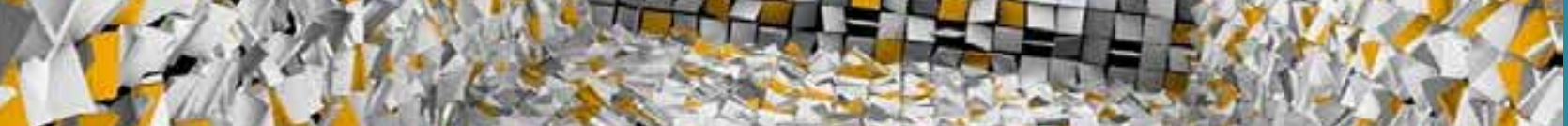

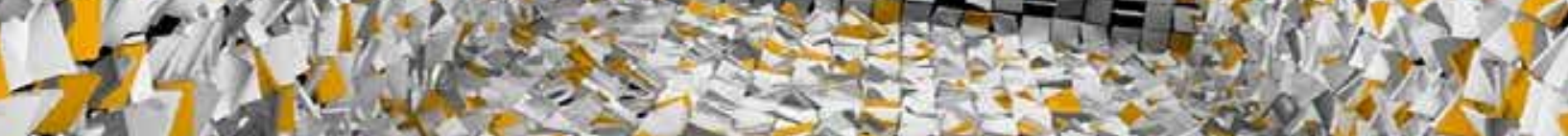

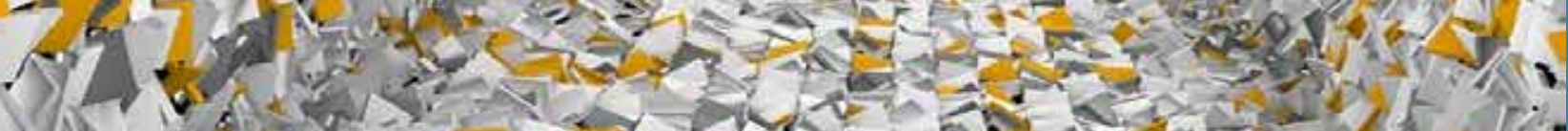
L.

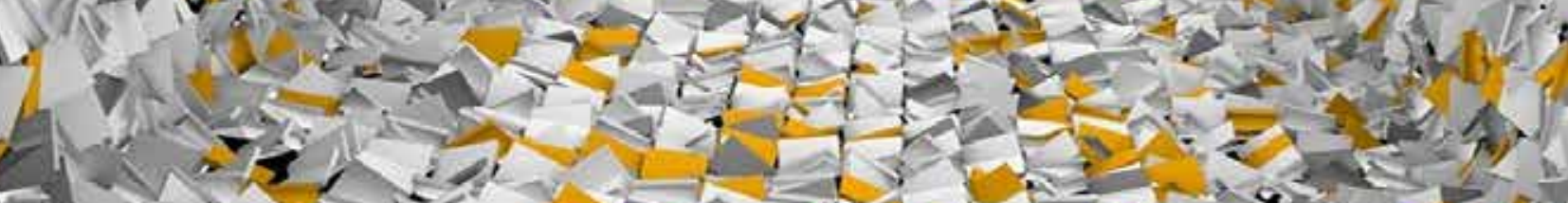

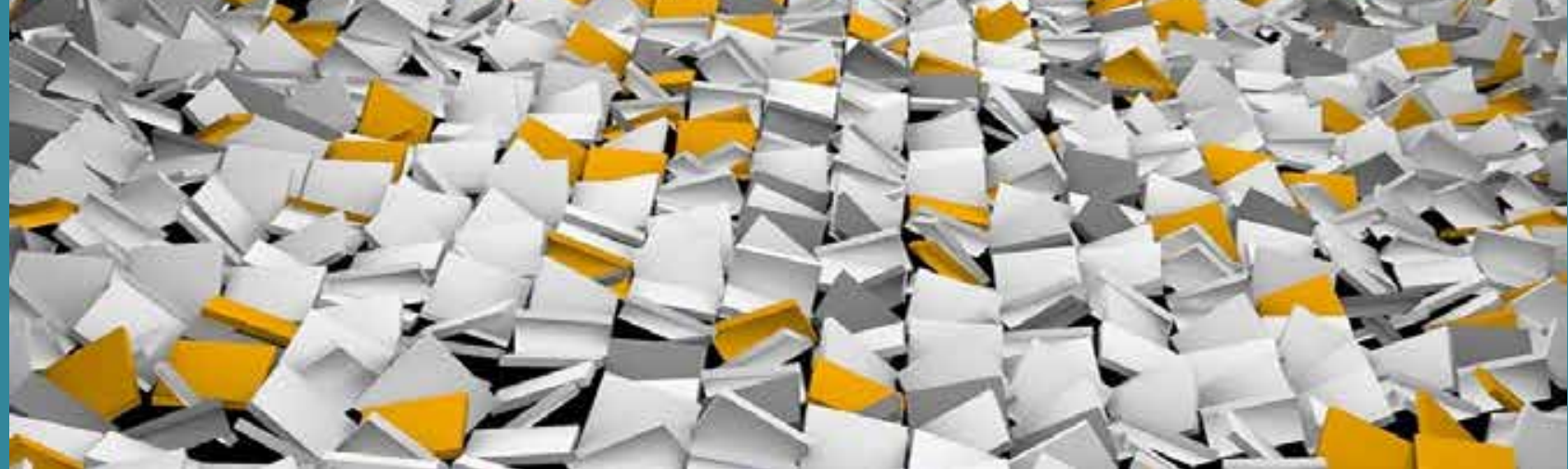




\section{CAPÍTULO V}

\section{DISCUSIÓN GENERAL Y CONCLUSIONES}

El presente trabajo abarca el estudio de la helmintofauna de 12 especies de murciélagos colectados principalmente en localidades de la provincia de Corrientes, cuya diversidad de quirópteros se estima en aproximadamente 30 especies (Barquez, 2004), de modo que el número de taxones evaluados representa a más de un tercio de las especies presentes en el área de estudio. Así, se evaluaron cinco especies de molósidos (de ocho presentes): Eumops patagonicus, Eumops perotis, Molossops temminckii, Molossus molossus y Molossus rufus; cuatro especies de filostómidos (de ocho presentes): Artibeus lituratus, Desmodus rotundus, Platyrrhinus lineatus y Sturnira lilium; tres especies de vespertiliónidos (de 12 presentes): Eptesicus furinalis, Myotis albescens y Myotis cf nigricans. Si bien el número de individuos evaluados fue distinto para cada especie hospedadora, la curva de acumulación del total de especies muestra que el esfuerzo de muestreo fue satisfactorio para lograr datos fiables. De modo que los resultados obtenidos estarían caracterizando a la fauna de helmintos parásitos de los murciélagos analizados en el área de estudio.

Al iniciar el trabajo se plantearon algunos interrogantes respecto a cuales son los helmintos parásitos de murciélagos, como se distribuyen entre las especies hospedadoras, cómo se estructura la comunidad de helmintos en cada especie hospedadora, a qué nivel taxonómico del hospedador se enmarca la especificidad parasitaria, en qué contexto regional se inscriben los hallazgos locales, si existen variables biológicas propias del hospedador que condicionen las infecciones, entre otros. En este sentido, cabe resaltar que la mayoría de los trabajos referidos a helmintos parásitos de murciélagos tratan principalmente aspectos taxonómicos (e.g. Braun, 1900; Lent et al., 1945; Freitas y Dobbin Jr., 1962; Travassos y Freitas, 1964; Mañé-Garzón y Telias, 1965; Travassos et al., 1969; Caballero y Caballero, 1969; Marshall y Miller, 1979; Thatcher, 1993; Caro et al., 2003), en algunos casos con datos de prevalencia e intensidad o abundancia (e.g. Guzmán Cornejo et al., 2003; Nogueira et al., 2004; Lunaschi y Notarnicola, 2010; Pesenti et al., 2015) y solo unos pocos abordan aspectos ecológicos (Lotz y Font, 1985; Esteban et al., 2001; Oviedo inéd.). Por lo antedicho resulta de interés abordar el estudio de helmintos de murciélagos de modo integral, aportando datos que expliquen el comportamiento de estos parásitos en relación con su entorno más íntimo (el hospedador) y su entorno más amplio (el ambiente).

En cuanto a los helmintos que parasitan murciélagos del Nordeste se logró la identificación de 12 taxones, dos cestodes Vampirolepis guarany y Vampirolepis cf. macroti (Hymenolepididae), siete trematodes Anenterotrema eduardocaballeroi, Anenterotrema liliputianum (Anenterotrematidae), Gymnoacetabulum talavarensis, Ochoterenatrema 
labda, Paralecithodendrium aranhai (Lecithodendriidae), Limatulum oklahomense (Phaneropsolidae) y Urotrema scabridum (Urotrematidae) y tres nematodes Pterygodermatites sp. (Rictulariidae), Anoplostrongylus sp. (Trichostrongylidae) y Capillaria sp. (Trichuridae). Se observa aquí un número de taxones de helmintos que acompaña el número de especies hospedadoras analizadas (a excepción de Desmodus rotundus y Platyrrhinus lineatus, las 10 especies restantes presentaron al menos una especie de helminto), este hecho coincide con el análisis efectuado por Santos y Gibson (2015) en el que expresan que la diversidad de helmintos conocida en América del Sur es apenas mayor que la de sus hospedadores, considerando 114 taxones de helmintos en 92 especies de murciélagos, sugiriendo que existe una subestimación de la hemintofauna asociada a quirópteros. En el presente trabajo se menciona la posibilidad de una nueva especie de Anoplostrongylus (Nematoda) y de una diversidad oculta en el complejo Urotrema scabridum (Trematoda), por lo que existe la posibilidad que el número de taxones hallados sea superior, más aun teniendo en cuenta los recientes resultados sobre nematofauna de murciélagos de las Yungas (Argentina) en el que se registraron 35 taxones de nematodes en 31 especies de murciélagos (Oviedo inéd.) y, si a estos resultados se sumara la fauna de cestodes y trematodes, el número de taxones de helmintos sería considerablemente mayor. La continuidad y profundización del estudio taxonómico, como el desarrollado en esta investigación, permite avanzar en el conocimiento y generar las bases para el estudio sobre la relación parásito/hospedador/ambiente.

Al analizar la distribución de los helmintos en las distintas especies hospedadoras se observó que los trematodes fueron los más frecuentes, presentes en seis especies de murciélagos, los de mayor riqueza de especies (siete taxones), así como los de mayor prevalencia, abundancia e intensidad media. El hecho de que los trematodes sean helmintos heteroxenos y que la mayoría de los murciélagos analizados sean insectívoros explicaría su presencia y colonización.

El hábito trófico de los hospedadores marcó una clara distinción de la fauna de helmintos, dado que en los murciélagos frugívoros (Artibeus lituratus y Sturnira lilium (Phyllostomidae) solo se hallaron dos helmintos (Vampirolepis guarany (Cestoda) y Capillaria sp. (Nematoda) que se caracterizan por presentar ciclos de vida directo e indirecto, es decir que poseen una alternativa de transmisión sin la participación de un hospedador intermediario, por lo que la ausencia de consumo de invertebrados no sería limitante para el desarrollo de ambos ciclos, hecho que explica su hallazgo en consumidores de frutos.

Entre los murciélagos insectívoros se verificó una distinción entre la familia Molossidae y Vespertilionidae, en la primera se observó una riqueza de especies de 11 taxones de helmintos, mientras que en los vespertiliónidos la riqueza fue de siete taxones. Las diferencias en la riqueza muestran que Anenterotrema eduardocaballeroi, Anenterotrema liliputianum y Pterygodermatites sp. son exclusivas de la familia Molossidae, mientras Vampirolepis of macroti lo es de la familia Vespertilionidae. Asimismo, Limatulum oklahomense, si bien está presente en ambas familias, muestra una mejor adaptación en los ves- 
pertiliónidos, más precisamente en los Myotis, reflejada en su prevalencia $(29,3 \%)$ e intensidad media (13,7 en Myotis cf nigricans). Estos resultados son una aproximación para definir a que nivel taxonómico del hospedador se expresa la especificidad parasitaria.

Al analizar las poblaciones componentes se observa que en los molósidos, Urotrema scabridum fue la especie dominante, de mayor abundancia e intensidad media mientras que en los vespertiliónidos la especie dominante, de mayor abundancia e intensidad media fue Limatulum oklahomense. No obstante, al comparar la comunidad componente de los distintos hospedadores se observaron valores similares de diversidad, equitabilidad y dominancia, reflejando baja dominancia y representatividad equivalente de los taxones parásitos.

Respecto a las variables biológicas evaluadas, se verificó una diferencia estadísticamente significativa entre machos y hembras únicamente del molósido $E$. patagonicus, justificada por el comportamiento diferencial de los machos que aumentan su exposición a estadios infectivos al tener un mayor rango de desplazamiento. Sería de esperar que ocurra lo mismo en las otras especies hospedadoras, sin embargo en el presente trabajo se observó solamente en E. patagonicus, probablemente debido al mayor número de individuos evaluados que permitieron un análisis estadístico más preciso.

En cuanto al tamaño de los hospedadores y su relación con la intensidad de infección, se observaron relaciones inversas con el peso del hospedador, hecho que contraría lo esperado ya que, en términos generales, los individuos de mayor tamaño suponen mejores condiciones para el establecimiento y desarrollo de los parásitos. En este sentido, al considerar que el mayor tamaño indicaría mayor edad del hospedador, la adquisición creciente de inmunidad en los hospedadores de mayor edad podría explicar la relación negativa con la intensidad de parásitos, verificada en el presente estudio (Anderson y May, 1985).

Al integrar los resultados de la presente investigación con datos previos se observan distintos patrones en la distribución geográfica de los helmintos. De este modo, si consideramos que la mayoría de los taxones identificados son heteroxenos y generalistas, el encuentro con sus hospedadores definitivos no sería una limitante para su dispersión, entonces uno de los elementos condicionantes sería la presencia de sus hospedadores intermediarios, a la vez que el consumo diferencial de presas por parte de los murciélagos está en relación con la disponibilidad de recursos en un área. Así, por ejemplo entre los trematodes se aprecian dos extremos, Ochoterenatrema labda estaría restringida únicamente a Argentina mientras que Urotrema scabridum muestra una amplia distribución en Centro y Sudamérica. Surge con claridad la necesidad de encarar estudios integrales a fin de dilucidar este aspecto con mayor precisión. Asimismo, si bien las localidades de muestreo abarcan las distintas eco-regiones representadas en el área de estudio, el número de murciélagos evaluados no se distribuyó equitativamente para dar lugar a un análisis que incluya las variables ambientales, por lo que se espera aumentar el tamaño de la muestra en cada ecorregión a fin de obtener un plantel de hospedadores que permita abordar este aspecto. 
Finalmente, los resultados obtenidos aportan a la caracterización de la fauna de helmintos asociadas a las especies de murciélagos evaluadas al tener en cuenta los registros previos para cada hospedador, de modo que se adicionan 23 nuevas asociaciones a las ya conocidas; en algunos casos como en E. patagonicus y Myotis albescens los aportes nuevos superan a los conocidos.

La presente investigación intentó responder a los objetivos planteados aportando datos relevantes y abriendo nuevos interrogantes que requieren la continuidad de los estudios en helmintos parásitos de murciélagos. 


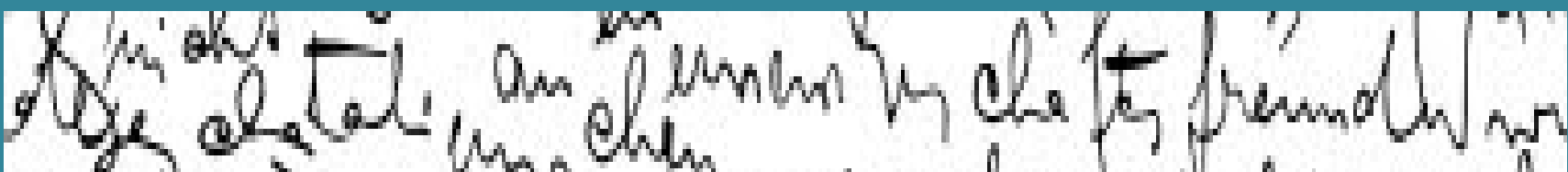

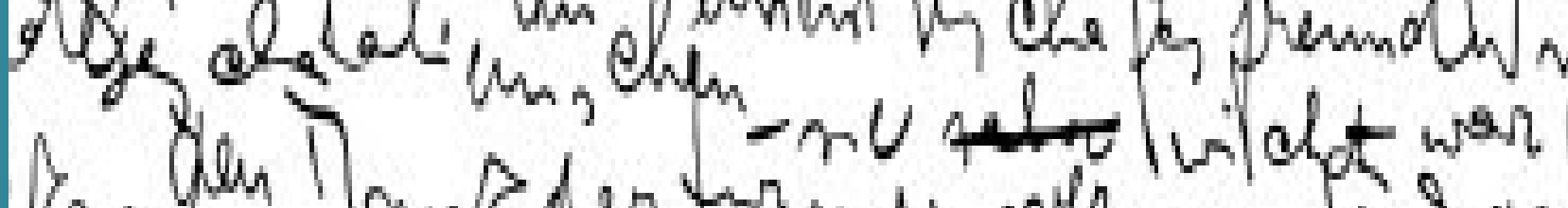

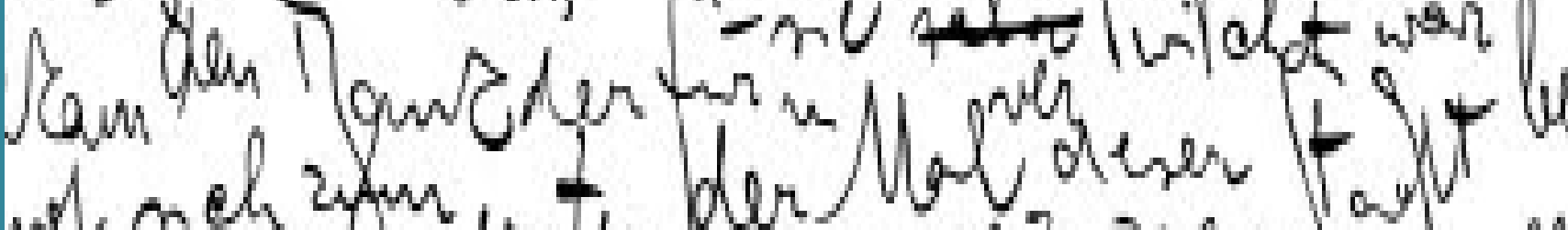

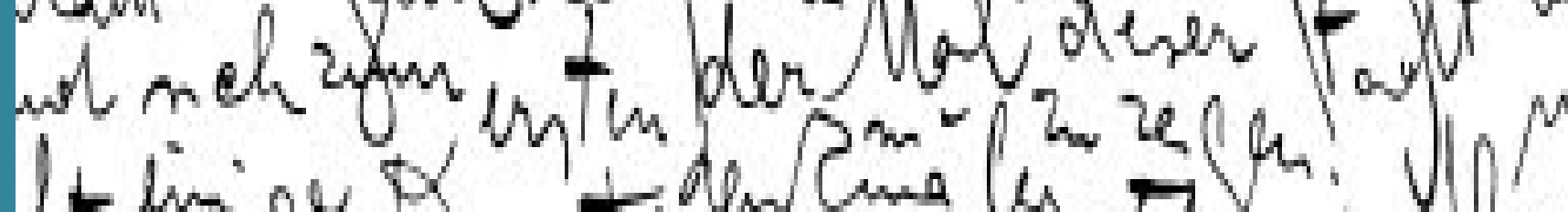

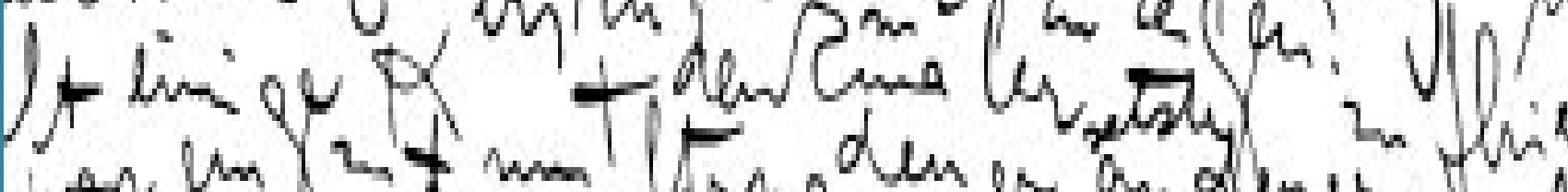

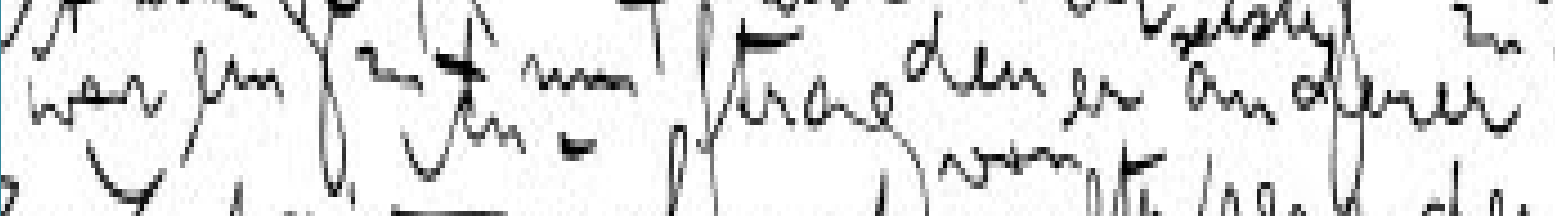

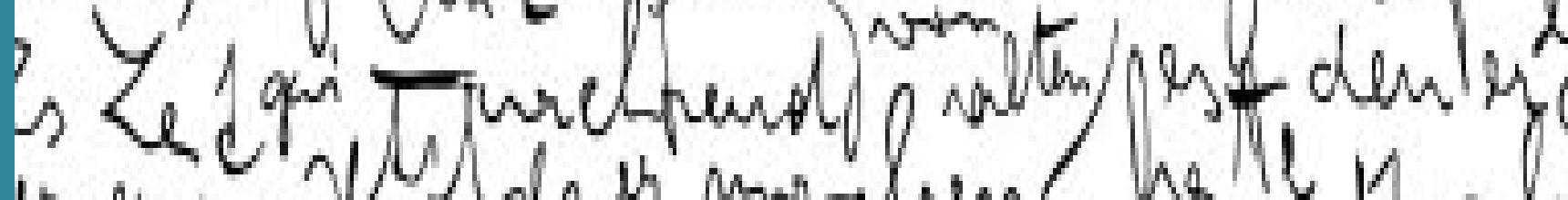
en

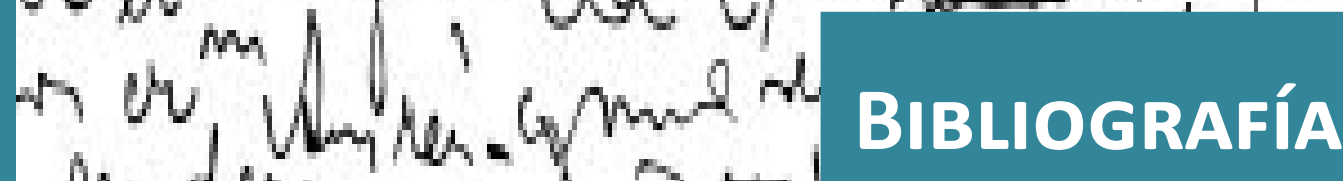
M den

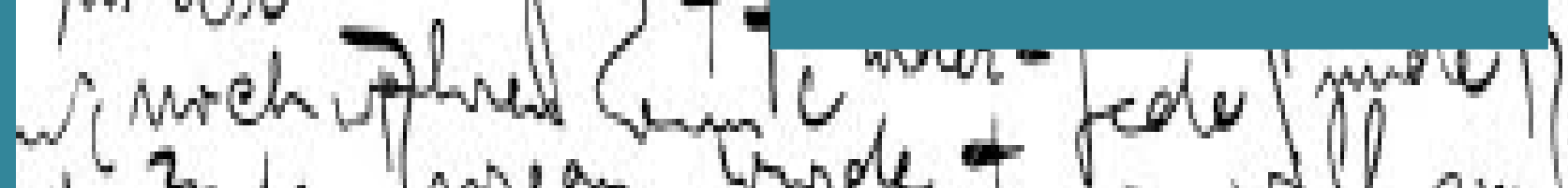

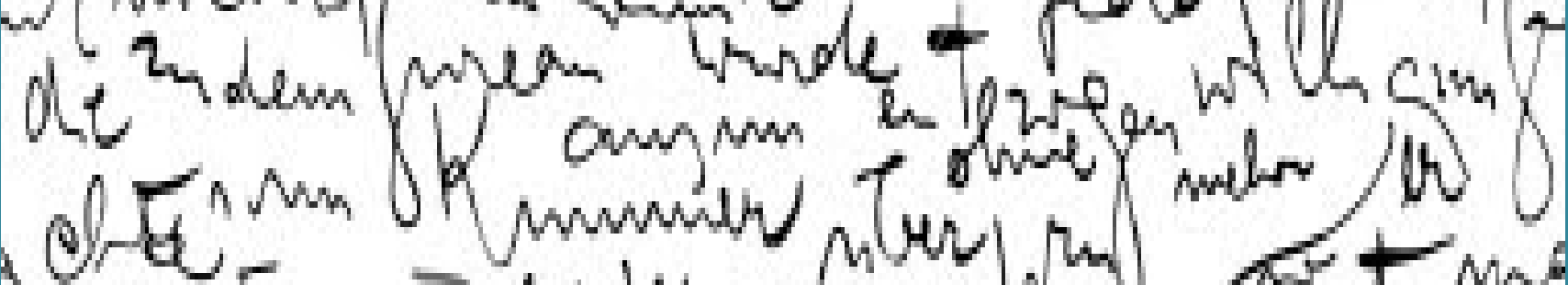

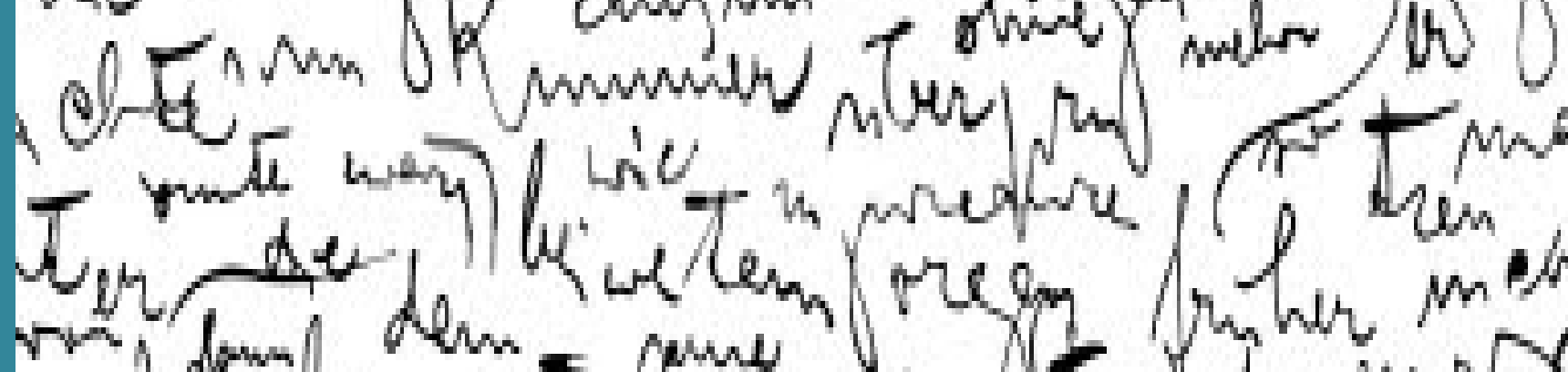

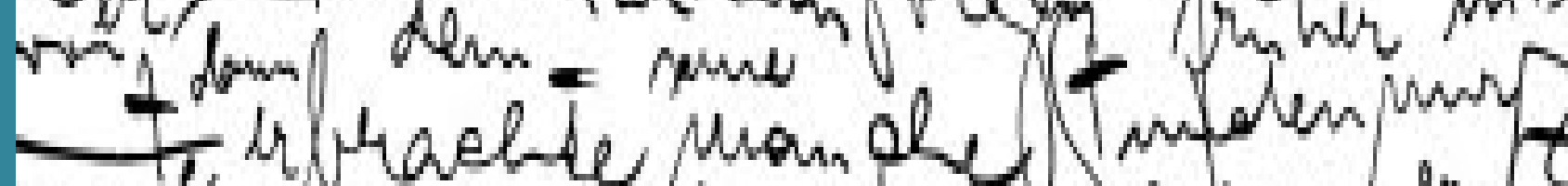

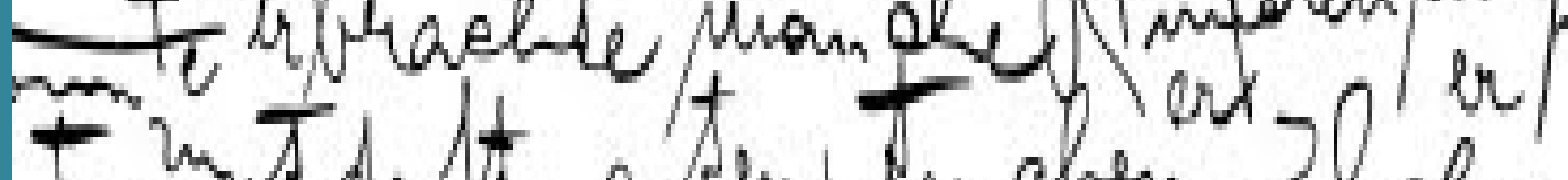

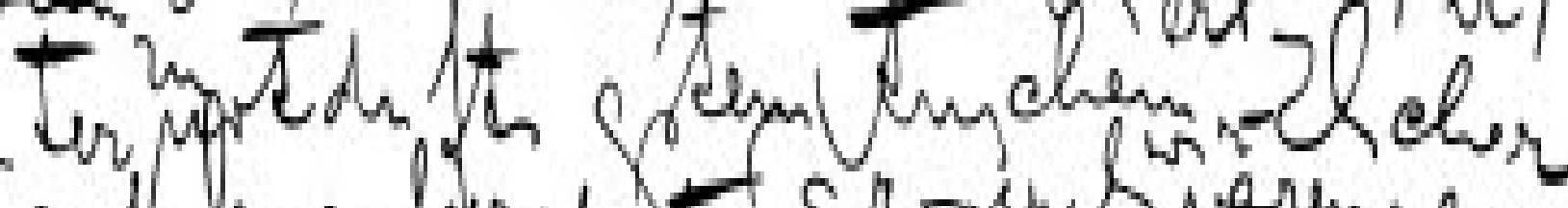

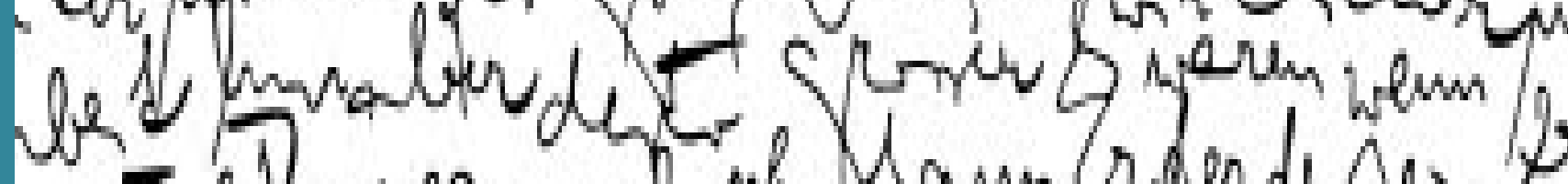

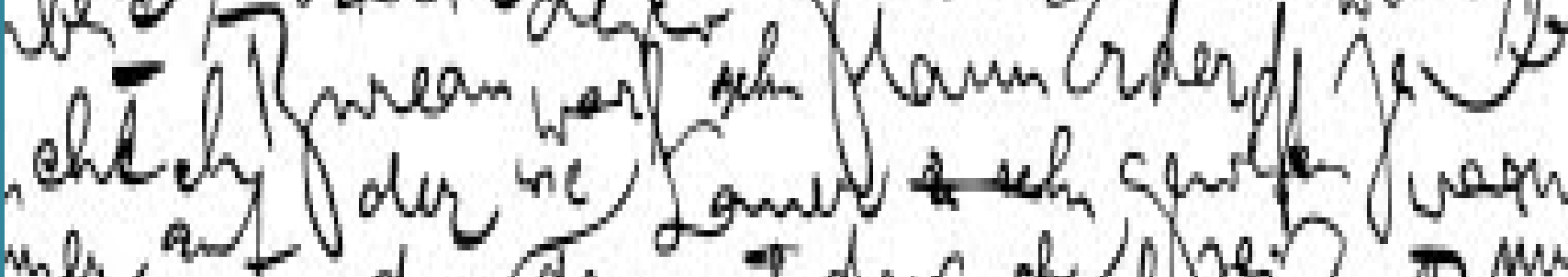

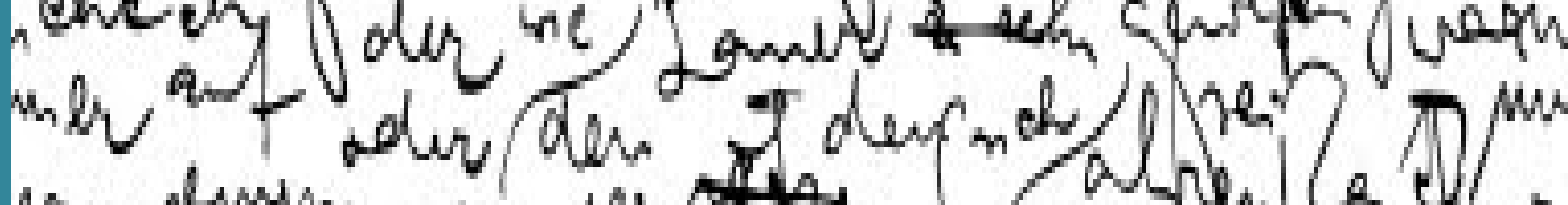

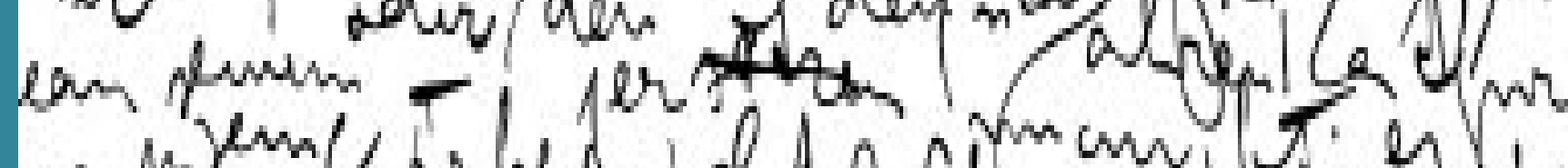

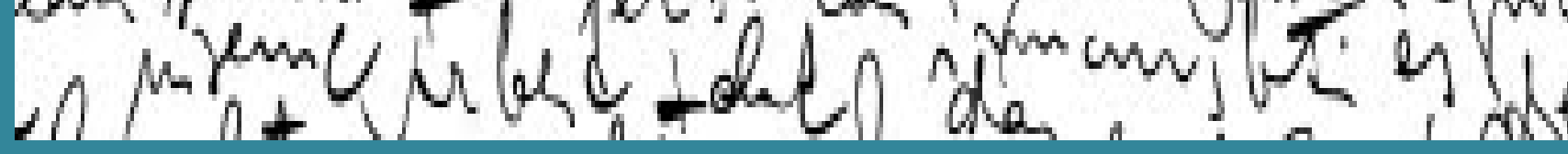




\section{BIBLIOGRAFÍA}

Anderson RC. 2000. Nematode parasites of vertebrates. Their development and transmission. CABI Publishing. 2nd edition. 650 pp.

Anderson RC y May RM. 1985. Herd immunity to helminth infection and implications for parasite control. Nature 315:493-496.

Anderson RC, Chabaud AG y Willmott S. 2009. Keys to the nematode parasites of vertebrates. Archival volume, Wallingford, $\mathrm{CABI}, 463 \mathrm{pp}$.

Arneberg P. 2002. Host population density and body mass as determinants of species richness in parasite communities: comparative analyses of directly transmitted nematodes of mammals. Ecography 25 (1):88-94.

Bärtschi D. 2002. A study of the Chiroptera of Shipstern Nature Reserve and North-Eastern Belize (Central America) together with their ectoparasites (Streblidae, Nycterophiliinae, Acarina) and endoparasites (Cestoda, Nematoda, Trematoda, Acanthocephala). Occasional publication of the International Tropical Conservation Foundation 1-16.

Barquez RM. 2004. Murciélagos (Chiroptera-Mammalia) de la Mesopotamia Argentina. Miscelanea 12, 370 pp.

Barquez RM y Díaz M. 2009. Los murciélagos de Argentina: Clave de identificación. PCMA Publicaciones especiales № 1. Ediciones Magna, Argentina, 84 pp.

Barquez, RM, Díaz MM y Ojeda RJ. 2006. Mamíferos de Argentina. Sistemática y Distribución. Editorial SAREM, Mendoza, Argentina. Pp 375.

Barus V y del Valle MT. 1967. Systematic survey of nematodos parazitising bats (Chiroptera) in Cuba. Folia Parasitologica 14:121-140.

Begon M, Harper JL, y Townsend CR. 1996. Ecology: Individuals, Populations and Communities. 3rd ed. Blackwell Science, Oxford, UK.

Boeger WA, Thatcher VE y Marques AS. 1985. A validade de Czosnowia Zdzitowiecki, 1967, a redescricao de C. paraguayensis (Fischthal y Martin, 1978) n. comb. (Trematoda: Lecothodendriidae) e aspectos de sua patologia no fígado do morcego Molossus ater (Geoffrey), no Brasil. Studies on Neotropical Fauna and Environment 20: 7-155.

Boero JJ y Delpietro H. 1970. El parasitismo de la fauna autóctona. VII. Los parasitos de los murciélagos argentinos. Jornadas Internas de la Facultad de Ciencias Veterinarias. La Plata, 1970: 76-82.

Boero JJ y Led JE. 1971. El parasitismo de la fauna autóctona. V. Los parásitos de las aves argentinas. VI. Los parásitos de los ofidios argentinos. VII Los parásitos de los murciélagos argentinos. Analecta Veterinaria 3 (1, 2 y 3): 91-103. 
Braun M. 1900. Trematoden der Chiroptera. Annalen des KK Naturhistorischen Hofmuseums in Wien 15:217-236.

Bray RA, Gibson DI y Jianying Z. 1999. Urotrematidae Poche, 1926 (Platyhelminthes: Digenea) in chinese freshwater fishes. Systematics Parasitology 44:193-200.

Bray RA, Gibson DI y Jones A (eds.). 2008. Keys to the Trematoda Vol. 3. CAB International and Natural History Museum, London.

Brooks D y Hoberg E. 2000. Triage of Biosphere: The Need and Rationale for Taxonomic Inventories and Phylogenetic Studies and Parasites. Comparative Parasitology 67: 1-25.

Brower J y Zar J. 1977. Field and laboratory methods for general ecology. WMC Brown Company Publisher, USA 194 pp.

Brown A, Martinez Ortiz U, Acerbi M y Corcuera J (eds.). 2006. La Situación Ambiental Argentina. Brown, A. y Pacheco S. Propuesta de actualización del mapa ecorregional de la Argentina. Fundación Vida Silvestre Argentina, Buenos Aires.

Burkart R, Bárbaro NO, Sánchez RO y Gómez DA. 1999. "Ecorregiones de la Argentina", Buenos Aires, Administración de Parques Nacionales.

Bush AO. y Holmes JC. 1986. Intestinal parasites of lesser scaup ducks: an interactive community. Canadian Journal of Zoology, 64: 142-152.

Bush AO, Lafferty KD, Lotz JM, Shostak AW. 1997. Parasitology meets ecology on its own terms: Margolis et al. revisited. Journal of Parasitology 83:575-583.

Caballero E. 1940. Algunos tremátodos intestinales de los murciélagos de México. I. Anales del Instituto de Biología de la Universidad Nacional Autónoma de México, Serie Zoología 11:215-223.

Caballero y CE. 1943. Tremátodos de los murciélagos de México. IV. Descripción de un nuevo género de la subfamilia Lecithodendriinae Looss, 1902, y una nueva especie de Prosthodendrium Dollfus, 1931. Anales del Instituto de Biología, Universidad Nacional Autónoma de México, Serie Zoología 14 (1):173-193.

Caballero y CE. 1960. Trematodos de los murciélagos de México. VIII. Catálogo taxonómico de los trematodos que parasitan a los murciélagos (Mamalia, Chiroptera). Anales del Instituto de Biología de la Universidad Nacional Autónoma de México, Serie Zoología 31:215-287.

Caballero y CE. 1961. Trematodos de los murciélagos de México. VII. Catalogo taxonómico de los trematodos que parasitan a los murciélagos (Mammalia, Chiroptera Blumenbach, 1774). Anales del Instituto de Biología de la Universidad de Mexico, México DF 31:215-287. 
Caballero y CE. 1964. Helmintos de la República de Panamá, XXIV. Descripción de tres especies de tremátodos Lecithodendriidae que parasitan al murciélago Myotis nigricans nigricans (Schinz). Anales de la Escuela Nacional de Ciencias Biológicas 13:73-81.

Caballero y CE y Caballero G. 1969. Trematodos de los murciélagos de México. IX. Descripción de una nueva especies de Platynosomum Loos, 1907 y a continuación el primer suplemento del catálogo taxonómico de los trematodos que parasitan a los murciélagos. Revista de la Sociedad Mexicana de Historia Natural 30: 263-290.

Caballero E y. Brenes RR. 1957. Helmintos de la República de Costa Rica VI. Algunos tremátodos de peces, reptiles y mamíferos. Anales del Instituto de Biología, Universidad Nacional Autónoma de México, Serie Zoología 28:217-240.

Cabrera AL y Willink A. 1980. Biogeografía de América Latina. Secretaría General de la OEA, Monografía, 13: 1-122.

Cain GD. 1966. Helminth parasites of bats from carlsbad caverns, New Mexico. Journal of Parasitology 52:351-357.

Cardia DFF, Tebaldi JH, Fornazari F, Menozzi BD, Langoni H, Nascimento AA, Besciani KDS y Lux Hoppe EG. 2015. Pterygodermatites (Paucipectines) andyraicola n. sp. (Spirurida: Rictulariidae), an intestinal nematode of Neotropical Molossidae bats from Brazil. Comparative Parasitology 82 (2):296-300.

Caro F, Carvajal H, Bonelo A y Vélez I. 2003. Tremátodos de murciélagos de la ciudad de Cali y áreas vecinas (Colombia). Actualidades Biológicas 25:79-88.

Caspeta-Mandujano JM, Jiménez FA, Peralta-Rodriguez JL y Guerrero JA. 2013. Pterygodermatites (Pterygodermatites) mexicana n. sp. (Nematoda: Rictulariidae), a parasite of Balantiopteryx plicata (Chiroptera) in Mexico. Parasite 20:1-7.

Castiblanco F y Vélez I. 1982. Observación de trematodos digenéticos en murciélagos del Valle de Aburrá y alrededores. Actualidades Biológicas 11:129-142.

Chandler AC. 1938. A report on the parasites of a bat, Nycticeius humeralis, with descriptions of four new helminths. En: Livro Jubilar Profesor Travassos. p. 107-114.

Cuartas-Calle C y Muñoz-Arango J. 1999. Nematodos en la cavidad abdominal y el tracto digestivo de algunos murciélagos colombianos. Caldasia 21:10-25.

Delorme M y Thomas DW. 1999. Comparative analysis of digestive efficiency and nitrogen and energy requirements of the phyllostomid fruit-bat (Artibeus jamaicensis) and the pteropodid fruit-bat (Rousettus aegyptiacus). Journal Comparative Physiology $B$ 169:123-132.

Diesing KM. 1850. Systema Helminthum. Vol I. Braumuller, Vindobonae 679 pp.

Digiani MC y Durette-Desset MC. 2003a. Two new species of Nippostrongylinae (Nematoda: Heligmosomoidea: Heligmonellidae) from a Sigmodontine rodent in Argentina. Acta Parasitologica 48: 12-18. 
Digiani MC y Durette-Desset MC. 2003b. Suttonema delta n. g., n. sp. (Nematoda: Trichostrongylina: Heligmosomoidea) from Oxymycterus rufus (Rodentia: Sigmodontinae) in Argentina. Systematic Parasitology 55: 33-38.

Digiani MC, Sutton CA y Durette-Desset MC. 2003. A new genus of Nippostrongylinae (Nematoda: Heligmonellidae) from the water rat Scapteromys aquaticus in Argentina. Journal of Parasitology 89: 124-132.

Drago FB y Lunaschi LI. 2008. Description of a new species of Tylodelphys (Digenea, Diplostomidae) in the wood stork, Mycteria americana (Aves, Ciconiidae) from Argentina. Acta Parasitologica 53: 263-267.

Drago FB y Lunaschi LI. 2010. Digenea, Strigeidae, Australapatemon canadensis Dubois and Rausch, 1950: First record in South America and a new host record. Cheklist 6: 382384.

Drago F y Lunaschi L. 2011a. Digenean parasites of Ciconiiformbirds from Argentina. Revista Mexicana de Biodiversidad 82: 77-83.

Drago F y Lunaschi L. 2011b. A new species of Parastrigea (Digenea, Strigeidae) endoparasite of Buteo gallus urubitinga (Aves, Accipitridae) from Argentina. Helminthologia 48: 256-261.

Drago FB, Lunaschi LI, Delgado L y Robles R. 2007a. Helmintofauna de quirópteros de la Reserva Natural Punta Lara, Provincia de Buenos Aires. XXI Jornadas Argentinas de Mastozoología $\mathbf{N}^{\circ}$ 236, 255.

Drago FB, Lunaschi LI, Hinojosa-Saez AC y González-Acuña D. 2007b. First record of Australapatemon burti and Paramonostomum pseudalveatum (Digenea) from Anas georgica (Aves, Anseriformes) in Chile. Acta Parasitologica 52: 201-205.

Drago FB, Lunaschi LI y Schenone M. 2011. Digenean parasites of the Neotropic Cormorant, Phalacrocorax brasilianus (Gmelin, 1789) (Aves: Phalacrocoracidae) from Argentina: Distribution extension and new host records. Cheklist 7: 671-875.

Dubois G. 1960. Contribution à l' étude des trématodes de chiroptéres. Revision du sousgenre Prosthodendrium Dollfus, 1931 et des genres Lecithodendrium Looss, 1896 et Pycnoporus Looss 1899. Revue Suisse de Zoologie, Geneve 67:1-80.

Dubois G. 1983. Un neodiplostome peruvien, Noediplostomun (N.) vaucheri n. sp. (Trematoda: Strigeoidea: Diplostomidae), parasite d'une chauve-souris. Revue Suisse de Zoologie, Geneve 90:179-182.

Durette Desset MC. 1983. Keys to genera of the superfamily Trichostrongyloidea, p. 1-86. En RC Anderson y AG Chabaud (eds.). ClH key to the nematode parasites of vertebrates. Commonwealth Agricultural Bureaux, London UK: 1-68.

Durette Desset MC y Chabaud AG. 1977. Essai de classification des Nématodes Trichostrongyloidea. Annales de Parasitologie Humaine et Comparee 52(5): 539-558. 
Durette Desset MC y Chabaud AG. 1981. Nouvel essai de classification des nematodes Trichostrongyloidea. Annales de Parasitologie Humaine et Comparee 56(3): 297-312.

Esch GW y Fernández JC. 1993. A functional biology of parasitism. Ecology and evolutionary implications. Chapman y Hall (Eds.). 337 pp.

Esteban JG, Amengual B y Serra Cobo J. 2001. Composition and structure of helminth communities in two populations of Pipistrellus pipistrellus (Chiroptera: Vespeetilionidae) from Spain. Folia Parasitologica 48: 143-148.

Falcón Ordaz J., Guzmán Cornejo C., García Prieto L. y Gardner S.L. 2006. Tadaridanema delicatus (Schwartz, 1927) n. gen., n. com. (Trichostrongylina: Molineidae) parasite of Molossidae bats. Journal of Parasitology 92(5): 1035-1042.

Feliu C, Torres J, Miguel J, Segovia JM, Fons R. 2006. Digenean trematodes. En: Macromammals and Microparasites. From Evolutionary Ecology to Management (S. Morand, B. R. Krasnov, R. Poulineds.). Springer-Verlag Tokyo, Japan, pp. 13-28.

Fenton, MB, Acharya L, Audet D, Hickey MBC, Merriman C, Obrist MK, Syme DM, Adkins B. 1992. Phyllostomid bats (Chiroptera: Phyllostomidae) as indicators of habitat disruption in the Neotropics. Biotropica 24: 440-446.

Ferreira VS y Brasil-Sato MC. 1998. Digeneticos (Cercomeria, Lecithodendriidae) de morcegos (Chiroptera) dos municipios de Seropédica e Rio de Janeiro, do Estado do Rio de Janeiro, Brasil. Bios (Belo Horizonte) 6 (6):83-88.

Findley JS. 1993. Bats: a community perspective. Cambridge University Press. 173 pp.

Font WF y Lotz JM. 2008. Family Urotrematidae Poche 1926. En: Bray RA, Gibson DI y Jones A (eds.): Keys to the Trematoda. Vol 3. CAB International and Natural History Museum, London, pp. 441-445.

Foster HW y Mertins JW. 1996. Parasitic helminthes and arthropds from braziliam freetailed bats (Tadarida brasiliensis cynocephala) in Florida. Helminthological Society of Washington 63 (2): 240-245.

Freitas JFT. 1960. Sôbre uma nova espéce do gênero "Prosthodendrium" Dollfus, 1931 (Trematoda, Lecithodendriidae). Revista Brasileira de Biologia 20: 265-268.

Freitas JFT. 1961. Sobre o Paralecithodendrium liliputianun Travassos, 1928 (Trematoda). Memorias do Instituto Oswaldo Cruz 59: 45-57.

Freitas JFT y Dobbin JE Jr. 1962. Contribução ao conhecimento da fauna helmintológica de quirópteros no Estado de Pernambuco, Brasil. Anais da Faculdade de Farmácia 5: 53-83.

Freitas Texeira JF. 1934. Sobre as especies do genero Capillaria Zeder, 1800, parasitas de morcegos. Memorias do Instituto Oswaldo Cruz 28(2): 241-242.

Freitas Texeira JF y Lent H. 1936. Estudo sobre os Capilariinae parasitos de mamiferos (Nematoda: Trichuroidea). Memorias do Instituto Oswaldo Cruz 31(1): 85-160. 
Freitas Texeira JF y Machado de Mendonca J. 1963. Quarta especie do genero "Parallintoshius" Araujo, 1940 (Nemátodo, Trichostrongylidae). Revista Brasileira de Biologia 23: 223-226.

Gardner AL. 1977. Feeding habits. En: Biology of bats of the new world family Phyllostomidae. Part II. Baker JK, Jones JR y Carter DC (eds.). Special Publication Museum of Technical University 13. Pp 293-350.

Gardner AL. 2007. Mammals of South America. Volume 1: Marsupials, Xenarthrans, Shrews, and Bats. University of Chicago Press, Chicago, Illinois, and London, United Kingdom, 669 pp.

Gardner S y Jimenez Ruiz A. 2009. Methods for the study of bat endoparasites. En Ecological and behavioural methods for the study of bats. Kunz TH y Parsons S (eds.). The Johns Hopkins University Press, Baltimore, Maryland, pp. 795-805.

Georgiev BB, Bray RA y Littlewood DTJ. 2006. Cestodes of small mammal: Taxonomy and lifecycles. En: Macromammals and Microparasites. From Evolutionary Ecology to Management (S. Morand, B. R. Krasnov, R. Poulineds.). Springer-Verlag Tokyo, Japan, pp. 30-52.

Gibbons LM. 2010. Keys to the nematode parasites of vertebrates. Supplementary volume. Cambridge University Press, Cambridge, UK. 416 pp.

Gibson DI, Jones A, Bray RA. 2002. Keys to the Trematoda. CABI Publishing and The Natural History Museum, London.

Goldberg SR, Bursey CR y Cheam H. 1994. Gastrointestinal helminths of six anole species, Anolisar mouri, A. barahonae, A. bahorucoensis, A. brevirostris, A. chlorocyanus and $A$. coelestinus (Polychrotidae) from Hispaniola. Caribbean Journal of Science, Puerto Rico 32(1): 112-115.

Graczyk TK y Fried B. 2001. Helminths biology, adaptation, transmition and survival. Recent research development. Microbiology 5: 171-185.

Groschaft J y Valle MT. 1969. Trematodos de los murciélagos de Cuba. Torreia Nueva Series 18:1-20.

Guerrero R. 1985. Parasitología. En: El estudio de los mamíferos en Venezuela. Evaluación y perspectivas. Aguilera M (ed.). Fondo Editorial Acta Científica Venezolana, Caracas, Venezuela, pp. 35-91.

Gregory RD, Keymer AE y Harvey PH. 1996. Helminth parasite richness among vertebrates. Biodiversity and Conservation 5: 985-997.

Guzmán-Cornejo C, García-Prieto L, Pérez-Ponce de León G y Morales-Malacara JB. 2003. Parasites of Tadarida brasiliensis mexicana (Chiroptera: Molossidae) from Arid Regions of Mexico. Comparative Parasitology 70:11-25. 
Hammer O, Harper DAT y Ryan PD. 2001. PAST: Paleontological Statistics Software Package for Education and Data Analysis. Palaeontologia Electronica 4(1): 9.

Holmes JC y Price PW. 1986. Communities of parasites. En: Community Ecology: Pattern and Process. Anderson DJ y Kikkawa J (eds.). Oxford, Blackwell Scientific Publications, pp. 187-213.

Hudson P. 2006. Parasites, diversity and the ecosystem. En: Parasitism \& Ecosystems. Thomas F, Renaud F, Guégan J-F (eds.) Oxford University Press, New York, United States, pp.1-12.

Kehr Al y Hamann MI. 1995. (Revisiones) Estado actual de la teoría de la competencia como un factor organizador de las comunidades parasitarias de helmintos. Facena 11:115-122.

Kennedy CR. 1975. Ecological Animal Parasitology. Blackwell Scientific Publications. Oxford, London, $168 \mathrm{pp}$.

Khalil LF, Jones A y Bray RA. 1994. Keys to the Cestode Parasite of Vertebrates. CAB International, Albans, UK, $768 \mathrm{pp}$.

Kolenati FA. 1856. Die parasiten der Chiroptera. Brunn, pp 51.

Krasnov BR, Shenbrot GI, Khokhlova IS y Poulin R. 2004. Relationships between parasite abundance and the taxonomic distance among a parasite's host species: an example with fleas parasitic on small mammals. International Journal for Parasitology 34(11):1289-1297.

Kunz TH y Fenton MB (eds.). 2003. Bat Ecology. University of Chicago Press, Chicago, IL, $779 \mathrm{pp}$.

Kuris AM, Blaustein AR y Alio JJ. 1980. Hosts as islands. American Naturalist 116: 570-586.

Lamothe-Argumedo R, García-Prieto L, Osorio-Sarabia D y Pérez-Ponce de León G. 1997. Catálogo de la Colección Nacional de Helmintos. Universidad Nacional de Autónoma de México, Instituto de Biología, México, 211 pp.

Lent $\mathbf{H}$ y Texeira de Freitas JF. 1936. Estudo sobre as Capillariinae parasitos de mamíferos. Memorias instituto Oswaldo Cruz 31: 85-160.

Lent H y Texeira de Freitas JF. 1940. Histiostrongylus actacanthus n. sp. (Nematoda: Strongyloidea). Argentine Institute Benjamin Bapstista 6: 92-96.

Lent H, Texeira de Freitas JF y Cavalcanti Proenca M. 1945. Trematódeos de morcegos coleccionados no Paraguay. Revista Brasileira de Biología 5: 499-507.

Lent H, Texeira de Freitas JF y Cavalcanti Proenca M. 1946. Algunos nemátodes de murciélagos colecionados em Paraguay. Revista Brasileira de Biología 6: 488-497. 
Lopez Neyra CR. 1947. Los Capillarinae. Memorias de la Real Academia de Ciencias Exactas, Físicas y Naturales de Madrid 12: 1-248.

Lotz JM y Font WF. 1985. Structure of enteric helminth communities in two populations of Eptesicus fuscus (Chiroptera). Canadian Journal of Zoology 63:2969-2978.

Lotz JM y Font WF. 2008. Family Phaneropsolidae Mehra, 1935. En: Bray RA, Gibson DI y Jones A (Eds.): Keys to the Trematoda. Vol 3. CAB International and Natural History Museum, London, pp. 545-562.

Lunaschi L. 2002a.Tremátodos Lecithodendriidae y Anenterotrematidae de Argentina, México y Brasil. Anales del Instituto de Biología de la Universidad Nacional Autónoma de México, Serie Zoología 73:1-10.

Lunaschi L. 2002b. Redescripción y comentarios taxonómicos sobre Ochoterenatrema labda (Digenea: Lecithodendriidae), parásitos de quirópteros en México. Anales del Instituto de Biología de la Universidad Nacional Autónoma de México, Serie Zoología 73:11-18.

Lunaschi L. 2004. Redescripción de Limatuloides limatulus (Braum) Dubois, 1964 (Trematoda, Lecithodendriidae), un parásito de Tadarida brasiliensis (Geof.) (Chiroptera, Molossidae) de Argentina. Gayana 68:102-107.

Lunaschi L. 2005. Redescripción y reubicación sistemática del trematodo Topsiturvitrema verticalia (Trematoda: Digenea) en una familia nueva. Revista de Biología Tropical. 54 (3): 1- 5.

Lunaschi L. 2006. Redescripción y reubicación sistemática del trematodo Topsiturvitrema verticalia (Trematoda: Digenea) en una familia nueva. Revista de Biología Tropical 54: 1041-1045.

Lunaschi Li y Drago F. 2004. Descripción de una especie nueva de Tylodelphis (Digenea: Diplostomidae) parásita de Podiceps major (Aves: Podicepedidae) de Argentina. Anales del Instituto de Biología de la Universidad Autónoma de México. Serie Zoología 75 (2): 245-252.

Lunaschi Li y Drago F. 2005. Primer registro Neodilpostomun travassosi (Digenea, Diplostomidae) de Argentina. Revista Mexicana de Biodiversidad 76: 97-100.

Lunaschi Li y Drago F. 2006. Description of a new species of Dolichorchis (Digenea, Diplostomidae) in the cocoa heron Ardea cocoi (Aves, Ardeidae), from Argentina. Acta Parasitologica 51(1): 47-47-50.

Lunaschi L. y Drago F. 2007. Checklist of digenean parasites of wild mammals from Argentina. Zootaxa 1580:35-50.

Lunaschi LI y Drago FB. 2009a. Digenean parasites of six species of birds from Formosa Province, Argentina. Revista Mexicana de Biodiversidad 80: 39-46. 
Lunaschi LI y Drago FB. 2009b. Species of Strigea (Digenea: Strigeidae), parasites of the savanna hawk Buteogallus meridionalis (Aves: Accipitridae) from Argentina, with the description of a new species. Folia Parasitologica 56: 268-274.

Lunaschi LI y Drago FB. 2010a. A new species of Petasiger (Digenea, Echinostomatidae) parasitizing Podiceps major and Rollandiarolland (Aves, Podicipedidae) from Buenos Aires Province, Argentina. Acta Parasitologica 55: 230-234.

Lunaschi LI y Drago FB. 2010b. A new species of Centrorhynchus (Acanthocephala, Centrorhynchidae) endoparasite of Guira guira (Aves, Cuculidae) from Argentina. Helminthologia 47: 38-47.

Lunaschi LI y Drago F. 2011. A revision of Anenterotrema Stunkard, 1938 (Digenea, Anenterotrematidae) and a key to its species. Zootaxa 2775 (2775): 50-64.

Lunaschi LI y Drago F. 2012. Digenean parasites of Cariama cristata (Aves, Gruiformes) from Formosa Province, Argentina, with the description of a new species of the genus Strigea. Acta Parasitologica 57 (1): 26-33.

Lunaschi LI, Cremonte F y Drago FB. 2007. Checklist of digenean parasites of birds from Argentina. Zootaxa 1403: 1-36.

Lunaschi L y Notarnicola J. 2010. New host records for Anenterotrematidae, Lecithodendriidae and Urotrematidae trematodes in bats from Argentina, with redescription of Anenterotrema liliputianum. Revista Mexicana de Biodiversidad 81: 281- 287.

Lunaschi LI, Urriza M y Merlo Alvarez VH. 2003. Limatulum oklahomense Macy, 1932 in Myotis nigricans (Chiroptera) from Argentina and a redescription of L. umbilicatum (Vélez et Thatcher, 1990) comb. nov. (Digenea, Lecithodendriidae). Acta Parasitológica 48: 172-175.

MacArthur RH y Wilson EO. 1967. The Theory of Island Biogeography. Monographs in Population Biology, No. 1, Princeton University Press, Princeton, NJ, 215 pp.

Macy RW. 1931. A key to the species of Hymenolepis found in bats and the description of a new species, $H$. christensoni, from Myotis lucifugus. Transactions of the American Microscopical Society 50: 344-347.

Macy RW. 1933. A review of the Trematoda family Urotrematidae with the description of a new genus and two new species. Transactions of the American Microscopical Society 52:247-254.

Magurran AE. 1988. Ecological diversity and its measurements. Princeton University Press, Princeton. $179 \mathrm{pp}$.

Mañé-Garzón F y Gonzáles LE. 1976. Digenea de los murciélagos del Uruguay, I. Limatulum brevicoecumn. sp. del estómago de Myotis levis levis (I. Geoffroy). Revista de Biología del Uruguay 4:79-84. 
Mañé-Garzón F y Telias D. 1965. Un nuevo trematodo del genero Urotrema de la rata de agua y redescripción de Urotrema scabridum Braun, 1900. Comunicaciones Zoológicas del Museo de Historia Natural de Montevideo 8: 1-9.

Marshall M y Miller G. 1979. Some digenetic trematodes from Ecuadorian Bats including five new species and one new genus. Journal of Parasitology 65: 909-917.

Molin R. 1861. Versucheiner Monographic der Filarien. Sitzungsb. K. Akademie der Wissenschaften in Wien 28: 365-461.

Morand S y Harvey PH. 2000. Mammalian metabolism, longevity and parasite species richness. Proceedings of the Royal Society of London B 267: 1999-2003.

Morand S, Krasnov BR, Poulin R y Degen AA. 2006. Who is who and how they interact? En: Micromammals and Macroparasites. Morand S., Krasnov B. R. y R. Poulin, eds. Springer, New York, pp. 1-9.

Muñoz P, Fredes F, Raffo E, González Acuña D, Muñoz L y Cid C. 2011. New report of parasite-fauna of the free-tailed bat (Tadarida brasiliensis, Geoffroy, 1824) in Chile. Veterinary Research Communications 35(1): 61-66.

Navone GT, Lareschi M y Notarnicola J. 2010. Los roedores sigmodontinos y sus parásitos en la región pampeana. En: Biología y Ecología de pequeños roedores en la región pampeana de Argentina. Enfoques y perspectivas. Polop JJ y Busch M (eds.). Editorial Universidad Nacional de Córdoba, Córdoba, Argentina. Pp. 217-261.

Nogueira MR, de Fabio SP, Peracchi AL. 2004. Gastrointestinal helminth parasitism in fruit-eating bats (Chiroptera, Sternodermatinae) from western Amazonian Brazil. Revista de Biologia Tropical 52 (2): 387-392.

Noronha D, Vicente JJ y Magalhaes Pinto R. 2002. A survey of new host records for nematodes from mammals deposited in the Helminthological Collection of the Oswaldo Cruz Institute (CHIOC). Revista Brasileira de Zoologia 19: 945-949.

Notarnicola J. 2004. Taxonomía y biología de las filarias de animales silvestres y de importancia sanitaria en la República Argentina. Tesis Doctoral FCNyM- UNLP. 186 pp.

Ochoa J. 1992. Venezuela's bats: A case for conservation. Bats 10 (3): 10-13.

Odening K. 1973. Tremátodos de los quirópteros cubanos. Torreira Nueva Serie 28: 3-21.

Oviedo MC. Inédito. Biología y sistemática de nematodos parásitos de quirópteros de las Yungas de la Argentina. Tesis Doctoral FCN-UNT. 402 pp.

Oviedo MC. 2009. Nemátodos parásitos de murciélagos (Mammalia: Chiroptera) de Entre Ríos, Argentina. Terceras Jornadas de Jóvenes Investigadores UNT, 1-15.

Oviedo MC, Notarnicola J, Miotti D y Claps L. 2015. Emended description of Litomosoides molossi (Nematoda: Onchocercidae) and first records of Litomosoides species parasitizing argentinean bats. Journal of Parasitology, en prensa. 
Oviedo MC, Ramallo G y Claps L. 2009a. Nemátodos parásitos de Murciélagos de la Provincia de Entre Ríos, Argentina. Acta Bioquímica Clínica Latinoamericana supl. 1: 165.

Oviedo MC, Ramallo G y Claps L. 2009b. Nemátodos parásitos de Murciélagos (Mammalia: Chiroptera) de Entre Ríos, Argentina. Serie Monográfica y Didáctica Facultad de Ciencias Naturales e Instituto Miguel Lillo, Universidad Nacional de Tucumán 48: 223.

Oviedo MC, Ramallo G, Miotti D y Claps L. 2009c. Descripción y caracterización morfométrica de Tricholeiperia proencai (Nematoda: Trichostrongyliodea), parásito de Noctilio leporinus (Chiroptera: Noctilionidae) en la Argentina. Serie Monográfica y Didáctica Facultad de Ciencias Naturales e Instituto Miguel Lillo, Universidad Nacional de Tucumán 48: 224.

Oviedo MC, Ramallo G y Claps L. 2010. Una especie nueva de Cheiropteronema (Nematoda: Molineidae) en Artibeus planirostris (Chiroptera: Phyllostomidae) en la Argentina. Iheringia, Série Zoologia 100 (3): 242-246.

Oviedo MC, Ramallo G, Claps LE y Miotti MD. 2012. A new species of Biacantha (Nematoda: Molineidae), a parasite of the common vampire from the Yungas, Argentina. Journal of Parasitology 98 (6): 1209-15.

Pérez-Ponce de León G, León-Regagnon V y García-Vargas F. 1996. Helminth parasites of bats from the Neotropical Region of Mexico. Bat Research News 37(1): 3-6.

Perez-Vigueras IP. 1934. Notas sobre las especies de Filaroidea encontradas en Cuba. Memorias Sociedad Poey, 8: 55-60.

Perez-Vigueras IP. 1935. Torrestrongylustorrei n. gen. n. sp., parasito de Chiroptera. Memorias de la Sociedad Cubana de Historia Natural 9: 57-58.

Perez-Vigueras IP. 1936. Notas sobre la fauna parasitológica de Cuba. Memorias de la Sociedad Cubana de Historia Natural 10: 53-86.

Pérez Vigueras I. 1940. Notas sobre algunas especies nuevas de trematodes y sobre otras poco conocidas. Revista de la Universidad de Habana 5:217-242.

Perez-Vigueras IP. 1941a. Nota sobre el género Histiostrongylus Molin, 1861. Revista de Medicina Tropical Parasitologica de La Habana 7: 67-72.

Perez-Vigueras IP. 1941b. Nota sobre Hymenolepis chiropterophila n. sp. y clave para la determinación de Hymenolepis de Chiroptera. Universidad de La Habana 6: 152-163.

Perez-Vigueras IP. 1942. Athesmiaparkeri n. sp. (Trematoda, Dicrocoeliidae) parásito del intestino de Artibeus jamaicensis parvipes (Chiroptera). Memorias de la Sociedad Cubana de Historia Natural 16: 67-69.

Pérez-Ponce de León G, León-Régagnon V y García-Vargas F. 1996. Helminth parasites of bats from the Neotropical Region of Mexico. Bat Research News 37: 3-6.

Pesenti TC, Gomes SN, Rui AM y Müller G. 2015. Helminths in Tadarida brasiliensis (Chi- 
roptera: Molossidae) from Southern Brazil. Neotropical Helminthology 9 (1): 13-20.

Portes Santos C y Gibson DI. 1998. Apharingotremalenti n.sp., a new anenterotrematid trematode from the gall-bladderof some Amazonianbats, with comments on Anenterotrema Stunkard, 1938 and Apharyngotrema Marshall and Miller, 1979. Systematic Parasitology 41: 149-156.

Poulin R. 1998. Evolutionary ecology of parasites. From individuals to communities. Chapman y Hall. London, UK. 212 pp.

Poulin R. 2014. Parasite biodiversity revisited: frontiers and constraints. International Journal for Parasitology 44 (9): 581-589.

Poulin R y Morand S. 2000. The diversity of parasites. Quarterly Review of Biology 75: 277-293.

Poulin R y Morand S. 2004. Parasite Biodiversity. Smithsonian Books, Washington. 216 pp.

Poulin R y Moulliot D. 2004. The evolution of taxonomic diversity in helminthes assemblages of mammalian hosts. Evolutionary Ecology 18: 231-247.

Quentin JC. 1969. Essai de classification des nematodes rictulaires. Mémoires du Muséum National d'Histoire Naturelle 54: 1-115.

Ramallo G, Oviedo MC y Claps L. 2007. Nematofauna parásita de quirópteros de la Provincia de Entre Ríos, Argentina: Informe preliminar. Serie Monográfica y Didáctica Facultad de Ciencias Naturales e Instituto Miguel Lillo, Universidad Nacional de Tucumán 46: 97.

Ramírez-Chaves HE, Mejía-Egas y Zambrano-G G. 2008. Anotaciones sobre dieta, estado reproductivo, actividad y tamaño de colonia del murciélago mastín común (Molossus molossus: Molossidae) en la zona urbana de Popayán, Departamento del Cauca, Colombia. Chiroptera Neotropical 14 (2): 384-389.

Rego AA. 1961. Nota prévia sobre um novo Vampirolepis parasita de quirópteros (Cestoda, Hymenolepididae). Atas Sociedade Biologica Rio de Janeiro, Ano 5, 5: 32-34.

Reiczigel y Rozsa, 2005. Quantitative Parasitology 3.0. Budapest.

Rutkowska MA. 1980. The helminthofauna of bats (Chiroptera) from Cuba. I. A review of nematodes and acanthocephalans. Acta Parasitologica Polonica 26 (17): 153-186.

Salgado Maldonado G. 2007. Manual de Parasitología con énfasis en helmintos parásitos de peces de agua dulce y otros animales silvestres de México. Instituto de Biología. Universidad Nacional Autónoma de México UNAM. Proyecto de apoyo a proyectos para innovación y mejoramiento de la enseñanza.

Santos CE y Gibson DI. 2015. Checklist of the Helminth Parasites of South American Bats. Zootaxa 3937 (3): 471-499.

Sardella NH y Timi JT. 2004. Parasites of Argentine hake in the Argentine Sea: population 
and infracommunity structure as evidence for host stock discrimination. Journal of Fish Biology 65: 1472-1488.

Sosa M, De Aseenção A y Soriano PJ. 1996. Dieta y patrón reproductivo de Rhogeessa minutilla (Chiroptera: Vespertilionidae) en una zona árida de Los Andes de Venezuela. Revista Biologia Tropical 44 (2): 867-875.

Sukhdeo MVK y Bansemir AD. 1996. Critical resources that influence hábitat selection decisions by gastrointestinal helminth parasites. International Journal for Parasitology 26: $483-498$.

Sutton CA y Lunaschi L. 1980. Contribución al conocimiento de la fauna parasitológica argentina. VIII. Nuevo digeneo de Cloephaga picta leucoptera (Gemlin). Neotropica 26 (75): 13-17.

Sutton CA y Lunaschi L. 1990. Contribución al conocimiento de la fauna parasitológica argentina XVI. Digeneos en Holochilus brasiliensis vulpinus (Brants) y Oryzomys flavescens (Waterhouse) de Argentina y Uruguay. Neotropica 36: 13-22.

Sutton CA y Lunaschi L. 1994. Estudio sobre digeneos parásitos de roedores Cricetidae y Muridae de la provincia de Buenos Aires. Argentina. Neotropica 40: 61-72.

Sutton CA, Ostrowsky de Nuñez M, Lunaschi LI y Allekotte R. 1997. Los digeneos Notocotyloidea de Hydrochaeris hydrichaeris (Rodentia) de Argentina. Gayana Zoologica 61 (1): 23-31.

Stunkard HW. 1938. Parasitic flatworms from Yucatan. Carnegie Institution of Washington publications 491: 33-50.

Sutton CA y Lunaschi L. 1990. Contribución al conocimiento de la fauna parasitológica argentina XVI. Digeneos en Holochilus brasiliensis vulpinus (Brants) y Oryzomys flavescens (Waterhouse) de Argentina y Uruguay. Neotropica 36: 13-22.

Thatcher VE. 1982. Five new neotropical species of Lecithodendriidae (Trematoda: Digenea) including three new genera, all from Panamanian and Colombian mammals. Proceedings of the Helminthological Society of Washinton 49: 45-55.

Thatcher VE. 1993. Trematódeos Neotropicais. Instituto Nacional de Pesquisas da Amazônia, Manaus. 553 pp.

Thomas DW. 1984. Fruit intake and energy budgets of frugivorous bats. Physiological Zoology 57: 457-467.

Travassos L. 1918. Trichostrongylidae brazileiros. Revista Brasileira do SCiencia, Rio de Janeiro 3: 191-205.

Travassos L. 1921. Contribucões para o conhecimento da fauna helmintológica brasileira. XV. Sobre as especies brasileiras da Familia Lecithodendriidae Odhner, 1911. Archivos da Escola Superior de Agricultura Medicina Veterinaria 5: 73-79. 
Travassos L. 1928. Contribucões para o conhecimento de Lecithodendriidae de Brasil. Memorias Instituto Oswaldo Cruz 21: 189-199.

Travassos L. 1937. Revisão da família Trichostrongylidae Leiper, 1912. Monograph of the Institute of Oswaldo Cruz, Rio de Janeiro, Brazil, № 1, 512 pp.

Travassos L. 1955. Sobre dois novos Dicrocoelium de Chiroptera. Anales Academia Brasileira de Ciencia 27: 561-565.

Travassos L y Freitas JFT. 1964. Pesquisas helmintológicas realizadas em Maicuru, estado do Pará. Publicações Avulsas do Museu Paraense Emilio Goeldi 2: 3-16.

Travassos L, Teixeira de Freitas JF y Kohn A. 1969. Trematódeos do Brasil. Memórias do Instituto Oswaldo Cruz 67: 1-886.

Ubelaker JE. 1970. Some observations on ecto and endoparasites of Chiroptera. En: About bats. BH Slaugthter y DW Walton (eds.). Southern Methodist University, Dallas, Texas, pp 247-261.

Ubelaker JE, Specian RD y Duszynski DW. 1977. Endoparasites. En: Biology of bats of the New World Family Phyllostomidae. Part III. Baker RJ, Jones JK and Carter DC (eds.). Specials Publications Musseum of Texas Technical University 13: 1-364.

Vaucher C. 1981. Helminthes parasites du Paraguay II. Postorchigenes mbopi n. sp. (Trematoda: Lecithodendriidae) chez Lasiurus ega argentines (Thomas). Bulletin de la Société Neuchâteloise des Sciences Naturelles 104: 47-51.

Vaucher C. 1986. Helminthes parasites du Paraguay XI: Hymenolepididae (Cestoda) parasites de Chiroptères Molossidae, avec descrption de deux espèces nouvelles. Revue Suisse Zoologie 93: 393-407.

Vaucher C. 1992. Revision of the genus Vampirolepis Spasskij, 1954 (Cestoda: Hymenolepididae). Memorias Instituto Oswaldo Cruz, 87 (I): 299-304.

Vaucher C y Durette Desset MC. 1980. Allintoshius baudi n. sp. (Nematoda: Trichostrongyloidea) parasite du Murin Myotis aelleni Baud, 1979 et redescription de A. tadaridae (Caballero, 1942). Revue Suisse Zoologie 86 (1): 267-278.

Vélez I y Thatcher VE. 1990. Cinco especies de Lecithodendriidae (Trematoda) en murciélagos de Colombia, incluyendo tres nuevos géneros. Revista Brasileira de Zoología 7: 155-164.

Vélez I y Thatcher VE. 1992a. Cinco especies de Lecithodendriidae (Trematoda) en murciélagos de Colombia, incluyendo tres nuevos géneros. Revista Brasileira de Zoologia 7: 155-164.

Vélez I y Thatcher VE. 1992b. Nudacotyle carollia sp. nov. (Trematoda, Nudacotylidae) parasito intestinal de Carollia perspicillata L. (Chiroptera) en Colombia. Revista Brasileira de Zoologia 7: 69-72. 
Viana. 1924. Tentativa de catalogação das especies brazileiras de trematodeos. Memórias do Instituto Oswaldo Cruz 17(1): 95-227.

Vicente JJ, Oliveira Rodrigues E, Correa Gomes D y Magalhaes Pinto R. 1997. Nematóides do Brasil. Parte V: Nematóides de Mamíferos. Revista Brasileira de Zoologia 14 (1): 1-452.

Vitone ND, Altizer S y Nunn CL. 2004. Body size, diet and sociality influence the species richness of parasitic worms in anthropoid primates. Evolutionary Ecology Research 6: 183-189.

Vitousek PM, Mooney HA, Lubchenco J y Melillo JM. 1997. Human Domination of Earth's Ecosystems. Science 277 (5325): 494-499.

Windsor DA. 1998. Controversies in parasitology. Most of the species on Earth are parasites. International Journal for Parasitology 28: 1939-1941.

Wisnivesky C. 2003. Efectos de las infecciones parasitarias sobre las poblaciones de hospederos. En: Ecología y epidemiologia de las infecciones parasitarias. Wisnivesky C eds. LUR Libro Universitario Regional. Cartago, Costa Rica, pp. 141-2.

Yamaguti S. 1971. Synopsis of digenetic trematodes of vertebrates. Keigaku Publishing Company, Tokio. 1074 pp.

Yamaguti S. 1975. A synoptical review of life histories of digenetic trematodes of vertebrates. Keigaku, Tokio. 590 pp.

Zamparo D, Brooks DR y Tkach V. 2005. Urotrema shirleyae n. sp. (Trematoda: Digenea: Urotrematidae) in Norops oxylophus and N. cupreus (Squamata: Iguania: Polychrotidae) from the Area de Conservación Guanacaste, Costa Rica. Journal of Parasitology 91: 648-652.

Zdzitowiecki K y Rutkowska MA. 1980. The helminthofauna of bats (Chiroptera) from Cuba. II. A review of cestodes with description of four new species and key to Hymenolepididae of American bats. Acta Parasitologica Polonica XXVI 18: 187-200. 


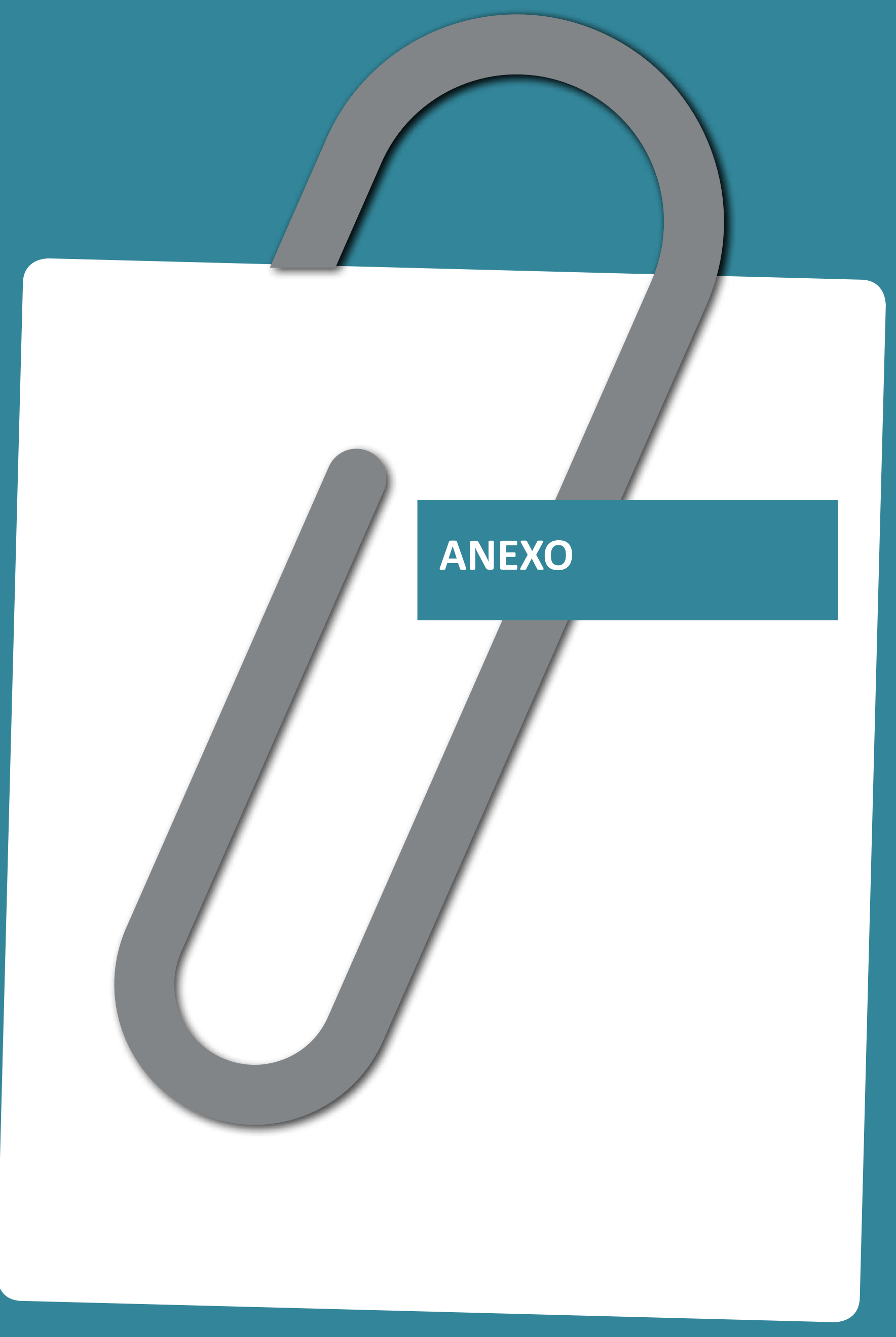




\section{ANEXO}

Tabla A.1. Peso y longitud de los murciélagos analizados para el estudio de la helmintofauna, discriminados por sexo.

\begin{tabular}{|c|c|c|c|c|c|c|c|}
\hline \multicolumn{2}{|c|}{ Hospedador } & \multirow{2}{*}{ Sexo } & \multirow{2}{*}{$n$} & \multicolumn{2}{|c|}{ Peso (gr) } & \multicolumn{2}{|c|}{ Longitud (mm) } \\
\hline Familia & Especie & & & $X \pm D S$ & Min-Max & $X \pm D S$ & Min-Max \\
\hline \multirow{13}{*}{ 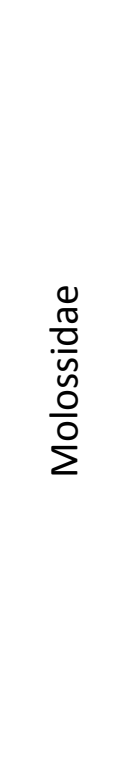 } & \multirow{3}{*}{$\begin{array}{c}\text { Eumops } \\
\text { patagonicus }\end{array}$} & $\widehat{0}$ & 19 & $15,1 \pm 2,65$ & $11,71-23,93$ & $113,68 \pm 10,18$ & $99-150$ \\
\hline & & 우 & 47 & $14,95 \pm 3,28$ & $10,82-33,63$ & $111,45 \pm 6,83$ & $98-140$ \\
\hline & & Total & 66 & $14,99 \pm 3,09$ & $10,82-33,63$ & $112,09 \pm 7,92$ & $98-150$ \\
\hline & $\begin{array}{l}\text { Eumops } \\
\text { perotis }\end{array}$ & $\hat{\sigma}$ & 1 & 65 & - & 162 & - \\
\hline & \multirow{3}{*}{$\begin{array}{l}\text { Molossops } \\
\text { temminckii }\end{array}$} & $\hat{o}$ & 3 & $8,35 \pm 4,82$ & $8,2-8,5$ & $83,33 \pm 0,58$ & $83-84$ \\
\hline & & $q$ & 2 & $8,3 \pm 0,42$ & $8-8,6$ & $84,5 \pm 4,95$ & $81-88$ \\
\hline & & Total & 5 & $8,3 \pm 3,73$ & $8-8,6$ & $83,8 \pm 2,59$ & $81-88$ \\
\hline & \multirow{3}{*}{$\begin{array}{l}\text { Molossus } \\
\text { molossus }\end{array}$} & $\hat{0}$ & 2 & $18,46 \pm 6,61$ & $13,75-23,1$ & $129 \pm 22,63$ & $113-145$ \\
\hline & & o & 4 & $15,48 \pm 2,04$ & $14,1-18,5$ & $121,25 \pm 13$ & $110-140$ \\
\hline & & Total & 6 & $16,46 \pm 3,68$ & $13,75-23,1$ & $123,83 \pm 14,82$ & $110-145$ \\
\hline & \multirow{3}{*}{$\begin{array}{l}\text { Molossus } \\
\text { rufus }\end{array}$} & $\widehat{0}$ & 8 & $31,94 \pm 7,39$ & $22,1-45,3$ & $127,63 \pm 8,33$ & $114-135$ \\
\hline & & q & 12 & $29,5 \pm 5,43$ & $23,8-40,4$ & $127,5 \pm 5,44$ & $120-135$ \\
\hline & & Total & 20 & $30,5 \pm 6,22$ & $21,1-45,3$ & $127,6 \pm 6,53$ & $114-135$ \\
\hline \multirow{12}{*}{ 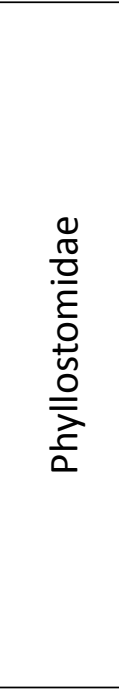 } & \multirow{3}{*}{$\begin{array}{l}\text { Artibeus } \\
\text { lituratus }\end{array}$} & 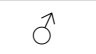 & 3 & $67,1 \pm 13,26$ & $53,5-80$ & $104,33 \pm 9,29$ & 98-115 \\
\hline & & q & 5 & $66,86 \pm 12,84$ & $50,1-81,1$ & $93 \pm 11,94$ & $82-111$ \\
\hline & & Total & 8 & $66,95 \pm 12,02$ & $50,1-81,1$ & $97,25 \pm 11,85$ & $82-115$ \\
\hline & \multirow{3}{*}{$\begin{array}{l}\text { Desmodus } \\
\text { rotundus }\end{array}$} & $\hat{\sigma}$ & 2 & $48,85 \pm 1,77$ & $47,6-50,1$ & $74,5 \pm 3,54$ & $72-77$ \\
\hline & & q & 2 & $44,35 \pm 2,05$ & $42,9-45,8$ & $93 \pm 1,41$ & $92-94$ \\
\hline & & Total & 4 & $46,6 \pm 3,03$ & $42,9-50,1$ & $83,75 \pm 10,9$ & $72-94$ \\
\hline & \multirow{3}{*}{$\begin{array}{l}\text { Platyrrhinus } \\
\text { lineatus }\end{array}$} & $\hat{\sigma}$ & 6 & $23,94 \pm 1,7$ & $22,4-26,3$ & $70 \pm 4,3$ & $65-75$ \\
\hline & & q & 3 & $24,13 \pm 0,61$ & $23,6-24,8$ & $67,67 \pm 4,16$ & $63-71$ \\
\hline & & Total & 9 & $24 \pm 1,39$ & $22,4-26,3$ & $69,22 \pm 4,02$ & $63-75$ \\
\hline & \multirow{3}{*}{$\begin{array}{l}\text { Sturnira } \\
\text { lilium }\end{array}$} & $\hat{0}$ & 3 & $22,1 \pm 0,85$ & $21,3-23$ & $84,33 \pm 16,74$ & $65-94$ \\
\hline & & q & 6 & $18,4 \pm 1,24$ & $16,5-20,1$ & $62,8 \pm 4,4$ & $58-70$ \\
\hline & & Total & 9 & $19,6 \pm 2,13$ & $16,5-23$ & $70 \pm 14,6$ & $58-94$ \\
\hline \multirow{9}{*}{ 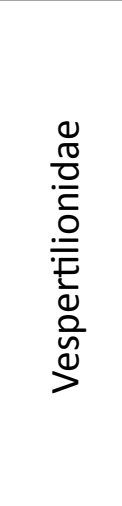 } & \multirow{3}{*}{$\begin{array}{l}\text { Eptesicus } \\
\text { furinalis }\end{array}$} & $\hat{0}$ & 2 & $8,95 \pm 2,05$ & $7,5-10,4$ & $90,5 \pm 7,78$ & $85-96$ \\
\hline & & q & 14 & $10,5 \pm 1$ & $9-12$ & $100,9 \pm 3,71$ & $97-110$ \\
\hline & & Total & 16 & $10,31 \pm 1,2$ & $7,5-12$ & $99,59 \pm 5,35$ & $85-110$ \\
\hline & \multirow{3}{*}{$\begin{array}{l}\text { Myotis } \\
\text { albescens }\end{array}$} & 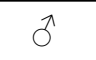 & 3 & $5,22 \pm 0,57$ & $4,56-5,6$ & $81,33 \pm 1,15$ & $80-82$ \\
\hline & & q & 31 & $5,27 \pm 0,35$ & $4,41-6,3$ & $85,48 \pm 3,08$ & $79-92$ \\
\hline & & Total & 34 & $5,26 \pm 0,37$ & $4,41-6,3$ & $85,12 \pm 3,18$ & $79-92$ \\
\hline & \multirow{3}{*}{$\begin{array}{l}\text { Myotis cf } \\
\text { nigricans }\end{array}$} & 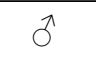 & 13 & $5,48 \pm 0,44$ & $5-6,3$ & $80,77 \pm 6,08$ & $74-94$ \\
\hline & & q & 18 & $6,17 \pm 0,39$ & $5,2-6,9$ & $82,17 \pm 3,76$ & $75-89$ \\
\hline & & Total & 31 & $5,9 \pm 0,53$ & $5-6,9$ & $81,6 \pm 4,83$ & $74-94$ \\
\hline
\end{tabular}


Tabla A.2. Vampirolepis guarany. Valores morfométricos discriminados por hospedador. Promedio \pm desvío estándard (Mínimo-Máximo), salvo indicación contraria medidas expresadas en micras $(\mu \mathrm{m})$.

\begin{tabular}{lccc}
\hline & \multicolumn{3}{c}{ Hospedador } \\
\cline { 2 - 4 } & $\begin{array}{c}\text { Eumops patagonicus } \\
\mathrm{n}=3\end{array}$ & $\begin{array}{c}\text { Molossus rufus } \\
\mathrm{n}=2\end{array}$ & $\begin{array}{c}\text { Artibeus lituratus } \\
\mathrm{n}=3\end{array}$ \\
\hline Longitud total $(\mathrm{mm})$ & $43 \pm 1,73(42-45)$ & $42 \pm 1,41(41-43)$ & $46,33 \pm 2,1(41-48)$ \\
Ancho máximo $(\mathrm{mm})$ & $1,93 \pm 0,06(1,9-2)$ & $1,75 \pm 0,07(1,7-1,8)$ & $1,97 \pm 0,5(1,8-2,1)$ \\
Diámetro escólex & $282 \pm 3(279-285)$ & $266 \pm 24,04(249-283)$ & $298 \pm 19,08(286-320)$ \\
Diámetro ventosas & $111,67 \pm 7,64(105-120)$ & $107 \pm 7,07(102-112)$ & $123,67 \pm 9,87(117-135)$ \\
Número de ganchos & 24 & 24 & 24 \\
Longitud ganchos & $49,67 \pm 0,58(49-50)$ & $49(49)$ & $51(51)$ \\
Diámetro huevos & $56,67 \pm 2,52(54-59)$ & $51,5 \pm 2,12(50-53)$ & $56,33 \pm 1,53(55-58)$ \\
\hline
\end{tabular}

Tabla A.3. Anenterotrema eduardocaballeroi. Valores morfométricos discriminados por hospedador. Promedio \pm desvío estándard (Mínimo-Máximo), medidas expresadas en micras $(\mu \mathrm{m})$.

\begin{tabular}{lcc}
\hline & \multicolumn{2}{c}{ Hospedador } \\
\cline { 2 - 3 } & Molossops temminckii & Molossus rufus \\
& $\mathrm{n}=4$ & $\mathrm{n}=4$ \\
\hline Largo del cuerpo & $365 \pm 78,5(310-480)$ & $317,5 \pm 9,57(310-330)$ \\
Ancho del cuerpo & $211,3 \pm 12,5(195-225)$ & $173 \pm 14,6(152-185)$ \\
Largo ventosa oral & $92 \pm 5,72(85-98)$ & $94,5 \pm 6,6(85-100)$ \\
Ancho ventosa oral & $106 \pm 4(100-108)$ & $110 \pm 2,31(108-112)$ \\
Largo ventosa ventral & $92,25 \pm 3,7(87-95)$ & $91,7 \pm 6,2(85-97)$ \\
Ancho ventosa ventral & $89,7 \pm 3,3(85-92)$ & $96,2 \pm 3,7(91-100)$ \\
Largo bolsa del cirro & $39 \pm 1,2(38-40)$ & $41 \pm 2,6(38-44)$ \\
Ancho bolsa del cirro & $48 \pm 8,5(42-60)$ & $52 \pm 1,63(50-54)$ \\
Largo testículo derecho & $36,7 \pm 2,2(35-40)$ & $39,2 \pm 4,2(36-45)$ \\
Ancho testículo derecho & $36,2 \pm 1,3(35-38)$ & $35,7 \pm 1,5(35-38)$ \\
Largo testículo izquierdo & $40,2 \pm 1,3(39-42)$ & $43,7 \pm 2,4(42-47)$ \\
Ancho testículo izquierdo & $43,2 \pm 1,5(42-45)$ & $42,7 \pm 5,9(35-49)$ \\
Largo ovario & $32 \pm 2,8(30-36)$ & $33 \pm 3,4(30-37)$ \\
Ancho ovario & $38 \pm 4,3(32-42)$ & $44 \pm 0,8(43-45)$ \\
Largo huevos & 27 & $28,2 \pm 1,2(27-30)$ \\
Ancho huevos & $16,5 \pm 0,6(16-17)$ & $15,5 \pm 1(15-17)$ \\
\hline
\end{tabular}


Tabla A.4. Gymnoacetabulum talavarensis. Valores morfométricos discriminados por hospedador. Promedio \pm desvío estándard (Mínimo-Máximo), medidas expresadas en micras $(\mu \mathrm{m})$.

\begin{tabular}{lcc}
\hline & \multicolumn{2}{c}{ Hospedador } \\
\cline { 2 - 3 } & Eumops patagonicus \\
$\mathrm{n}=4$ & Myotis albescens \\
& $712,5 \pm 29,9(680-750)$ & $577,5 \pm 75,8(500-680)$ \\
\hline Largo del cuerpo & $912,5 \pm 91(810-1000)$ & $877,5 \pm 47,8(810-920)$ \\
Ancho del cuerpo & $73 \pm 11,5(60-85)$ & $75 \pm 6(70-82)$ \\
Largo ventosa oral & $76,2 \pm 9,03(67-88)$ & $76,2 \pm 15,4(55-92)$ \\
Ancho ventosa oral & $124,5 \pm 51(90-200)$ & $149,2 \pm 25,08(120-180)$ \\
Largo ventosa ventral & $182,5 \pm 22,17(150-200)$ & $179 \pm 11,9(164-190)$ \\
Ancho ventosa ventral & $96 \pm 8,04(87-105)$ & $94,2 \pm 4,2(88-97)$ \\
Largo saco del psuedocirro & $100 \pm 9,8(92-112)$ & $99 \pm 2,6(96-102)$ \\
Ancho saco del psuedocirro & $136,2 \pm 31,2(100-175)$ & $130,5 \pm 15,6(110-148)$ \\
Largo testículo derecho & $205,2 \pm 21,6(184-235)$ & $155,5 \pm 44,08(110-205)$ \\
Ancho testículo derecho & $143,5 \pm 18,4(118-162)$ & $119 \pm 25,5(102-156)$ \\
Largo testículo izquierdo & $128,2 \pm 33,7(95-175)$ & $117,7 \pm 27,5(96-155)$ \\
Ancho testículo izquierdo & $130 \pm 11,6(117-145)$ & $112,2 \pm 28,8(87-147)$ \\
Largo ovario & $117,2 \pm 38,5(80-167)$ & $117,5 \pm 16,4(97-135)$ \\
Ancho ovario & $18 \pm 2,4(15-20)$ & $17,7 \pm 0,5(17-18)$ \\
Largo huevos & $9,75 \pm 0,5(9-10)$ & $9,5 \pm 0,6(9-10)$ \\
Ancho huevos & &
\end{tabular}


Tabla A.5. Paralecithodendriun aranhai. Valores morfométricos discriminados por hospedador. Promedio£desvío estándard (Mínimo-Máximo), medidas expresadas en micras ( $\mu \mathrm{m})$.

\begin{tabular}{lcc}
\hline & \multicolumn{2}{c}{ Hospedador } \\
\cline { 2 - 3 } & Eumops patagonicus & Myotis cf nigricans \\
$\mathrm{n}=4$ & $\mathrm{n}=6$ \\
\hline Largo del cuerpo & $584,5 \pm 73,5(523-690)$ & $502 \pm 60,7(420-583)$ \\
Ancho del cuerpo & $679,5 \pm 53,02(625-750)$ & $513,7 \pm 80,9(360-580)$ \\
Largo ventosa oral & $68 \pm 5,7(62-75)$ & $63 \pm 4,7(55-68)$ \\
Ancho ventosa oral & $77,5 \pm 6,81(71-87)$ & $61,7 \pm 6,9(50-68)$ \\
Largo ventosa ventral & $92,5 \pm 2,1(90-95)$ & $70 \pm 8,1(57-79)$ \\
Ancho ventosa ventral & $94,2 \pm 1,5(92-95)$ & $68,8 \pm 10,9(52-79)$ \\
Largo esófago & $93,5 \pm 5,1(89-100)$ & $89,7 \pm 3,4(85-95)$ \\
Largo saco del psuedocirro & $167,2 \pm 19,4(150-197)$ & $105,2 \pm 11,1(90-123)$ \\
Ancho saco del psuedocirro & $168,2 \pm 25,4(138-200)$ & $134,5 \pm 26,6(92-165)$ \\
Largo testículo derecho & $102,7 \pm 2,1(100-105)$ & $96,5 \pm 5,9(85-101)$ \\
Ancho testículo derecho & $144,7 \pm 20,4(121-165)$ & $93,7 \pm 20,3(75-121)$ \\
Largo testículo izquierdo & $103,5 \pm 7,8(94-112)$ & $87,5 \pm 8,1(77-95)$ \\
Ancho testículo izquierdo & $117,5 \pm 12,3(106-135)$ & $96,7 \pm 11,9(75-108)$ \\
Largo ovario & $119,2 \pm 10,3(107-130)$ & $73,8 \pm 10,9(65-93)$ \\
Ancho ovario & $106,7 \pm 5,4(100-112)$ & $87,2 \pm 6,8(82-98)$ \\
Largo huevos & 20 & 20 \\
Ancho huevos & 10 & 10 \\
\hline
\end{tabular}

Tabla A.6. Limatulum oklahomense. Valores morfométricos discriminados por hospedador. Promedio \pm desvío estándard (Mínimo-Máximo), medidas expresadas en micras ( $\mu \mathrm{m})$.

\begin{tabular}{lccc}
\hline & \multicolumn{3}{c}{ Hospedador } \\
\cline { 2 - 4 } & $\begin{array}{c}\text { Molossus rufus } \\
\mathrm{n}=1\end{array}$ & Myotis albescens & Myotis cf nigricans \\
& 582 & $556 \pm 23,9(536-600)$ & $\mathrm{n}=5$ \\
\hline Largo del cuerpo & 432 & $501,5 \pm 30,4(460-550)$ & $415,8 \pm 57,5(330-481)$ \\
Ancho del cuerpo & 169 & $179,7 \pm 19,9(168-220)$ & $157 \pm 7,6(150-165)$ \\
Largo ventosa oral & 182 & $204,2 \pm 12,9(192-225)$ & $208,8 \pm 26,4(180-240)$ \\
Ancho ventosa oral & 182 & $205,7 \pm 13,6(188-222)$ & $187,2 \pm 10,6(172-200)$ \\
Largo ventosa ventral & 188 & $246,7 \pm 35,2(214-304)$ & $218,4 \pm 27,1(200-262)$ \\
Ancho ventosa ventral & 137 & $122,2 \pm 20,06(107-159)$ & $90 \pm 10,8(72-99)$ \\
Largo bolsa del cirro & 85 & $89,5 \pm 3,3(85-95)$ & $74,8 \pm 5,7(70-84)$ \\
Ancho bolsa del cirro & 95 & $112 \pm 4,5(105-117)$ & $91,4 \pm 8,5(80-100)$ \\
Largo testículo derecho & 88 & $91,7 \pm 5,2(85-100)$ & $88,6 \pm 4,2(83-95)$ \\
Ancho testículo derecho & 92 & $93,7 \pm 1,5(92-95)$ & $92,4 \pm 0,9(92-94)$ \\
Largo testículo izquierdo & 100 & $110 \pm 4,05(105-115)$ & $102,4 \pm 3,8(98-108)$ \\
Ancho testículo izquierdo & 70 & $91 \pm 9,8(81-107)$ & $71,2 \pm 1,1(70-72)$ \\
Largo ovario & 78 & $102 \pm 12,2(90-112)$ & $82,8 \pm 16,2(55-95)$ \\
Ancho ovario & 18 & $20,3 \pm 0,8(20-22)$ & 20 \\
Largo huevos & 10 & $10,3 \pm 0,5(10-11)$ & $9,6 \pm 0,5(9-10)$ \\
Ancho huevos & & &
\end{tabular}




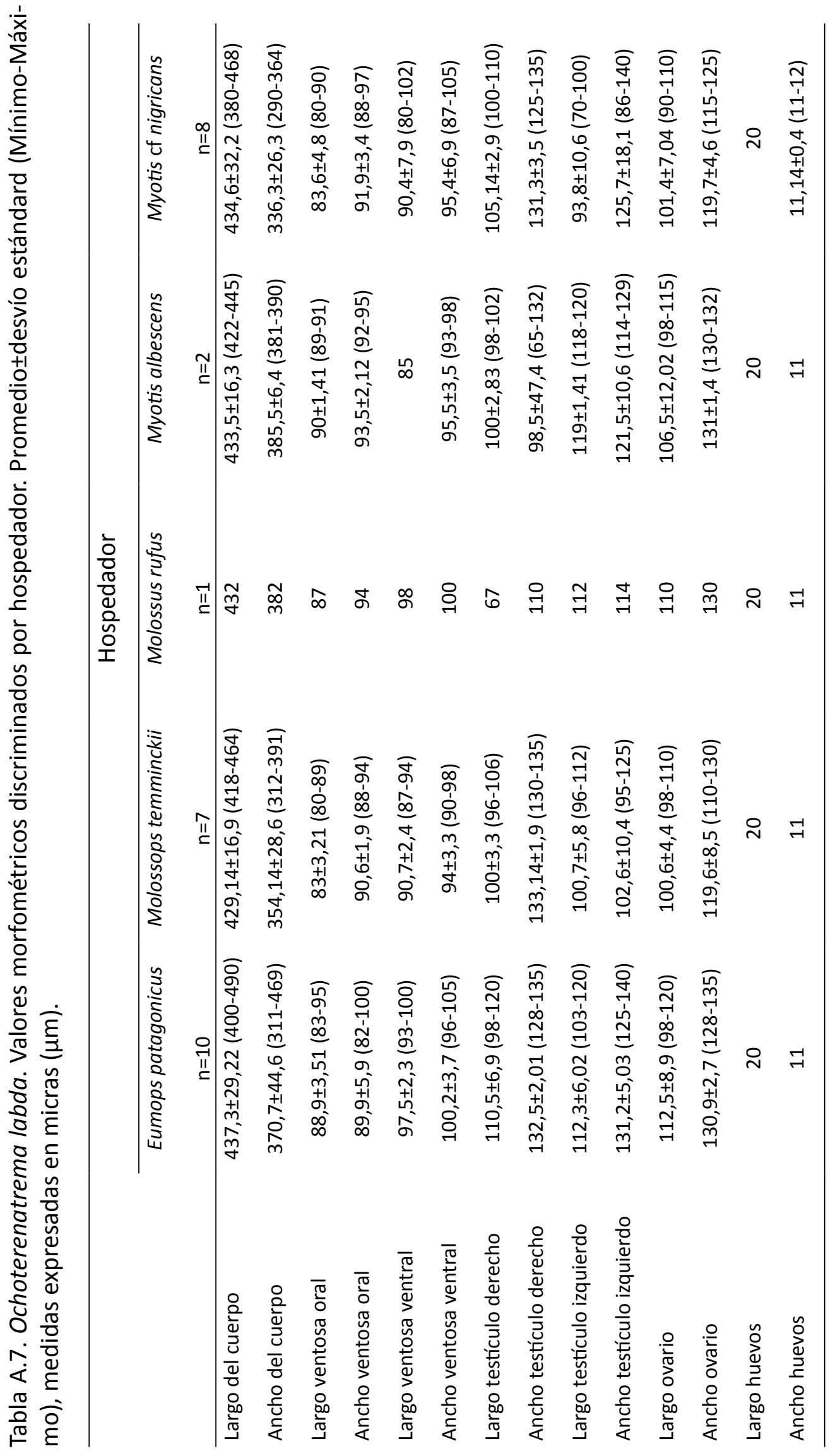




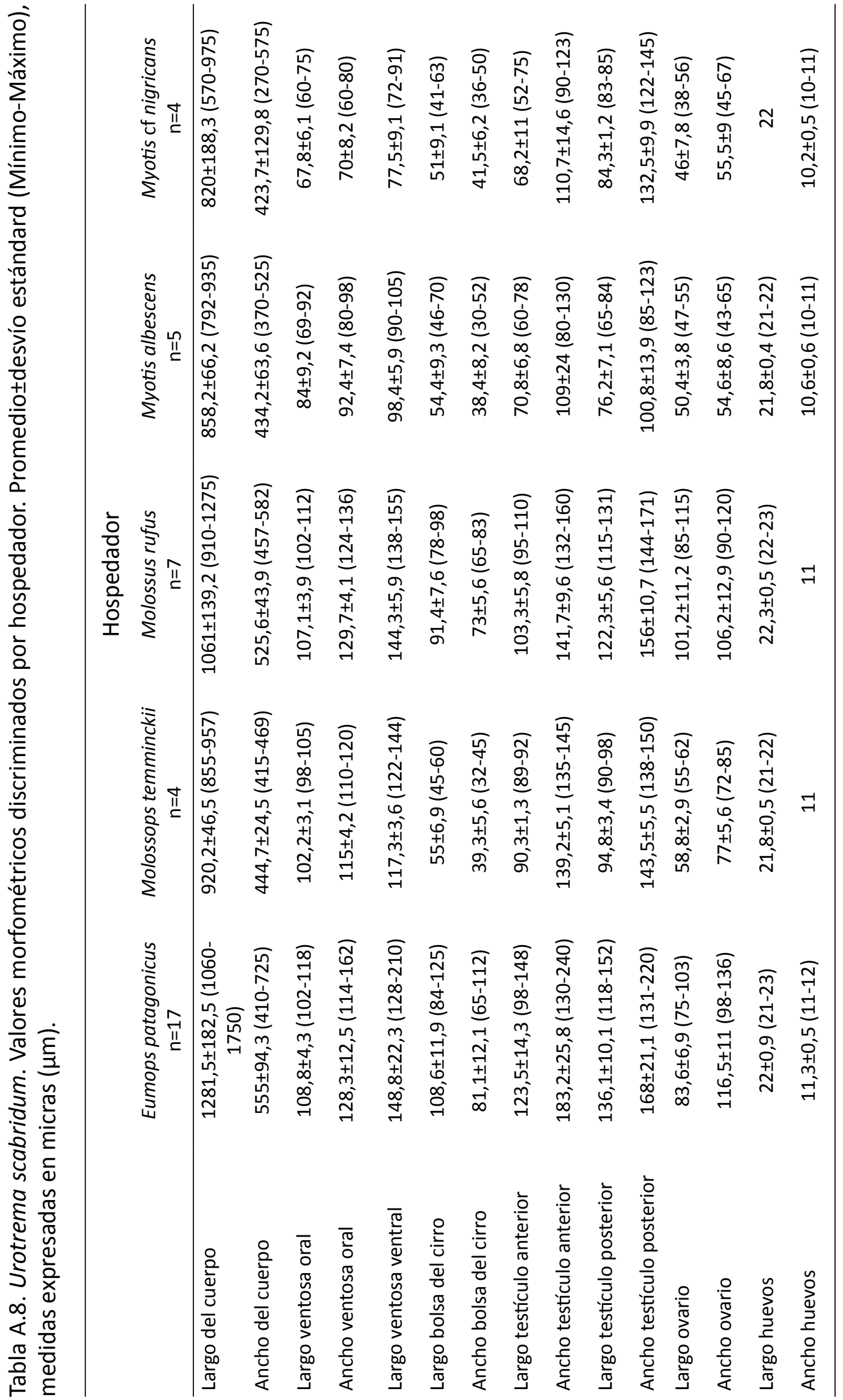


